\title{
Acetylene in Organic Synthesis: Recent Progress and New Uses
}

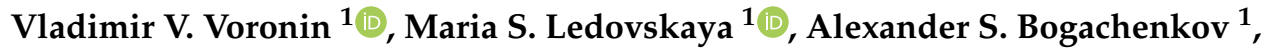 \\ Konstantin S. Rodygin ${ }^{1}$ and Valentine P. Ananikov $1,2, * \mathbb{D}$ \\ 1 Institute of Chemistry, Saint Petersburg State University, Universitetsky prospect 26, Peterhof 198504, Russia; \\ volgo-vv@mail.ru (V.V.V.); maria.s.ledovskaya@gmail.com (M.S.L.); alexterve@gmail.com (A.S.B.); \\ konstantinrs@rambler.ru (K.S.R.) \\ 2 N. D. Zelinsky Institute of Organic Chemistry Russian Academy of Sciences, Leninsky prospect 47, \\ Moscow 119991, Russia \\ * Correspondence: val@ioc.ac.ru
}

Received: 16 August 2018; Accepted: 17 September 2018; Published: 24 September 2018

\begin{abstract}
Recent progress in the leading synthetic applications of acetylene is discussed from the prospect of rapid development and novel opportunities. A diversity of reactions involving the acetylene molecule to carry out vinylation processes, cross-coupling reactions, synthesis of substituted alkynes, preparation of heterocycles and the construction of a number of functionalized molecules with different levels of molecular complexity were recently studied. Of particular importance is the utilization of acetylene in the synthesis of pharmaceutical substances and drugs. The increasing interest in acetylene and its involvement in organic transformations highlights a fascinating renaissance of this simplest alkyne molecule.
\end{abstract}

Keywords: acetylene; vinylation; cross-coupling; addition reactions; drugs; pharmaceutical substances; biologically active molecule; monomers; polymers

\section{Introduction}

Since the discovery of acetylene, new areas of acetylene chemistry have been continuously developed. The rich scope of chemical transformations available for a $\mathrm{C} \equiv \mathrm{C}$ triple bond can be exemplified by coupling [1-5] and addition reactions [6,7]. The removal of trace acetylene from ethylene has led to another important process, selective hydrogenation of acetylene [8]. Recently, several opportunities of controlled accommodation of acetylene in microporous materials have appeared [9]. New functional materials allow separating, sensing and storing acetylene and other small molecules [10,11].

Acetylene, or ethyne, with the molecular formula $\mathrm{C}_{2} \mathrm{H}_{2}$, is the simplest alkyne. Due to its structural simplicity and high reactivity, acetylene represents a versatile building block for organic synthesis, and its chemistry has evolved rapidly [12]. In recent reviews [13,14] acetylene is compared with ethylene. Acetylene is commonly obtained from coal and natural gas and these sources will last longer than current oil sources. Acetylene chemistry is therefore of high importance in various aspects [15].

Acetylene can be produced by several well-established methods. One of them is based on the reaction of calcium carbide (obtained from coal and lime) with water [16]. The other methods include partial combustion of hydrocarbons, electrothermal cracking in an electric arc furnace, and thermal cracking with heat carriers $[14,16]$.

Pure acetylene is a colorless gas with no odor. It is lightweight and flammable, with a high combustion temperature [17]. Due to this, acetylene is widely used in welding [16,18]. It is also 
suitable for brazing, cutting, hardening, texturing, and thermal spraying of many materials. Besides, the acetylene flame is extraordinary bright, which formerly contributed to the wide use of carbide lamps. The term "carbide lamp" reflects the interaction of calcium carbide with water, followed by burning of the released acetylene in another compartment of the device [19].

Chemical applications of acetylene are diverse, and a brief summarized scope is shown in Scheme 1. Some of them are of great practical relevance, e.g., the vinylation reaction (Scheme 1, path a) [20], a common route to vinyl-containing monomers for polymeric materials production. Polyvinyl derivatives are indispensable components of many varnishes, paints, adhesives, packing materials [15], in electroluminescent materials [21], coatings or fillers for pharmaceutical excipients and many more [22].

Hydrochlorination of acetylene (Scheme 1, path $b$ ), or addition of hydrochloric acid, is the simplest and widely used route to vinyl chloride [16], a commodity chemical used for production of the polyvinyl chloride resins [23]. Polyvinyl chloride is the third most commonly used sort of plastic, behind polyethylene and polypropylene, and the global demand for it continues to increase [24].

The other way of industrial acetylene utilization is carbonylation (Scheme 1, path $c$ ). By this way acrylic acid and derivatives can be obtained [25]. Produced on a global scale of more than three million tons a year, acrylic acid is widely used as a basic material for paints, plastics, superabsorbent polymers, and rubbers [26-28]. Partial reduction of acetylene (Scheme 1, path $d$ ) provides alternative means for ethylene synthesis [29-33]. This reaction has industrial prospects that will be discussed in detail.

Ethynylation with acetylene (Scheme 1, paths $e$ and $f$ ) is a powerful approach to prepare substituted acetylenes. Ethynylation strategies include the base-catalyzed addition of acetylene to carbonyl compounds (Favorskii reaction, path $e$ ) $[34,35]$ and various cross-coupling reactions (path $f$ ) [36-38].

Addition of ketoximes to acetylene (Scheme 1, path $g$ ) provides an access to a range of pyrroles, indoles, and related compounds $[13,39]$ for applications in pharmaceutical chemistry, polymer synthesis, and dye manufacturing [21,22,40].

Cycloaddition reactions with acetylene (Scheme 1, path $h$ ) provide a shortcut to isoxazoles, pyrazoles, and triazoles [41-44]. This segment of acetylene chemistry is especially promising for obtaining novel heterocyclic molecules.

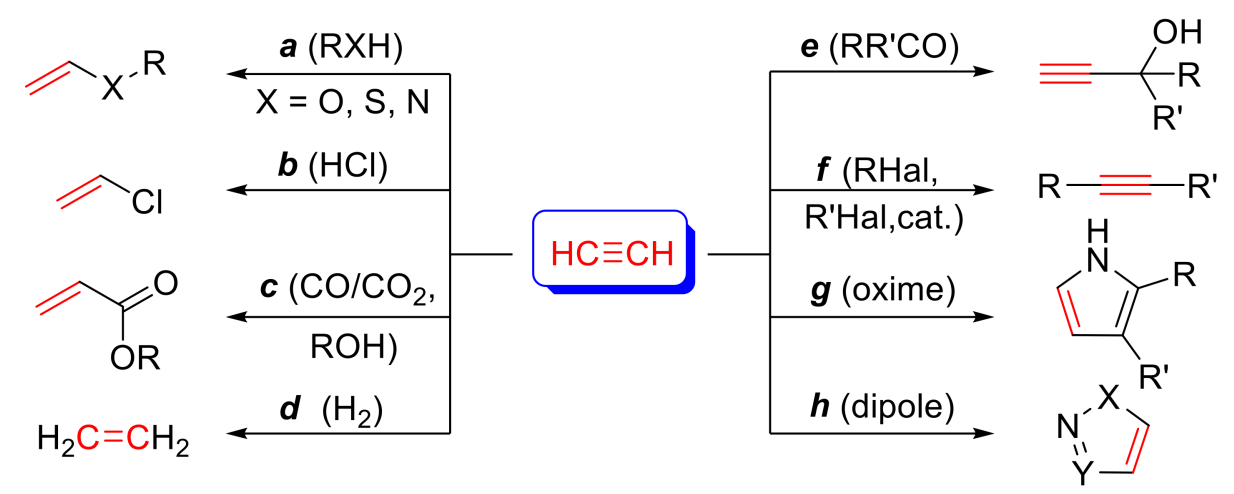

Scheme 1. Representative examples in acetylene chemistry.

This review discusses recent advances in acetylene chemistry by describing the most important processes at various levels of chemical complexity. Recent literature within the time period of 2013-2018 was considered to highlight emerging directions and applications in organic chemistry. Representative examples in each research direction are provided to cover most important trends in synthetic acetylene chemistry. It should be emphasized that the present review is focused on the reactions of acetylene $\left(\mathrm{C}_{2} \mathrm{H}_{2}\right)-\mathrm{a}$ fascinating molecule with significant practical importance and future potential. Reactions involving substituted alkynes have been described in details elsewhere and these discussions were not repeated here. 


\section{Acetylene in Organic Synthesis}

Versatile and ubiquitously used synthetic transformations of acetylene involve functionalization of the $\mathrm{C} \equiv \mathrm{C}$ bond; these processes are considered first (Section 2.1). Next, access to acrylic acid derivatives (Section 2.2) and preparation of substituted alkynes (Section 2.3) are discussed, followed by preparation of heterocyclic molecules (Section 2.4). Selected applications of acetylene in the synthesis of drugs and pharmaceutical substances is highlighted in a separate section (Section 2.5). Synthetic organic and organometallic reactions are also considered (Sections 2.6 and 2.7), followed by industry-related reactions involving hydrogenation, hydrochlorination reactions and their mechanisms (Sections 2.8 and 2.9). Finally, useful emerging concepts from the chemistry of alkynes are briefly mentioned (Section 2.10).

\subsection{Functionalization of Triple Bond}

Polymerization of vinyl-containing substrates has been a subject of close attention for many years. Polyvinyl compounds constitute a basis of many composites including paints, adhesives, varnishes, packaging [15], electroluminescent materials [21], pill coatings and many more [22]. Despite the widest range of applications, their chemistry is still in progress. Vinyl ethers, thioethers, sulfur- and nitrogen analogs become increasingly involved in synthesis of various cyclic compounds [45-50], natural substances, and medicinal chemicals [51,52], hence the demand for their development, modification, and systematization. A number of studies have been devoted to metathesis $[53,54]$ and cross-coupling reactions of vinyl derivatives $[55,56]$. This section presents a review of the latest achievements in this field.

\subsubsection{Synthesis of Vinyl Ethers}

Addition of alcohols to acetylenes was introduced by Favorskii $[57,58]$. While studied isomerization of alkynes in the presence of alcohols and alkalis, he found that the alcohols react with acetylenes to give ethers. Later on, this reaction was turned into an industrial method for vinyl ether synthesis based on the addition of alcohols to acetylene, known as vinylation $[14,20]$. Under industrial conditions, it is carried out in autoclaves at elevated pressures and high temperatures in the presence of alkaline catalysts [13,14]. It can be performed on a smaller scale in special laboratory reactors or standard flasks and tubes. In the laboratory practice of the last decade, gaseous acetylene is frequently and effectively replaced with calcium carbide as an acetylene source. Calcium carbide readily reacts with water and produces gaseous acetylene [59]. Here we will consider the recent examples of acetylene and carbide usage in vinyl ether synthesis.

The reaction of alcohols with acetylene can be classified as nucleophilic addition to carbon-carbon triple bond (Scheme 2). This process requires the presence of a base as a catalyst. The base interacts with an alcohol molecule $\mathbf{1}$ giving alcoholate anion $\mathbf{2}$. The alkoxide ion reacts with acetylene forming the corresponding carbanion 3. The latter acts with the molecule of alcohol or water, thus giving vinyl ether $4[20,60]$.

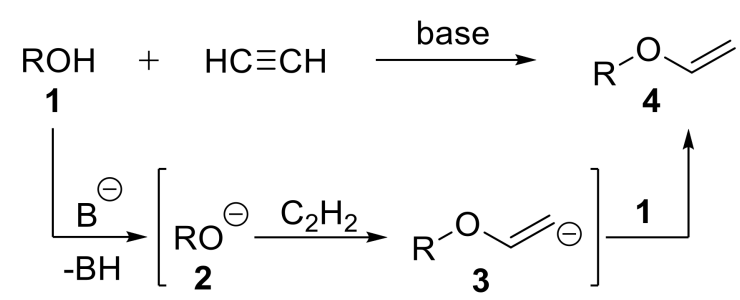

Scheme 2. Synthesis of vinyl ethers involving acetylene.

An effective vinylation methodology for 3,4,5-trimethoxybenzyl alcohol (5) was proposed [61]. The resulting 3,4,5-trimethoxybenzyl vinyl ether (6) is a promising starting material for drug synthesis. 
The reaction was carried out under the standard vinylation conditions [20]: superbasic KOH-DMSO system as a reaction media, high temperature and elevated acetylene pressure. The desired vinyl derivative was isolated in $85 \%$ yield (Scheme 3 ).<smiles>COc1cc(CO)cc(OC)c1OC</smiles>

5

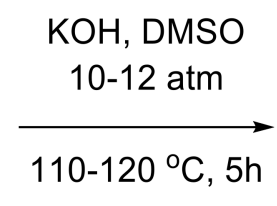<smiles>C=COCc1cc(OC)c(OC)c(OC)c1</smiles>

$6(85 \%)$

Scheme 3. 3,4,5-Trimethoxybenzyl vinyl ether synthesis.

Vinylation of triterpenoid 7 under atmospheric acetylene pressure resulted in vinyl derivative $\mathbf{1 0}$ in good yield (64\%) [62]. Formation of the oxygen bridge was thought to occur through intramolecular formation of vinyl ether 8 with its subsequent devinylation-cyclization and vinylation of the last OH-group (Scheme 4). The side product 9 with a free hydroxyl group can be easily converted to the desired ether $\mathbf{1 0 .}$

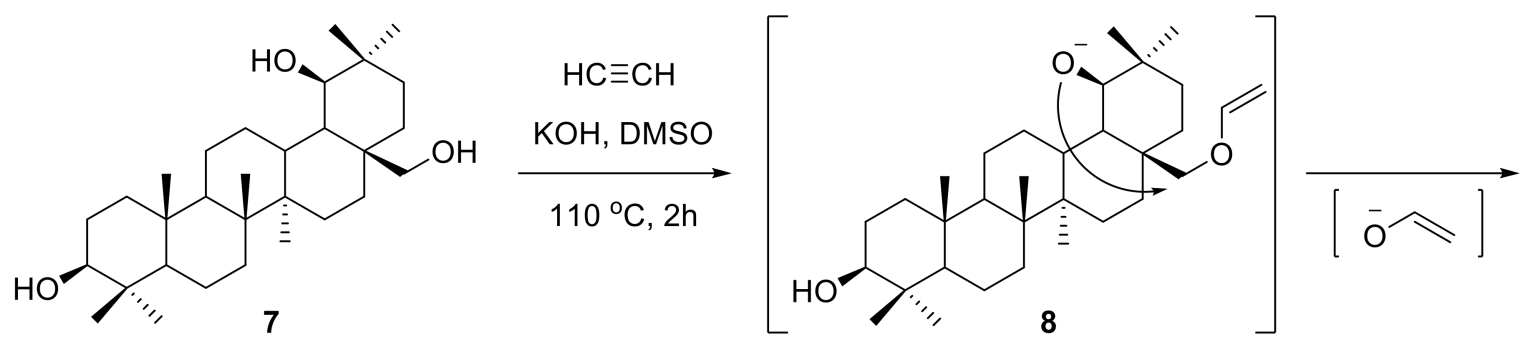

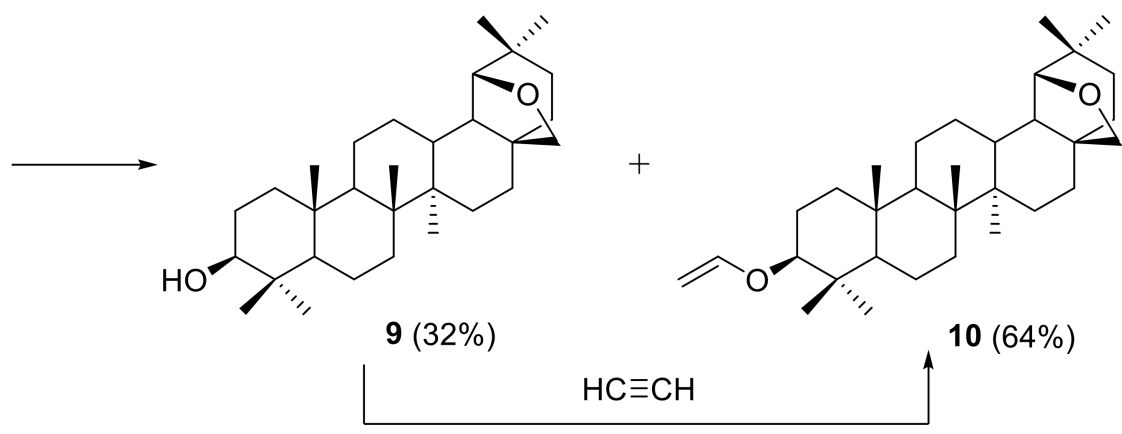

$\mathrm{KOH}, \mathrm{DMSO}, 110^{\circ} \mathrm{C}, 90 \mathrm{~min}(72 \%)$

Scheme 4. Triterpenoid vinylation.

Another recently published example of superbase-catalyzed (KOH-DMSO system-mediated) vinylation involves hydroxymethyl- and $\alpha$-hydroxyethylferrocenes 11 [63]. Vinyl ethers 12 were obtained in excellent yields (Scheme 5) and represented a promising route for development of new polymeric materials with specific physical and chemical properties.
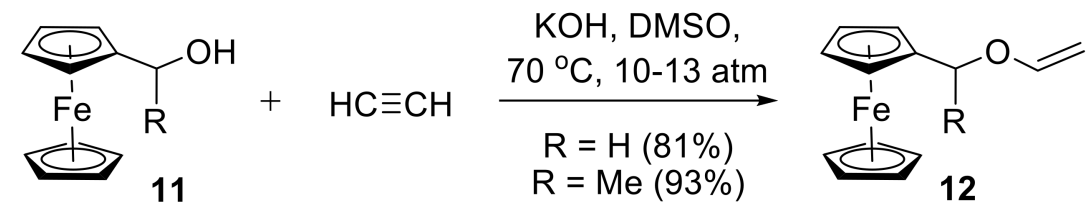

Scheme 5. Reaction of ferrocene-derived alcohols with acetylene. 
Despite the outstanding chemical versatility of acetylene and the widest range of possibilities for its application, it is a highly flammable gaseous substance [64]. Safety precautions should be taken to avoid its leakage and explosion. Besides, gaseous materials usage requires additional measuring equipment and high-pressure furnishing. The development of alternatives for gaseous acetylene is an important problem of modern chemistry. A reasonable solution of these complications is provided by utilization of calcium carbide as an in situ source of acetylene, which is immediately released upon reaction of $\mathrm{CaC}_{2}$ with water (Scheme 6) [59]. A small admixtures of water does not interfere with the vinylation, and sometimes is even favorable $[60,65]$.

$$
\mathrm{CaC}_{2}+2 \mathrm{H}_{2} \mathrm{O} \longrightarrow \mathrm{HC} \equiv \mathrm{CH}+\mathrm{Ca}(\mathrm{OH})_{2}
$$

Scheme 6. Reaction of calcium carbide with water.

Successful vinylation of benzyl alcohols $\mathbf{1 3}$ with calcium carbide was performed without any complicate equipment [66]. The reactions were conducted in standard reaction tubes or in a flask for gram-scale synthesis. The desired vinyl ethers 14 were obtained in good to excellent yields (Scheme 7). Using $\mathrm{CaC}_{2}$ instead of gaseous acetylene provides certain economy, as only 2.5 to 3.3 -fold excess of it is required to complete the reaction. Similar reactions with gaseous acetylene (see Schemes 3-5) were carried out under high acetylene pressures (10-13 atm) or in acetylene flow [61-63].<smiles>[R][C-]1C=CC=C(C([R])O)C=C1</smiles><smiles></smiles>

$\mathrm{R}^{1}=\mathrm{H}: \mathrm{R}^{2}=\mathrm{H}, \mathrm{Et},(\mathrm{Me})_{2}$, cyclopropyl;

$\mathrm{R}^{2}=\mathrm{H}: \mathrm{R}^{1}=2-\mathrm{MeO}, 4-\mathrm{MeO}, 4-\mathrm{Cl}, 3-\mathrm{CF}_{3}, 4-{ }^{t} \mathrm{Bu}, 2,3-$ butadiene-1,4-diyl

Scheme 7. Vinylation of benzyl alcohols with calcium carbide.

Apart from benzyl alcohols, the successful vinylation of dodecyl alcohol (15a), 3-phenylpropanol (15b) and 3-(pyridine-2-yl)propanol (15c) was also performed under the same conditions (Scheme 8) [66]. Vinyl ethers 16a-c were obtained in very good yields. For phenethyl alcohol (17), the unexpected formation of styrene 19 instead of vinyl ether 18 was observed (Scheme 8).<smiles>[R]CCC[18OH]</smiles>

16a-c

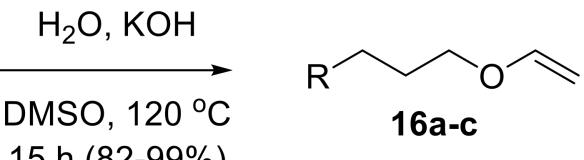

$\mathrm{R}=\mathrm{C}_{9} \mathrm{H}_{19}(\mathbf{a}), \mathrm{Ph}(\mathbf{b}), 2-$ pyridyl (c)

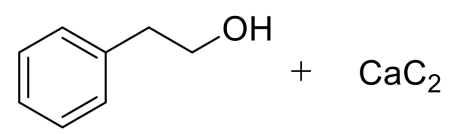

17

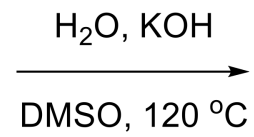

$15 \mathrm{~h}$<smiles>C=COCCc1ccccc1</smiles>

$18(0 \%)$<smiles>C=Cc1ccccc1</smiles>

$19(44 \%)$

Scheme 8. Vinylation of alcohols with calcium carbide.

The reaction of phenols 20 with calcium carbide as an acetylene source was carried out at similar conditions $[67,68]$. Apparently, $\mathrm{Cs}_{2} \mathrm{CO}_{3}$ is also capable of providing a superbasic system with DMSO. The method allows obtaining vinyl derivatives 21 in up to 96\% yields (Scheme 9A). Using the developed 
technique, diphenyl carbonate 22 was also transformed to phenyl vinyl ether (23) in $73 \%$ yield (see Scheme 9B) [67].

A

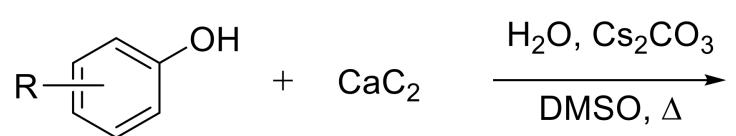

20<smiles>[R][X]1=CC=CC(OC=C)=CC=1</smiles>

$21(20-96 \%)$

$\mathrm{R}=\mathrm{H}$, 4- ${ }^{\mathrm{t}} \mathrm{Bu}$, 3-ethynyl, 2- $\mathrm{NH}_{2}$, 3- $\mathrm{NH}_{2}, 4-\mathrm{NH}_{2}$, 4-MeO, 2- $\mathrm{NH}_{2}-4-\mathrm{MeO}$, 2,3-( $\mathrm{MeO})_{2}$, 2-Br, 3-Br, 4-Br, 4-I, 4-C(O) $\mathrm{NH}_{2}$, 2,3-butadiene-1,4-diyl, 3,4-butadiene-1,4-diyl,

B

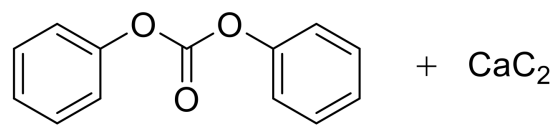

22<smiles>CO[R6]([O-])([O-])O[Na]</smiles>

3 days<smiles>C=COc1ccccc1</smiles>

$23(73 \%)$

Scheme 9. The synthesis of aryl vinyl ethers with calcium carbide.

The vinylation of 1,5-pentanediol, ethylene glycol, glycerol and erythritol with carbide was also performed in a superbasic $\mathrm{Cs}_{2} \mathrm{CO}_{3}$-DMSO system [67]. The corresponding vinyl derivatives 24-27 were obtained in moderate to excellent yields (Scheme 10).

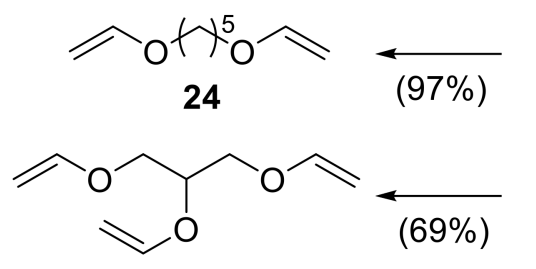

26

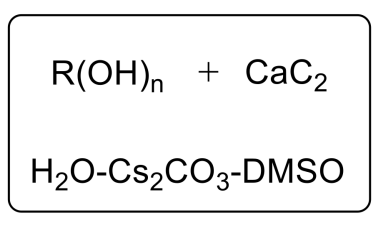

$(43 \%)$<smiles>C=COCCOC=C</smiles>

Scheme 10. Polyvinyl ethers synthesis with in situ generated acetylene.

Another synthetic procedure for vinylation of alcohols and phenols was recently developed [69,70]. It employs $\mathrm{KOH}-\mathrm{DMSO}-\mathrm{KF}$ and $\mathrm{K}_{2} \mathrm{CO}_{3}$-DMSO-KF ternary mixtures instead of the renowned $\mathrm{KOH}-\mathrm{DMSO}$ and $\mathrm{Cs}_{2} \mathrm{CO}_{3}$-DMSO systems. Potassium fluoride significantly accelerates the reaction [70]. The KOH-DMSO-KF mixture works well for aliphatic alcohols, particularly steroids and carbohydrates, giving vinyl ethers 28 in good to excellent yields (Scheme 11) [69,70]. It also favors the reaction with ferrocenyl alcohol and allows obtaining its vinylated derivative $28 \mathrm{~g}$ in $76 \%$ yield. The alternative $\mathrm{K}_{2} \mathrm{CO}_{3}$-DMSO-KF system is perfect for vinylation of phenols.

In general, both acetylene and calcium carbide as an acetylene source can be used in vinyl ether synthesis. The reaction of alcohols with acetylene or $\mathrm{CaC}_{2}$ is applicable to a wide variety of substrates. It can effectively proceed with aliphatic substrates, phenols, naphthols, ferrocene-derived alcohols, nitrogen-containing substrates, carbohydrates, etc. Using calcium carbide in a laboratory is preferable for its convenience and safety, as $\mathrm{CaC}_{2}$ is a solid material that can be easily quantified and handled without special equipment. Direct addition of carbide into the mixture allows carrying out the reaction under milder conditions. When using gaseous acetylene, the expenditure is considerably higher, even under low pressures, because the constant gas flow must be maintained until the end of the reaction. 


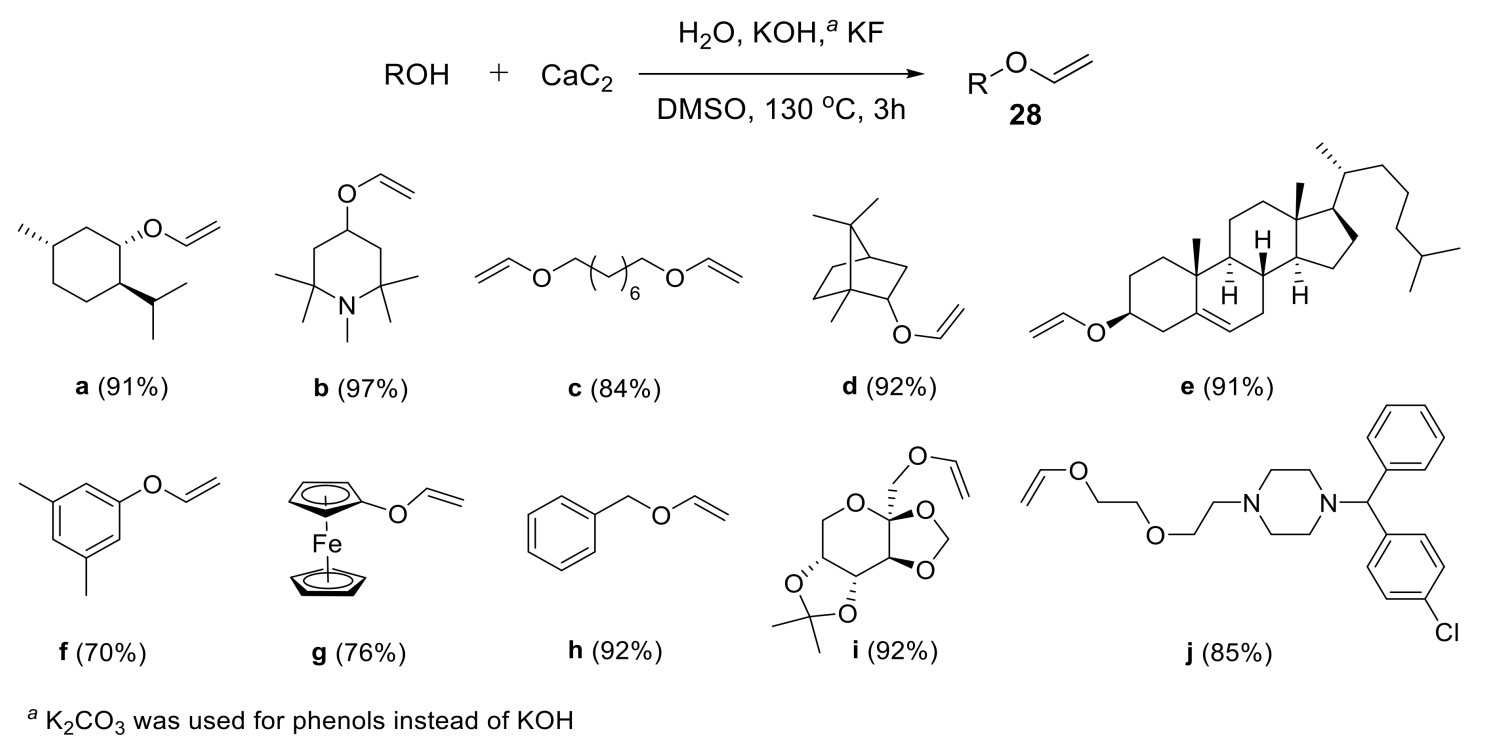

Scheme 11. Representative scope of alcohols vinylation with $\mathrm{CaC}_{2}$ in $\mathrm{KOH}-\mathrm{DMSO}-\mathrm{KF}$ system.

\subsubsection{Synthesis of S-, Se- and Te-Vinyl Derivatives}

Organochalcogen compounds occupy an important niche in contemporary organic synthesis due to their availability, rich chemistry [71-73] and the biological activities [74]. Among the organochalcogen compounds, vinyl chalcogenides have attracted a considerable attention in recent years [75-77]. Vinyl sulfides are of particular interest as intermediates for various organic transformations. Sulfur-containing polymers derived from vinyl monomers have attracted a great deal of attention, due to their potential applications in numerous areas in polymer research. For example, they have a wide variety of applications in plastic lenses, optical disc substrates, optical adhesives or encapsulants, antireflective coatings, photoresists [75-79].

Addition of thiols and selenols to acetylene is the simplest route to vinyl sulfides and vinyl selenides. It is chemically similar with the nucleophilic addition of alcohols to acetylene described previously and it is also require basic catalysis [20], and is accordingly called thiovinylation.

The common approach to this reaction based on the use of gaseous acetylene was proposed recently. The simplest alkyl vinyl sulfides 31a-d and phenyl vinyl sulfide 31e were synthesized in excellent yields [80]. On the first step, generation of potassium thiolate 30 from thiol 29 occurred (Scheme 12). Potassium thiolate further reacted with acetylene and water giving vinyl ether 31. This approach can be considered as green, because the reactions were performed in aqueous media. It is probably applicable to a wide range of thiols. Its serious disadvantage is the high acetylene pressure requirement.

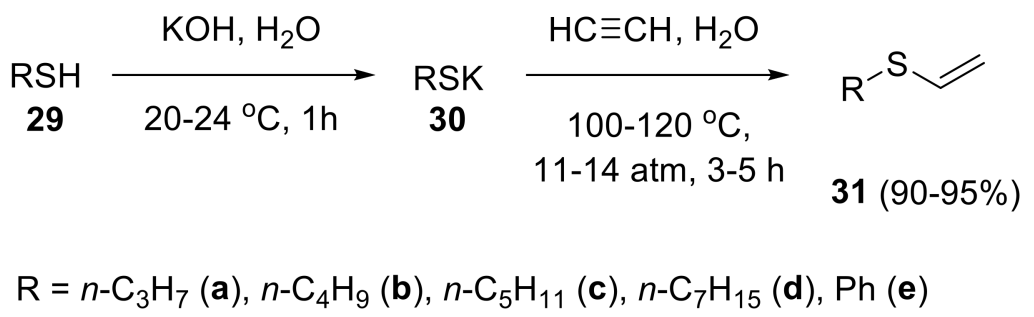

Scheme 12. Addition of thiols to acetylene.

The same is possible with calcium carbide as an acetylene source [81,82]. The wide substrate scope of $\mathrm{CaC}_{2}$-mediated thiovinylation includes thiophenols [81], alkyl thiols [81], dithiols [82], and imidazole and benzimidazole thiols (Scheme 13) [82]. For most of them, vinyl sulfides 32 were obtained 
in excellent yields (88-96\%), with exceptions of the pyridine-2-thiol and 1-methylimidazole-2-thiol addition to acetylene that resulted in $72 \%$ and $58 \%$ yields, respectively.

$$
\mathrm{RSH}+\mathrm{CaC}_{2} \underset{\mathrm{DMF}, 100^{\circ} \mathrm{C}, 3 \mathrm{~h}}{\stackrel{\mathrm{H}_{2} \mathrm{O}, \mathrm{KOH}}{\longrightarrow}} \mathrm{R}^{-\mathrm{S}}
$$

$32(58-96 \%)$

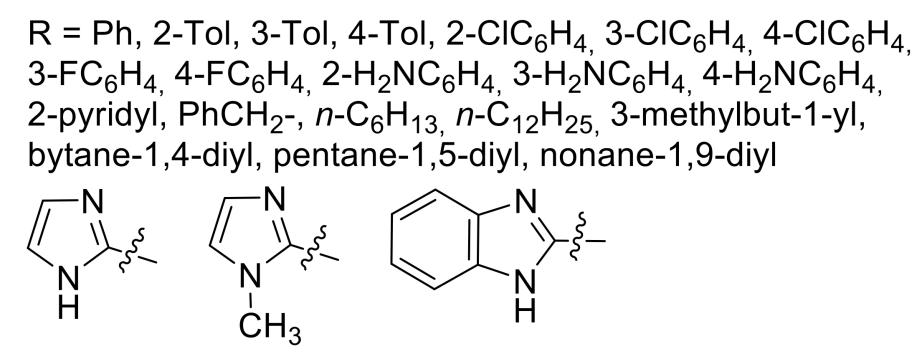

Scheme 13. Reactions of carbide-induced acetylene with thiols.

Phenyl selenol (33) was also modified by calcium carbide. Vinyl derivative 34 was obtained in $62 \%$ yield (Scheme 14 ) [81].

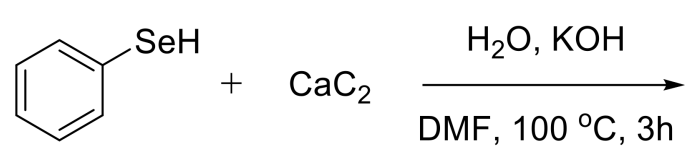

33<smiles>C=C[Se]c1ccccc1</smiles>

$34(62 \%)$

Scheme 14. Phenyl vinyl selenide synthesis with calcium carbide.

Another reaction, which is also acetylene-dependent, allows obtaining vinyl chalcogenides from disulfides, diselenides, and ditellurides; it leads to vinyl sulfides, vinyl selenides, and vinyl tellurides, respectively. It has several reported implementations $[61,83,84]$. The first resulted from interaction of a dichalcogenide 35 with gaseous acetylene in the presence of a reducing agent, e.g., hydrazine- $\mathrm{KOH}$ mixture or sodium borohydride. To complete the reaction, the presence of the reducing agent is required (Scheme 15) [61,84]. Using this methodology, the corresponding vinyl chalcogenides $\mathbf{3 6}$ were obtained in excellent yields.

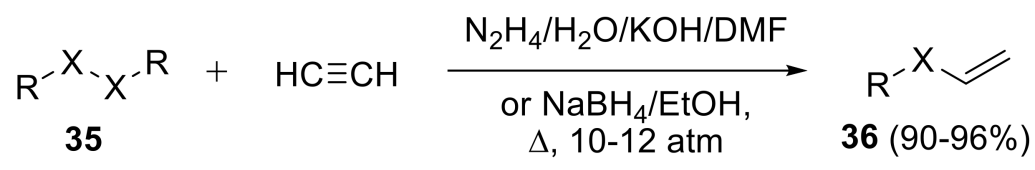$$
\mathrm{RX}=3,4,5-(\mathrm{MeO})_{3} \mathrm{C}_{6} \mathrm{H}_{2} \mathrm{CH}_{2} \mathrm{~S}, 2-\mathrm{PyS}, 2-\mathrm{PySe}, 2-\mathrm{PyTe}
$$$$
\text { 2-Py = 2-pyridyl }
$$

Scheme 15. Vinyl chalcogenide synthesis.

The reaction proceeds in two steps. At first, dichalcogenide 35 interacts with the reducing-basic mixture giving potassium chalcogenide 37 (Scheme 16), which further reacts with acetylene and water to produce vinyl derivative 36 [84]. 


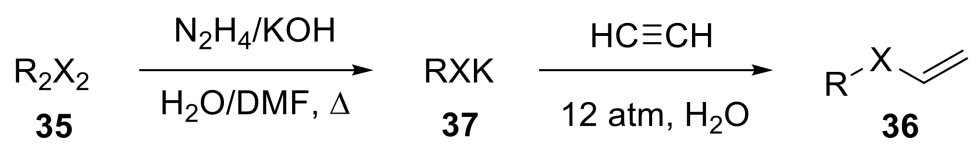

$\mathrm{X}=\mathrm{S}, \mathrm{Se}, \mathrm{Te}$

Scheme 16. The mechanism of vinyl chalcogenides formation.

Another variation on the theme was recently proposed [61,83,84]. In this setting, alkyl or aryl halide was directly exposed to sulfur, selenium or tellurium one-flask with a reducing agent and acetylene. Heating of this mixture under high acetylene pressure promoted formation of vinyl chalcogenides in moderate yields (52-68\%) [83,84].

The third protocol for synthesis of vinyl chalcogenides from dichalcogenides and acetylene is based on the in situ generation of the acetylene itself. As a source of acetylene calcium carbide can be used [85]. Vinyl sulfides 38a and phenyl vinyl selenide (38b) were obtained in up to $93 \%$ yields (Scheme 17), although in a number of cases the yields are diminished by competitive formation of bis-chalcogenide derivatives 39 .

$$
\begin{aligned}
& \mathrm{H}_{2} \mathrm{O}, \mathrm{KOH} \text {, DMSO, }
\end{aligned}
$$

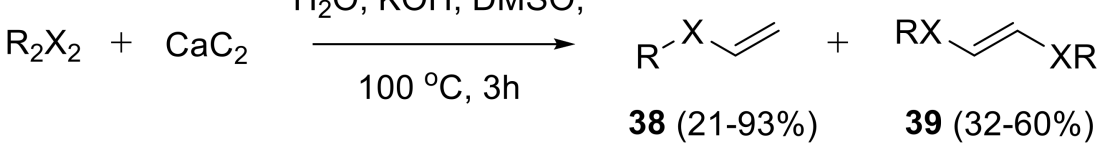

$$
\begin{aligned}
& \mathrm{X}=\mathrm{S}(\mathbf{a}): \mathrm{R}=\mathrm{Ph}, 3-\mathrm{Tol}, 4-\mathrm{Tol}, 4-\mathrm{ClC}_{6} \mathrm{H}_{4}, 4-\mathrm{FC}_{6} \mathrm{H}_{4}, 2-\mathrm{Py}, n-\mathrm{C}_{12} \mathrm{H}_{25}, n-\mathrm{C}_{8} \mathrm{H}_{17} \text {, } \\
& \text { c- } \mathrm{C}_{6} \mathrm{H}_{11}, 4,5 \text {-epoxycaryophyllyl-9-ylmethyl; } \mathrm{X}=\mathrm{Se}(\mathbf{b}): \mathrm{R}=\mathrm{Ph}
\end{aligned}
$$

Scheme 17. Reactions of carbide-induced acetylene with dichalcogenides.

Thus, reactions of thiols and selenols (or dichalcogenides) with acetylene (or calcium carbide as its source) provide convenient access to the wide range of vinyl chalcogenides. Availability of both acetylene and calcium carbide associates with good prospects of development in this direction.

\subsubsection{Synthesis of N-Vinyl Derivatives}

$\mathrm{N}$-Vinylated compounds are versatile building blocks for polymerization. The nitrogen-containing polymers showed exceptional electroluminescent properties and photoconductivity and widely used in the pill coating or excipient formulations [21,22,86-89]. The synthesis of $\mathrm{N}$-vinyl derivatives is a demanded goal of modern chemistry.

A simplest synthetic route to $\mathrm{N}$-vinyl derivatives is provided by addition of nitrogen compounds to acetylene. For example, reaction of indole (40) with acetylene in the presence of potassium hydroxide gives $N$-vinylindole (41) in $94 \%$ yield (Scheme 18) [90]. This reaction illustrates common route to vinylated nitrogen derivatives due to the high availability of acetylene and the wide scope of potentially suitable nitrogen substrates [20].

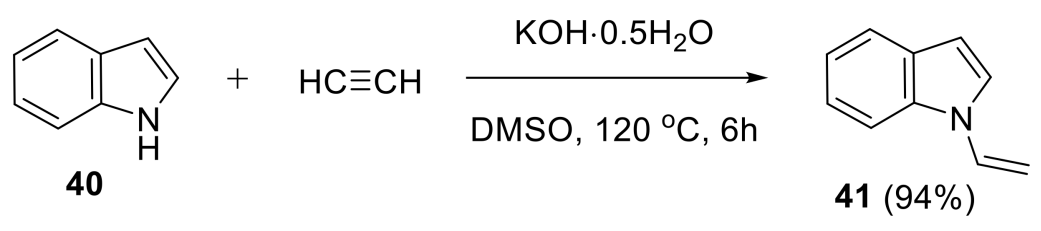

Scheme 18. N-Vinyl indole synthesis.

Replacement of gaseous acetylene with solid calcium carbide, proposed in several recent publications [68,91], seems reasonable. Calcium carbide facilitated obtaining of N-vinylindoles 43 from the corresponding substituted indoles 42 in good to excellent yields (Scheme 19) [68]. The reaction 
was performed in a $\mathrm{Cs}_{2} \mathrm{CO}_{3}$-DMSO mixture, similarly with the above-mentioned protocol for alcohol vinylation. In one case, reaction of $1 \mathrm{H}$-indol-5-ol (44) with $\mathrm{CaC}_{2}$ reproducibly resulted in formation of a divinyl derivative 45 .

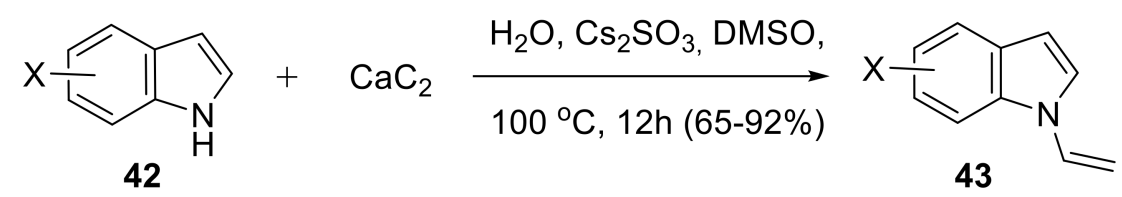

$\mathrm{X}=\mathrm{H}, 2-\mathrm{Me}$, 3-Me, 5-Me, 3-Ph, 3-Br, 5-Br, 5-Cl, 5-F, 5-MeO, 5- $\mathrm{NH}_{2}$, 6,7-butadiene-1,4-diyl<smiles>O=S(=O)(O[Na])O[Na]</smiles><smiles>C=COc1ccc2c(ccn2C=C)c1</smiles>

Scheme 19. Vinylation of indoles with carbide-induced acetylene.

A new protocol was developed for the carbide-mediated nitrogen core vinylation in superbasic KOH-KF-DMSO system (Scheme 20) [91]. Its application to various indoles, carbazoles, diaryl amines, pyrroles, pyrazoles, and other nitrogen substrates results in moderate to good yields of the target products, additionally increased by the presence of fluoride.

$$
\underset{\mathrm{R}^{2^{2}}}{\mathrm{R}^{1}}+\mathrm{CaC}_{2} \underset{\mathrm{DMSO}, 130^{\circ} \mathrm{C}, 4 \mathrm{~h}}{\stackrel{\mathrm{H}_{2} \mathrm{O}, \mathrm{KOH}, \mathrm{KF}}{\mathrm{R}^{2^{2}}}} \stackrel{\mathrm{R}^{1}}{\mathrm{~N}}
$$<smiles>C=Cn1ccc2ccccc21</smiles><smiles>C=Cn1ccc2cccc(CC)c21</smiles><smiles>C=Cn1c2ccccc2c2ccccc21</smiles><smiles>C=Cn1c2c(c3ccccc31)CCCC2</smiles><smiles>C=CN(c1ccccc1)c1ccccc1</smiles><smiles>C=CN(c1ccccc1)c1ccc2ccccc2c1</smiles><smiles>C=CN1c2ccccc2N=C(N2CCN(C)CC2)c2cc(C)sc21</smiles><smiles>C=Cn1cccc1</smiles><smiles>C=Cn1nc(C)cc1C</smiles>

Scheme 20. Representative scope of amine core vinylation with $\mathrm{CaC}_{2}$.

Thus, both acetylene and calcium carbide effectively promote the synthesis of vinyl indoles. The reaction has a wide substrate scope, as it also works for diarylamines, indoles, carbazoles, and other nitrogen heterocycles. 


\subsubsection{Synthesis of C-Vinyl Derivatives}

Vinylation of carbon atoms with acetylene affords a number of important polymers, e.g., polystyrenes for manufacturing of plastic tableware, packaging, building blocks and accessories (insulation, tapes, plugs, cases), and other useful items [92].

Acetylene gas was successfully used in the synthesis of fluorinated styrene compounds. The transition metal-catalyzed reaction was accelerated by a stop-flow micro-tubing reactor developed by the authors [93]. Within this device, fluorinated aryl bromides 46 reacted with acetylene in the presence of iridium photocatalyst 47 and diisipropyl ethylamine giving the corresponding vinyl derivatives 48 in $37-70 \%$ yields (Scheme 21). Application of this approach is compromised by formation of side products.<smiles>[R]c1c(F)c(F)c(Br)c(F)c1[18F]</smiles>

$\mathrm{R}=\mathrm{F}, \mathrm{Br}, \mathrm{NH}_{2}, \mathrm{CO}_{2} \mathrm{Me}, \mathrm{Ph}, 4-\mathrm{PhOC}_{6} \mathrm{H}_{4}, \mathrm{Naph}, 1 \mathrm{H}$-pyrrol-1-yl, $1 H$-imidazol-1-yl, $1 H$-benzo[d] imidazol-1-yl; $\mathrm{CR}=\mathrm{N}$

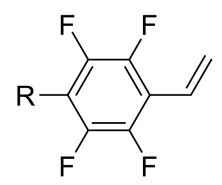

$48(37-70 \%)$

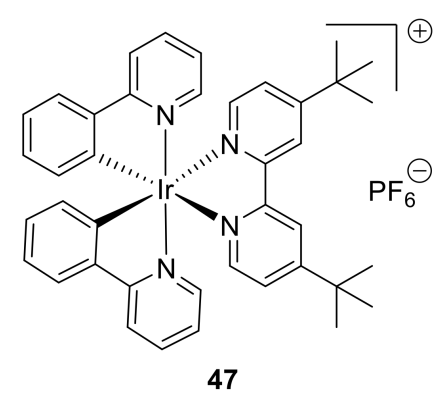

Scheme 21. Styrenes synthesis with acetylene.

A recently published example of a modification of $N$-benzyl-3-hydroxy-2-oxindole (49) with acetylene involves ruthenium carbonyl catalysis [94]. The reaction proceeds in the presence of 1,3-bis(diphenylphosphino)propane and adamantanecarboxylic acid and allows obtaining vinyl derivative 50 in 69\% yield (Scheme 22). This product is a potential spirooxindole precursor with specific arrangement of functional groups in its structure [94].

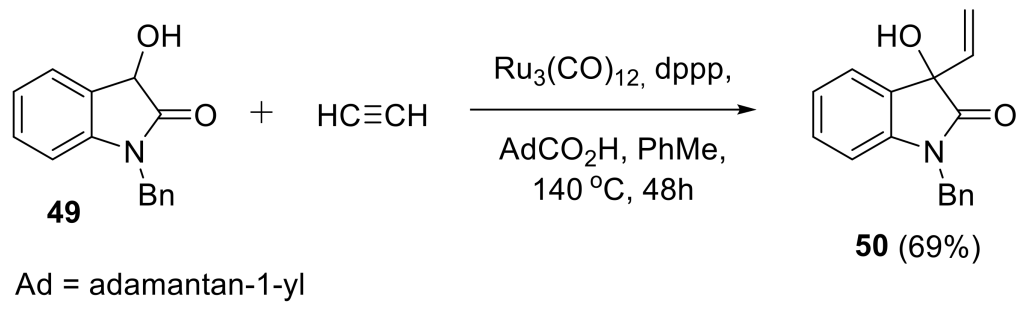

Scheme 22. Modification of N-benzyl-3-hydroxy-2-oxindole with acetylene.

The examples of C-vinylation are of certain theoretical importance and immense practical relevance. Further progress in discovering their potential is expected in the near future.

\subsection{Synthesis of Acrylic Acid Derivatives}

Acrylic acid (AA) and its derivatives are important components of plastics, rubbers, superabsorbent polymers, and paints. In industry, AA is prepared by partial oxidation of propene [95], which is refined from petroleum. Carbonylation of acetylene, introduced by Reppe [96], represents an alternative route to AA, which is better in terms of atom economy and independence from oil sources (Scheme 23).

$$
\mathrm{HC} \equiv \mathrm{CH}+\mathrm{CO}+\mathrm{H}_{2} \mathrm{O} \underset{\mathrm{T}, \mathrm{P}}{\stackrel{\mathrm{cat}}{\longrightarrow}} \stackrel{\mathrm{OH}_{\mathrm{OH}}}{\stackrel{\mathrm{O}}{\longrightarrow}}
$$

Scheme 23. Catalytic carbonylation of acetylene. 
Reppe used the nickel carbonyl as a catalyst to yield AA under $313.15 \mathrm{~K}$ and $0.1 \mathrm{MPa}$. Ni-Catalysts, especially nickel halides, are commonly used as homogeneous catalysts for AA production [14,97]. $\mathrm{Ni}_{2} \mathrm{O}_{3}$ is active as a heterogeneous catalyst in the presence of copper salts [98]. It was experimentally compared with $\mathrm{NiO}$ and other common homogeneous catalysts, including $\mathrm{NiBr}_{2}, \mathrm{NiCl}_{2}, \mathrm{Ni}\left(\mathrm{NO}_{3}\right)_{2}$, and $\mathrm{Ni}(\mathrm{OAc})_{2}$. Under fixed conditions $\left(4 \mathrm{MPa}, 235^{\circ} \mathrm{C}\right.$, and $\mathrm{CuBr}_{2}$ as a promoter), $\mathrm{Ni}_{2} \mathrm{O}_{3}$ showed the best average activity with $764.6(\mathrm{~mol} \mathrm{AA})(\mathrm{mol} \mathrm{Ni})^{-1} \mathrm{~h}^{-1}$. It could be reused at least five times without loss of activity and regenerated through calcination within $400^{\circ} \mathrm{C}$. The other catalysts' activities were related as $\mathrm{Ni}(\mathrm{OAc})_{2}>\mathrm{NiCl}_{2} \approx \mathrm{NiBr}_{2}>\mathrm{NiO}>\mathrm{Ni}\left(\mathrm{NO}_{3}\right)_{2}>\mathrm{Ni}(\mathrm{OAc})_{2} / \mathrm{PPh}_{3} /$ methanesulfonic acid.

Molecular sieves (zeolites) are one of the most common and versatile heterogeneous catalysts [99]. Zeolite-based Ni catalysts were tested in acetylene carbonylation [97,100]. Comparison of the catalysts prepared by using different supports and nickel introduction procedures (incipient wetness impregnation and aqueous ion exchange) revealed the best catalytic activity of Ni-exchanged $Y$ zeolites in the presence of $\mathrm{Cu}$ salt as a promoter $(62 \mathrm{~g} \mathrm{AA} /($ gcat. $\mathrm{h}))$. Multiple reuse of $\mathrm{NiY}$ in a batch reactor confirmed its stable activity at $235^{\circ} \mathrm{C}$ and $3.6 \mathrm{MPa}$ of initial total pressure.

An alternative acetylene carboxylation approach is based on using formic acid (FA) instead of toxic $\mathrm{CO}$. FA provides an efficient in situ source of $\mathrm{CO}$ for hydrocarboxylation and hydroformylation of olefins [101].

Hydrocarboxylation of acetylene with FA in the presence of palladium catalysts and a catalytic amount of benzoic or acetic anhydride is shown in Scheme 24 [28].

$$
\mathrm{HC} \equiv \mathrm{CH}+\mathrm{HCO}_{2} \mathrm{H} \underset{\text { solvent, } 60-140^{\circ} \mathrm{C}, 12 \mathrm{~h}}{\stackrel{\mathrm{Pd} / \text { Xantphos }}{\mathrm{Bz}_{2} \mathrm{O} \text { or } \mathrm{Ac}_{2} \mathrm{O}}}
$$

Scheme 24. Hydrocarboxylation of acetylene with FA.

Procedure of hydrocarboxylation with FA promotes conversion of acetylene into AA with TONs of up to $350 \mathrm{~s}^{-1}$ under mild conditions in the presence of $\left[\mathrm{Pd}_{2}(\mathrm{dba})_{3}\right] \cdot \mathrm{CHCl}_{3}$. Effects of reaction temperature, acetylene pressure, FA concentration, and reaction time on the outcomes are presented in Figures 1-4.

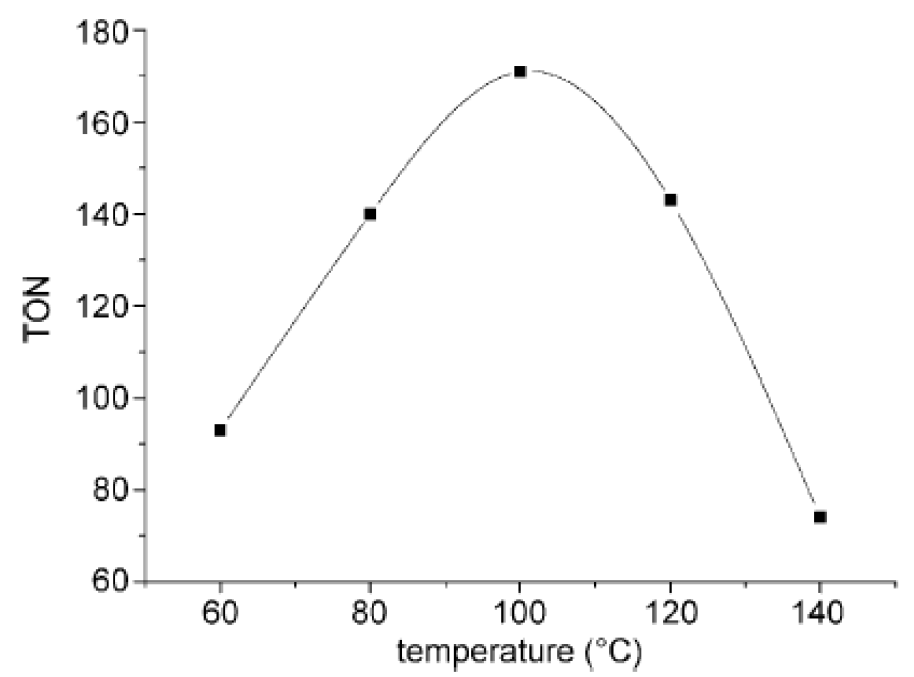

Figure 1. Effect of reaction temperature on acetylene hydrocarboxylation. Reaction conditions: $\left[\mathrm{Pd}_{2}(\mathrm{dba})_{3}\right] \cdot \mathrm{CHCl}_{3}(2.5 \mathrm{mmol})$, Xantphos $(50 \mathrm{mmol})$, benzoic anhydride $(0.1 \mathrm{mmol}), \mathrm{HCO}_{2} \mathrm{H}(1.5 \mathrm{mmol})$, acetylene (initial pressure $10 \mathrm{~atm}, \mathrm{ca} .12 \mathrm{mmol})$, in THF $(3 \mathrm{~mL})$ for $12 \mathrm{~h}$ (reproduced with permission from [28]. Copyright 2015, WILEY-VCH Verlag GmbH \& Co., KGaA). 


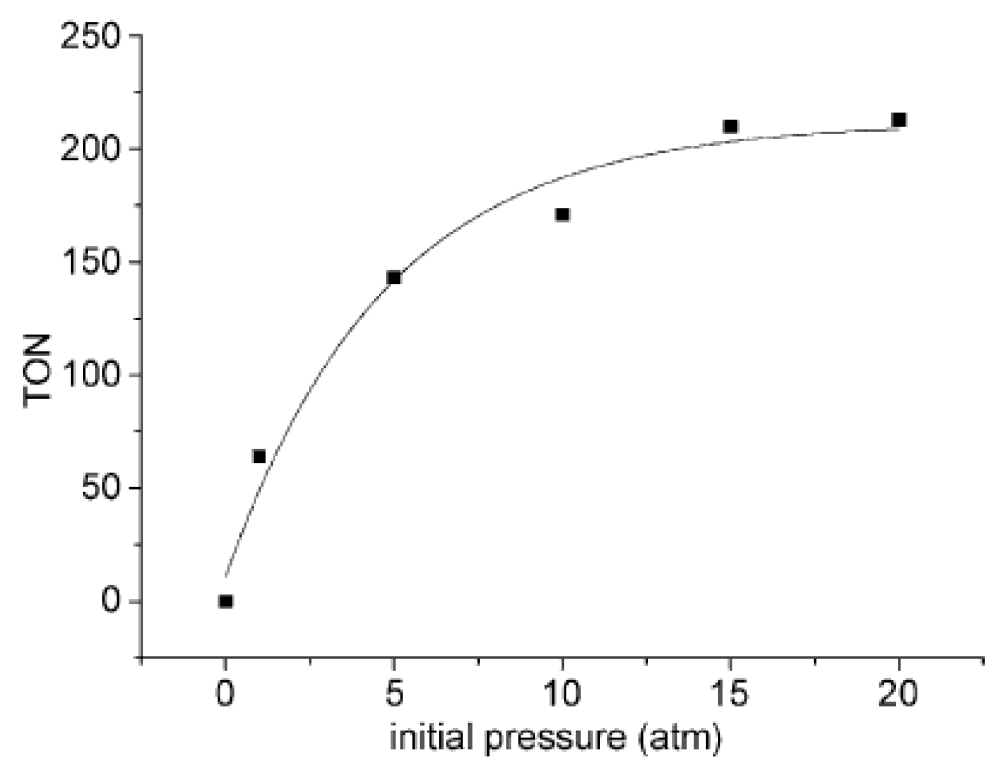

Figure 2. Effect of initial pressure on acetylene hydrocarboxylation. Reaction conditions: $\left[\mathrm{Pd}_{2}(\mathrm{dba})_{3}\right] \cdot \mathrm{CHCl}_{3}(2.5 \mathrm{mmol})$, Xantphos $(50 \mathrm{mmol})$, benzoic anhydride $(0.1 \mathrm{mmol}), \mathrm{HCO}_{2} \mathrm{H}(1.5 \mathrm{mmol})$, in THF ( $3 \mathrm{~mL}$ ) at $100{ }^{\circ} \mathrm{C}$ for $12 \mathrm{~h}$ (reproduced with permission from [28]. Copyright 2015, WILEY-VCH Verlag $\mathrm{GmbH} \& \mathrm{Co}$. KGaA).

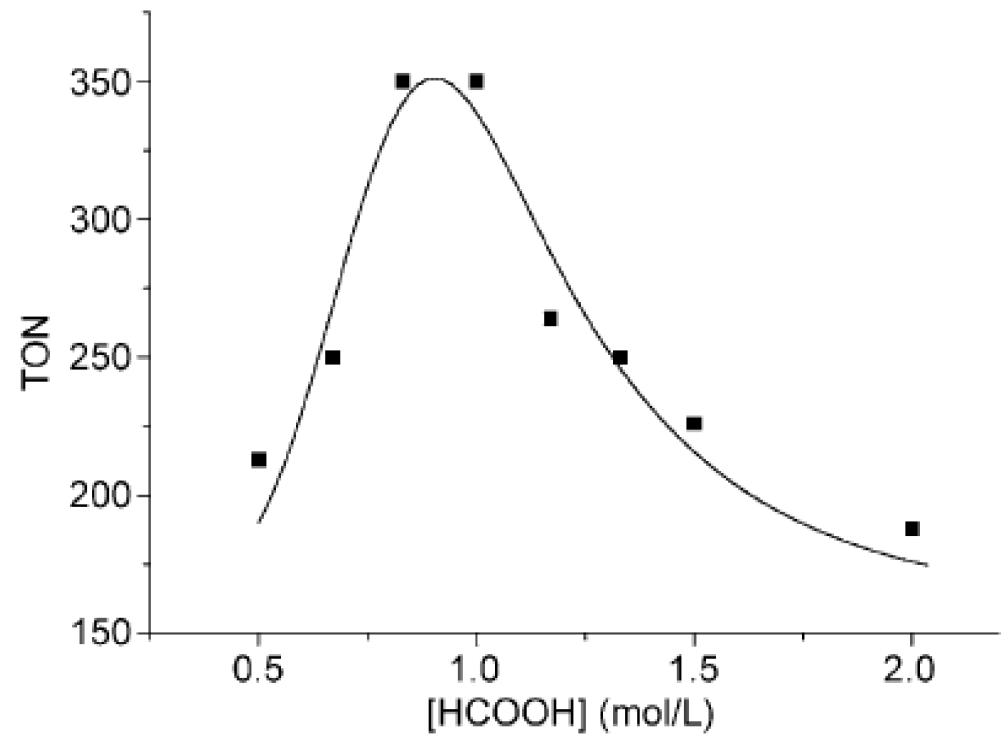

Figure 3. Effect of FA formic acid concentration on acetylene hydrocarboxylation. Reaction conditions: $\left[\mathrm{Pd}_{2}(\mathrm{dba})_{3}\right] \cdot \mathrm{CHCl}_{3}(2.5 \mathrm{mmol})$, Xantphos $(50 \mathrm{mmol})$, benzoic anhydride $(0.1 \mathrm{mmol})$, acetylene (initial pressure $15 \mathrm{~atm}$, ca. $18 \mathrm{mmol})$, in THF $(3 \mathrm{~mL})$ at $100{ }^{\circ} \mathrm{C}$ for $12 \mathrm{~h}$ (reproduced with permission from [28]. Copyright 2015 WILEY-VCH Verlag GmbH \& Co. KGaA). 


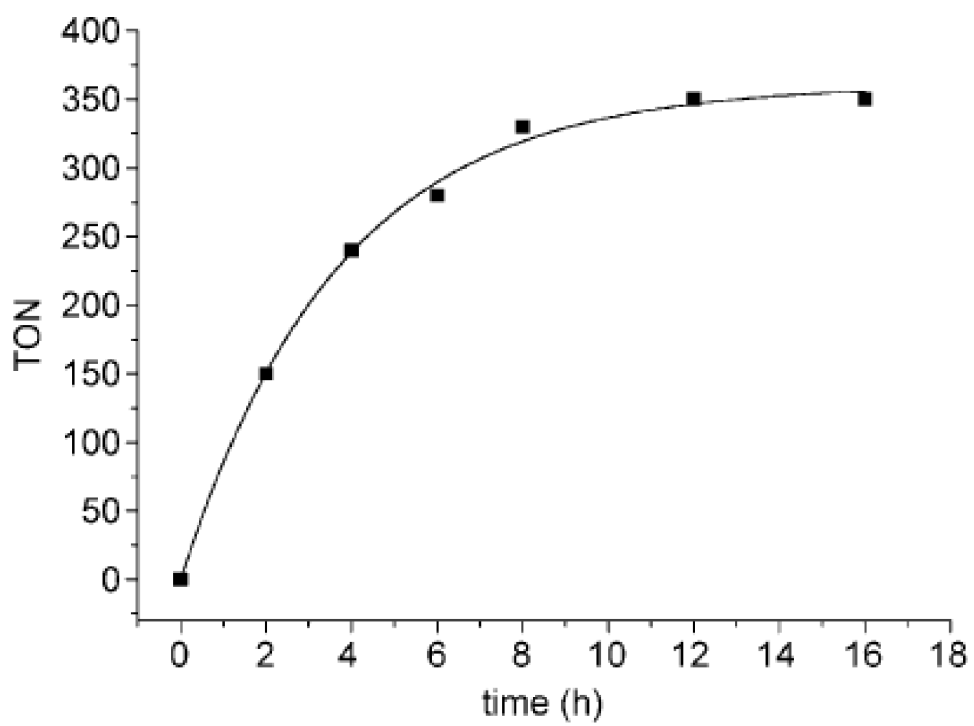

Figure 4. Effect of reaction time on acetylene hydrocarboxylation. Reaction conditions: $\left[\mathrm{Pd}_{2}(\mathrm{dba})_{3}\right] \cdot \mathrm{CHCl}_{3}(2.5 \mathrm{mmol})$, Xantphos $(50 \mathrm{mmol})$, benzoic anhydride $(0.1 \mathrm{mmol}), \mathrm{HCO}_{2} \mathrm{H}(3 \mathrm{mmol})$, acetylene (initial pressure $15 \mathrm{~atm}$, ca. $18 \mathrm{mmol}$ ), in THF $(3 \mathrm{~mL})$ at $100{ }^{\circ} \mathrm{C}$ (reproduced with permission from [28]. Copyright 2015 WILEY-VCH Verlag GmbH \& Co. KGaA).

The same combined catalytic system is suitable for effective hydrocarboxylation of other terminal alkynes. Its application to internal alkynes provides 2,3-substituted derivatives of AA in up to $97 \%$ yields.

Homogeneous catalytic systems composed of 2-pyridyl-diphenylphosphine (2-PyPPh$)$, palladium acetate $\left(\mathrm{Pd}(\mathrm{OAc})_{2}\right)$, and sulfonic acid are highly active and selective in alkyne carbonylation (Scheme 25) [102]. Synthesis of a 2-PyPPh 2 ligand-based porous organic polymer (POL-2V-P,N) laid the foundation for Pd/POL-2V-P,N catalyst. It is prepared by immobilizing $\mathrm{Pd}(\mathrm{OAc})_{2}$ on the POL-2V-P,N support [103]. The heterogenized Pd/POL-2V-P,N catalyst shows higher activity in acetylene methoxycarbonylation than the corresponding Pd-P,N complex under the same conditions.

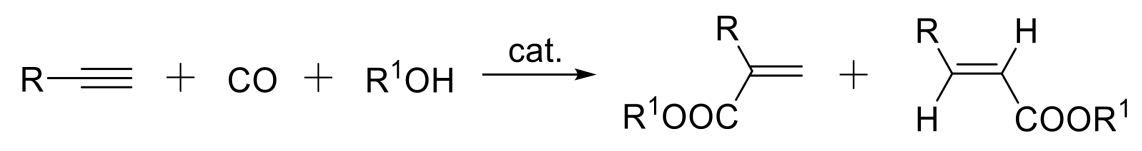

cat.: $\mathrm{Pd}(\mathrm{OAc})_{2} / 2-\mathrm{PyPPh}_{2} / \mathrm{Acids}$

Scheme 25. Palladium-catalyzed hydrocarbonylation of terminal alkynes.

A multifunctional copolymer $\left(\mathrm{PyPPh}_{2}-\mathrm{SO}_{3} \mathrm{H} @\right.$ porous organic polymers, POPs) was prepared by combining acidic groups and heterogeneous $\mathrm{P}, \mathrm{N}$ ligands through the copolymerization of vinyl-functionalized 2-pyridyldiphenylphosphine (2-PyPPh $\mathrm{Ph}_{2}$ and $p$-styrene sulfonic acid (Scheme 26) [104].

In comparison with traditional homogeneous $\mathrm{Pd}(\mathrm{OAc})_{2} / 2_{2}-\mathrm{PyPPh}_{2} / \mathrm{P}$-toluenesulfonic acid catalysts, the copolymer supported palladium catalyst ( $\left.\mathrm{Pd}-\mathrm{PyPPh}-\mathrm{SO}_{3} \mathrm{H} @ \mathrm{POPs}\right)$ exhibits higher activity in alkoxycarbonylation of terminal alkynes under the same conditions. The advantage is attributed to synergistic action of the single-site $\mathrm{Pd}$ centers, 2- $\mathrm{PyPPh}$ ligands, and $\mathrm{SO}_{3} \mathrm{H}$ groups, as well as the swelling properties and high enrichment of the reactant concentrations by the porous catalyst. 


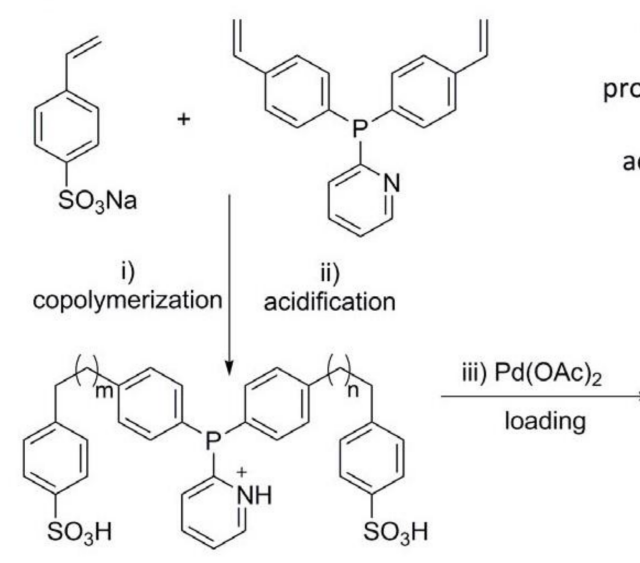

$\mathrm{PyPPh}_{2}-\mathrm{SO}_{3} \mathrm{H} @$ Porous Organic Polymers

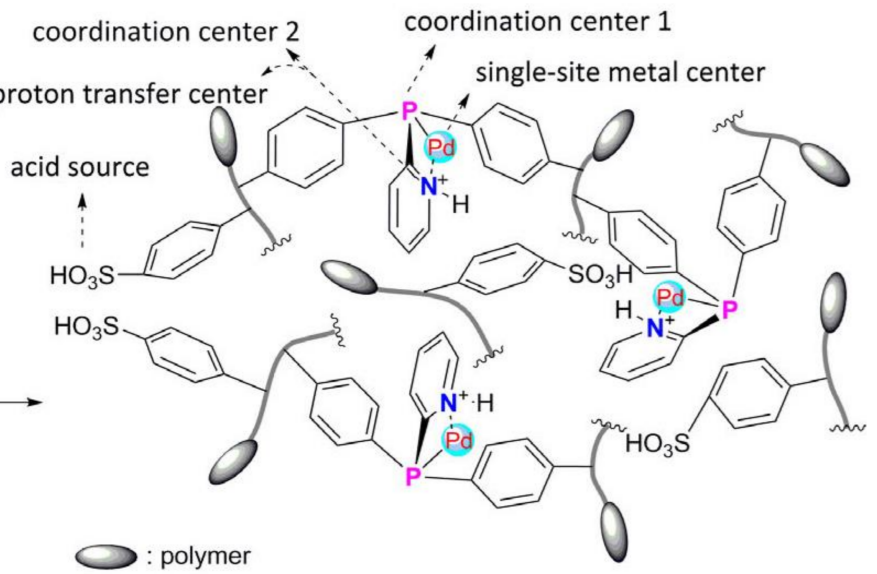

Pd-PyPPh ${ }_{2}-\mathrm{SO}_{3} \mathrm{H} @$ Porous Organic Polymers

Scheme 26. Synthesis of $\mathrm{Pd}-\mathrm{PyPPh}_{2}-\mathrm{SO}_{3} \mathrm{H} @ P O P$ catalyst. Reagents and conditions: (i) $\mathrm{H}_{2} \mathrm{O}, \mathrm{THF}$, AIBN, $120^{\circ} \mathrm{C}$; (ii) $1 \mathrm{M} \mathrm{H}_{2} \mathrm{SO}_{4}$; (iii) $\mathrm{Pd}(\mathrm{OAc})_{2}$, THF.

\subsection{Preparation of Substituted Alkynes}

\subsubsection{Cross-Coupling Reactions}

Sonogashira reaction was discovered in 1975 [105] and represents a fascinating route to various alkynes. Sonogashira cross coupling of acetylene with iodo- and bromoarenes can be successfully applied to obtain symmetric diaryl ethynes [42,106-108]. For example, palladium-catalyzed Sonogashira coupling of acetylene with methyl 4-iodobenzoate (51) gives 4,4'-(1,2-ethynediyl)-bisbenzoic acid (52), a comonomer for the synthesis of liquid crystalline polymer (Scheme 27) [107].

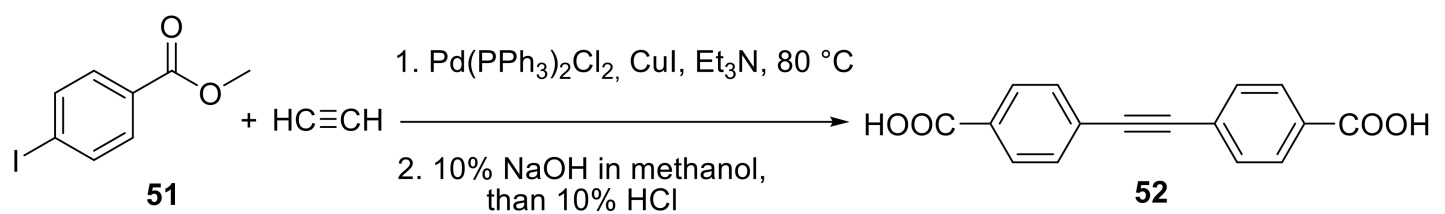

Scheme 27. Palladium-catalyzed Sonogashira coupling of acetylene with methyl 4-iodobenzoate.

In recent studies $[37,42,106]$, calcium carbide was directly used as an acetylene source in cross-coupling reactions to synthesize symmetric diaryl ethynes. Sonogashira coupling of generated from $\mathrm{CaC}_{2}$ and water acetylene with aryl halides $\mathbf{5 3}$ gave rise to substituted diphenylacetylenes $\mathbf{5 4}$ (Scheme 28) [42]. The reaction was carried out in a multiphase one-pot system with fluorinated solvent Galden HT135. The solvent formed a liquid membrane, which separates $\mathrm{CaC}_{2}$ from the water phase and facilitates reagents transport in a controllable manner.

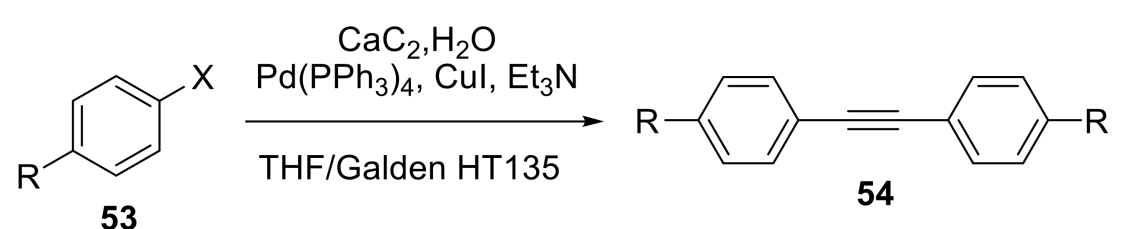

53

$$
\begin{gathered}
\mathrm{R}=\mathrm{H}, \mathrm{Me}, \mathrm{OMe}, \mathrm{F}, \mathrm{CF}_{3} ; \mathrm{X}=\mathrm{I}(78-97 \%) \\
\mathrm{R}=\mathrm{CF}_{3} ; \mathrm{X}=\mathrm{Br}(53 \%)
\end{gathered}
$$

Scheme 28. Cross-coupling with $\mathrm{CaC}_{2}$-derived acetylene. 
Sufficiently good yields were obtained with aryl iodides; the yields for aryl bromides were significantly lower. Using di(4-trifluoromethylphenyl)acetylene resulted in moderate yields of the product (Scheme 28), and 1-bromo-4-methylbenzene showed no reactivity under these conditions [42]. Tetra-n-butyl ammonium fluoride (TBAF) effectively promoted Sonogashira cross coupling reactions between the in situ released acetylene and aryl bromides [106]. For example, yield of diphenylacetylene 55 was increased up to $97 \%$ by using TBAF as an additive (Scheme 29) [106].

$$
\mathrm{Ph}-\mathrm{Br} \underset{\mathrm{TBAF} \cdot 3 \mathrm{H}_{2} \mathrm{O}, \mathrm{DMSO}, 65^{\circ} \mathrm{C}}{\stackrel{\mathrm{Pd}(\mathrm{OAC})_{2}, \mathrm{PPh}_{2}, \mathrm{Cu}(\mathrm{acac})_{2}}{\longrightarrow}} \mathrm{Ph} \underset{\mathbf{5 5 ( 9 7 \% )}}{\stackrel{=}{=}} \mathrm{Ph}
$$

Scheme 29. Catalytic synthesis of diphenylacetylene.

Palladium-catalyzed cross coupling of arylboronic acids or arylboronic pinacol esters with the carbide-derived acetylene led to corresponding diaryl ethynes 56 (Scheme 30) [37]. The synthesis was initiated by simple mixing of the components and afforded the desired products in satisfactory yields.

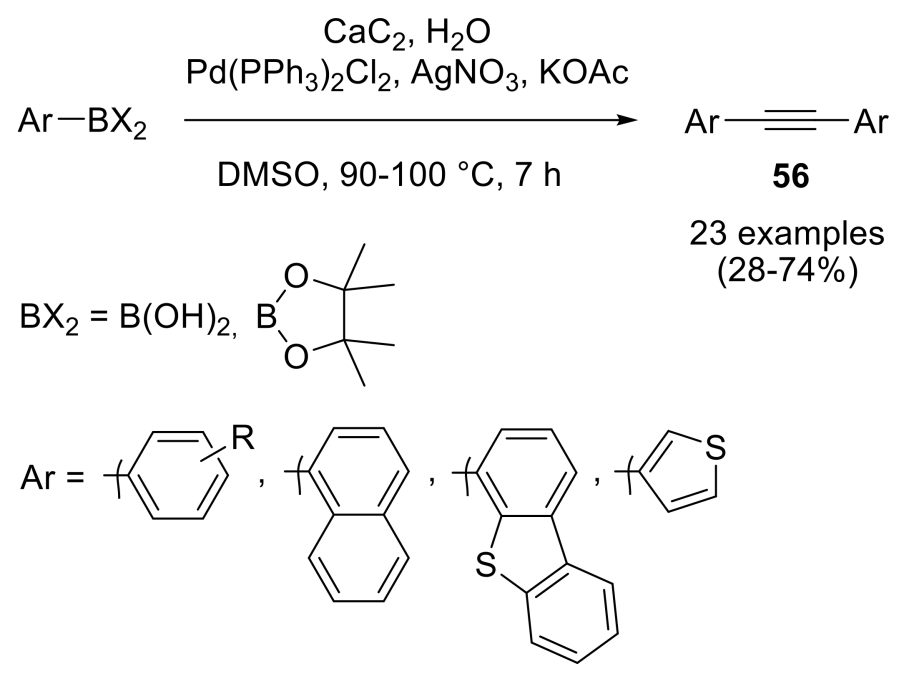

Scheme 30. Catalytic synthesis of diarylethynes.

Catalytic cross coupling with acetylene allows facile production of terminal alkynes, versatile building blocks for drug development and material synthesis. However, constructing terminal alkynes directly from acetylene is problematic due to the low selectivity between terminal and symmetric disubstituted alkynes. This obstacle can be successfully resolved by using flow reactors $[93,109]$. Significant improvements of the reactivity and selectivity result from the distinguished gas/liquid interfacial contact. Sonogashira coupling between acetylene and aryl iodides $\mathbf{5 7}$ in a stop-flow microtubing reactor convincingly affords terminal arylacetylenes 58 as major products (Scheme 31) [93].

Mono-vs. disubstituted product selectivities of the TBAF-promoted Sonogashira coupling of arylhalides 60 with carbide-derived acetylene under various conditions have been examined in a pilot study [106]. The best monosubstitution selectivity was achieved when extra amounts of TBAF and water were gradually added to the reaction mixture during the reaction. The ratio of calcium carbide and water is also important; the best results were obtained at $\mathrm{H}_{2} \mathrm{O}: \mathrm{CaC}_{2}$ molar ratio of 1.3:1. Reactions with 4-methyl-, 4-phenyl-, 4-(dimethylamino)phenyl bromides and 3,5-dimethylphenyliodide gave the corresponding monosubstituted products 61 in $28-57 \%$ yields. Using other aryl halides afforded mixtures of mono- and di-coupled products (with 61:62 ratio of 1:1 to 4:1) in 57-90\% yields (Scheme 32). 


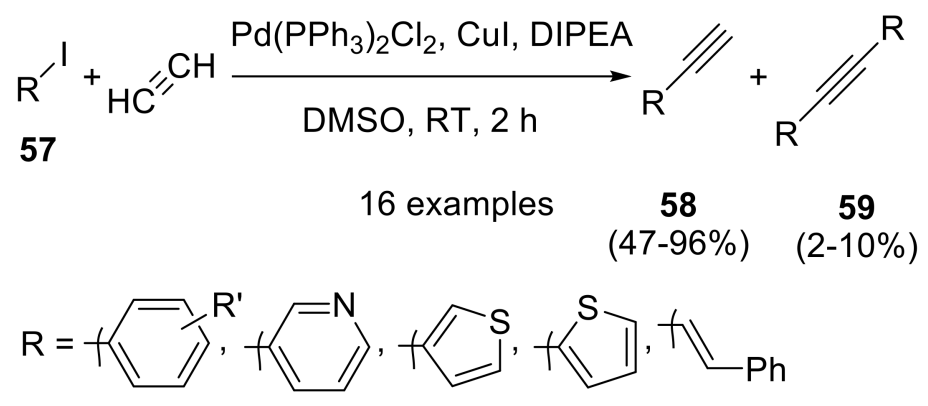

Scheme 31. Sonogashira coupling with aryl iodides in a flow reactor.

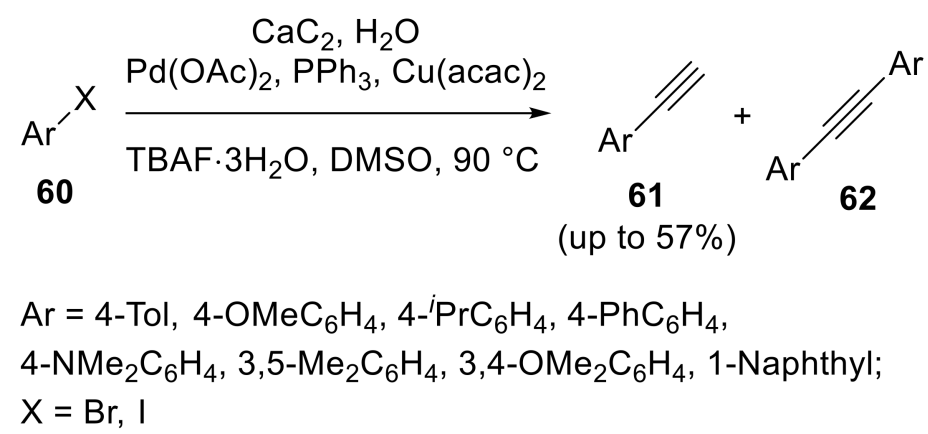

Scheme 32. TBAF-promoted Sonogashira coupling of arylhalides with $\mathrm{CaC}_{2}$-derived acetylene.

A three-component aldehyde-alkyne-amine coupling reaction was also possible with calcium carbide as an acetylene source [42]. The reaction has been originally performed with cyclohexanone (instead of aldehydes) in the multiphase one-pot system with fluorous liquid membrane Galden HT135. The system allows obtaining up to $75 \%$ yields of the desired products (Scheme 33).
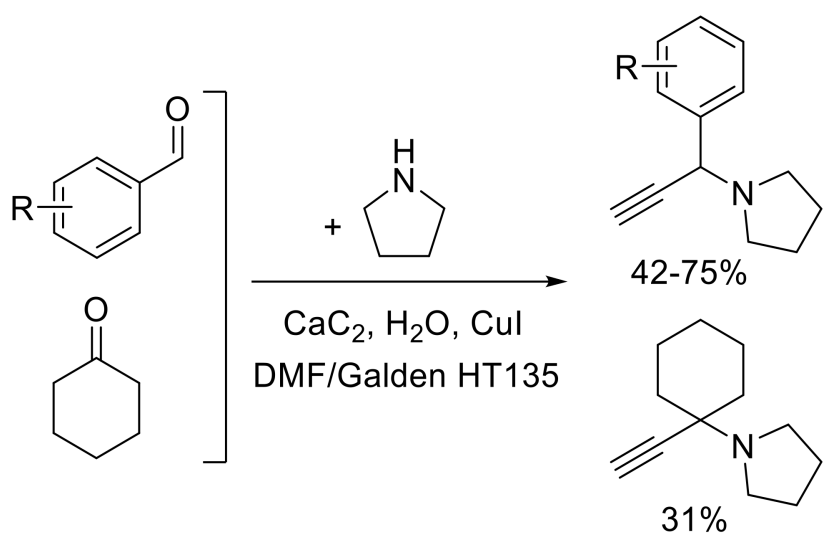

$\mathrm{R}=\mathrm{H}, 4-\mathrm{OMe}, 4-\mathrm{Me}, 2,5-(\mathrm{OMe})_{2}$

Scheme 33. Three-component aldehyde-alkyne-amine coupling.

A copper-catalyzed Sonogashira-type reaction provides the means for allylation of acetylene with allyl halides [110]. Mono-coupled product 64 can be obtained in up to $80 \%$ yield by cross-coupling of acetylene with allyl halides 63 under atmospheric pressure in the presence of copper(I) iodide, a base, and a reducing agent. Excess amounts of allyl halide over acetylene lead to predominant formation of disubstituted product 65 in up to $72 \%$ yield (Scheme 34 ). 


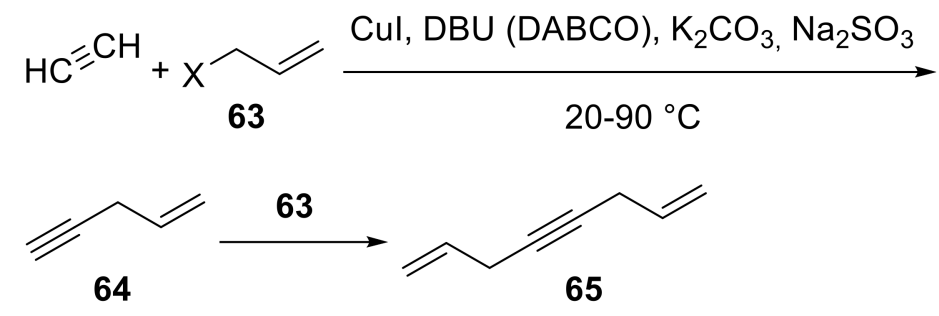

$\mathrm{X}=\mathrm{I}, \mathrm{Br}, \mathrm{Cl}$

Scheme 34. Copper-catalyzed Sonogashira-type allylation.

A recently reported catalytic system promoted oxidative homocoupling of acetylene under oxygen atmosphere in the presence of carbon-supported gold nanoparticles [111]. The reaction resulted in 70\% yield of corresponding dimer 66 (Scheme 35) [111].

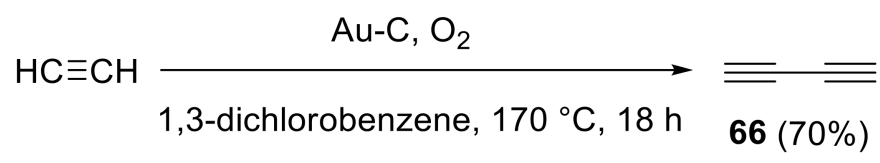

Scheme 35. Gold-catalyzed oxidative homocoupling.

\subsubsection{Favorskii Reaction}

Introduced in the early 20th century by Favorskii [112] the reaction for obtaining propargyl alcohols by alkynylation of carbonyl compounds is still a heavy hitter [34,113-120]. Convenient and mild synthetic procedures for alkynylation of various aldehydes and ketones have been recently reported by Trofimov et al. [34,113,114]. The catalytic system $\mathrm{KOH}-\mathrm{H}_{2} \mathrm{O}-\mathrm{DMSO}[34,113]$ was appropriate for the synthesis of secondary propargyl alcohols 68 from aromatic and heteroaromatic aldehydes 67 and acetylene (Scheme 36). The reaction was performed under atmospheric pressure, at constant bubbling of acetylene through a reaction mixture. The target products were obtained in satisfactory yields.

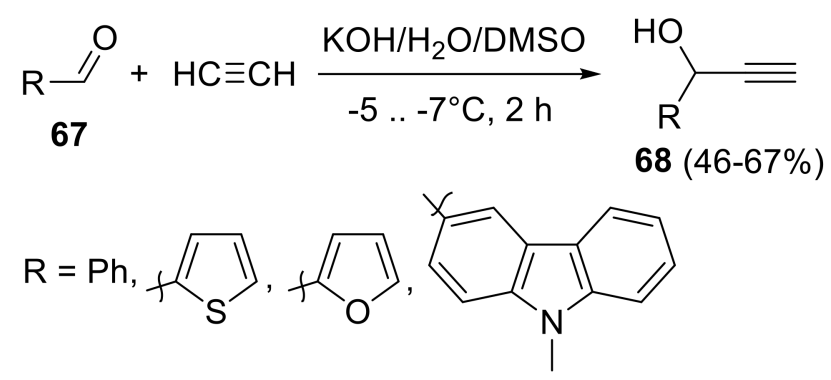

Scheme 36. Synthesis of secondary propargyl alcohols from aldehydes.

The procedure was modified by addition of ethanol to the $\mathrm{KOH}-\mathrm{H}_{2} \mathrm{O}-\mathrm{DMSO}$ system and used for the Favorskii reaction of alkyl aryl ketones 69 with acetylene (Scheme 37) [114]. The desired tertiary propargyl alcohols $\mathbf{7 0}$ were obtained in good yields. 


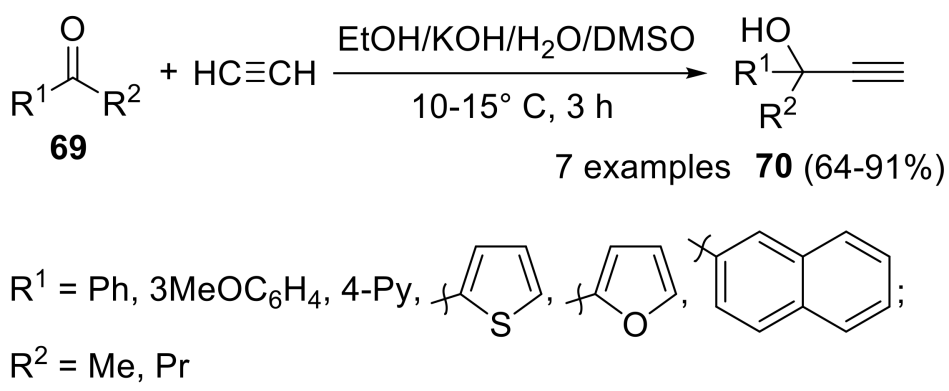

Scheme 37. Reaction of alkyl aryl ketones with acetylene.

The $\mathrm{Bu}_{4} \mathrm{NOH}-\mathrm{H}_{2} \mathrm{O}-\mathrm{DMSO}$ [115] catalytic system was suitable for alkynylation of both aromatic and aliphatic aldehydes and ketones. The reaction was carried out in a flow reactor under atmospheric pressure of acetylene. This protocol was efficient for different types of substrates: propargylic alcohols were prepared in high yields from aromatic, heteroaromatic, cyclic and acyclic aliphatic carbonyl compounds (Scheme 38).

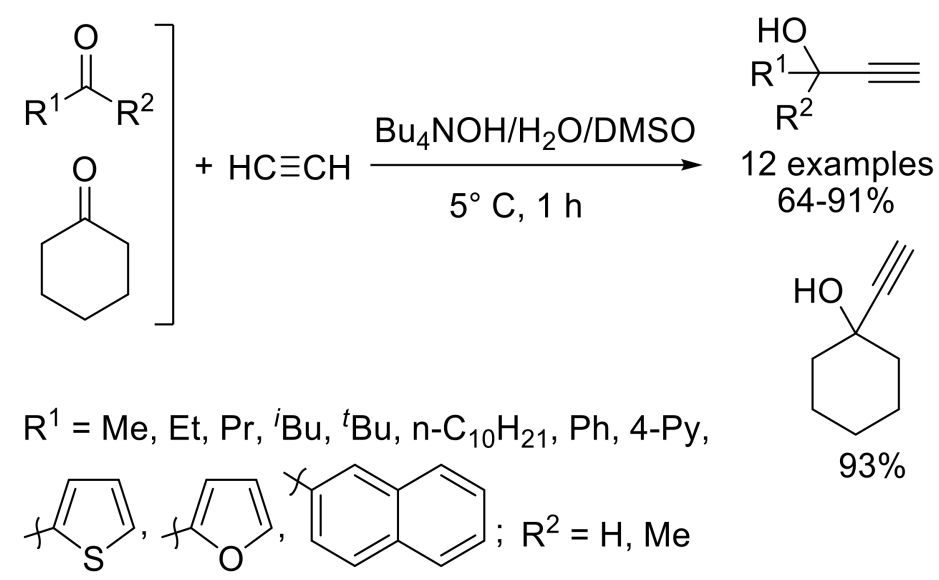

Scheme 38. $\mathrm{Bu}_{4} \mathrm{NOH}-$ mediated alkynylation of carbonyl compounds.

The synthesis of ferrocene-derived propargylic alcohol demonstrates the versatility of Favorskii reaction. 1-Phenyl-1-ferrocenyl-2-propin-1-ol (72) was formed through passing of acetylene into a $\mathrm{KOH}$ suspension in THF with benzoylferrocene 71 (Scheme 39) [116].

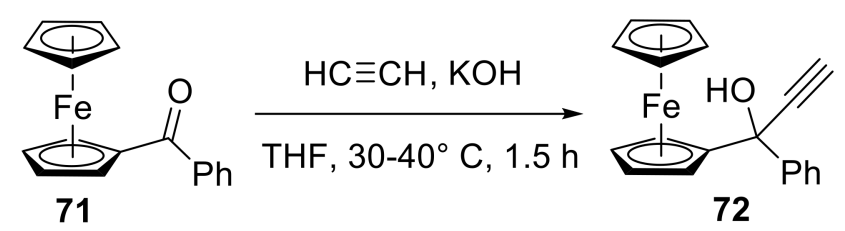

Scheme 39. Synthesis of ferrocene-substituted propargyl alcohols.

Alkynylation of carbonyl compounds with metal acetylides represents an alternative to the direct base-catalyzed alkynylation with gaseous acetylene $[117,118]$. Reaction of aldehydes and ketones with in situ generated ethynylmagnesium bromide is carried out in a commercially available falling film microreactor (FFMR) [117]. Consistent gas-liquid contact in the continuous microflow setting is a prerequisite for effective generation of ethynyl-Grignard reagent from $\mathrm{EtMgBr}$ and acetylene. The protocol affords a number of propargyl alcohols in high yields and short reaction times, under atmospheric pressure and low reaction temperature (Scheme 40). 


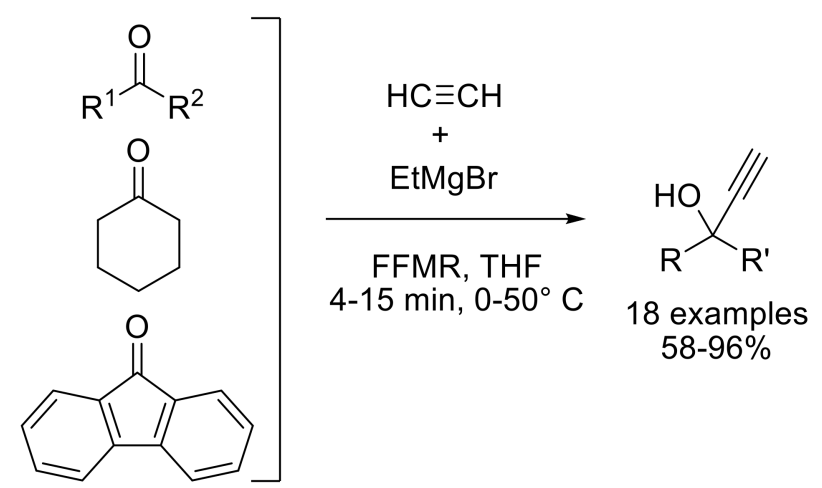

$\mathrm{R}^{1}=\mathrm{Ph}, 4-\mathrm{MeOC}_{6} \mathrm{H}_{4}, 4-\mathrm{BrC}_{6} \mathrm{H}_{4}, 2-\mathrm{BrC}_{6} \mathrm{H}_{4}, 4-\mathrm{ClC}_{6} \mathrm{H}_{4}$, 4- $\mathrm{FC}_{6} \mathrm{H}_{4}, 3,4,5-(\mathrm{MeO})_{3} \mathrm{C}_{6} \mathrm{H}_{2}$, 4-Py, n-Bu, Me,

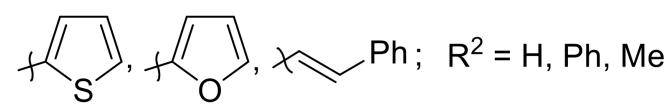

Scheme 40. Favorskii alkynylation with in situ generated ethynylmagnesium bromide.

Lithium acetylide was used for the preparation of decalin-derived acetylenic alcohol 74, an intermediate for the multistep synthesis of racemic forskolin [118]. Selective addition of monolithium acetylide to one of the two carbonyl groups in cis-decalin $\mathbf{7 3}$ and subsequent epimerization in the presence of aluminum oxide afforded trans-decalin 74 in overall yield $82 \%$ (Scheme 41 ).<smiles>CC1=CCC2(C)C(C)(C)C(C)=CC(=O)[C@]2(C)C1=O</smiles>

73

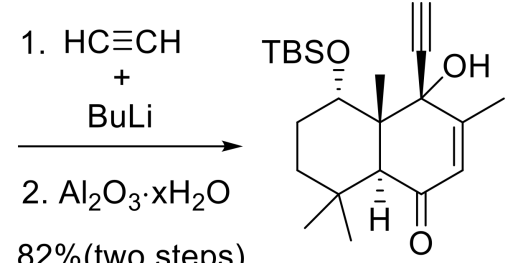

74

Scheme 41. Favorskii alkynylation with in situ generated lithium acetylide.

Replacement of gaseous acetylene with solid calcium carbide is frequently proposed in recent studies of Favorskii reaction $[119,120]$. Reactions can be performed for a wide substrate scope including aromatic and aliphatic aldehydes and ketones (Scheme 42).

TBAF [119] or $\mathrm{Cs}_{2} \mathrm{CO}_{3}$ [120] were used as catalysts, and using of TBAF provided higher yields. Activation of calcium carbide by fluoride is thought to generate an acetylide "ate"-complex that readily adds to carbonyl groups [119]. Both Sonogashira cross coupling and Favorskii alkynylation with acetylene are currently in demand. Mild and environmentally benign protocols for these reactions, including those with the in situ generated acetylene, continuously evolve. 


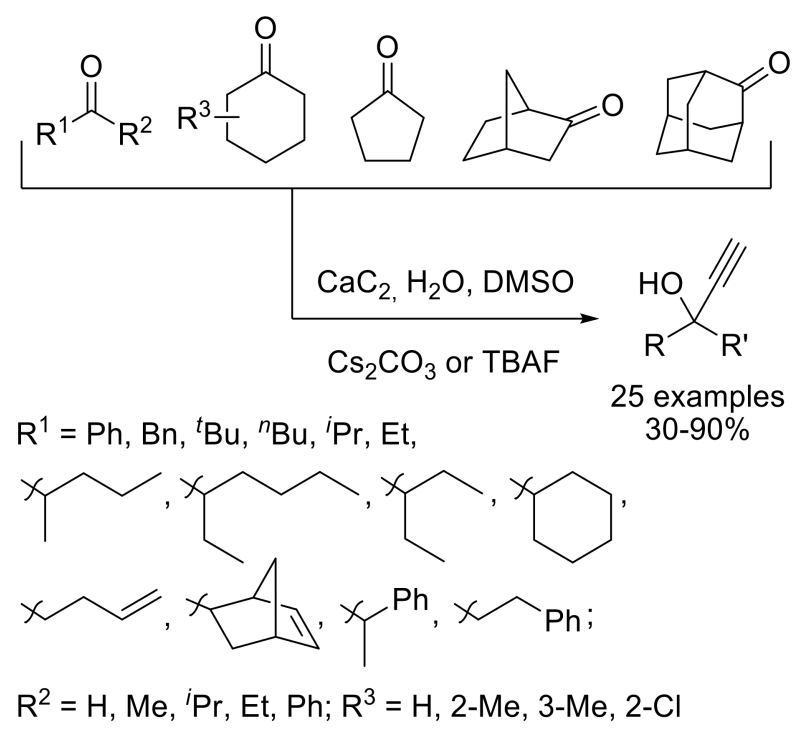

Scheme 42. Favorskii reaction with in situ generated acetylene.

\subsection{Synthesis of Heterocycles}

\subsubsection{Cycloaddition Reactions}

Priority of pot-, atom-, and step-economy is one of the prevailing concepts in modern applied chemistry [121]. Cycloaddition reactions of acetylene fully conform to these rules, which makes these reactions especially relevant. Cycloaddition usually implies formation of several C-C and C-heteroatom bonds in one synthetic operation. Besides, these reactions afford many useful heterocyclic compounds. In particular, [3 + 2]-cycloaddition reactions of acetylene with active dipoles are increasingly used in synthesis of five-membered heterocycles [41-44,122-128].

1,2,3-Triazoles are produced in the copper-catalyzed click-reactions of organic azides with acetylene [44,122-124]. These reactions can be performed in aqueous media under atmospheric pressure [44,122]. A handy procedure for obtaining 1-substituted 1,2,3-triazoles involves CuI-Et $3 \mathrm{~N}$ as a catalyst and water as a solvent [44]. Its application to a variety of substrates facilitates transformation of substituted phenyl, benzyl, and octyl azides into corresponding substituted triazoles 75 in up to $96 \%$ yield (Scheme 43 ).

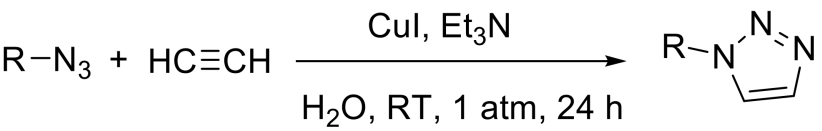

$$
\begin{aligned}
& 75(29-96 \%) \\
& \mathrm{R}=\mathrm{Ph}, 2-\mathrm{Tol} \text {, 3-Tol, 4-Tol, 4- } \mathrm{MeOC}_{6} \mathrm{H}_{4}, 2-\mathrm{ClC}_{6} \mathrm{H}_{4} \text {, } \\
& \text { 3- } \mathrm{ClC}_{6} \mathrm{H}_{4}, 4-\mathrm{ClC}_{6} \mathrm{H}_{4}, 4-\mathrm{BrC}_{6} \mathrm{H}_{4}, 4-\mathrm{NO}_{2} \mathrm{C}_{6} \mathrm{H}_{4} \text {, } \\
& \text { 4-EtOCOC } 6 \mathrm{H}_{4}, 3-\mathrm{CNC}_{6} \mathrm{H}_{4}, 2-\mathrm{HOC}_{6} \mathrm{H}_{4}, \mathrm{Bn}, 1-\text { octyl }
\end{aligned}
$$

Scheme 43. [3 + 2]-Cycloaddition of azides to acetylene, method 1 .

A water soluble catalyst 77 based on $N$-heterocyclic carbenes-Cu complex for [3+2]-cycloaddition of azides 76 and acetylene was proposed [122]. Various alkyl and benzyl triazoles 78 were obtained in high yields using 77 as catalyst. The reactions were carried out in water or 1:1 DMSO/water mixture (Scheme 44). 


$$
\begin{aligned}
& \underset{76}{\mathrm{R}-\mathrm{N}_{3}}+\mathrm{HC} \equiv \mathrm{CH} \underset{\mathrm{H}_{2} \mathrm{O} \text { or } \mathrm{H}_{2} \mathrm{O}: \text { DMSO 1:1 }}{\mathbf{7 7}, \mathrm{Et}_{3} \mathrm{~N}} \mathrm{R}-\mathrm{N}^{-\mathrm{N}} \\
& \text { RT, } 1 \text { atm, } 12-24 \text { h } \quad 78 \text { (75-99\%) }
\end{aligned}
$$

$\mathrm{R}=\mathrm{Bn}, 4-\mathrm{FBn}, 4-\mathrm{CNBn}, 4-\mathrm{NO}_{2} \mathrm{Bn}, \mathrm{Ph}\left(\mathrm{CH}_{2}\right)_{2}$, Me, 1-heptyl,<smiles>C=CCCC=[14CH]C(=O)OC(=O)I</smiles>

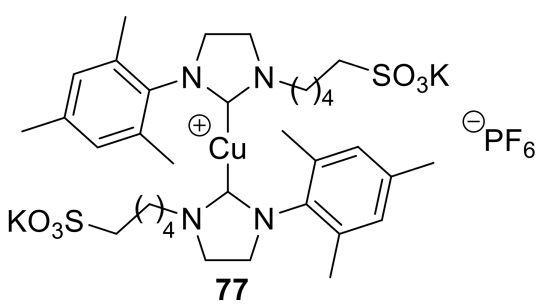

Scheme 44. [3 + 2]-Cycloaddition of azides to acetylene, method 2 .

Triazole-fused benzoheterocycles were prepared via $\mathrm{Cu}$-catalyzed click-reaction of $o$-iodo-azides 79 with acetylene and subsequent Pd-catalyzed intramolecular coupling [123]. The triazole-fused isoindole derivative 80 can be obtained in one-pot manner. Obtaining of six-, seven- and eight-membered heterocycles $\mathbf{8 1}$ requires a two-step procedure (Scheme 45 ).<smiles>N#[W]c1ccccc1I</smiles>

79

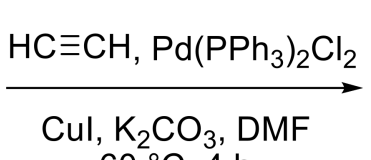
$60^{\circ} \mathrm{C}, 4 \mathrm{~h}$<smiles>c1ccc2c(c1)Cn1nncc1-2</smiles>

$80(60 \%)$

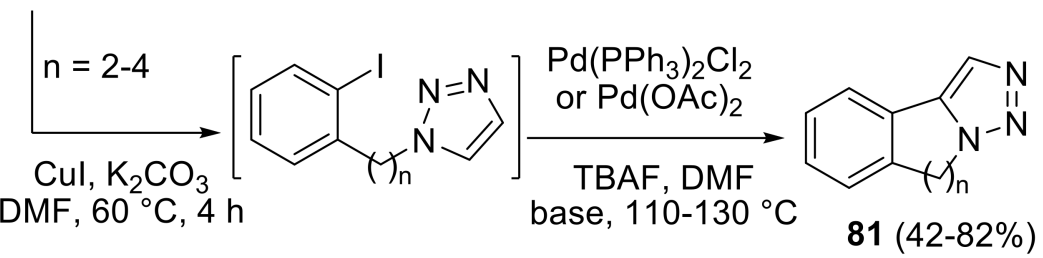

Scheme 45. Click-reaction of o-iodo-azides with $\mathrm{C}_{2} \mathrm{H}_{2}$.

Identical Cu-catalyzed cycloadditions can be performed with calcium carbide instead of gaseous acetylene [42]. Triethylamine serves as a solvent and base simultaneously, while Galden HT135 effectively separates $\mathrm{CaC}_{2}$ from the organic phase. Benzyl azides with variously substituted phenyl rings undergo cyclization with the released acetylene to afford good yields of the corresponding triazoles (Scheme 46).

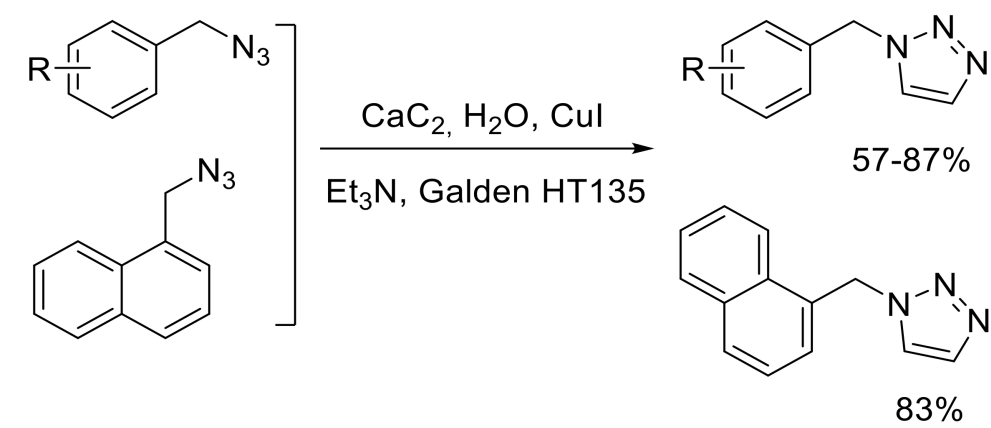

$\mathrm{R}=\mathrm{H}, 4-\mathrm{Me}, 2-\mathrm{Me}, 4-\mathrm{Cl}, 2-\mathrm{Cl}, 4-\mathrm{OMe}, 4-\mathrm{CF}_{3}$

Scheme 46. Cycloaddition with $\mathrm{CaC}_{2}$.

Similar 1,3-dipolar cycloadditions of the calcium carbide-derived acetylene to diazo compounds [126], nitrile oxides [41] and nitrile imines [43] were reported.

Calcium carbide was used as an acetylene source to react with a wide range of $N$-tosylhydrazones 82 derived from aldehydes or ketones, affording various substituted pyrazoles in good yields with high regioselectivities [126]. When $N$-tosylhydrazones were derived from aldehydes, the starting materials 
were smoothly transformed into the corresponding products 83 . Ketone-derived $N$-tosylhydrazones afforded the pyrazoles $\mathbf{8 4}$ and $\mathbf{8 5}$ with regioselectivities of more than 5:1 (Scheme 47).

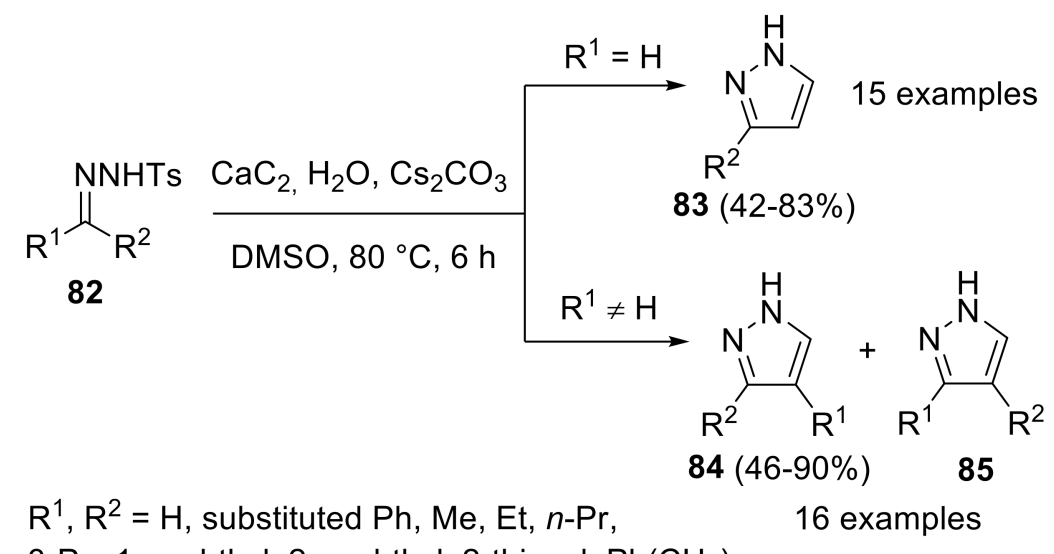

3-Py, 1-naphthyl, 2-naphthyl, 2-thienyl, $\mathrm{Ph}\left(\mathrm{CH}_{2}\right)_{2}$

Scheme 47. Synthesis of NH-pyrazoles from N-tosylhydrazones.

The mechanism of these transformations plausibly involves [3 +2$]$-cycloadditions of in situ generated diazo compounds followed by [1,5]-sigmatropic rearrangements (Scheme 48) [126]. Initial deprotonation of $\mathrm{N}$-tosylhydrazone 82 in the presence of $\mathrm{Cs}_{2} \mathrm{CO}_{3}$ gives cesium salt $\mathbf{A}$, which undergoes rapid transformation into reactive diazo compound $\mathbf{B}$. Its [3 + 2]-cycloaddition with acetylene affords a $3 H$-pyrazole compound $\mathrm{C}$. When $\mathrm{R}^{1}$ is $\mathrm{H}, 83$ is formed via [1,5-H]-shift and tautomerization. When $R^{1}$ is aryl and $R^{2}$ is alkyl, migration of $R^{1}$ or $R^{2}$ to $C 4$ occurs. Subsequent multiple [1,5]-sigmatropic rearrangements result in formation of $\mathbf{8 4}$ or $\mathbf{8 5}$. Since the migration ability of electron-rich aryl group is higher than that of alkyl group [126], migration of $R^{1}$ to $C 4$ is favored, and pyrazoles 84 predominate as major products. This proposed mechanism was supported by deuterium-labeling experiments [126].

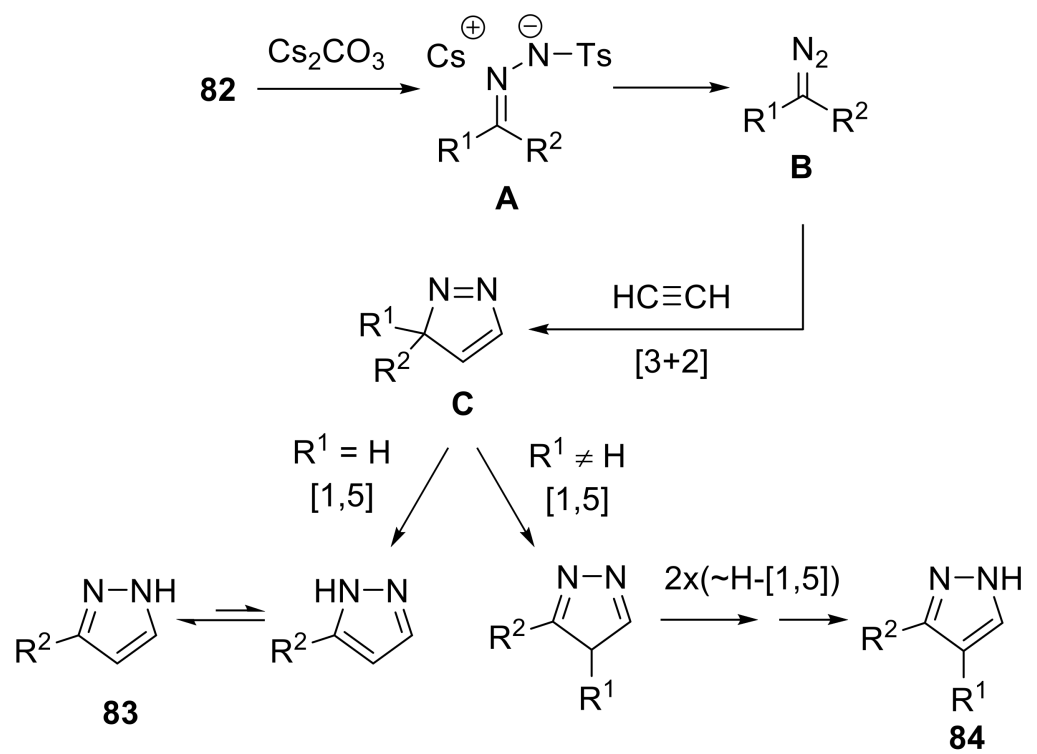

Scheme 48. NH-Pyrazole formation mechanism.

A convenient synthetic methodology for the one-pot preparation of isoxazoles $\mathbf{8 7}$ directly from the reaction of calcium carbide with aldoximes $\mathbf{8 6}$ was developed [41]. This method is based on a 1,3-dipolar cycloaddition of nitrile oxides to acetylene. Nitrile oxides precursors, chloroaldoximes 88 were formed in situ by aldoxime chlorination with $\mathrm{N}$-chlorosuccinimide (NCS). Reaction of $\mathrm{CaC}_{2}$ with the water provides the sources of both acetylene and $\mathrm{Ca}(\mathrm{OH})_{2}$ base to enable generation of nitrile 
oxides 89 . Various 3 -substituted isoxazoles 87 were synthesized from the corresponding aldoximes 86 in up to $95 \%$ yields (Scheme 49 ).

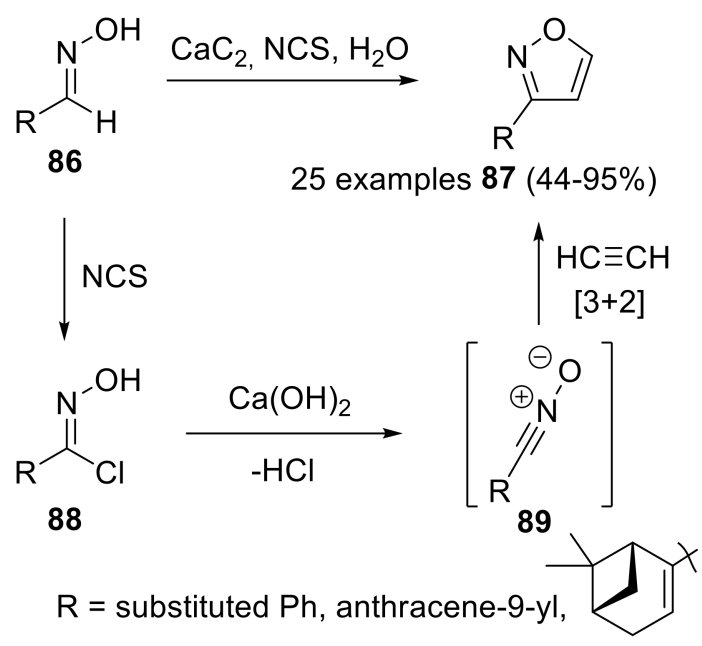

Scheme 49. $\mathrm{CaC}_{2}$-mediated synthesis of isoxasoles from aldoximes.

An efficient protocol for the preparation of 1,3-disubstituted pyrazoles 91 from [3+2]-cycloaddition reactions of in situ generated nitrile imines 92 with $\mathrm{CaC}_{2}$-derived acetylene was reported [43]. The reactions were performed in a two-chambered reactor in order to separate the water-sensitive nitrile imines from the acetylene-generating mixture. One part of the reactor was loaded with hydrazonoyl chloride precursors 90 of active nitrile imine species and $\mathrm{Et}_{3} \mathrm{~N}$ as a base. The other part was used to generate acetylene from $\mathrm{CaC}_{2}$ and water. Escaping from the carbide chamber, acetylene readily dissolves in the reaction mixture with nitrile imines freshly derived from hydrazonoyl chlorides and $\mathrm{Et}_{3} \mathrm{~N}$ as a base. A variety of 1,3-disubstituted pyrazoles 91 were produced in up to quantitative yields by this approach (Scheme 50).

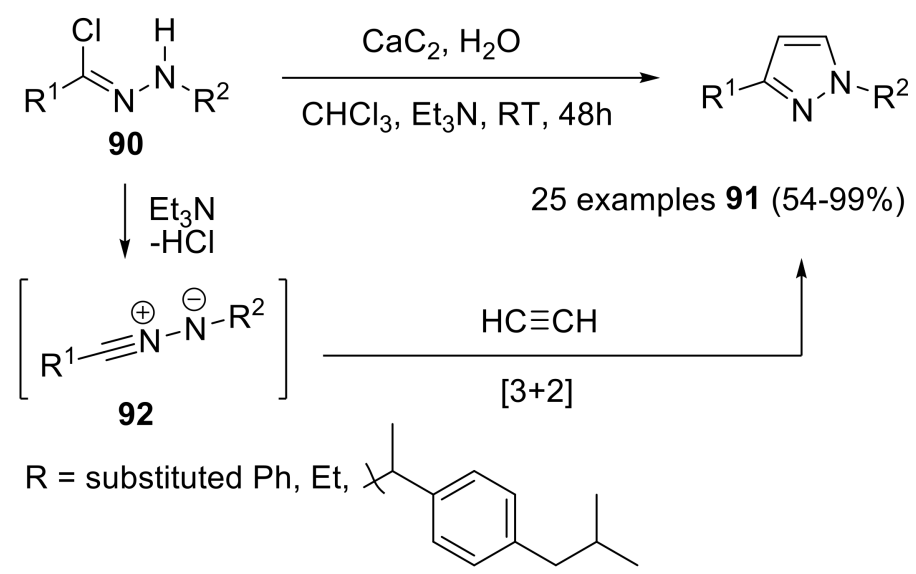

Scheme 50. Obtaining 1,3-disubstituted pyrazoles by [3+2]-cycloaddition.

Utilization of carbide and water as an acetylene source in cycloaddition reactions is not just safe and convenient, but allows to obtain deuterium-labeled heterocycles by using deuterated water, as exemplified by syntheses of 4,5-dideuteroisoxazoles and 4,5-dideuteropyrazoles [41,43].

Unusual dipoles, diazoalkane complexes 93 reacted with acetylene under mild conditions [127]. The reactions proceeded through the [3 +2$]$-cycloaddition of the acetylene to the coordinated diazoalkane, yielded $3 \mathrm{H}$-pyrazole derivatives 94 (Scheme 51). 


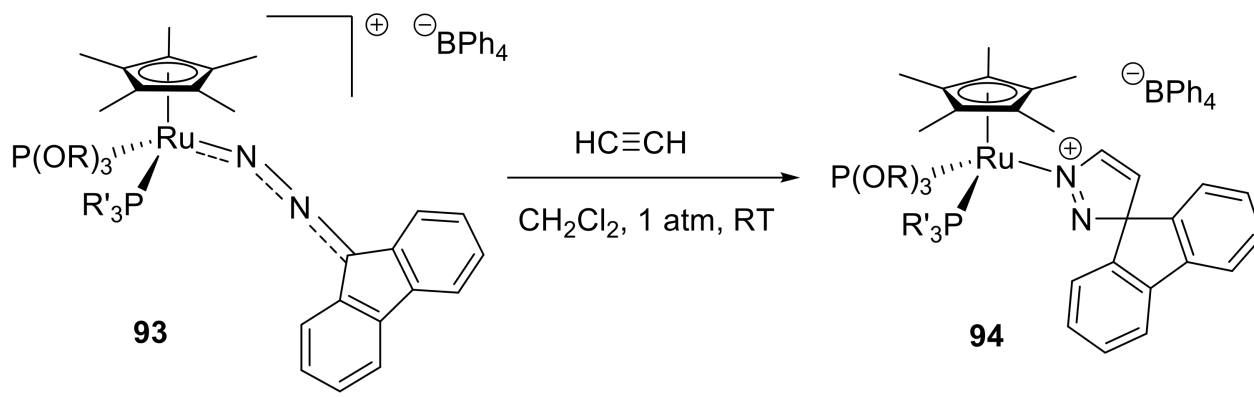

$\mathrm{R}=\mathrm{Me}, \mathrm{Et} ; \mathrm{R}^{\prime}=\mathrm{OEt}, \mathrm{Ph}$

Scheme 51. Synthesis of $3 \mathrm{H}$-pyrazole derivatives of diazoalkane dipole complexes.

Three-component cycloaddition reactions of acetylene were also described [129-132]. Rhodium-catalyzed [4 $2+2]$-cycloaddition of dienynes and acetylene gave rise to oxygenand nitrogen-containing polycyclic cyclooctatrienes in moderate to good yields (Scheme 52) [129]. The desired products were obtained in greater than 20:1 diasteromeric excess.

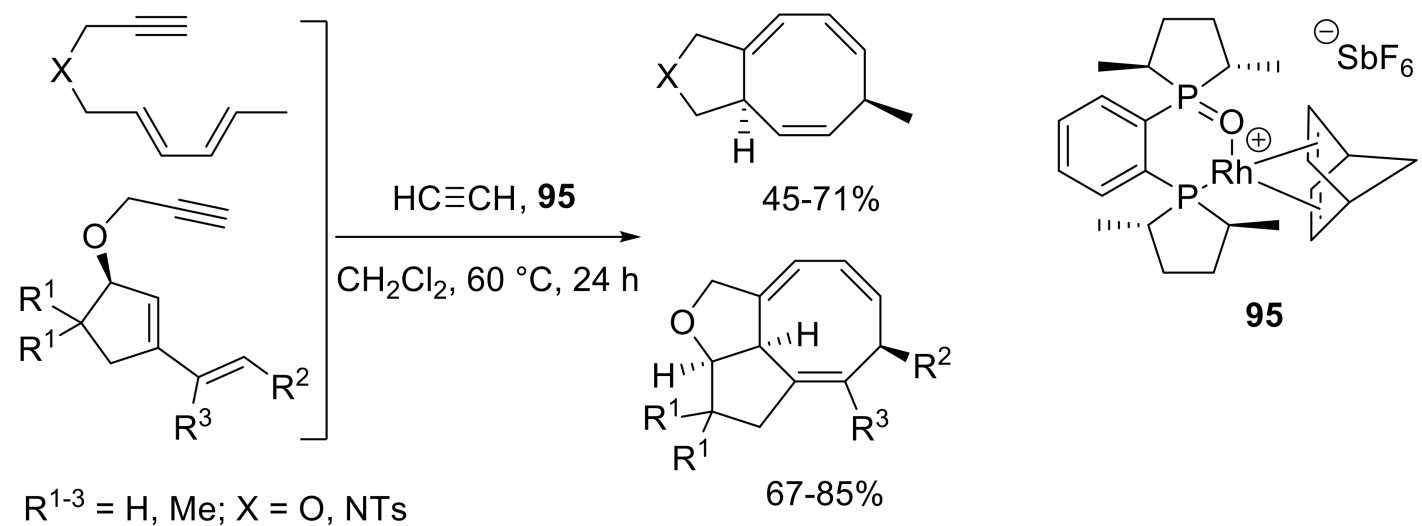

Scheme 52. Three-component cycloaddition with acetylene.

Cobalt-mediated [2 + 2 +2]-cycloaddition reaction of acetylene and diyne 96 afforded bicyclic product 97, which was employed as an intermediate in the total synthesis of the putative structure of xylarinol B (Scheme 53) [130].

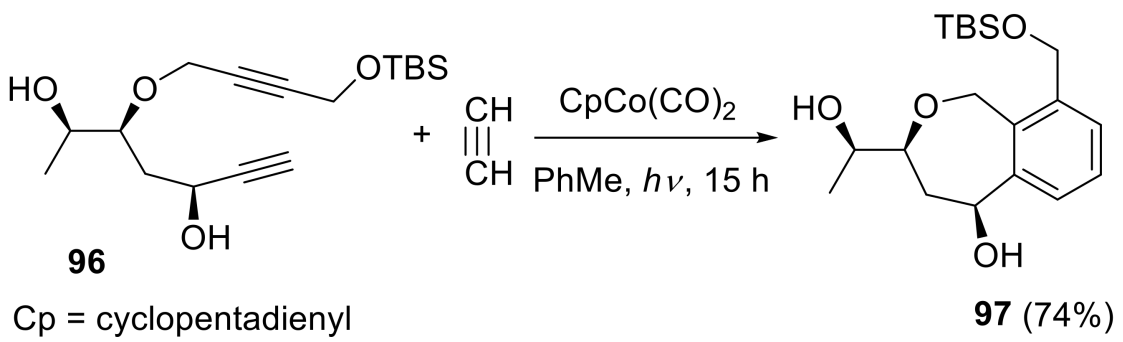

Scheme 53. Cobalt-catalyzed [2+2+2]-cycloaddition.

Synthesis of boron-containing heterocycles [131,132] through [2+2+2]-cycloaddition reactions involving acetylene was also reported. In addition, [2 + 2]-cycloaddition with acetylene were used for the preparation of Ge- [133], Si- and Ti-containing [134] inorganic heterocycles. 


\subsubsection{Trofimov Reaction}

Reaction of ketoximes with acetylene under superbasic conditions, known as Trofimov reaction, is widely used for synthesis of pyrroles and 1-vinylpyrroles [13,39]. The reaction mechanism [39] involves initial O-vinylation of starting oxime 98 and subsequent [3,3]-sigmatropic shift in the intermediate O-vinyl oxime 99 to form aldehyde-imine compound 100. The aldehyde-imine intermediate undergoes a cyclization-dehydration-tautomerization sequence to give pyrrole 101 . Further reaction with the second acetylene molecule leads to the formation of N-vinyl pyrrole 102 (Scheme 54).<smiles>[R]C/C(CC#CC)=N/OCC</smiles>

98<smiles>[R]C1=NC(O)CC1[R]</smiles>

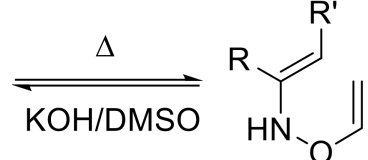

99<smiles>[R]C1=NC(C)=CC1[R]</smiles><smiles>[R]c1cc[nH]c1[R]</smiles>

101<smiles>[R]C(=N)C([R])CC=O</smiles>

100

Scheme 54. Trofimov reaction.

Heterocyclization of ketoximes with acetylene into pyrroles and N-vinylpyrroles is normally performed in an autoclave under an initial acetylene pressure of 8-16 atm (most commonly 10-12 atm) [135] with $\mathrm{KOH}-\mathrm{DMSO}$ as a superbase [135]. A recently developed modification of the procedure involves a flow reactor [136]; it allows to perform the synthesis of 3-alkyl-2-phenyl-1-vinylpyrroles under atmospheric acetylene pressure (Scheme 55) [137].

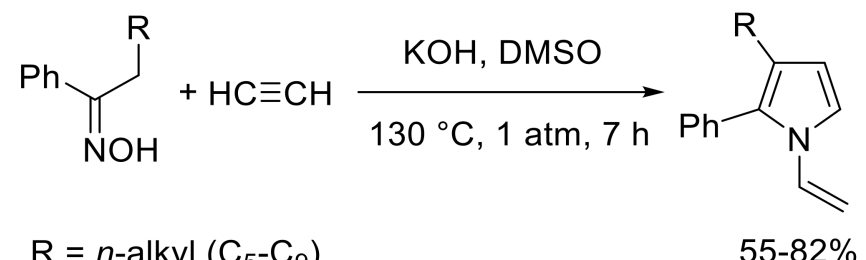

Scheme 55. A modified procedure for obtaining 3-alkyl-2-phenyl-1-vinylpyrroles.

The substrate scope of Trofimov reaction is constantly expanding [138-140]. The synthesis of 3-(E)-styrylpyrroles 104 from (E)-styrylmethyl ketoximes 103 and acetylene was recently reporded [138]. Phenyl- and naphthyl-derivatives 104a gave rise to the corresponding 1-vinylpyrroles 104a. $1 \mathrm{H}$-Pyrrole $\mathbf{1 0 4 b}$ was obtained from biphenyl-derived oxime 103b (Scheme 56).
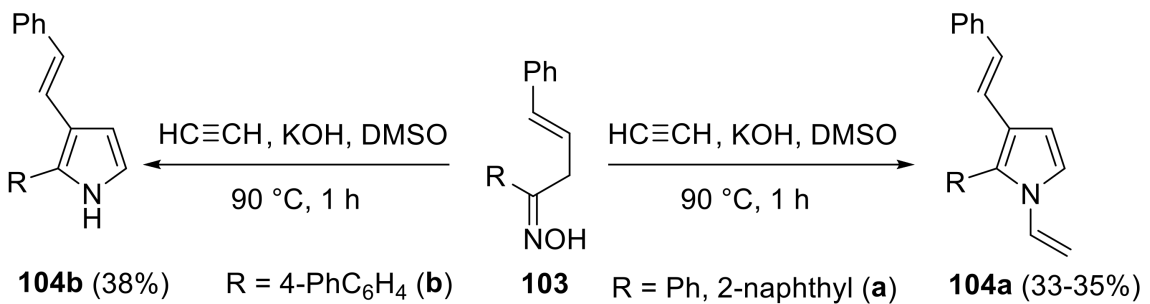

Scheme 56. Synthesis of 3-(E)-styrylpyrroles from $(E)$-styrylmethyl ketoximes.

Other biphenyl-derived oximes 105 reacted with acetylene under superbasic conditions to afford predominantly 1-vinylpyrroles 106 [139]. 1-Unsubstituted pyrroles 107 can be obtained by devinylation of 1-vinylpyrroles 106 in the presence of mercuric acetate (Scheme 57) [139]. 
<smiles>[R]CC(=N)c1ccc(-c2ccccc2)cc1</smiles>

$\mathrm{R}=\mathrm{H}, \mathrm{Ph}$<smiles>[R]c1ccn(C=C)c1-c1ccc(-c2ccccc2)cc1</smiles>

$106(40-53 \%)$

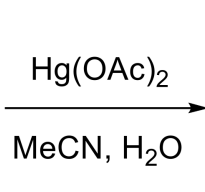<smiles>[R]c1cc[nH]c1-c1ccc(-c2ccccc2)cc1</smiles>

Scheme 57. Trofimov heterocyclization of bifenyl-derived oximes.

Various 2-arylpyrroles 108 were synthesized through the Trofimov reaction directly from calcium carbide as an acetylene source (Scheme 58) [40].

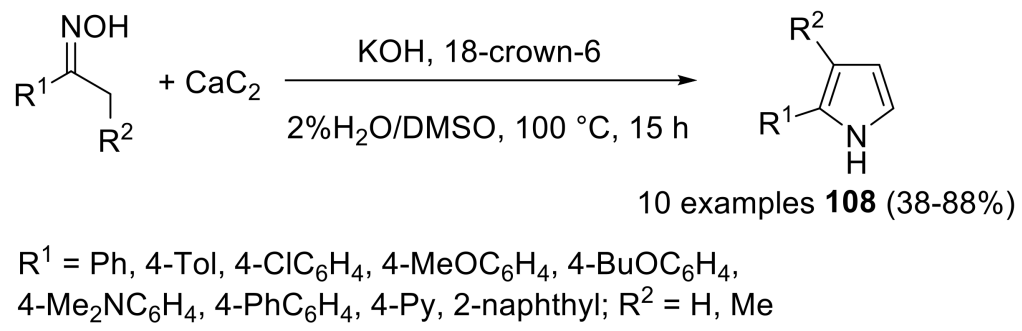

Scheme 58. Synthesis of 2-arylpyrroles with calcium carbide and water.

The reactions were performed using DMSO with $2 \%$ of water as a solvent. 18 -Crown- 6 was used as a catalyst to improve the pyrroles yields. It proceeds selectively and results in formation of $1 H$-pyrroles with only trace amounts of 1-vinylpyrroles When using ketoximes with only one neighboring $\mathrm{C}-\mathrm{H}$ bond, the formation of $1 \mathrm{H}$-pyrroles is inhibited. In such cases the intermediate 5-hydroxypyrrolines $[141,142]$ and $3 H$-pyrroles $[143,144]$ can be isolated as main products. Reactions of acetylene with various sec-alkyl aryl ketoximes $\mathbf{1 0 9}$ afforded the corresponding 5-hydroxypyrrolines 110 in moderate yields [141,142]. The reaction can be performed in a one-pot manner [141] or in a two-step sequence [142] isolating O-vinylketoxime intermediates 111 in low yields (Scheme 59).

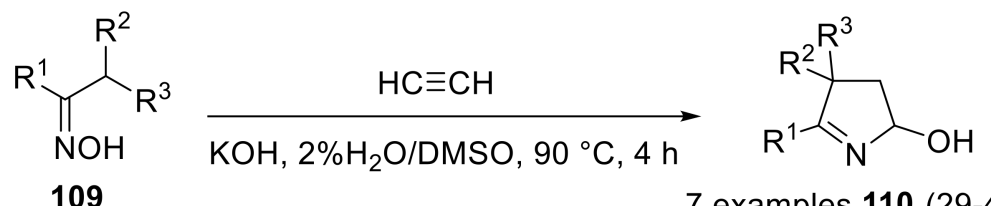

109

7 examples $110(29-44 \%)$

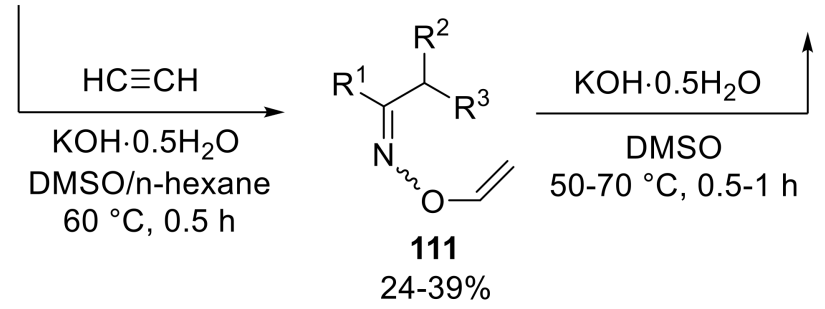

$$
\mathrm{R}^{1}=\mathrm{Ph}, 4-\mathrm{Tol}, 2,5-\mathrm{Me}_{2} \mathrm{C}_{6} \mathrm{H}_{3} \text {, 2-furyl; } \mathrm{R}^{2}=\mathrm{R}^{3}=\mathrm{Me} \text { or } \mathrm{R}^{2}-\mathrm{R}^{3}=-\left(\mathrm{CH}_{2}\right)_{5}-
$$

Scheme 59. Reaction of acetylene with ketoximes.

\subsubsection{Other Reactions for Accessing Heterocyclic Molecules}

As an alternative to Favorskii reaction, ketones and acetylene can undergo a one-pot cascade cyclization to give 7-methylene-6,8-dioxabicyclo[3.2.1] octanes [145-150]. Under optimized conditions [145,146] a variety of bicyclic products were obtained from dialkyl [145] and aryl alkyl $[146,147]$ ketones (Scheme 60). 


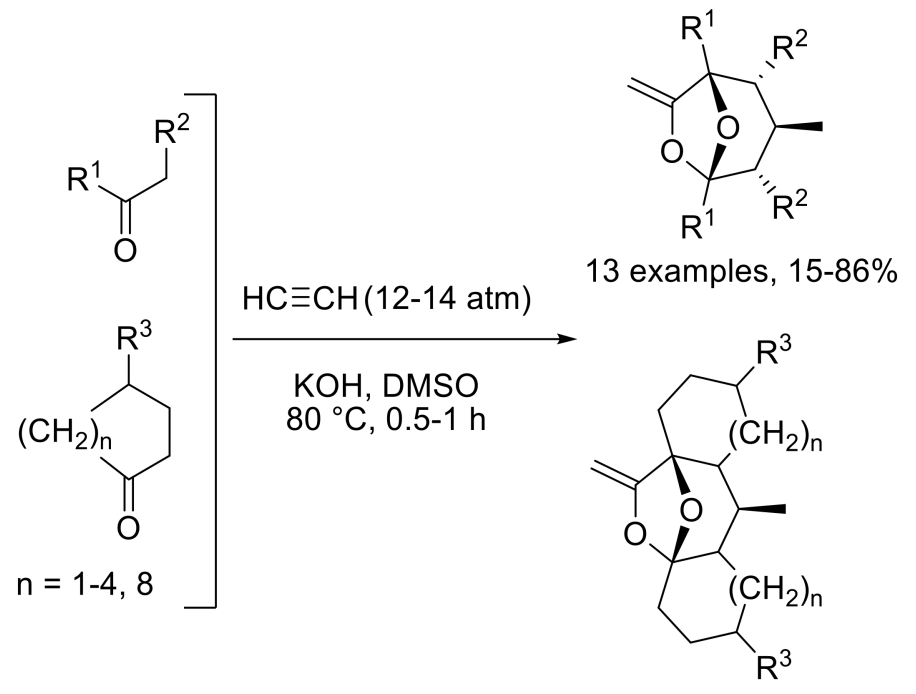

8 examples, $25-54 \%$

$\mathrm{R}^{1}={ }^{t} \mathrm{Bu},{ }^{i} \mathrm{Bu}$, cyclohexyl, adamantane-1-yl, $\mathrm{Ph}, 4-\mathrm{Tol}$, 4- $\mathrm{ClC}_{6} \mathrm{H}_{4}, 4-\mathrm{FC}_{6} \mathrm{H}_{4}, 4-\mathrm{PhC}_{6} \mathrm{H}_{4}, 3-\mathrm{MeOC}_{6} \mathrm{H}_{4}$, 2-naphthyl, phenentren-2-yl, 2-thienyl; $\mathrm{R}^{2}=\mathrm{H}, \mathrm{Me} ; \mathrm{R}^{3}=\mathrm{H}$, Me

Scheme 60. Reaction of acetylene and ketones.

A proposed mechanism for this reaction involves the following cascade transformations [145]. A superbase-promoted addition of the initial ketone to acetylene yields an intermediate 2-propenyl ketone, which undergoes prototropic isomerization into 1-propenyl ketone $\mathbf{A}$. The next step involves Michael addition of a second initial ketone molecule to $\mathbf{A}$ thus affording 1,5-diketone $\mathbf{B}$. Further on, an acetylene unit is added to a carbonyl group of $\mathbf{B}$ to form acetylenic ketoalcohol $\mathbf{C}$. Subsequent cascade cyclizations include reversible formation of hemiacetal $\mathbf{D}$, which undergoes nucleophilic addition to the triple bond and becomes the exocyclic enol ether moiety in the final product (Scheme 61).
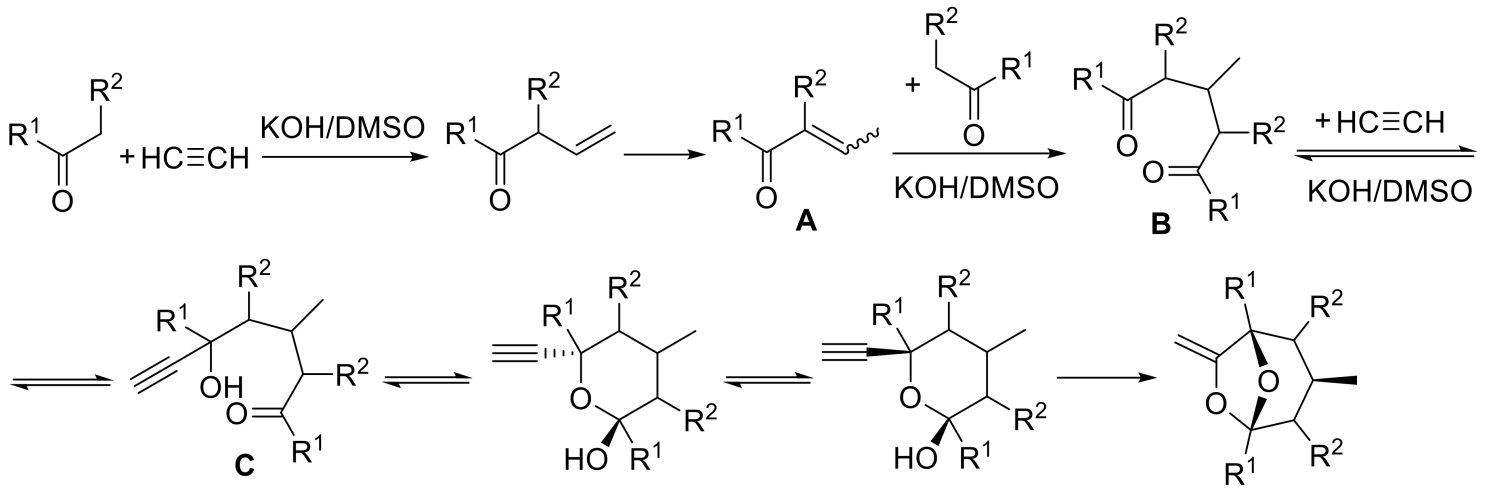

Scheme 61. Plausible mechanism of acetylene and ketones reaction.

The mechanism implies that 1,5-diketones readily cyclize with acetylene under superbasic conditions to give 7-methylene-6,8-dioxabicyclo[3.2.1]octanes. Indeed, the alkyl and aryl substituted 1,5-diketones are susceptible to cascade cyclization with acetylene [148]. The reactions were performed under conditions similar to those for the monoketones and afforded both symmetrically and unsymmetrically substituted 7-methylene-6,8-dioxabicyclo[3.2.1]octanes 112 (Scheme 62). 


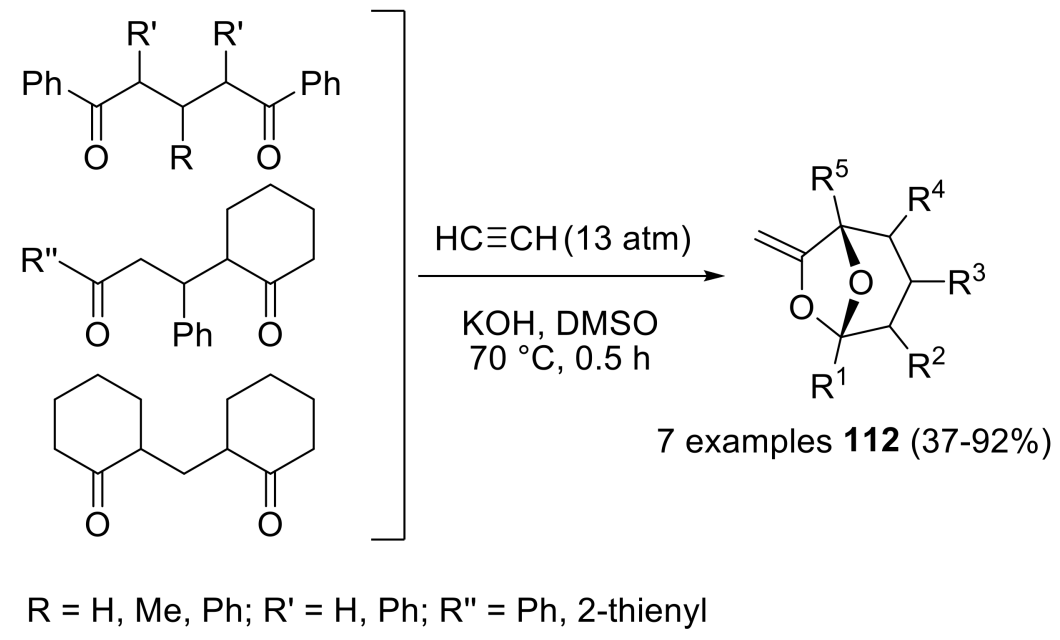

Scheme 62. Cascade cyclization of ketones with acetylene under superbase conditions.

A recently reported synthesis of methyl-substituted benzofuran rings resulted from combination of calcium carbide-derived acetylene with salicylaldehyde $p$-tosylhydrazones 113a and 2-hydroxyacetophenone $p$-tosylhydrazones $\mathbf{1 1 3}$ [151]. The reactions were performed with a copper chloride catalyst. Various 2-methylbenzofurans 114a and 2,3-dimethylbenzofurans 114b were obtained in satisfactory yields (Scheme 63).

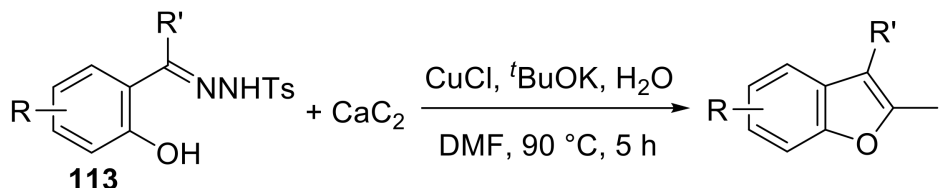

R: alkyl, Hal, MeO, $\mathrm{Et}_{2} \mathrm{~N}, \mathrm{Ph}$, benzo;

27 examples $114(34-85 \%)$ $\mathrm{R}^{\prime}=\mathrm{H}(\mathbf{a}), \mathrm{Me}(\mathbf{b})$

Scheme 63. Calcium carbide-based synthesis of benzofuran derivatives.

The following mechanism was proposed for this reaction (Scheme 64) [151]. Initial reaction of calcium carbide with water in the presence of $\mathrm{CuCl}$ gives ethynylcopper as an intermediate and coincides with the in situ formation of 2-(diazomethyl)phenol 115. The ethynylcopper intermediate reacts with 2-(diazomethyl)phenol to give a copper-carbene species $\mathbf{A}$, which transforms into $\mathbf{B}$ by reductive elimination. Subsequent acidolysis of $\mathbf{B}$ leads to intramolecular cyclization to afford the final product 116.

A palladium-catalyzed cascade protocol for the synthesis of 4-methyl-1-(1H-pyrrolo[2,3- $b$ ]quinoxalin-2-yl)cyclohexanols 119a and 2-phenyl-1-(1H-pyrrolo[2,3-b]quinoxalin-2-yl)propan-1-ols $119 \mathbf{b}$ from $\mathrm{N}$-alkyl(aryl)-3-chloroquinoxalin-2-amines 117, calcium carbide and cyclohexanones 118a or 2-phenylpropanal $\mathbf{1 1 8 b}$ has been developed [152]. 


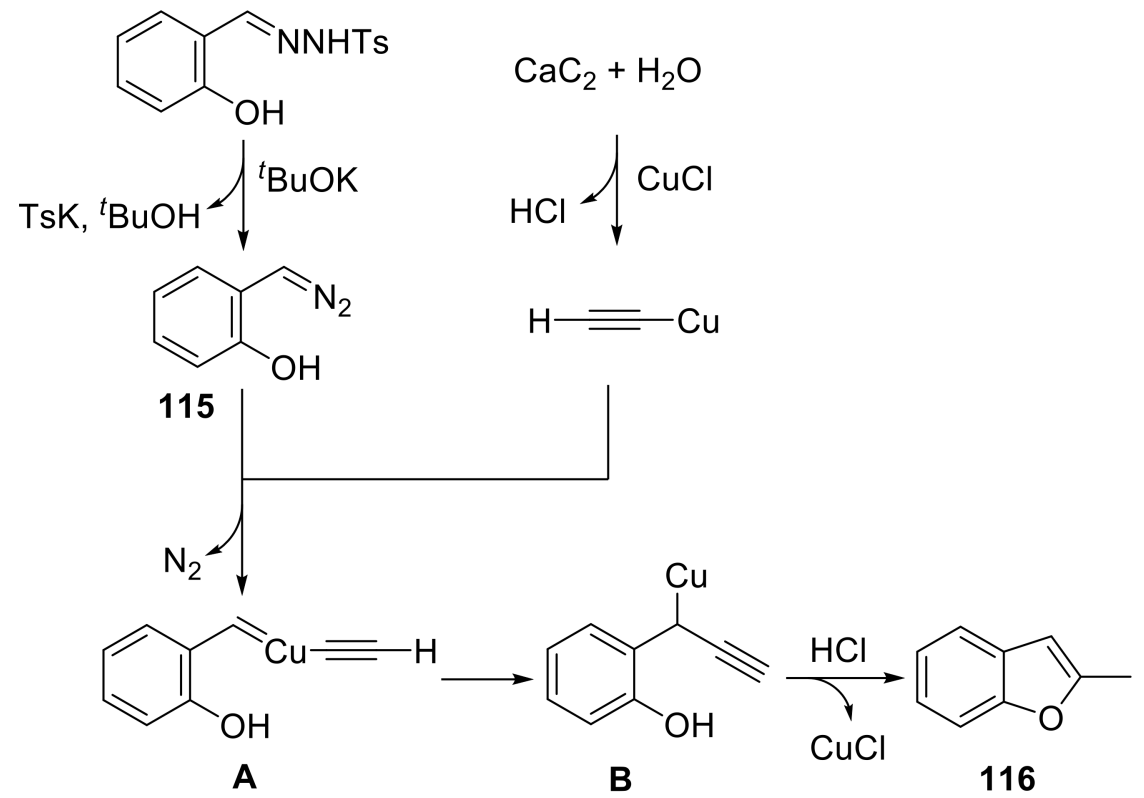

Scheme 64. Mechanism of benzofuran formation.

The reactions were performed in the presence of catalytic amounts of $\mathrm{Pd}\left(\mathrm{PPh}_{3}\right)_{2} \mathrm{Cl}_{2}$ in a DMSO $/ \mathrm{H}_{2} \mathrm{O}$ solvent mixture. This copper-free one-pot Sonogashira-type synthesis provided high yields of 2,3-disubstituted pyrrolo[2,3-b]quinoxalines (Scheme 65)A proposed reaction mechanism [152] includes the following steps. Initially, calcium acetylide $\mathbf{A}$ is generated from $\mathrm{CaC}_{2}$ and water. Aldehyde or ketone activation by cesium cation promotes a nucleophilic attack of acetylide $\mathbf{A}$ on the carbonyl group to afford propargyl alcohol C via intermediate B. A subsequent palladium-catalyzed cross-coupling reaction involves heteroaryl chloride $\mathbf{1 1 7}$ and propargyl alcohol $\mathbf{C}$ to afford intermediate D. At the final step, ring closure by intramolecular hydroamination leads to the formation of 2-substituted pyrrolo[2,3-b]quinoxalines 119 (Scheme 66).
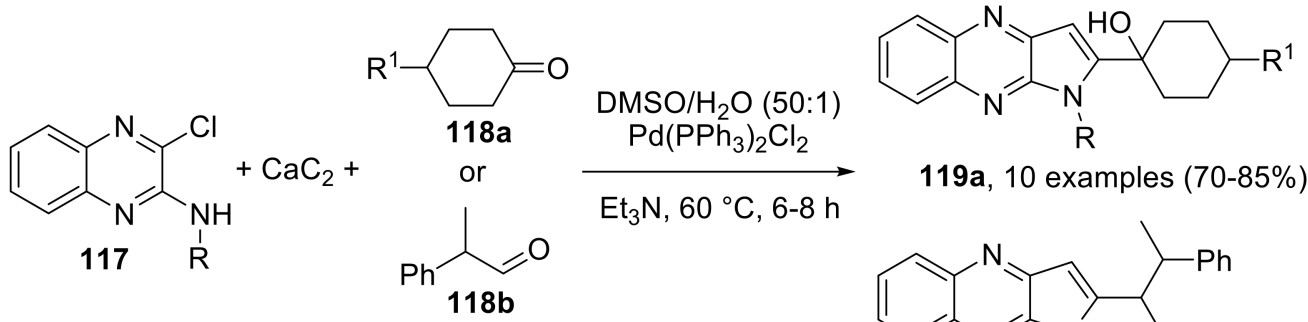

119a, 10 examples $(70-85 \%)$<smiles>[R]n1c(C(O)C(C)c2ccccc2)cc2nc3ccccc3nc21</smiles>

119b, 2 examples $(70 \%)$

$\mathrm{R}=\mathrm{Me}, \mathrm{Et}, \mathrm{Pr}, \mathrm{Bu}$, cyclohexyl, $\mathrm{HO}\left(\mathrm{CH}_{2}\right)_{2}, \mathrm{Ph}, 4-\mathrm{MeC}_{6} \mathrm{H}_{4}$; $\mathrm{R}^{1}=\mathrm{H}, \mathrm{Me}$

Scheme 65. Pd-catalyzed amine/aldehyde/acetylene reaction. 


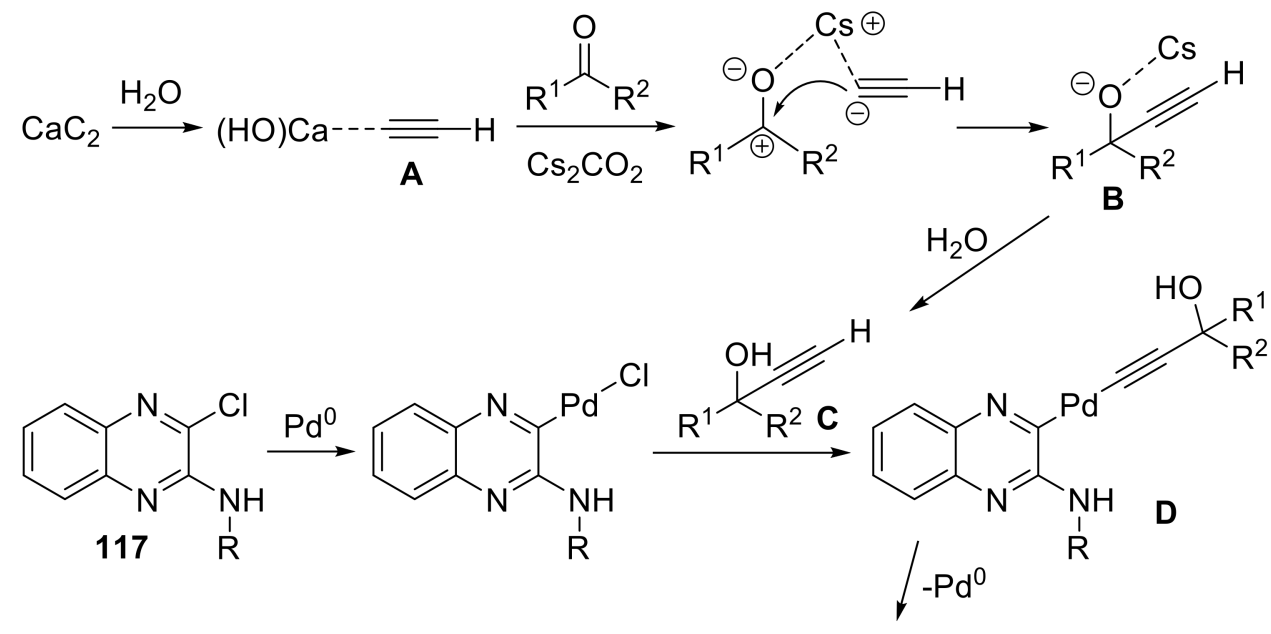<smiles>[R]Nc1nc2ccccc2nc1C#CC([R])([R])O</smiles>

Scheme 66. Proposed mechanism of three component coupling.

In summary, acetylene is available and flexible starting material for heterocycles synthesis. The classical protocols for 1,3-dipolar cycloaddition and Trofimov reaction are constantly modified, and new methodologies based on cascade reactions of acetylene continuously develop, as they allow obtaining fine and versatile heterocyclic compounds from simple and inexpensive chemicals.

\subsection{Applications in Medicinal Chemistry and Drug Discovery}

Acetylene is involved in drug synthesis by two chemical approaches: reactive species vinylation and Favorskii reaction.

Vinylation of trifluoroethanol $\mathbf{1 2 0}$ with acetylene gave an inhalation anesthetic fluoroxene $\mathbf{1 2 2}$ (Scheme 67) [153]. The transformation was performed in two steps: first, the starting alcohol was treated with potassium, and then the resulting alkoxide $\mathbf{1 2 1}$ was heated under the elevated pressure in a metal pressure reactor giving the vinyl ether $\mathbf{1 2 2}$.<smiles>[R]COCCO</smiles>

120<smiles>C#CC(C)(C)OCC(F)(F)F</smiles>

$150^{\circ} \mathrm{C}, 5 \mathrm{~h}$<smiles>C=COCC(F)(F)F</smiles>

122

Scheme 67. Synthesis of fluoroxene by trifluoroethanol vinylation.

Fluroxene (122) was also prepared from acetylene by an alternative two-step procedure (Scheme 68) [154]. First, trifluoroethanol (120) reacted with acetylene in the presence of mercury oxide and boron trifluoride diethyl etherate giving di(2,2,2-trifluoroethyl) acetaldehyde acetal. The latter was heated with montmorillonitrile producing 122. 


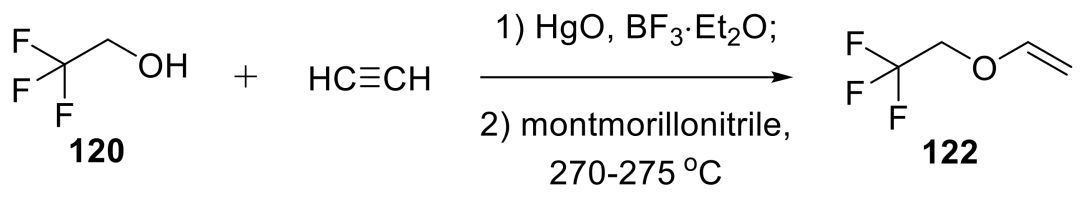

Scheme 68. Two-step fluoroxene synthesis.

The Favorskii reaction is usually performed either by using a Grignard method, or in the presence of a base (Scheme 69) [155]. The first procedure involves a preliminary reaction of acetylene with Grignard reagent or lithium, sodium, potassium in liquid ammonia or lithium-organic compounds [155-157]. The resulting acetylide reacts with the ketone giving a tertiary acetylenic alcohol. The second procedure is equally widespread $[155,158]$. Both procedures afford acetylenic alcohols from aldehydes and ketones with arbitrarily chosen substituents in moderate to excellent yields [155-158].

$$
\begin{aligned}
& \underset{\mathrm{R}^{2}}{\mathrm{R}^{1}}+\mathrm{HC} \equiv \mathrm{CH} \stackrel{\text { base, } \mathrm{M} \text { or } \mathrm{RMX}}{\longrightarrow} \begin{array}{c}
\mathrm{HO} \\
\mathrm{R}^{1}> \\
\mathrm{R}^{2}
\end{array} \\
& \text { up to } 90 \% \\
& \mathrm{R}^{1}=\mathrm{H}, \mathrm{Alk} \text {, alkenyl, alkynyl, } \mathrm{Ar} ; \mathrm{R}^{2}=\mathrm{Alk} \text {, alkenyl, alkynyl, Ar; } \\
& \mathrm{M}=\mathrm{Li}, \mathrm{Na}, \mathrm{K} ; \mathrm{RMX}=\mathrm{RLi}, \mathrm{RMgHal}
\end{aligned}
$$

Scheme 69. The Favorskii reaction general scheme.

A sedative drug ethchlorvynol 124 was obtained from ethyl $\beta$-chlorovinyl ketone $\mathbf{1 2 3}$ and lithium acetylenide in $80 \%$ yield (Scheme 70 ). Lithium acetylide was generated from acetylene and lithium metal in liquid ammonia. The procedure allows obtaining a range of ethynyl $\beta$-halogenvinyl carbinols [157].

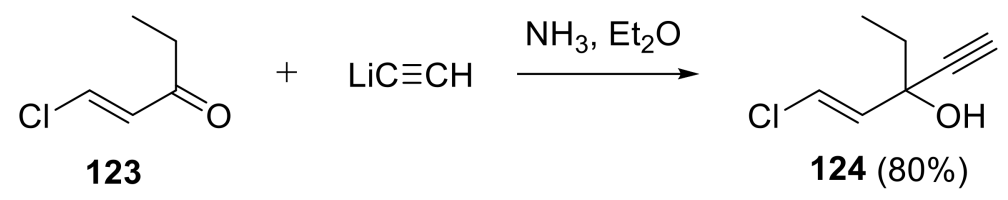

Scheme 70. Ethchlorvynol synthesis.

Combining the Favorskii reaction with other synthetic methods, some terpenes were synthesized [156]. Starting from ketone $\mathbf{1 2 5}$ and sodium acetylide, generated by bubbling of acetylene throught sodium-ammonia mixture, the precursor 126 of isophytol 127 was obtained (Scheme 71). Isophytol 127 can be converted to rac-vitamin $K_{1} 128$ in some steps. Linalool 129 and nerolidol 130 can be obtained by similar procedures, starting from acetone and subsequently involving Favorskii reaction with partial hydrogenation and condensations [156]. 


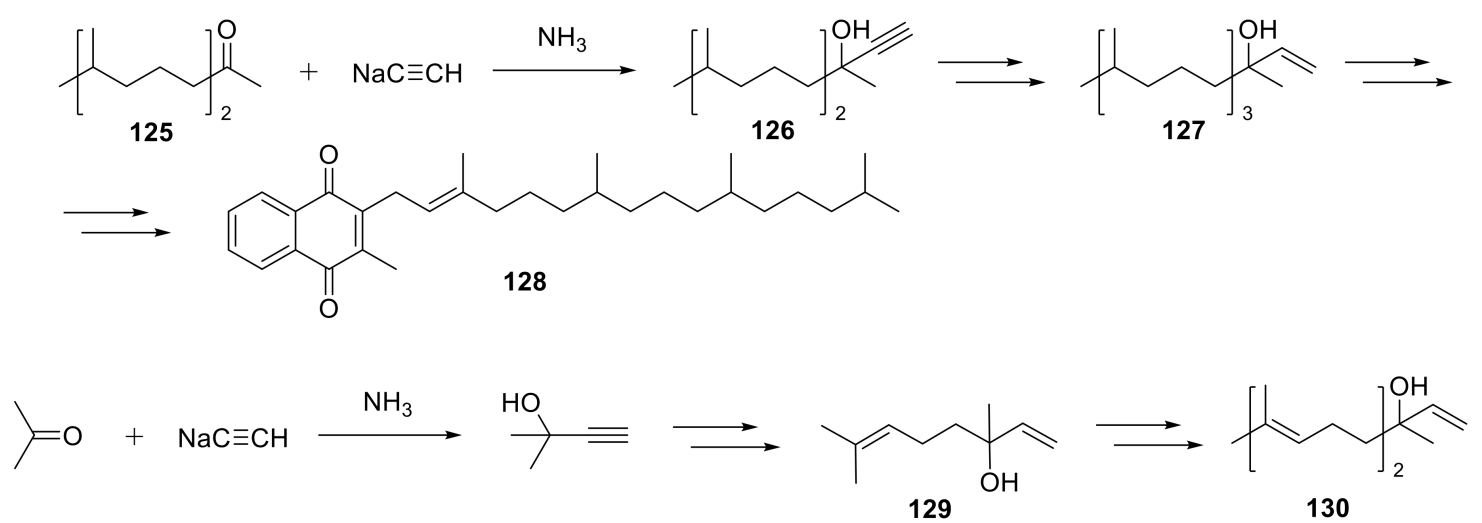

Scheme 71. Terpene synthesis with acetylene.

The wide class of steroids ethynyl derivatives was synthesized by Favorskii reaction. These substances are used for the improvement of elderly human health and well-being quality (hormonal therapy), the treatment of rheumatic diseases, to improve sports performance and in cancer therapy $[159,160]$.

17-Ethynylestradiol [161,162] (132a) and its prodrug quinestrol [163] (132b), which are used in female hormonal therapy, were obtained from estrone (131a) and estrone 3-cyclopentyl ether (131b), correspondingly (Scheme 72). Both ethynyl derivatives can be produced from acetylene in the presence of strong bases as catalysts or from ethynyl magnesium bromide or ethynyl lithium as a starting material [161-163]. Quinestrol can be produced by etherification of 17-ethynylestradiol [159].

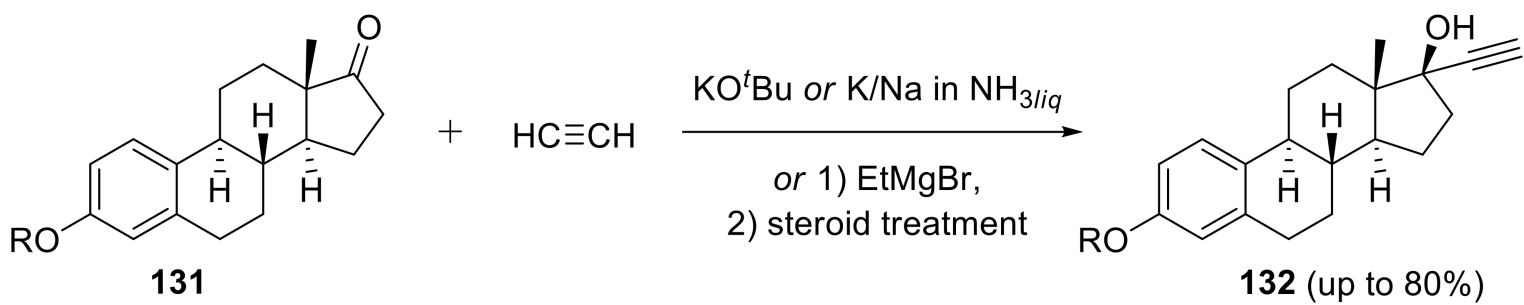

$R=H(a)$, cyclopentyl (b)

Scheme 72. Synthesis of 17-ethynylestradiol and quinestrol.

Another prodrug of 17-ethynylestradiol, mestranol (134), was synthesized recently from the solid acetylene source, calcium carbide, and estrone 3-methyl ether (133) (Scheme 73) [119]. The presence of fluoride reportedly enhances the reaction. Such procedures are safer than the use of gaseous acetylene in the presence of metals and strong bases.<smiles>COc1ccc2c(c1)CCC1C2CC[C@]2(C)C(=O)CC[C@@H]12</smiles>

133

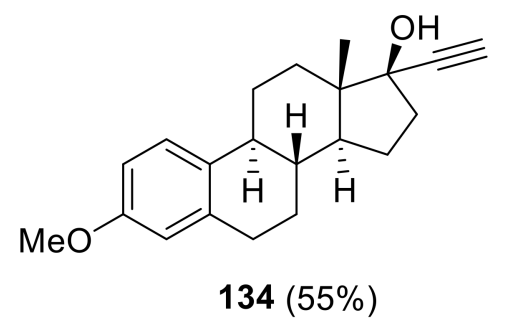

$134(55 \%)$

Scheme 73. Synthesis of mestranol by Favorskii reaction. 
A similar synthetic procedure allows obtaining desogestrel, a highly potent oral contraceptive medication (136, Scheme 74). Subsequential reaction of acetylene with lithium in ethylenediamine and the isomeric starting material $\mathbf{1 3 5}$ gave $\mathbf{1 3 6}$ in 83\% yield [164].<smiles>C#CC[C@@H]1C(=C)C[C@]2(CC)C(=O)CC[C@H]2[C@H]1CC=C1CCCC[C@H]1C</smiles>

135
$\mathrm{Li}$, ethylenediamine, $\mathrm{rt}, 2 \mathrm{~h}$

then $135, \mathrm{rt}, 2 \mathrm{~h}$

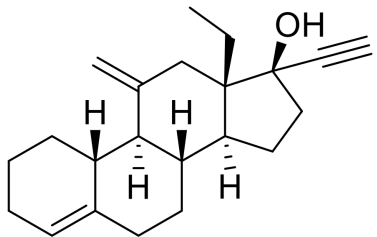

$136(83 \%)$

Scheme 74. Synthesis of desogestrel.

Eplerenone, which is used in the treatment of congestive heart failure and hypertension, can be synthesized by Favorskii reaction. The key step in its synthesis is provided by a reaction of acetylene with TMS-protected precursor 137 (Scheme 75). This step gave an acetylene-derived alcohol 138, which was successively converted into eplerenone $\mathbf{1 3 9}$ [165].

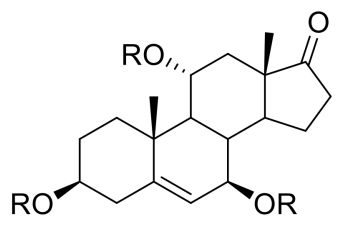

137

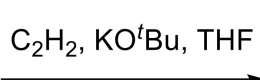<smiles>C=C[C@]1(O)CC[C@H]2[C@@H]3[C@H](O)C=C4C[C@@H](O)CC[C@]4(C)[C@H]3[C@H](O)C[C@]21C</smiles>

$138(92 \%)$

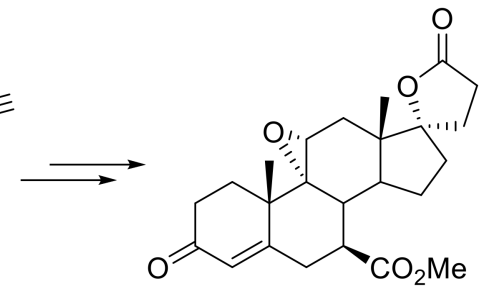

139 $\mathrm{R}=\mathrm{TMS}$

Scheme 75. Eplerenone precursor synthesis by Favorskii reaction.

Favorskii reactions with acetylene, acetylenides, or calcium carbide provide a neat and effective means for the synthesis of ethynyl-substituted steroids $[159,160,166]$. The approach allows obtaining a wide range of active pharmaceutical ingredients for hormone medications, anti-rheumatic and other anti-inflammatory drugs, medications for prevention and treatment of heart disorders, and many more [167].

\subsection{Organometallic Complexes of Acetylene}

Transition metal alkynyl complexes are potent intermediates in supramolecular design and organometallic synthesis [168-171]. Their tunable nature makes them excellent candidate molecules in non-linear optics $[172,173]$ and polymer chemistry $[174,175]$, as antitumor drugs $[176,177]$ and luminescent materials $[178,179]$. In most cases, acetylene is utilized as a bridge and possesses a high potential due to possibility of Sonogashira-like reactions.

A symmetrical bis(alkynyl) derivative $\mathbf{1 4 1}$ is obtained essentially in compliance with the established Sonogashira mechanism (Scheme 76) [180]. The reaction is carried out under atmospheric acetylene pressure; it is initiated by mixing acetylene with metal cluster 140 in 2:1 molar ratio. 

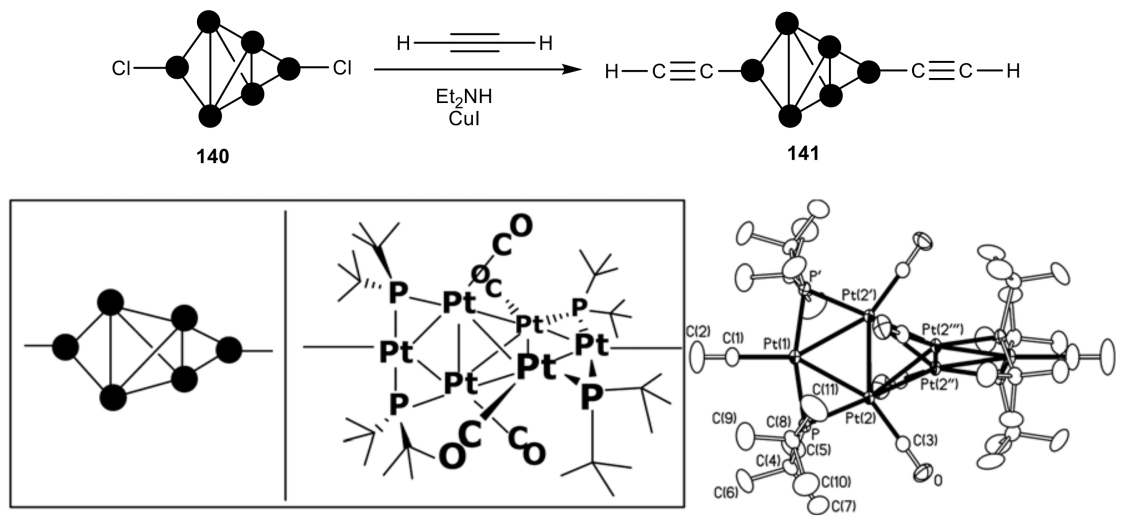

Scheme 76. Synthesis and 3D representations of symmetrical bis-alkynyl derivative 141. Hydrogen atoms are omitted for clarity. Thermal ellipsoids are set at $30 \%$ probability. ' $=1-\mathrm{x}, 1-\mathrm{y}, \mathrm{z} ;{ }^{\prime \prime}=\mathrm{y}, 1-$ $\mathrm{x},-\mathrm{z} ;{ }^{\prime \prime \prime}=1-\mathrm{y}, \mathrm{x},-\mathrm{z}$. (Reproduced with permission from ref. [180]. Copyright 2016 the Royal Society of Chemistry.).

Insertion of acetylene into Pt-X bonds of square planar $\left[\mathrm{PtX}_{2}\left(\mathrm{~N}^{\wedge} N\right)\right]$ complexes $(\mathrm{X}=\mathrm{Cl}$, $\mathrm{Br}, \mathrm{I})$, e.g., [ $\mathrm{PtX}_{2}\left(\mathrm{Me}_{2}\right.$ phen)] complexes 142, has been demonstrated [181]. Formation of $\mathrm{Pt}(\mathrm{II})$ five-coordinate comlexes is favored when $\mathrm{X}=$ bromide or iodide; with chloride, the complexes show negligible reactivity. The obtained five-coordinate complexes $\left[\mathrm{PtX}_{2}\left(\eta^{2}-\mathrm{CH} \equiv \mathrm{CH}\right) \mathrm{Me}_{2}\right.$ phen $\left.)\right] 144$ quickly relapse into four-coordinate alkenyl complexes $\left[\mathrm{PtX}_{2}\left(\eta^{1}-E-\mathrm{CH}=\mathrm{CHX}\right) \mathrm{Me}_{2}\right.$ phen $\left.)\right]$ 143. Excess of acetylene results in equilibrium between four- and five- coordinate complexes. Facile substitution of the $\pi$-bonded acetylene with free olefins or CO results, respectively, in alkene-alkenyl 145 or carbonyl-alkenyl 146 complexes (Scheme 77). In some cases, it is possible to isolate Pt-containing intermediates with acetylene to study kinetics and other properties [182].

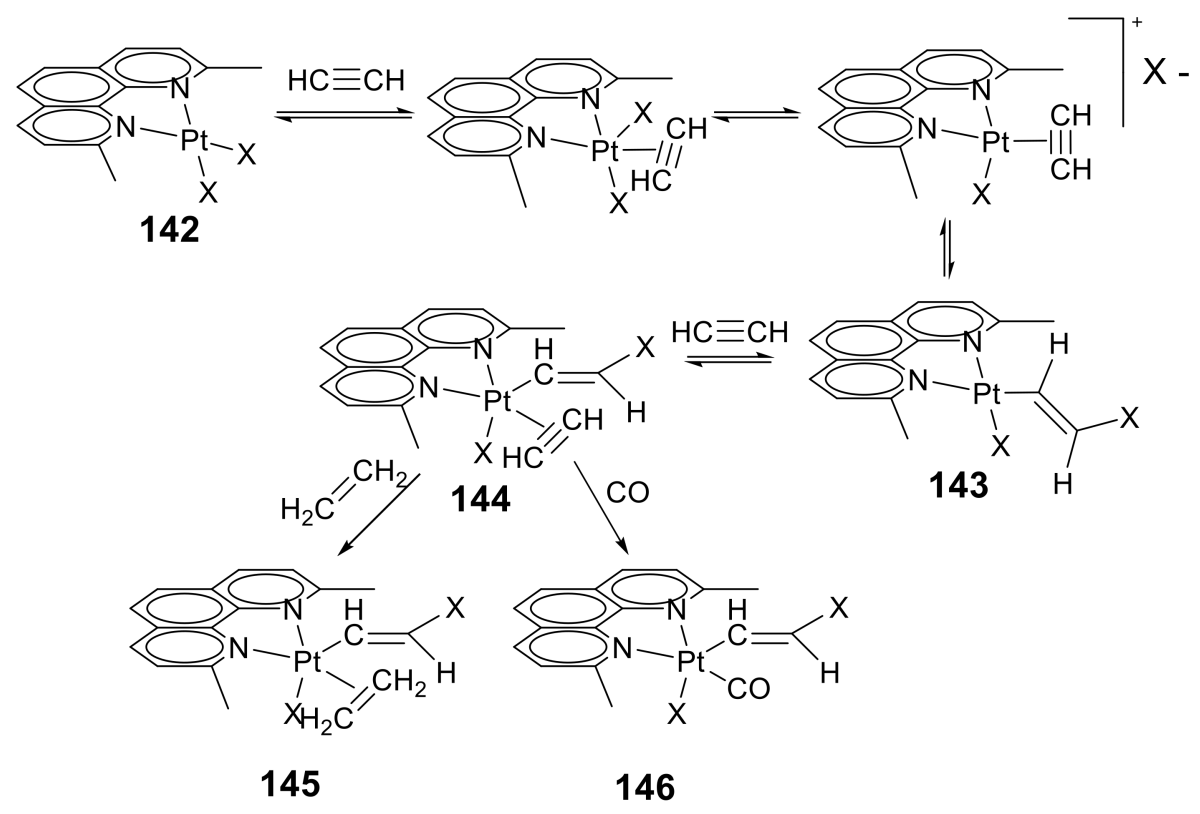

Scheme 77. A mechanism proposed for the formation of acetylene-alkenyl complexes.

An unusual heterobimetallic $\mathrm{Au}(\mathrm{I}) / \mathrm{Pt}(\mathrm{II})$ complex with acetylide $(-\mathrm{C} \equiv \mathrm{CH})$ bridge was formed in reaction between $\mathrm{Au}(\mathrm{I})$ and $\mathrm{Pt}(0)$ complexes 147 and 148 [183]. These complexes with bulky ligands terphenyl phosphine and tri-tert-butylphosphine, respectively, act as a Lewis acid and a Lewis base. The metal pair acquires a remarkable capacity of activating acetylene molecule. Upon exposure of benzene solutions of complexes 147 and 148 to acetylene their color instantly changes from bright 
yellow to intense orange. According to NMR data, the Au and Pt complexes were converted into two structurally distinct products (Scheme 78 ). In complex 149, the triple bond bridge is $\pi$-bonded to a cationic $\mathrm{Au}$ (I) center and $\sigma$-bonded to a $\mathrm{Pt}(\mathrm{II})$ hydride fragment. In complex 150, which lacks the triple bond, the metals are linked by a $\mu$-ethene-1,2-diyl moiety.

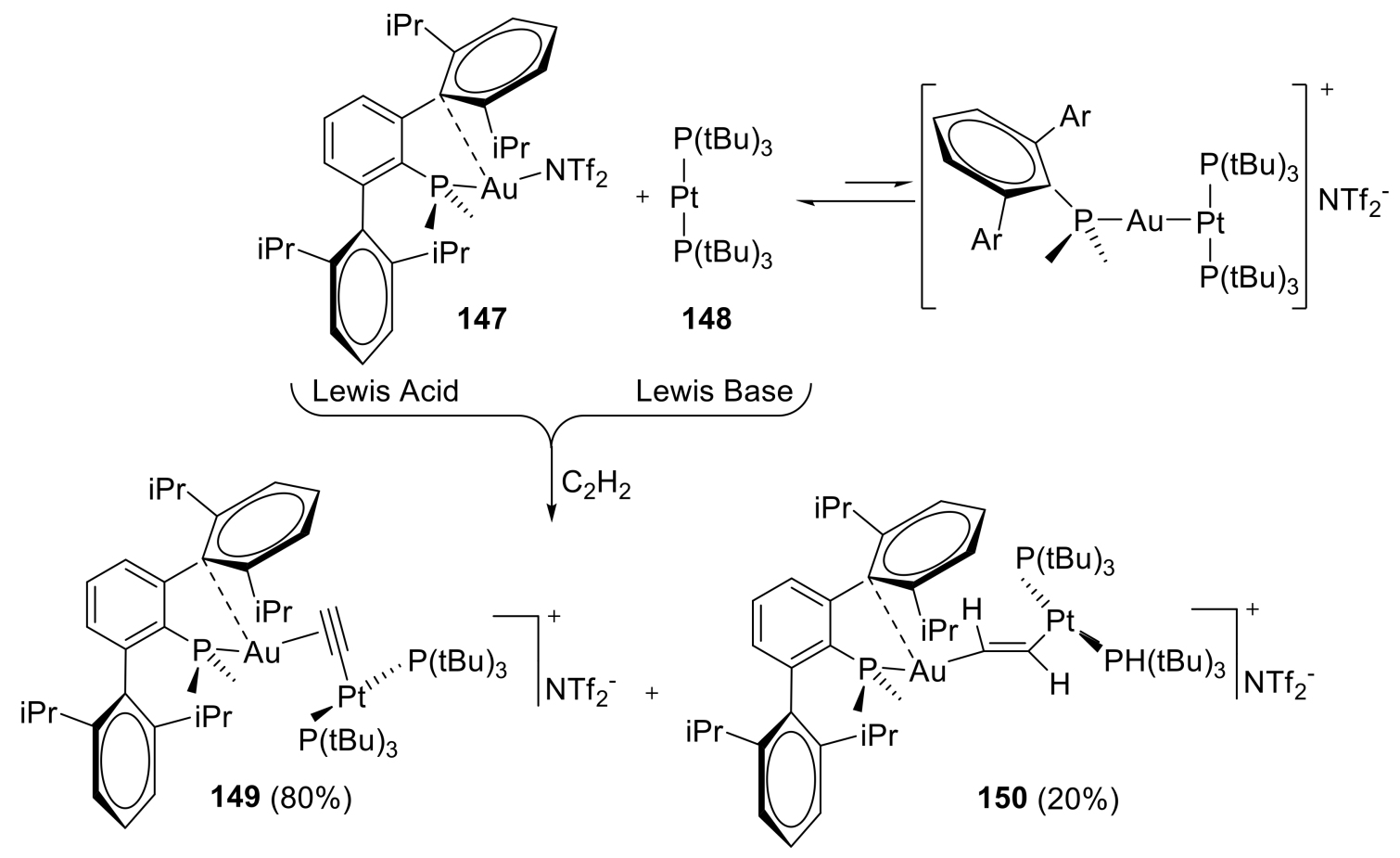

Scheme 78. Reaction of Au and Pt complexes with acetylene.

Hydroarylation of alkynes provides a valuable route to various alkenes, although chemo-, regio and stereoselectivities of this reaction may be compromised by collateral formation of diaryl alkanes, dialkenyl arenes, and aryl dienes. An in situ generated dicationic complex [Pt(2,6-bis(dephinylphosphinomethyl)pyridine) $\left.\mathrm{C}_{2} \mathrm{H}_{2}\right]\left(\mathrm{BF}_{4}\right)_{2} 151$ reacts with arenes [184]. Only electron-rich arenes are incorporated into arylalkenyl products 152 (Scheme 79). Another interesting study of unsaturated $\mathrm{Pt}$ (II) complex showed tautomerization of acetylene to vinylidene [185]. In this case, $\mathrm{C}-\mathrm{C}$ bond formation occurs via isomeric methyl vinylidene structure instead of the classical migratory insertion reactivity. Vinylidene formation is also characteristic of the iridium

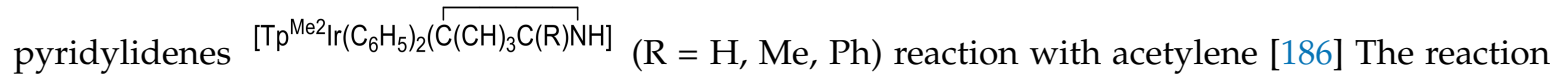
afforded four-membered iridacycles with $\operatorname{IrC}\left(=\mathrm{CH}_{2}\right) \mathrm{N}$ moiety. 


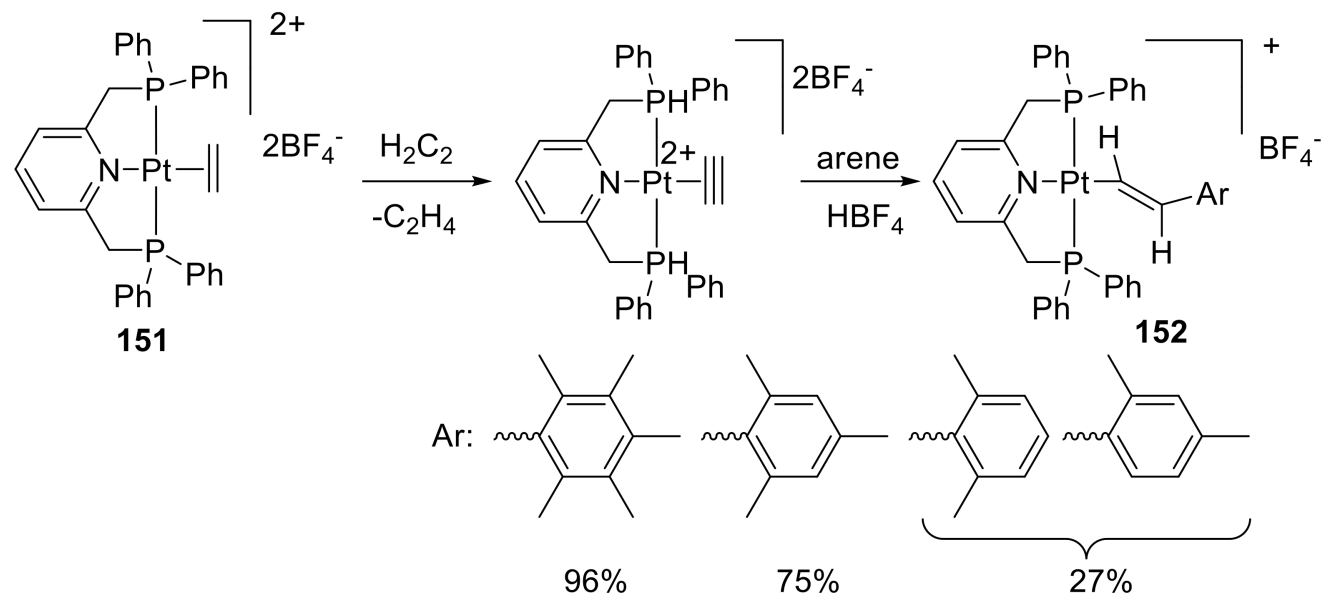

Scheme 79. Pt-catalyzed selective hydroarylation.

Insertion into Ir-H bond is also possible. Acetylene and terminal alkynes react with Ir complex 153 to produce five-coordinate styryl derivatives 154 (Scheme 80). The short-lived yellow-orange six-coordinate vinyl complexes are emissive upon photoexcitation [187].

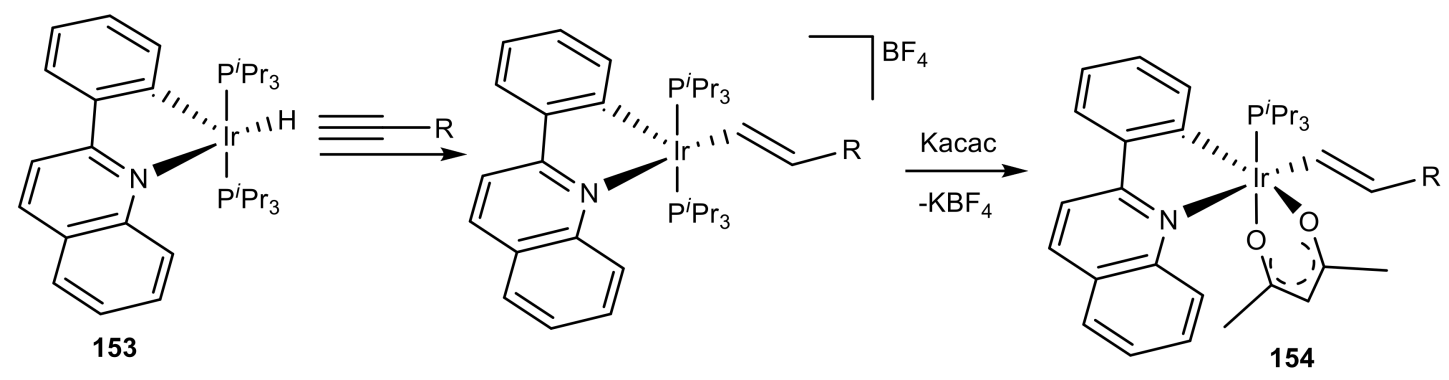

Scheme 80. Preparation of Ir-based vinyl and styryl compounds.

An electrophilic cationic complex $\left[\left(\eta^{5}-\mathrm{C}_{5} \mathrm{Me}_{5}\right) \operatorname{Ir}\left(\mathrm{C}^{\wedge} \mathrm{P}\right)\right]^{+}$reacted with acetylene at room temperature to form the $\left[\left(\eta^{5}-\mathrm{C}_{5} \mathrm{Me}_{5}\right) \operatorname{Ir}\left(\mathrm{C}^{\wedge} \mathrm{P}\right)\left(\eta^{2} \text {-acetylene }\right)\right]^{+} \pi$ adducts 155 [188]. The $\mathrm{C}-\mathrm{C}$ bond formation led to an iridium-bound alkene moiety as a thermodynamic product, whereas similar complexes with bulkier alkynes underwent further transformation into allylic structures. NMR experiments with D-labeled compounds implicated an undetected vinylidene structure, $\mathrm{Ir}=\mathrm{C}=\mathrm{C}(\mathrm{H}) \mathrm{Ph}$, in the key $\mathrm{C}-\mathrm{C}$ bond formation. Heating of complex 155 solution in a pressure vessel afforded an extraordinary thermostable complex 156 (Scheme 81).

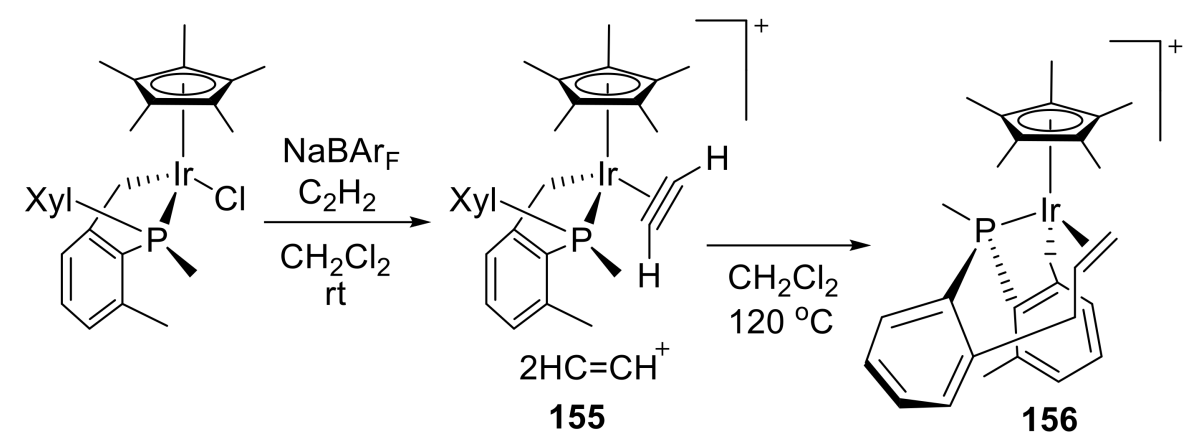

Scheme 81. Synthesis of $\left[\left(\eta^{5}-\mathrm{C}_{5} \mathrm{Me}_{5}\right) \operatorname{Ir}\left(\mathrm{C}^{\wedge} \mathrm{P}\right)\right]^{+}$acetylene adduct and its thermal transformation.

Selective insertion of alkynes into Mo-H and $\mathrm{W}-\mathrm{H}$ bonds was catalyzed by $\mathrm{Pd}(0)$ complex and resulted in alkenylmolybdenum and alkenyltungsten complexes [189]. Interestingly, no incorporation 
of deuterium into trans and geminal positions of vinyltungsten complex 157 was observed in the reaction of acetylene with tungsten complex $\mathrm{WDCp}(\mathrm{CO})_{3}$ (Scheme 82). Tungsten complexes with diphosphines $\left[\mathrm{Tp}^{*} \mathrm{~W}(\mathrm{CO})(\mathrm{I})\left\{\eta^{2}-\mathrm{C}_{2}\left(\mathrm{PPh}_{2}\right)_{2}\right\}\right]\left(\mathrm{Tp}^{*}=\right.$ hydrido-tris $(3,4,5$-trimethyl-pyrazolyl)borate $)$ showed highly reversible redox potentials [190]. A variety of substituted bisphosphine acetylene bridged dinuclear complexes with a side-on bound $\mathrm{Tp} * \mathrm{~W}(\mathrm{CO})(\mathrm{I})$ moiety and a chelate-like coordinated $\mathrm{PtCl}_{2}$ unit was reported [191].

$$
\equiv+\underset{93 \% \mathrm{D}}{\mathrm{WDCp}(\mathrm{CO})_{3}} \frac{\mathrm{Pd}\left(\mathrm{PPh}_{3}\right)_{4}(5 \mathrm{~mol} \%)}{\mathrm{C}_{6} \mathrm{D}_{6}, 20^{\circ} \mathrm{C}, 16 \mathrm{~min}} \underbrace{}_{\mathrm{D}} \sum_{157}^{\mathrm{WCp}(\mathrm{CO})_{3}}
$$

Scheme 82. Acetylene insertion into deuterated tungsten complex.

Thus, promotion of acetylene insertion by metal atoms results in modified metal complexes, which can be isolated. Various metal complexes are used as catalysts or building blocks and also, notably, in luminescence applications. Here we descried a few representative examples of reactions with organometallic complexes, where a number of other possibilities are available as well as other terminal alkynes react with metal complexes in a similar manner [192].

\subsection{Miscellaneous Synthetic Transformations}

Other applications of acetylene involve addition, cycloaddition, and polymerization reactions. A reaction of tellurium tetrabromide with acetylene in tetrachloromethane provides stereoselective synthesis of (E)-2-bromovinyltellurium tribromide 158 (Scheme 83) [193].

$$
\mathrm{HC} \equiv \mathrm{CH}+\mathrm{TeBr}_{4} \frac{\mathrm{CCl}_{4}, 20-70{ }^{\circ} \mathrm{C}}{2-5 \mathrm{~atm}} \underset{158}{\mathrm{Br}} \underset{\sim}{\sim} \mathrm{TeBr}_{3}
$$

Scheme 83. Synthesis of (E)-2-bromovinyltellurium tribromide.

Compounds with 2-bromovinyltellanyl group are used in stereoselective syntheses of alkenes via consecutive replacement of bromine and tellurium atoms by organic groups in cross-coupling reactions [194].

The reaction of iodomethane and acetylene in the presence of $\mathrm{Na}_{2} \mathrm{PtCl}_{4}$ and $\mathrm{NaI}$ yielded a mixture of iodoethylenes (Scheme 84) [195]. A mechanism proposed by the authors involved intermediate formation of a $\mathrm{Pt}(\mathrm{IV})$ methyl vinyl derivative by iodoplatination of acetylene with a reversibly formed $\mathrm{Pt}(\mathrm{IV})$ methyl complex.

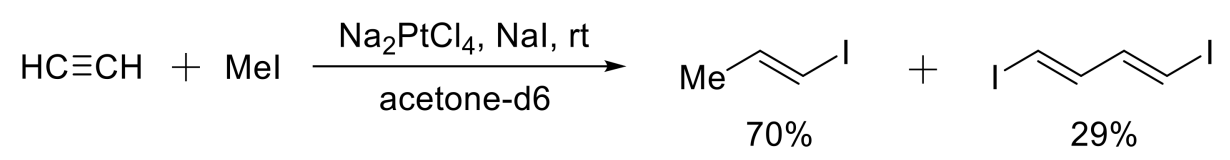

Scheme 84. Pt(IV)-catalyzed addition of iodomethane to acetylene.

Another example of catalytic addition to acetylene, preparation of 1,2-bis(diphenylphosphino)ethane dioxide $\left(\mathrm{dppeO}_{2}\right)$, proceeded in the presence of $t$-BuOLi (Scheme 85) [196]. A possible mechanism for this reaction includes deprotonation of $\mathrm{Ph}_{2} \mathrm{P}(\mathrm{O}) \mathrm{H}$ by $t$-BuOLi. The resulting formation of anion $\mathbf{A}$ directs the catalytic cycle toward dppeO $\mathrm{P}_{2}$. 


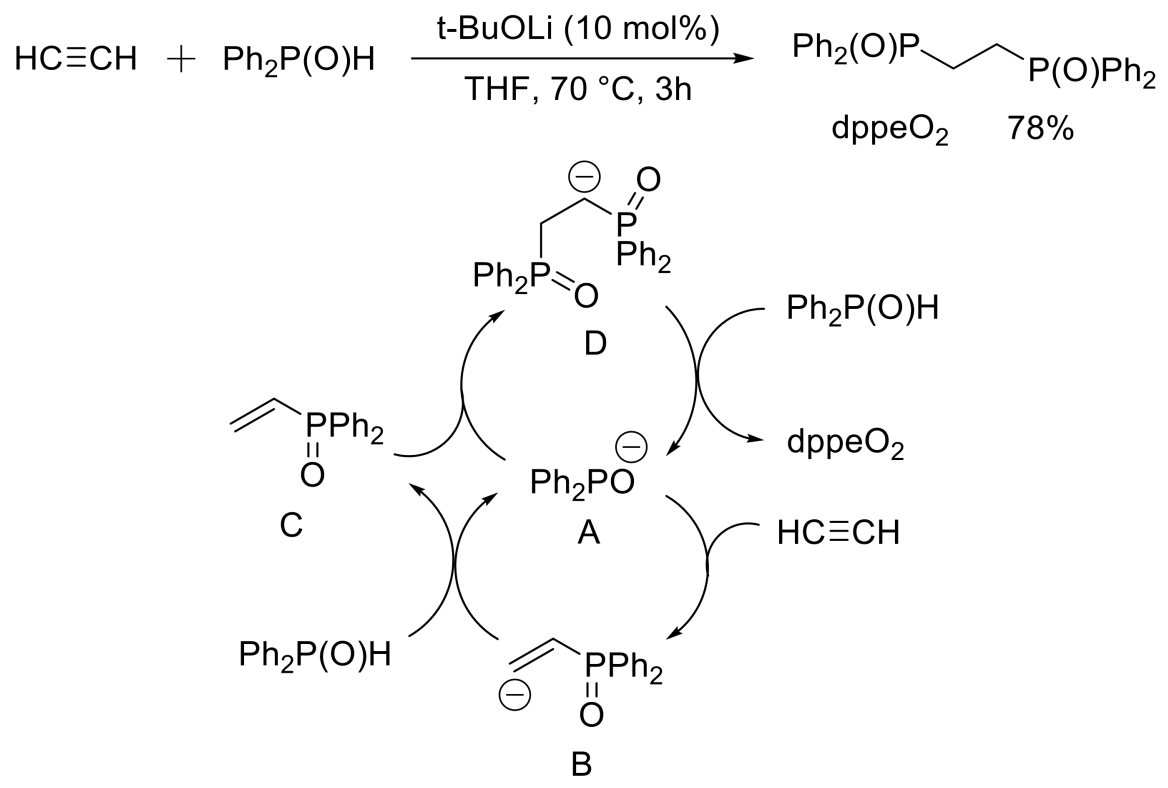

Scheme 85. A mechanism proposed for the formation of dppe oxide.

A tandem addition reaction of acrolein with acetylene to form (E)-5-bromopent-4-enal $\mathbf{1 6 0}$ involved $\mathrm{Pd}(\mathrm{OAc})_{2}$ as a catalyst (Scheme 86) [197]. The best yields (73\%) are obtained under optimized conditions of $1.5 / 1 \mathrm{AcOH} / \mathrm{H}_{2} \mathrm{O}$ molar ratio, $\mathrm{C}_{2} \mathrm{H}_{2}$ pressure of $1.2 \mathrm{~atm}$ for $72 \mathrm{~h}$ at $25^{\circ} \mathrm{C}$, with $1 \mathrm{mmol} \%$ $\mathrm{Pd}(\mathrm{OAc})_{2}, 1 \mathrm{~mol} \% \mathrm{LiBr}$, and $1.2 \mathrm{~mol} \%$ acrolein.

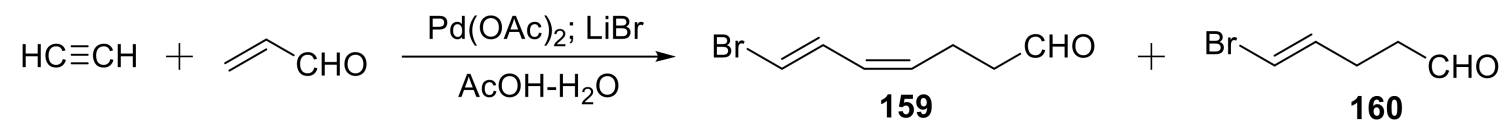

Scheme 86. Pt(II)-catalyzed addition of acrolein to acetylene in the presence of LiBr.

(E)-5-Bromopent-4-enal $\mathbf{1 6 0}$ provides starting material for synthesis of (4E,6Z,10Z)-hexadeca-4,6,10-trien-1-ol 161 and (4E,6E,10Z)-hexadeca-4,6,10-trien-1-ol 162 [197], the active pheromone components of cocoa pod borer moth (Conopomorpha cramerella), the most injurious pest that damages cocoa plantations in Southeast Asia (Scheme 87) [198].

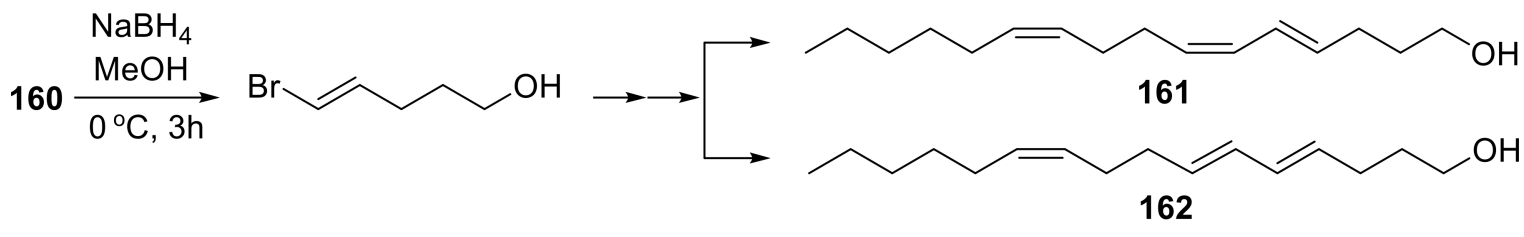

Scheme 87. Synthesis of $(4 E, 6 Z, 10 Z)$-hexadeca-4,6,10-trien-1-ol $\mathbf{1 6 1}$ and (4E,6E,10Z)-hexadeca-4,6,10-trien-1-ol 162.

Direct carboxylation of acetylene with $\mathrm{CO}_{2}$ in the presence of 1,5,7-triazabicyclo[4.4.0]dec-1-ene (TBD) led to acetylene dicarboxylic acid derivatives (Scheme 88) [199].

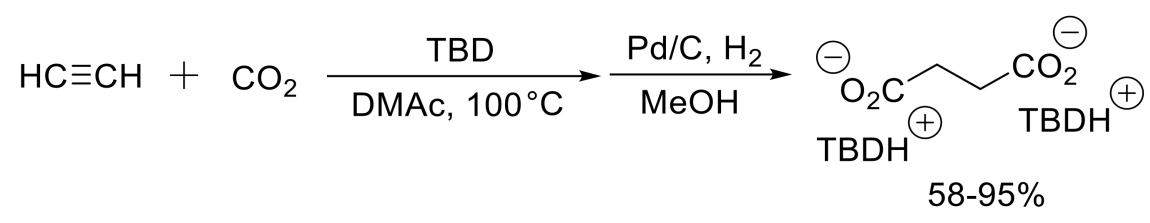

Scheme 88. Acetylene carboxylation in the presence of TBD. 
A possible mechanism for this reaction is shown in Scheme 89. The carboxylation is initiated by formation of a TBD-CO $\mathrm{CO}_{2}$ adduct, which undergoes nucleophilic addition of acetylene to afford a propiolate-TBD salt.

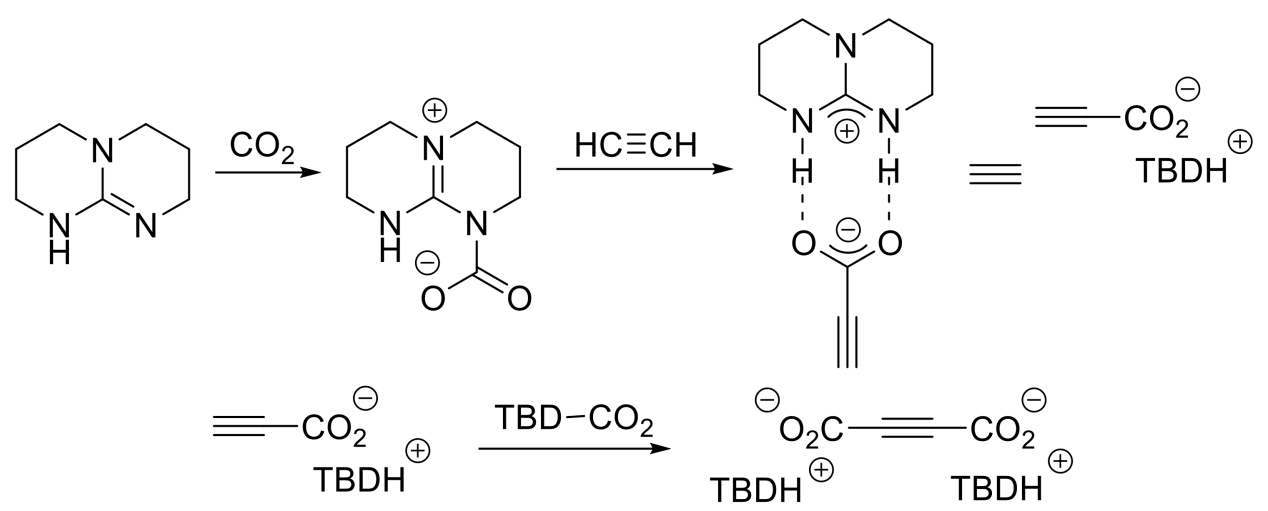

Scheme 89. A mechanism proposed for the TBD-promoted formation of acetylene dicarboxylic acid derivatives.

Enaminones 165 can be obtained by a three component reaction of calcium carbide, aryl aldehydes 163, and amines 164 (Scheme 90) [200].

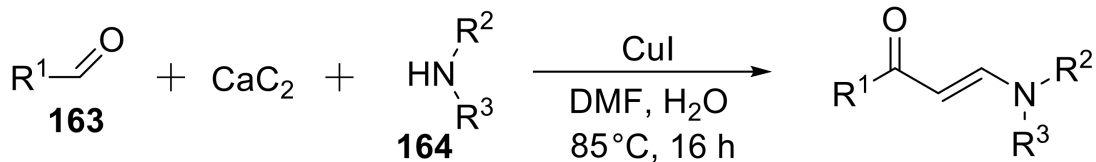

$$
\begin{aligned}
& \mathrm{R}^{1}=\operatorname{aryl} ; \mathrm{R}^{2}, \mathrm{R}^{3}=\text { alkyl } \quad 165(5-95 \%)
\end{aligned}
$$

Scheme 90. Three component synthesis of enaminones.

Another interesting example of acetylene addition is provided by a non-classical Diels-Alder reaction with substituted cyclobutadiene 166 [201]. The dried acetylene is bubbled into a toluene solution of pentafluorophenyltris(trimethylsilyl)cyclobutadiene to afford the Dewar benzene-like structure 167 (Scheme 91).
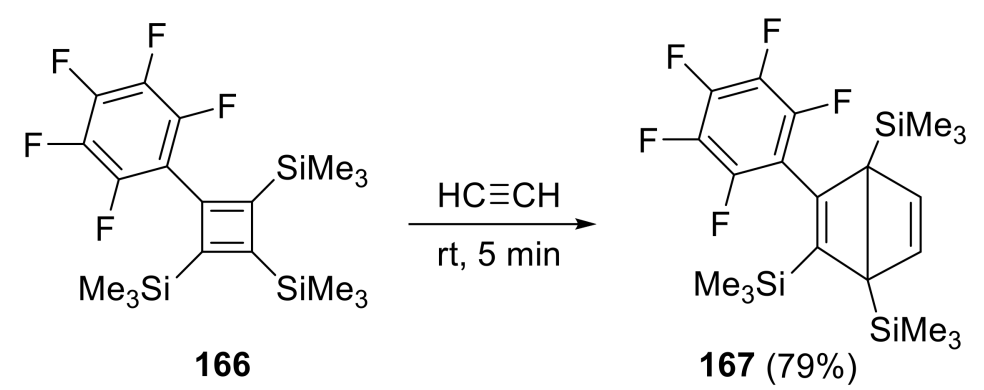

Scheme 91. [2 + 2]-Cycloaddition of acetylene to pentafluorophenyltris(trimethylsilyl)cyclobutadiene.

A catalytic insertion of acetylene into polystannane (Scheme 92) [202] provides an interesting link with the chemistry of polystannanes, the unique conductive main group polymers with a backbone composed entirely of tin [203]. 


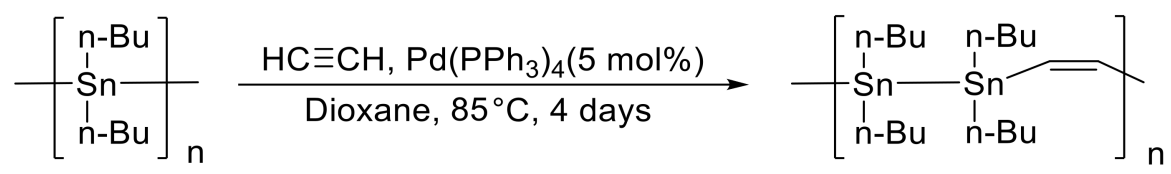

Scheme 92. Synthesis of polystannanes with $-\mathrm{CH}=\mathrm{CH}-$ link.

\subsection{Selective Semi-Hydrogenation of Acetylene}

Naphtha cracking generates streams of ethylene, which may be directly used in polymerization or partial oxidation to ethylene oxide. Acetylene impurities constitute $0.5-2 \mathrm{vol} \%$ of the primary ethylene streams. Their amount should be diminished to $5 \mathrm{vol} \%$ prior to polymerization. Acetylene, which is poisonous to the downstream polymerization catalysts, is removed from the gas mixture by hydrogenation. This step involves hydrogenation of acetylene to ethylene (i), hydrogenation of ethylene to ethane (ii), acetylene polymerization into green oil (iii), and carbonaceous deposition (iv, Scheme 93). The aim of the purification step is to achieve (i) avoiding (ii), (iii), and (iv).

$$
\begin{array}{ll}
\mathrm{C}_{2} \mathrm{H}_{2}+\mathrm{H}_{2} \rightarrow \mathrm{C}_{2} \mathrm{H}_{4} & \left(\Delta \mathrm{RH}=-174 \mathrm{~kJ} \mathrm{~mol}^{-1}\right) \\
\mathrm{C}_{2} \mathrm{H}_{4}+\mathrm{H}_{2} \rightarrow \mathrm{C}_{2} \mathrm{H}_{6} & \left(\Delta \mathrm{RH}=-136 \mathrm{~kJ} \mathrm{~mol}^{-1}\right) \\
2 \mathrm{C}_{2} \mathrm{H}_{4}+x \mathrm{H}_{2} \rightarrow \mathrm{C}_{4} \mathrm{H}_{4+2 x} \text { (green oil) } & \\
\mathrm{C}_{4} \mathrm{H}_{4+2 x}+n \mathrm{C}_{2} \mathrm{H}_{2}-y \mathrm{H}_{2} \rightarrow \text { carbonaceous deposits } &
\end{array}
$$

Scheme 93. Reaction possibilities of acetylene hydrogenation.

Selective hydrogenation of acetylene requires $\pi$-bonding of its molecules to the surface of a catalyst. The process is hindered when the adsorption centers are placed too densely; its performance can be enhanced by the active-site-isolation approach. As for the selectivity, all improvements fall into three groups. The first type of improvements results from modification of electronic properties of the catalyst is caused by alloying and/or support influence. The ligand effect [204] is caused by interaction of two metals and results in shift of their d-band center, which affects the adsorption strength and, the activation energy. Concomitant changes in structure and composition of the surface have modulatory effect on the number and geometry of the adsorption sites (the so-called ensemble effect). The emerging A sites are mainly responsible for selective acetylene hydrogenation, whereas the larger Pd ensembles, E sites, favor the ethylene-to-ethane conversion. The second type of selectivity improvements results from modification of the active site geometry and morphology. The third type of improvements is achieved by dilution or blocking of large active sites caused by reducing, deposition technique and ligands addition.

The catalysts used for selective acetylene hydrogenation can be divided into Pd-based (Pd/Ga [29,30], Pd/Ag [31-33], Pd/Cu [205]) and Pd-free, further subdivided into monometallic (Cu [206], Ag [207], Fe [208], Ni [209,210], Au [211]), bimetallic (Au/Ni [212,213], Au/Ag [214], $\mathrm{Ni} / \mathrm{Zn}$ [8], $\mathrm{Cu} / \mathrm{Al}$ hydrotalcite [215]), tri-metallic (Cu-Ni-Fe [216]), and metal free $\left(\mathrm{CeO}_{2}[217,218]\right)$. Today, Pd-based catalysts are often used for selective removal of acetylene $[219,220]$. However, they are prone to contamination with Pd carbides [221-223] and Pd hydrides [31,224], which worsen the performance and lead to over-hydrogenation $[225,226]$. Addition of carbon monoxide improves the selectivity, because $\mathrm{CO}$ competes for adsorption sites with ethylene but not acetylene [32,227]. However, $\mathrm{CO}$ co-feeding is inconvenient, as it requires continuous control of $\mathrm{CO}$ amounts in order to maintain the full acetylene conversion. In addition, CO promotes the formation of so-called green oil, which is composed of acetylene oligomers [210]. Although the activity of pure Pd is high, its selectivity is limited to $20 \%$ at $200{ }^{\circ} \mathrm{C}$ [228]. The optimum temperatures for such catalysts are much higher than those accepted in industry; besides, they are really expensive. Addition of the second metal improves the selectivity for two reasons: by changing electronic properties of $\mathrm{Pd}$ and by dilution of adsorption sites and thereby reducing the number of $\mathrm{E}$ sites. 
An alternative approach is based on addition of selective surface modifiers, that is, ligands with specific affinity to Pd surface. The ligands can be used during both liquid and gas phase hydrogenation. The nitrogen- [229,230], sulfur- [231,232], and phosphorus-containing [233,234] modifiers of this type usually enhance the selectivity by adsorption to the metal surface, which causes the decreasing the number of large Pd ensembles sites.

The third approach involves reducible oxide support modifications and deposition technique. $\mathrm{TiO}_{2}, \mathrm{La}_{2} \mathrm{O}_{3}, \mathrm{Nb}_{2} \mathrm{O}_{5}$, and $\mathrm{CeO}_{2}$ migrate onto the Pd surface during reduction, diluting the multiply coordinated sites and enriching the electron density of Pd [205,235-237] Dispersion across the surface of graphene [238] and insertion into zeolite frameworks [239] may also be considered as support modifications.

When pure palladium catalyzes acetylene hydrogenation, conversion and selectivity of the reaction depend on size and morphology of the metal particles. Acetylene hydrogenation is sensitive to the surface structure of Pd NPs. The most selective facet for acetylene hydrogenation is $\operatorname{Pd}(100)$. Cubic palladium nanoparticles (NPs) (100) facets can be prepared under controlled conditions [240-244]. Quite unluckily, the low-index facets of $\mathrm{Pd}[245,246]$ and $\mathrm{Pt}$ [247] are unstable and changed under the reaction conditions. After the reaction, the flat facets turn into sunken facets, and the cubic shape becomes twisted (Figure 5). The selectivity is maintained high for $27 \mathrm{~h}$ of the reaction and then sharply decreases [248]. Microstructural changes on the surface of the well-defined (100) facets result in rough (100) facets with steps and corners. These changes are induced by multiple repetitive adsorptions-desorptions.
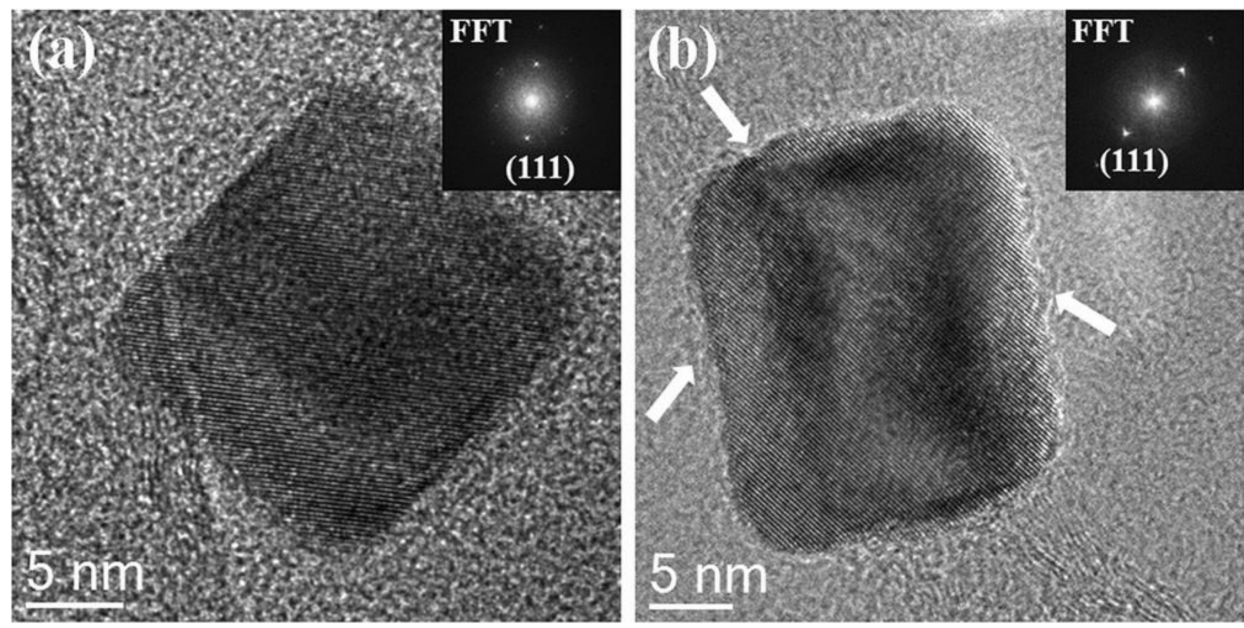

Figure 5. HR TEM images of palladium NPs after $2 \mathrm{~h}(\mathbf{a})$ and $55 \mathrm{~h}(\mathbf{b})$ of the reaction. White arrows indicate the sunken regions with steps and terraces. (Reproduced with permission from ref. [248]. Copyright 2017 WILEY-VCH Verlag GmbH \& Co. KGaA, Weinheim.).

Cubic NPs with $\operatorname{Pd}(100)$ facets show better results than spherical NPs of a similar size, which comprise significant portion of $\operatorname{Pd}(111)$ facets [249]. The temperatures of Pd hydride decomposition and hydrocarbon desorption for the cubic NPs are lower than for the spherical NPs. They also show higher acetylene conversion rates and better ethylene selectivity than $\mathrm{Pd}(222)$-faceted spherical particles (Figure 6) or smaller Pd(I) NPs prepared by using the incipient wetness method. 


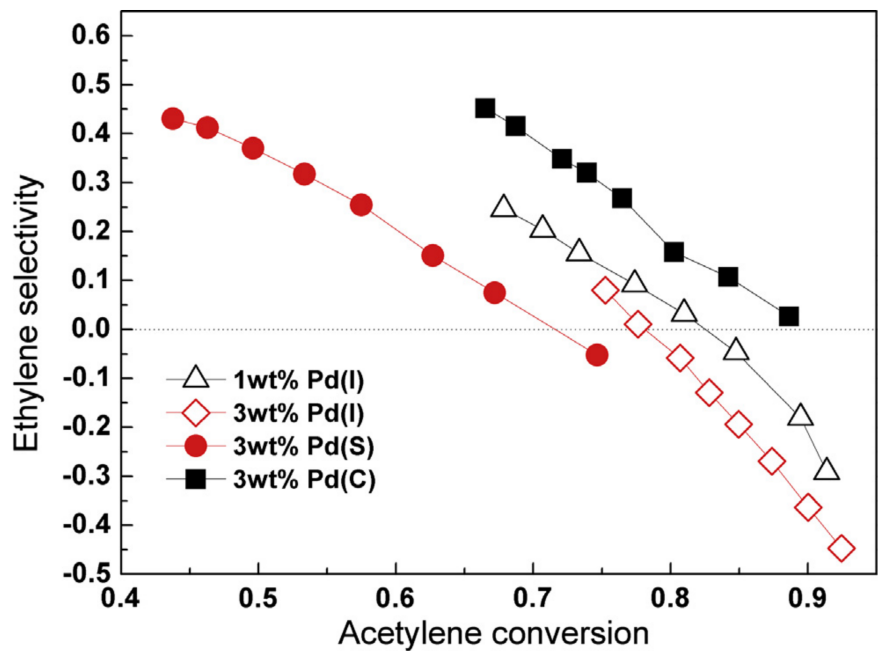

Figure 6. Ethylene selectivity as a function of acetylene conversion. Pd(I)-catalysts without defined morphology prepared by using the incipient wetness impregnation; $\mathrm{Pd}(\mathrm{S})$-catalyst with spherical particles; $\mathrm{Pd}(\mathrm{C})$-catalyst with cubic particles. Negative ethylene selectivity indicates net loss of ethylene due to over-hydrogenation and ethane production (reproduced with permission from [249]. Copyright 2013, Elsevier Inc.).

Surface acidity and basicity effect on the status of metals and on catalytic performance. Palladium supported hydrotalcite (Pd/HT) exhibits higher conversion of acetylene compared with aluminum oxide and magnesium oxide supports [250]. HT is a synthetic anionic clay, $\left[\mathrm{M}^{2+}{ }_{1-x} \mathrm{M}^{3+}{ }_{x}(\mathrm{OH})_{2}\right]^{x+}\left(\mathrm{A}^{n-}\right)_{x / n} \cdot m \mathrm{H}_{2} \mathrm{O}$, where $\mathrm{M}$ stands for metal cations and $\mathrm{A}$ represents an interlayer anion. After heat treatment, the interlayer anion and water are removed, leaving a mixture of metal oxides, which determines the acidity/basicity of the surface. Full conversion of acetylene over $\mathrm{Pd} / \mathrm{HT}$ is reached at $55{ }^{\circ} \mathrm{C}\left(\mathrm{Pd} / \mathrm{MgO}\right.$ and $\mathrm{Pd} / \mathrm{Al}_{2} \mathrm{O}_{3}$ are left behind with $31 \%$ and $22 \%$, respectively, Figure 7$)$. Ethylene selectivity of the system is $88 \%$ at $80 \%$ isoconversion, which is respectively 1.8 and 2.1 times higher than for $\mathrm{Pd} / \mathrm{MgO}$ and $\mathrm{Pd} / \mathrm{Al}_{2} \mathrm{O}_{3}$. It is well known that changing the support affects the parameters of catalytic reduction. Atomic Pd samples deposited on nanocarbons of differential morphology (representing different proportions of nanotubes, nanofibers, and other nanocarbon species) show differential conversions and selectivities [251].

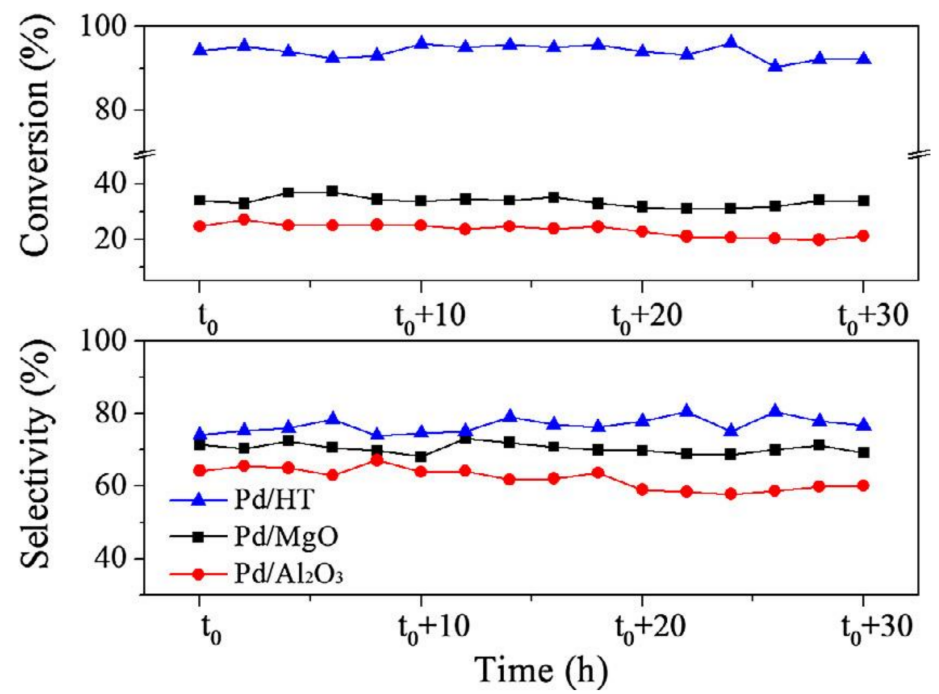

Figure 7. Plots of acetylene conversion and ethylene selectivity for Pd on different supports. (reproduced with permission from [250], Copyright 2015, Elsevier Inc.). 
Pd is usually present as a skin on the surface of a support layer. Dispersion of Pd active sites over the skin favors acetylene hydrogenation and inhibits over-hydrogenation and oligomer formation. Tunable thickness of a support layer allows effective control of $\mathrm{Pd}$ penetration range and results in uniform lateral distribution of Pd active sites. Egg-shell Pd/ $\alpha-\mathrm{Al}_{2} \mathrm{O}_{3} @ S i C$ catalysts with the controlled thickness of support layer (50-300 $\mu \mathrm{m}$, Figure 8) were obtained by a specifically developed procedure and tested in acetylene hydrogenation [252]. The catalysts had the same acetylene conversion but higher ethylene selectivity as compared with the conventional $\mathrm{Pd}-\mathrm{Ag} / \alpha-\mathrm{Al}_{2} \mathrm{O}_{3}$ catalyst.

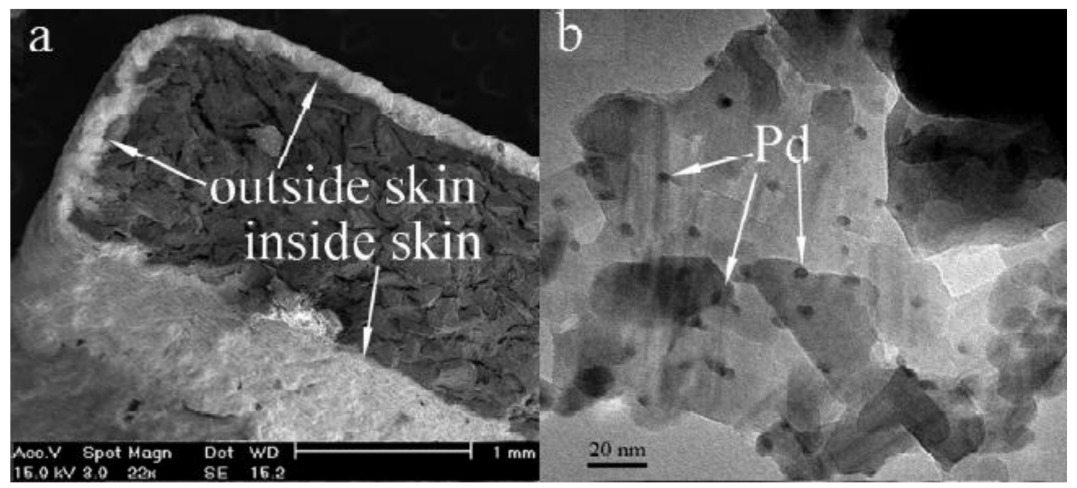

Figure 8. (a) SEM image of $\mathrm{Pd} / \alpha-\mathrm{Al}_{2} \mathrm{O}_{3} @ \mathrm{SiC}$ catalyst, (b) TEM image of Pd particles on $\mathrm{Al}_{2} \mathrm{O}_{3}$ layer of $\mathrm{Pd} / \alpha-\mathrm{Al}_{2} \mathrm{O}_{3} @ \mathrm{SiC}$ catalyst (reproduced with permission from [252]. Copyright 2016, the Royal Society of Chemistry).

A more than 10 times increase in surface area can be achieved by using porous hollow silica NPs as a coating in combination with monolithic cordierite as a ceramic substrate (Figure 9) [253]. Catalytic activity of the samples is enhanced by increasing reaction temperature, although by the cost of ethylene selectivity. The best results among the series are achieved for $\mathrm{PdO} / \mathrm{PHSNs}-\mathrm{Al}_{2} \mathrm{O}_{3} / \mathrm{MC}$ with $100 \%$ acetylene conversion and $47 \%$ ethylene selectivity. This study is an example of successful development of a new monolithic catalyst with increased surface area and maintainable mesoporous structure of the coating layer.
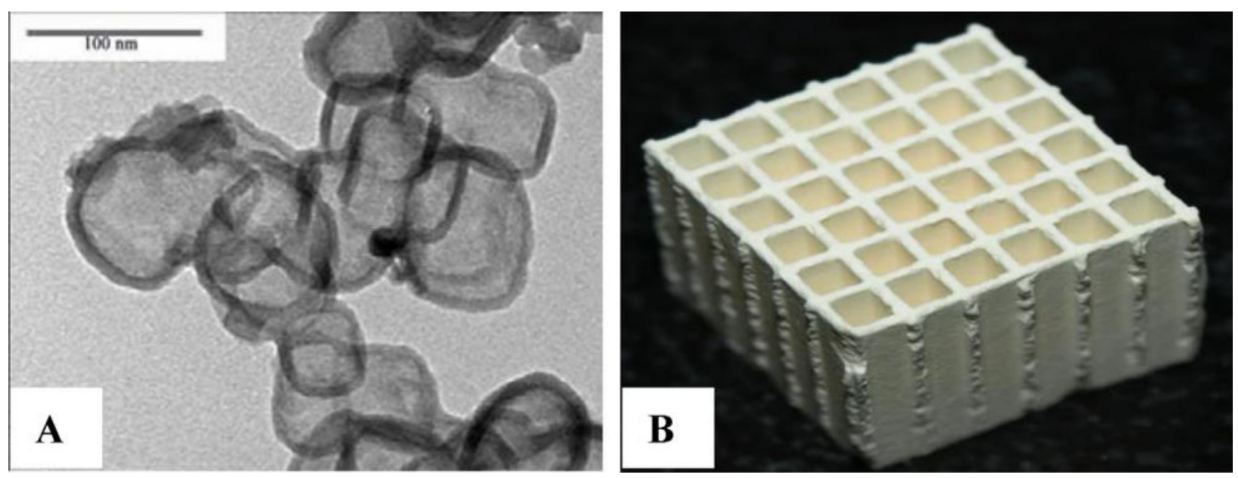

Figure 9. Porous hollow silica NPs (A) and monolithic cordierite (B) (reproduced with permission from [253]. Copyright 2013, Elsevier Inc.).

Ionic liquids stabilize nanoscale structures by forming the protective anionic and cationic layers [254,255]. Ionic liquid supports in gas phase hydrogenation, catalyzed by Pd, Ru, Ir, and Rh NPs, resulted in formation of 1,3-butadiene, C6-olefins, and benzene [256-258]. In the case of acetylene hydrogenation, ionic liquids with $\left[\mathrm{BF}_{4}\right]$ anion promote higher conversion and lower selectivity, whereas the effects of ionic liquids with $\left[\mathrm{PF}_{6}\right]$ anion are quite the opposite [259]. The Pd/BmimBF $4 / \mathrm{SiO}_{2}$ stability is slightly decreasing after $6 \mathrm{~h}$. The Ar plasma $/ \mathrm{H}_{2}$-treated $\mathrm{Pd} / \mathrm{EmimBF}_{4} / \mathrm{SiO}_{2}$ is $\mathrm{more}$ stable than the corresponding product of conventional reduction, due to minimized $\mathrm{Pd} / \mathrm{IL} / \mathrm{SiO}{ }_{2}$ 
fluctuation phenomena. Noteworthy, the size of Pd NPs and ionic liquids are stable under plasma conditions [260]. The catalytic properties of $\mathrm{Pd} / \mathrm{TiO}_{2}$ catalysts depend on the way of preparation (impregnation vs electroless deposition) and the type of atmosphere used for calcination- $\mathrm{O}_{2} / \mathrm{N}_{2}$ [261] or $\mathrm{H}_{2}$ [262]. Dispersion of $\mathrm{Pd}$ increased in the presence of $\mathrm{Ti}^{3+}$ significantly. $\mathrm{TiO}_{2}$ support prepared in $\mathrm{N}_{2}$ atmosphere under electroless conditions possessed similar average crystallite size, surface area and pore diameter resulted in improved catalytic performance. Full acetylene conversion with high ethylene selectivity (92\%) is achievable with $1 \% \mathrm{Pd} / \mathrm{TiO}_{2}-\mathrm{N}_{2}$. At the same time, $\mathrm{H}_{2}$ treatment of sol-gel derived $\mathrm{TiO}_{2}$ increases the number of $\mathrm{Ti}^{3+}$ defective sites on its surface.

Treatment of a $\mathrm{Pd} / \mathrm{TiO}_{2}$ catalyst with triphenylphosphine (TPP) improves the selectivity and limits over-hydrogenation under low pressures [263]. Acetylene and ethylene have similar rates of hydrogenation over the unmodified Pd catalyst (Figure 6, label 1). Adding CO (3 ppm) has little impact on the results; although it diminishes the ethylene conversion rate (Figure 6, label 2), continuous addition of $\mathrm{CO}$ is required to maintain the gain in selectivity. Adding TPP suppresses ethylene hydrogenation (Figure 10, label 3) and promotes a 10-fold decrease in formation of the gas phase-specific byproducts (Table 1). Probably, acetylene more readily adsorbs to the modified catalyst, whereas ethylene adsorption is hindered. Stability of TPP under both low and high pressures makes its superiority especially relevant.

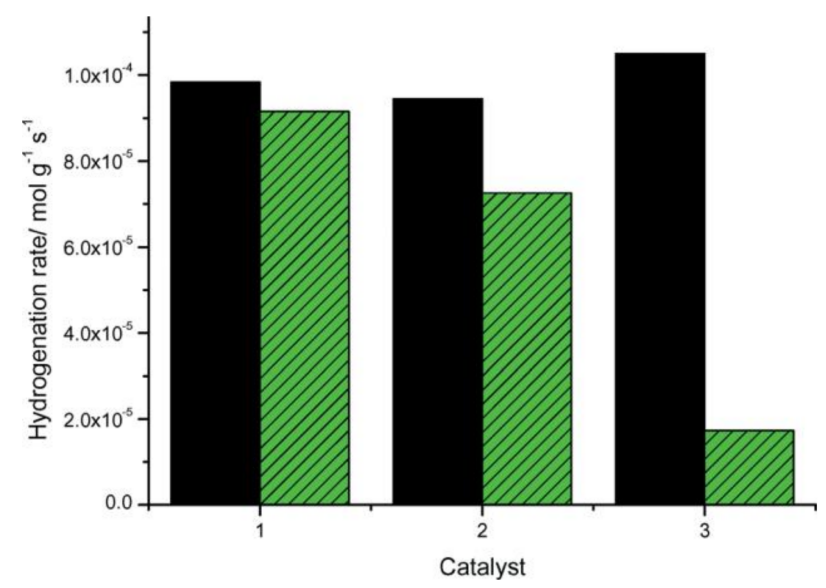

Figure 10. Hydrogenation rates of acetylene (black) and ethylene (shaded green): $1-\mathrm{Pd} / \mathrm{TiO}_{2}$, $2-\mathrm{Pd} / \mathrm{TiO}_{2}$ with $3 \%$ o $\mathrm{CO}$ in feed, 3- $\mathrm{PPh}_{3} 2.5 \mathrm{Pd} / \mathrm{TiO}_{2}$ (reproduced with permission from [263]. Copyright 2015, the Royal Society of Chemistry).

Table 1. Byproducts formed at $120 \mathrm{~min}$ of on-stream hydrogenation ( $323 \mathrm{~K}, 1 \mathrm{bar})$ for acetylene only, ethylene only, and acetylene/ethylene mixture.

\begin{tabular}{|c|c|c|}
\hline & Oligomers/FID Signal & Methane/FID Signal \\
\hline \multicolumn{3}{|c|}{ Acetylene only } \\
\hline $\mathrm{Pd} / \mathrm{TiO}_{2}$ & 248,173 & 61,404 \\
\hline $\mathrm{Pd} / \mathrm{TiO}_{2}+3 \% 0 \mathrm{CO}$ & 296,540 & 103,000 \\
\hline $\mathrm{PPh}_{3} 2.5 \mathrm{Pd} / \mathrm{TiO}_{2}$ & 315,656 & - \\
\hline \multicolumn{3}{|c|}{ Ethylene only } \\
\hline $\mathrm{Pd} / \mathrm{TiO}_{2}$ & 170 & 3445 \\
\hline $\mathrm{Pd} / \mathrm{TiO}_{2}+3 \%_{0} \mathrm{CO}$ & 799 & 3392 \\
\hline $\mathrm{PPh}_{3} 2.5 \mathrm{Pd} / \mathrm{TiO}_{2}$ & 290 & 3100 \\
\hline \multicolumn{3}{|c|}{ Mixed acetylene/ethylene reaction } \\
\hline $\mathrm{Pd} / \mathrm{TiO}_{2}$ & 52,415 & 14,763 \\
\hline $\mathrm{Pd} / \mathrm{TiO}_{2}+3 \% 0 \mathrm{CO}$ & 174,911 & - \\
\hline $\mathrm{PPh}_{3} 2.5 \mathrm{Pd} / \mathrm{TiO}_{2}$ & 4969 & 9393 \\
\hline $\mathrm{PPh}_{3} 10 \mathrm{Pd} / \mathrm{TiO}_{2}$ & 4332 & 6262 \\
\hline
\end{tabular}


Double additives ( $\mathrm{Ti}$ and La oxides) are moderate improvers of Pd catalysis [264]. La oxide is beneficial to the performance, but its reduction requires high temperatures. Ti oxide partially covered by La oxide maintained the modified geometric and electronic structures of the catalyst even after low-temperature reduction. It also confers higher ethylene selectivity than the single La oxide. Probably, Ti oxide prevents the La species from re-migrating during high-temperature reduction to their initial positions after air contact. In total, the Pd catalyst modified with Ti and La simultaneously exhibited the best results compared with pure Pd and monomodified catalysts (Figure 11).

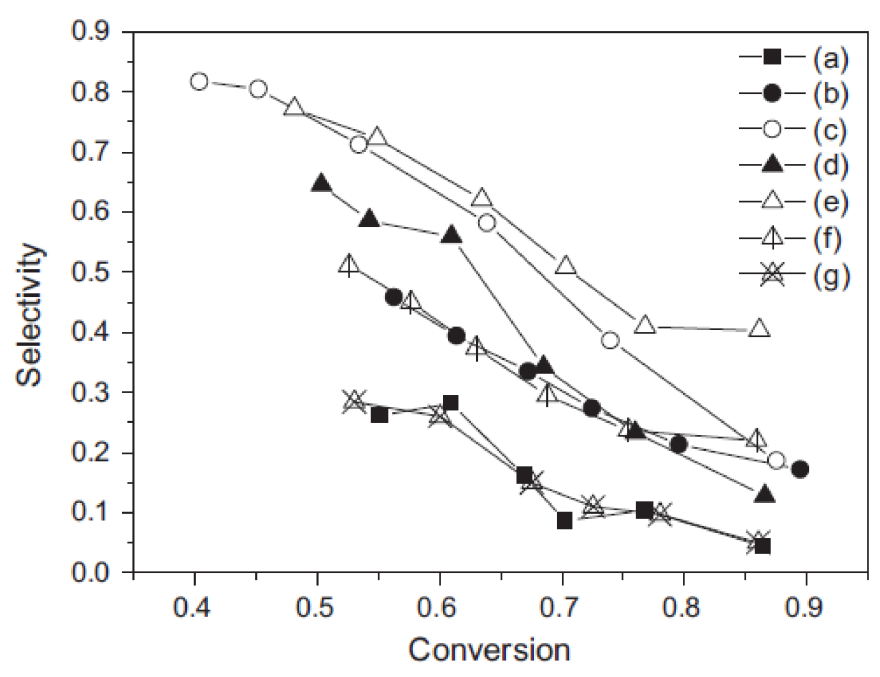

Figure 11. Performance of various Ti-modified Pd-La catalysts in acetylene hydrogenation. $\left(\mathrm{H}_{2} /\right.$ Acetylene $=2$, reaction temperature $\left.=60{ }^{\circ} \mathrm{C}\right)$. (a) $\mathrm{Pd} / 300$, (b) $\mathrm{Pd}-1 \mathrm{La} / 300$, (c) $\mathrm{Pd}-1 \mathrm{La} / 500$, (d) Pd-1La-0.1Ti/300, (e) Pd-1La-0.2Ti/300, (f) Pd-1La-0.4Ti/300, (g) Pd-0.2Ti/300 (reproduced with permission from [264]. Copyright 2014, Elsevier Inc.).

\subsubsection{Bimetallic Pd-based Catalysts: Pd and Ga/In}

As compared with ethylene, acetylene is much more soluble in acetone, dimethylformamide, $\mathrm{N}$-methylpyrrolidone (NMP) and some ionic liquids (Figure 12) [265]. At conversions near 100\%, ethylene selectivity becomes unevenly distributed between the liquid and gas phases. For instance, it may constitute $80-96 \%$ in the NMP liquid phase and $70 \%$ in gas phase. For this reason, NMP augments the hydrogenation, which a nonpolar solvent (e.g., decane) would be incapable of. NMP was also used for acetylene hydrogenation in the presence of $1 \% \mathrm{Pd} / \mathrm{Ga}_{2} \mathrm{O}_{3}$ catalyst [266]. Another study with a similar catalyst was less successful, providing only $53 \%$ acetylene conversion and $36 \%$ ethylene selectivity in liquid phase, possibly due to the low solubility of hydrogen in NMP in the presence of alloys with $0.5 \% \mathrm{Pd}-0.08 \% \mathrm{Ga}$ [267]. Low selectivity at full conversion was also reported for $\mathrm{Pd} / \mathrm{Ga}_{2} \mathrm{O}_{3}-\mathrm{Al}_{2} \mathrm{O}_{3}$ catalysts in NMP as a liquid phase [268]. 


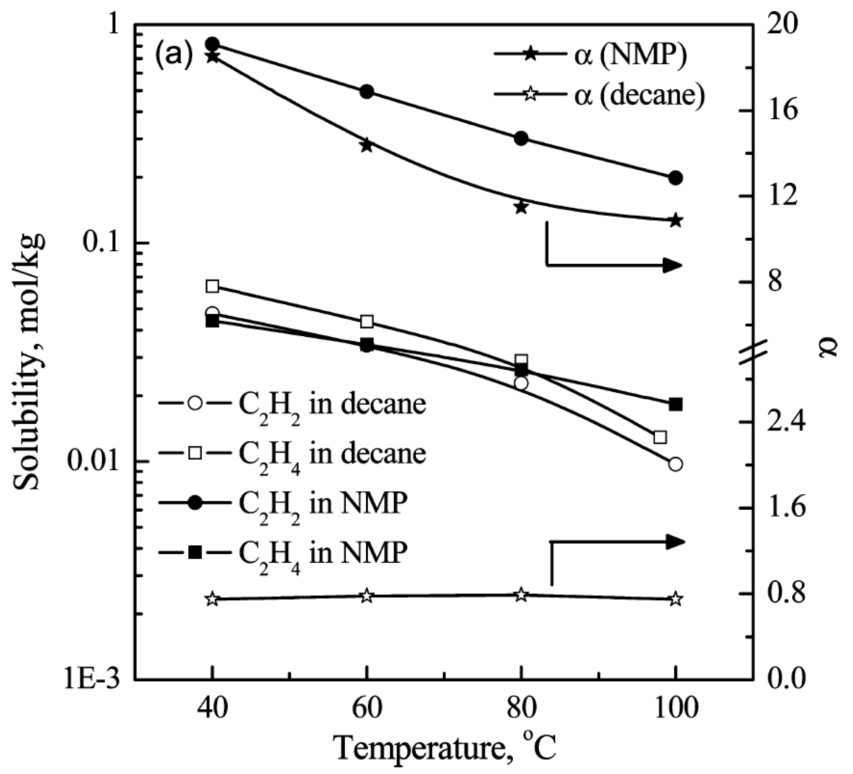

Figure 12. Solubility of acetylene and ethylene in NMP and decane. The catalyst is Pd/low surface area silica gel (reproduced with permission from [265]. Copyright 2013, American Chemical Society.).

A bimetallic Mg-Ga-Al-layered double hydroxide (LDH) Pd catalyst is more effective than a monometallic $\mathrm{Pd} / \mathrm{MgO}-\mathrm{Al}_{2} \mathrm{O}_{3}$ system [269]. Although bimetallic $\mathrm{Pd} / \mathrm{Ga}$ catalysts are just behind the pure Pd catalyst in activity, the bimetallic system shows much better selectivity in comparison with the monometallic $\mathrm{Pd} / \mathrm{MgO}-\mathrm{Al}_{2} \mathrm{O}_{3}$ catalyst without $\mathrm{Ga}$. High dispersion of bimetallic $\mathrm{Pd} / \mathrm{Ga}$ nanoalloy, with the average particle size of $2.6 \mathrm{~nm}$, is due to the uniform distribution of $\mathrm{Ga}$ and the electrostatic interaction between $\mathrm{Pd}$ and support layer (Figure 13). Strong adhesion of $\mathrm{MgGaAl}-\mathrm{LDH}$ to $\mathrm{Al}_{2} \mathrm{O}_{3}$ is a consequence of direct growth of the catalyst on the spherical $\mathrm{Al}_{2} \mathrm{O}_{3}$. Pure $\mathrm{Pd} / \mathrm{Ga}$ alloys $\left(\mathrm{GaPd}_{2}\right.$ and $\mathrm{GaPd}$ ) are also moderately active, but there was no rate limitation of acetylene concentration and occupation on the catalyst surface [270]. Inkjet printing allows to obtain Pd/Ga catalysts with thin, uniform and homogeneous wall coatings over the entire channel surface [271]. But even in this case the best ethylene selectivity is only $76 \%$. Using Ni instead of Ga in the NiMgAl-LDH catalysts is not particularly beneficial [272], although the strong interaction between $\mathrm{Pd}$ and Ni modulates the affinity of hydrogen to the catalyst surface in comparison with similar monometallic systems.

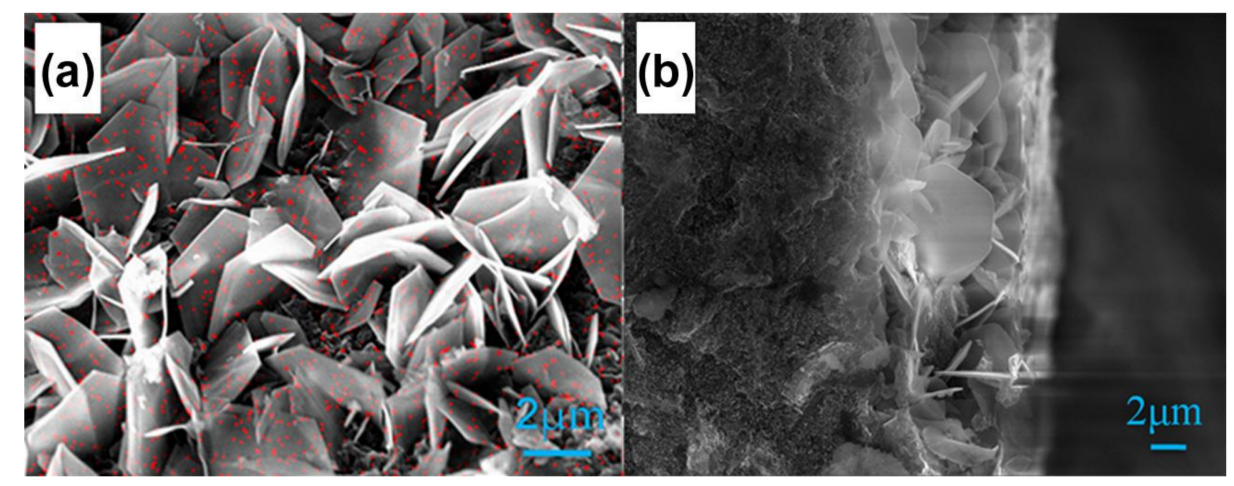

Figure 13. SEM images of the of the bimetallic Pd/Ga catalyst precursor from the surface (a) and in the cross section (b) (reproduced with permission from [269]. Copyright 2014, Elsevier Inc.).

Deposition of $\mathrm{Ga}_{2} \mathrm{O}_{3}$ adlayers on Pd particles supported on alumina enhance the catalyst performance by activating edge sites [273]. The atomic layer deposition results in $\mathrm{Ga}_{2} \mathrm{O}_{3}$ accumulation at the edges and open facets of Pd. These edges are transformed into catalytically active terrace-like 
sites. The treatment promotes an increase in the number of active sites and suppresses the formation of poisoning carbonaceous deposits on open facets. The catalytically active particles acquire polyhedron shape with (111) and (100) facets (Figure 14). They show 95\% ethylene selectivity at $75 \%$ acetylene conversion.
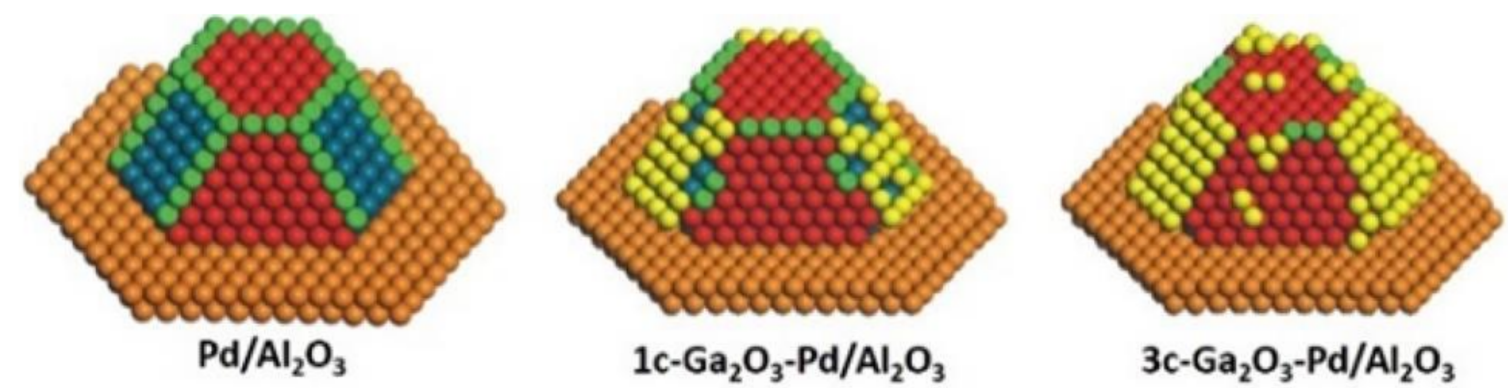

Figure 14. Schematic drawing of supported Pd particles in $\mathrm{Pd} / \mathrm{Al}_{2} \mathrm{O}_{3}$ - and $\mathrm{Ga}_{2} \mathrm{O}_{3}$-coated Pd particles in $1 \mathrm{c}-\mathrm{Ga}_{2} \mathrm{O}_{3}-\mathrm{Pd} / \mathrm{Al}_{2} \mathrm{O}_{3}$ and $3 \mathrm{c}-\mathrm{Ga}_{2} \mathrm{O}_{3}-\mathrm{Pd} / \mathrm{Al}_{2} \mathrm{O}_{3}$. The red, blue, green, orange, and yellow spheres represent terrace atoms of $\mathrm{Pd}$ (111) facets, facets other than $\mathrm{Pd}(111)$, corner and edge atoms of $\mathrm{Pd}(111)$ facets, $\mathrm{Al}_{2} \mathrm{O}_{3}$, and $\mathrm{Ga}_{2} \mathrm{O}_{3}$, respectively (reproduced with permission from [273]. Copyright 2016, American Chemical Society).

\subsubsection{Bimetallic Pd-based Catalysts: Pd and Zn/Co}

A series of $\mathrm{Pd} / \mathrm{ZnO}$ single-atom catalysts shows $80 \%$ ethylene selectivity at nearly full acetylene conversion [274]. Decreasing the Pd loading from $1 \%$ to $0.1 \%$ and reduction of the samples at relatively low temperatures of $\sim 100{ }^{\circ} \mathrm{C}$ leads to smaller Pd NPs with distributed single-atom Pd sites for the 0.01-Pd/ZnO catalyst (Figure 15). These high-valent Pd active sites promote electrostatic interactions with acetylene, but restrain ethylene hydrogenation due to the inability of $\sigma$-bond formation. Using $\mathrm{Zn}$ as an intermetallic catalyst instead of $\mathrm{ZnO}$ improves the performance to $90 \%$ selectivity at full conversion [275]. Nanostructured Pd-Zn-Pd ensembles have moderate $\sigma$-bonding mode for acetylene with two neighboring Pd sites and weak $\pi$-bonding of ethylene adsorption on the single Pd site.
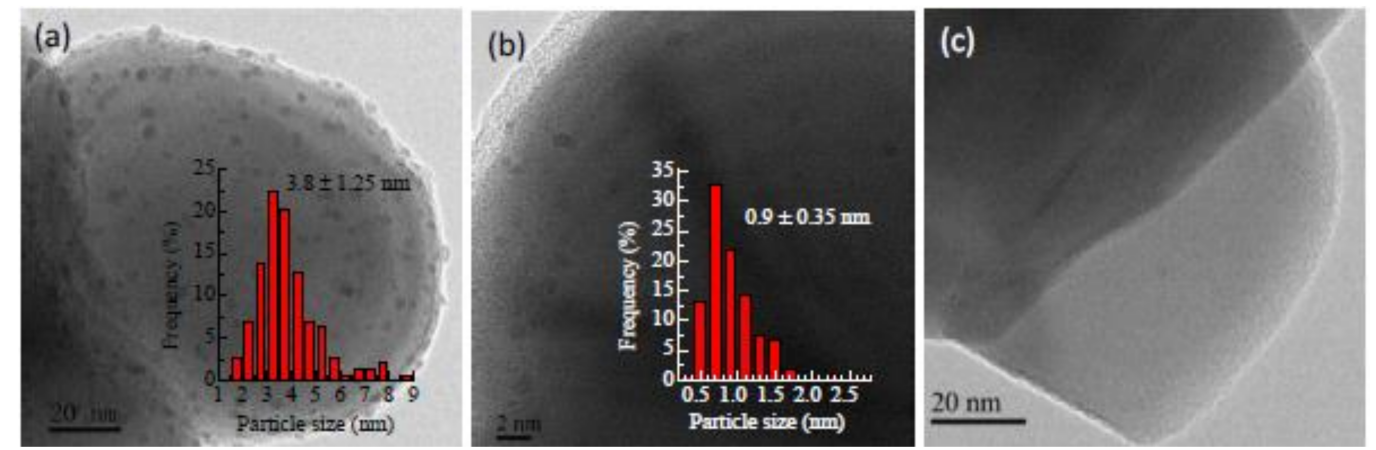

Figure 15. TEM images and particle size distributions of the catalysts: a- $1 \%-\mathrm{Pd} / \mathrm{ZnO}$; b-0.1\%-Pd/ZnO; c-0.01\%-Pd/ZnO reduced at $100{ }^{\circ} \mathrm{C}$ (reproduced with permission from [274]. Copyright 2016, Elsevier Inc.).

Well-defined hollow Zn/Co ZIF rhombic dodecahedron was obtained using special modification of ZIF-67@ZIF-8 structures in the presence of $\mathrm{Co}^{2+}$ [276]. A noble metal@MOF yolk-shell composite was prepared and tested as a catalyst for acetylene hydrogenation. The high-angle annular dark-field scanning TEM (HAADF-STEM) analysis showed that Pd@H-Zn/Co-ZIF was composed of hollow coordination polymer with embedded Pd NPs (Figure 16). The obtained catalysts were compared with Pd NPs in selective acetylene hydrogenation and demonstrated high activity and ethylene selectivity at mild temperatures. 

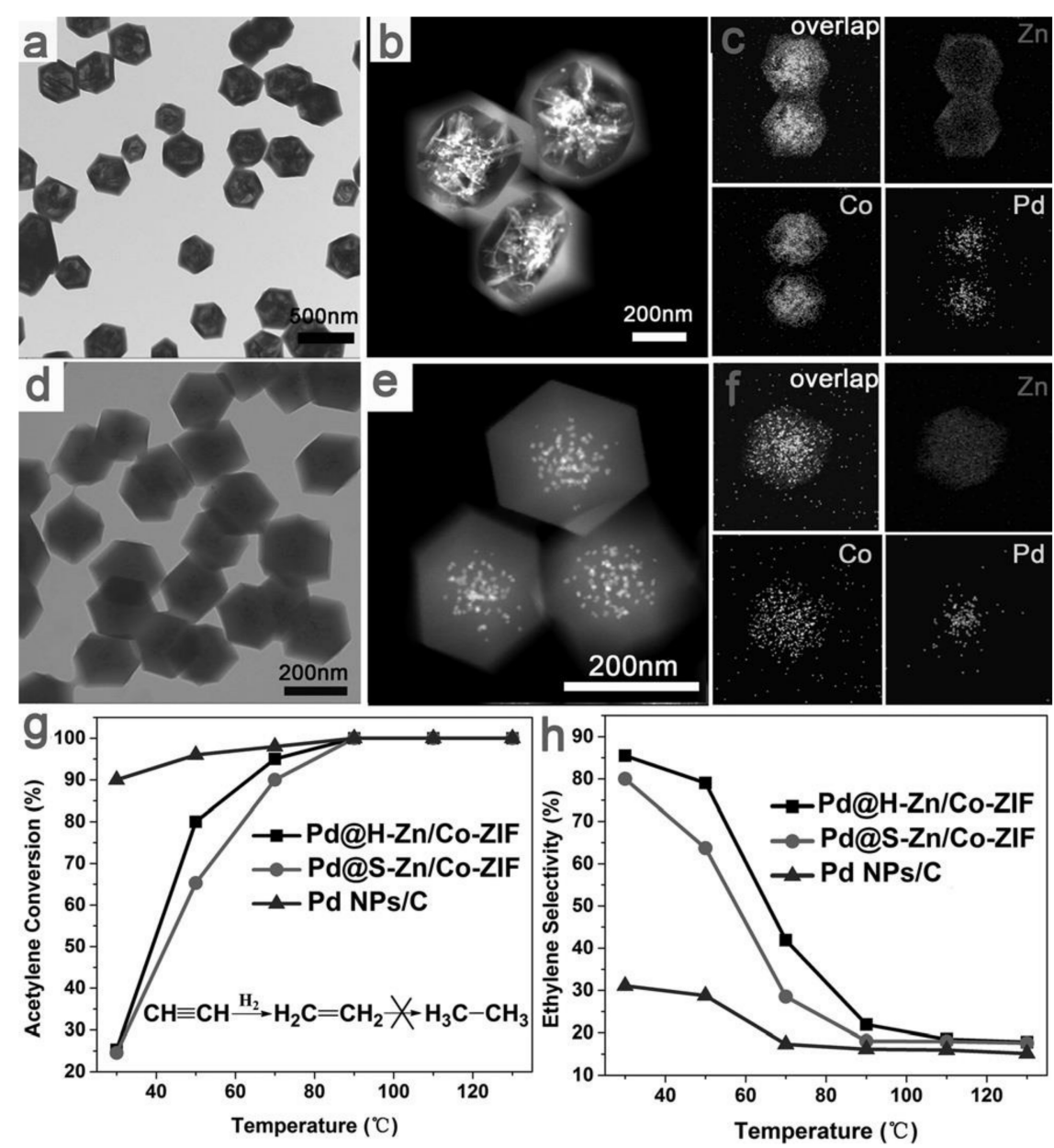

Figure 16. TEM pattern (a), HAADF-STEM image (b), and EDX mapping (c) of Pd@H-Zn/Co-ZIF. TEM pattern (d), HAADF-STEM image (e), and EDX mapping (f) of Pd@S-Zn/Co-ZIF. Acetylene conversion $(\mathbf{g})$ and ethylene selectivity $(\mathbf{h})$ as functions of temperature (reproduced with permission from [276]. Copyright 2015 WILEY-VCH Verlag GmbH \& Co. KGaA).

Polyols (tri-ethylene glycol and ethylene glycol) were used as a medium for $\mathrm{Pd} / \mathrm{Co}$ bimetallic system preparation [277]. CoPd NPs were deposited on active carbon, $\mathrm{MgO}$, and $\mathrm{Al}_{2} \mathrm{O}_{3}$ using poly(N-vinylpyrrolidone) as a stabilizing agent. Addition of Co led to formation of bimetallic NPs with better dispersion, as compared with monometallic Co or Pd NPs (Figure 17). Spherically shaped $\mathrm{Co} / \mathrm{Pd} \mathrm{NPs}$ of $3 \mathrm{~nm}$ diameter were catalytically active in hydrogenation and showed significantly higher ethylene selectivity, as compared with Pd NPs (Figure 18). The decreases in acetylene and ethylene adsorption heat were due to effects of $\mathrm{Co}$ on the electronic structure of $\mathrm{Pd}$, whereas the increase in ethylene selectivity was caused by separation of individual Pd sites by Co incorporation. 

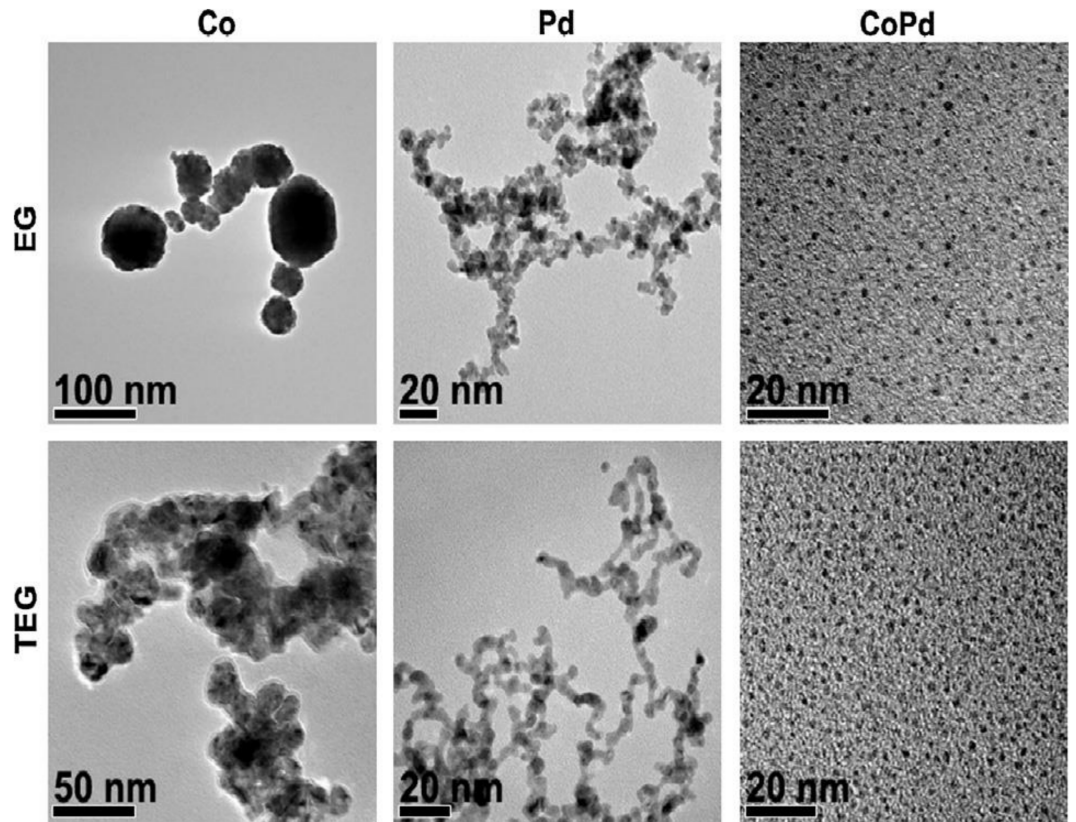

Figure 17. Representative TEM images of the $\mathrm{Co}, \mathrm{Pd}$ and $\mathrm{CoPd}$ nanoparticles and structures formed after refluxing for $1 \mathrm{~h}$ at $195^{\circ} \mathrm{C}$ in EG or at $280^{\circ} \mathrm{C}$ in TEG. EG-ethylene glycol, TEG — tri-ethylene glycol (reproduced with permission from [277]. Copyright 2013, Elsevier Inc.).
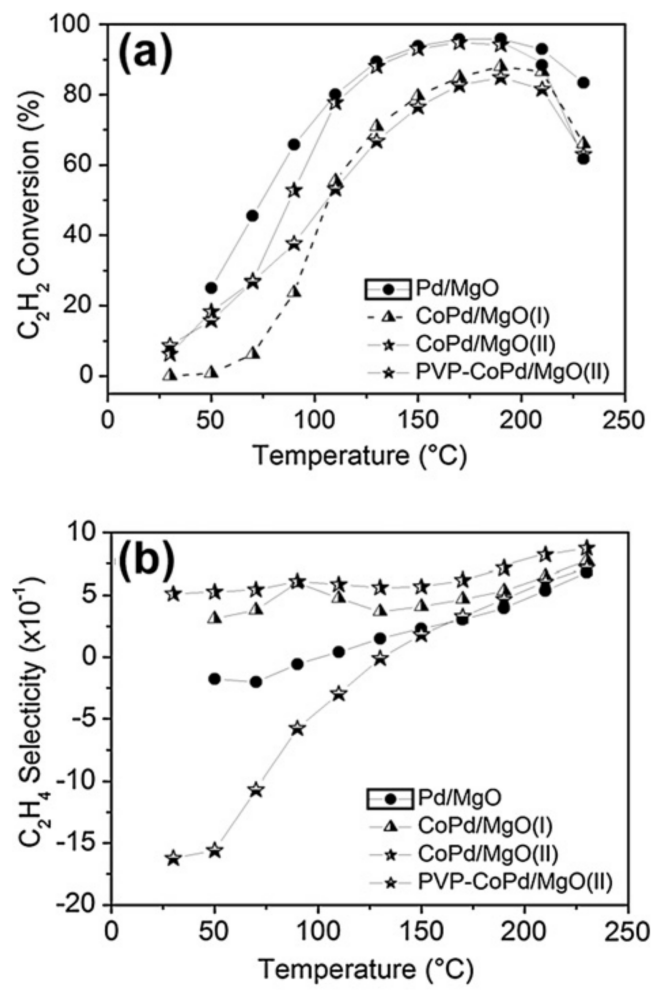

Figure 18. Cont. 


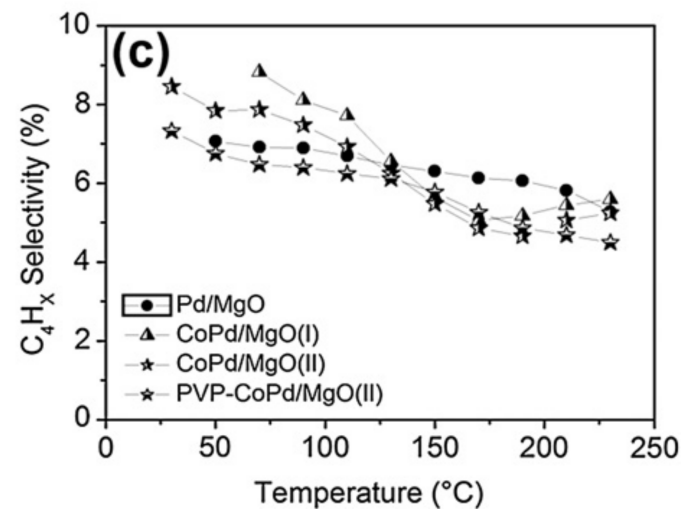

Figure 18. Acetylene conversion (a), ethylene selectivity (b), and C4 selectivity (c) as functions of temperature. Acetylene conversion is given by the difference of the inlet and outlet concentrations in vol \%. Ethane formation is given by vol\% of ethane in the reactor off-gas. (Conditions: $0.5 \mathrm{vol} \%$ $\mathrm{C}_{2} \mathrm{H}_{2}, 1 \mathrm{vol} \% \mathrm{H}_{2}$, and 70 vol \% $\mathrm{C}_{2} \mathrm{H}_{4}$ in $\mathrm{N}_{2}$, flow velocity $50 \mathrm{~mL} / \mathrm{min}$.) (reproduced with permission from [277]. Copyright 2013, Elsevier Inc.).

\subsubsection{Pd-Based Bimetallic Catalysts: $\mathrm{Pd}-\mathrm{Cu} / \mathrm{Ag} / \mathrm{Au}$}

Pd single-atom alloyed structures supported on silica, with ppm content of Pd, were alloyed with gold NPs and tested in hydrogenation [278]. Interestingly, the bimetallic systems showed a 1000\% better ethylene selectivity at $160{ }^{\circ} \mathrm{C}$ as compared to monometallic $\mathrm{Pd} / \mathrm{SiO}_{2}$ with similar $\mathrm{Pd}$ loadings (Figure 19).
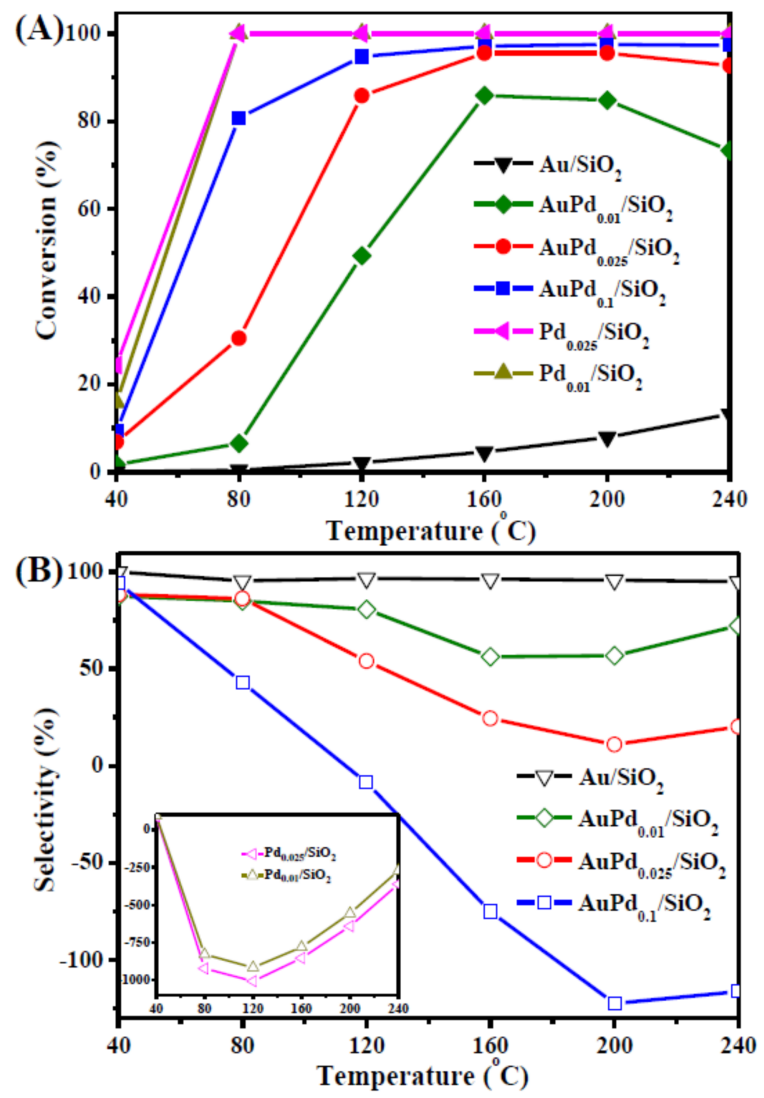

Figure 19. Conversion (A) and (B) selectivity as functions of temperature for acetylene semi-hydrogenation over $\mathrm{Au} / \mathrm{SiO}_{2}, \mathrm{AuPd} \mathrm{d}_{0.01} / \mathrm{SiO}_{2}, \mathrm{AuPd} \mathrm{A}_{0.025} / \mathrm{SiO}_{2}$ and $\mathrm{AuPd} \mathrm{P}_{0.1} / \mathrm{SiO}_{2}$ catalysts (reproduced with permission from [278]. Copyright 2014, the Royal Society of Chemistry.). 
The role of $\mathrm{Pd}$ in this case is to increase the conversion and to decrease the reaction temperatures, whereas $\mathrm{Au}$ provides isolation between $\mathrm{Pd}$ atoms and prevents acetylene over-hydrogenation. An $\mathrm{Au} / \mathrm{Pd}$ alloy with $\mathrm{TiO}_{2}$ support, prepared with the 2-nozzle system, exhibited the highest conversion (50\%) with high ethylene selectivity (95\%) at only $40{ }^{\circ} \mathrm{C}$ [279]. Partial coating of the most active bimetallic $\mathrm{Au} / \mathrm{Pd}$ particles with the Ti precursor afforded less active catalysts due to the formation of Ti-O species. Various configurations of the particles were achieved by using different types of feeding system (single- vs. double-nozzle). Formation of bimetallic NPs was minimized by separated feeding and enhanced by co-feeding.

The results of acetylene hydrogenation over $\mathrm{Ag}$ - and $\mathrm{Au}-\mathrm{Pd} / \mathrm{SiO}_{2}$ bimetallic catalysts suggest the possibility of two alternative pathways [280]. High coverage of Pd with Ag or Au leaves small ensembles of $\mathrm{Pd}$ sites, which adsorb acetylene as a $\pi$-bonded complex thus promoting its semi-hydrogenation to ethylene. The lower coverage leaves much larger, contiguous and merging $\mathrm{Pd}$ surface sites, where acetylene is adsorbed as a multi- $\sigma$-bonded complex preferably resolved by ethane formation.

The alumina phases of $\mathrm{Al}_{2} \mathrm{O}_{3}$ support and the mode of metal deposition on $\mathrm{TiO}_{2}$ support dramatically affect the Pd/Ag catalyst performance. Specific combinations of electrostatic properties with acidity determine differential strength of active sites: decreasing acidity of support is caused by a decrease in site strength [281]. A core-shell Pd@Ag bimetallic catalyst of this type, showing 73.5\% selectivity at $98.5 \%$ conversion, is prepared by photodeposition of $\mathrm{Pd}$ and $\mathrm{Ag}$, with the support acting as a photocatalyst during the preparation procedure [33]. The formed species have superficial Pd core and support specific growth of Ag on the Pd particle surface during the photocatalytic deposition process. Blockage of the high coordination Pd sites by the Ag shell, as well as the increased number of isolated $\mathrm{Pd}$ sites, results in better performance.

A defect-rich Pd/Ag catalyst on NiTi-layered double hydroxide support was tested in acetylene hydrogenation [282]. The compromise values of selectivity $(82 \%)$ and conversion ( $90 \%)$ were achieved by virtue of the small size and high dispersion of $\mathrm{Pd} / \mathrm{Ag}$ NPs and the abundance of $\mathrm{Ti}^{3+}$ defective sites. Withdrawing of electron density from $\mathrm{Ti}^{3+}$ by $\mathrm{Pd}$ enhanced the Pd-support interaction. Using $\mathrm{ZnAl}$ instead of $\mathrm{TiO}_{2}$ significantly improved the selectivity/conversion and also the oligomer selectivity [283]. Decreased amounts of carbonaceous deposits were observed for $\mathrm{PdAg} / \mathrm{ZnO}-\mathrm{Al}_{2} \mathrm{O}_{3}$ in comparison with $\mathrm{Pd} / \mathrm{Al}_{2} \mathrm{O}_{3}, \mathrm{PdAg} / \mathrm{Al}_{2} \mathrm{O}_{3}$, and $\mathrm{Pd} / \mathrm{ZnO}-\mathrm{Al}_{2} \mathrm{O}_{3}$ (Figure 20). The results were further improved to full acetylene conversion with $83.8 \%$ ethylene selectivity at $70{ }^{\circ} \mathrm{C}$ by using mixed $\mathrm{Mg}$-Ti supports [284]. Presumably, the moderate acidic sites of $\mathrm{Mg}_{0.5} \mathrm{Ti}_{0.5} \mathrm{O}_{\mathrm{y}}$ support accelerate hydrogen-spillover effect followed by facilitated hydrogen activation and dissociation. The selectivity is additionally improved by electron transfer from basic sites and $\mathrm{Ti}^{3+}$ species of $\mathrm{Mg}_{0.5} \mathrm{Ti}_{0.5} \mathrm{O}_{\text {y }}$ support. A silica gel-supported single-atom $\mathrm{Pd} / \mathrm{Ag}$ catalyst demonstrated 92.3\%/92.6\% selectivity/conversion due to extremely low content of $\mathrm{Pd}(\mathrm{ppm})$ [285]. The isolated electron-rich $\mathrm{Pd}$ atoms are capable of achieving the best results even in an ethylene-rich stream. 

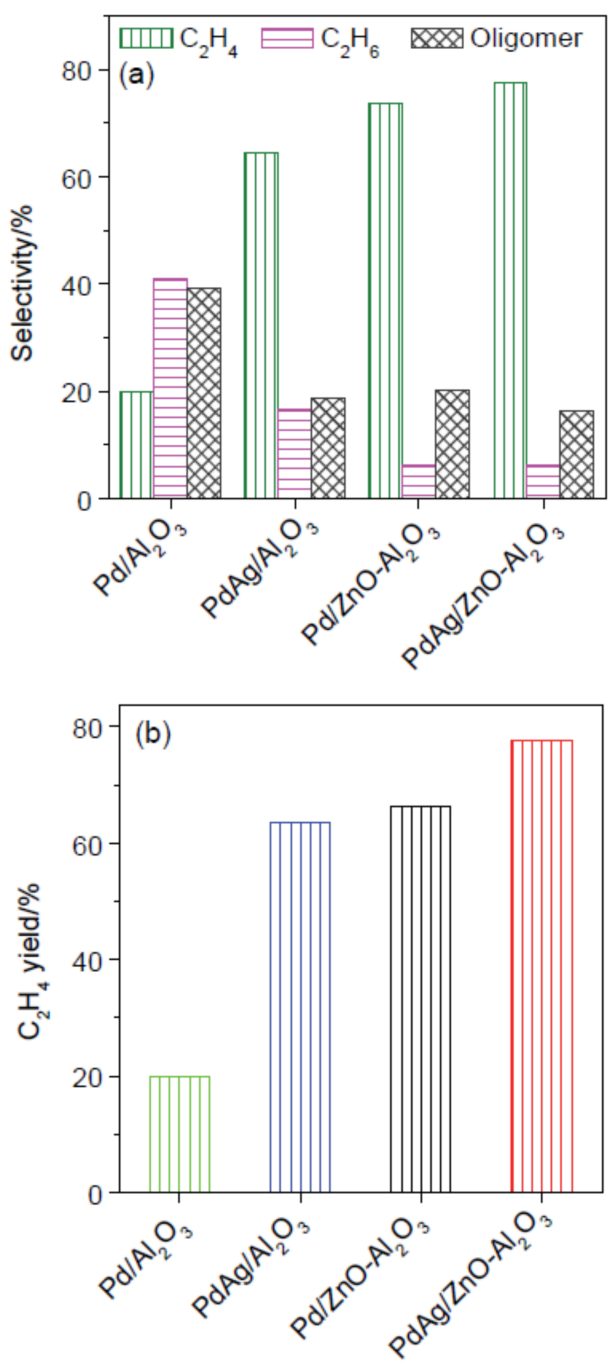

Figure 20. Product selectivities (a) and $\mathrm{C}_{2} \mathrm{H}_{4}$ yields (b) for PdAg/ZnAl catalysts, $180 \mathrm{~min}$ at $90{ }^{\circ} \mathrm{C}$ (reproduced with permission from [283]. Copyright 2017 WILEY-VCH Verlag GmbH \& Co. KGaA).

A bimetallic $\mathrm{Pd} / \mathrm{Cu}$ (1:50) catalyst on alumina showed a good 70\%/99\% selectivity/conversion at $423 \mathrm{~K}$ [286]. The catalyst combines the properties of $\mathrm{Cu}$ and $\mathrm{Pd}$; its high ethylene-selective activity at moderately low temperatures is attributed to facile dissociation of $\mathrm{H}_{2}$ on $\mathrm{Pd}$ with the immediate spillover onto $\mathrm{Cu}$ sites where the reaction proceeds. At lower temperatures, the ability of $\mathrm{Cu}$ to convert acetylene is poor $(9.59 \%$, Table 2$)$. At higher temperatures, the acetylene conversion increases and the ethane selectivity is kept constant, but the ethylene selectivity is limited to $72 \%$ because of oligomerization. A modified $\mathrm{Pd} / \mathrm{Al}_{2} \mathrm{O}_{3}$ catalyst shows better acetylene conversion at lower temperatures, but predominantly to ethane. Efficient and selective acetylene hydrogenation over $\mathrm{Pd} / \mathrm{Cu}$ catalysts proceeds at higher temperatures. Copper generally acts as a surface diluent decreasing the size of the palladium ensembles. After the hydrogenation over $\mathrm{Pd} / \mathrm{Cu}(111)$ catalyst, the products were simultaneously analyzed in gas phase [287], and reflection absorption infrared spectroscopy and Auger electron spectroscopy confirmed the presence of a carbonaceous layer on the surface (Figure 21). Palladium alters the nature of the carbonaceous species by promoting hydrogenation of polyacetylene, the product of copper-mediated acetylene coupling. 
Table 2. Acetylene conversion and ethylene/ethane/oligomer selectivities over $10 \% \mathrm{Cu} / \mathrm{Al}_{2} \mathrm{O}_{3}$ and $1.67 \% \mathrm{Pd} / \mathrm{Al}_{2} \mathrm{O}_{3}$.

\begin{tabular}{cccccc}
\hline Catalyst & $\begin{array}{c}\text { Temperature } \\
\text { (K) }\end{array}$ & $\begin{array}{c}\text { Acetylene } \\
\text { Conversion (\%) }\end{array}$ & $\begin{array}{c}\text { Ethylene } \\
\text { Selectivity (\%) }\end{array}$ & $\begin{array}{c}\text { Ethane } \\
\text { Selectivity (\%) }\end{array}$ & $\begin{array}{c}\text { Oligomer } \\
\text { Selectivity (\%) }\end{array}$ \\
\hline $10 \% \mathrm{Cu} / \mathrm{Al}_{2} \mathrm{O}_{3}$ & 323 & 9.59 & 53.2 & 9.9 & 37.0 \\
& 373 & 60.71 & 60.5 & 8.6 & 30.8 \\
& 423 & 99.20 & 71.5 & 8.0 & 20.5 \\
$1.67 \% \mathrm{Pd} / \mathrm{Al}_{2} \mathrm{O}_{3}$ & 323 & 85.17 & 0.0 & 93.1 & 6.9 \\
\hline
\end{tabular}

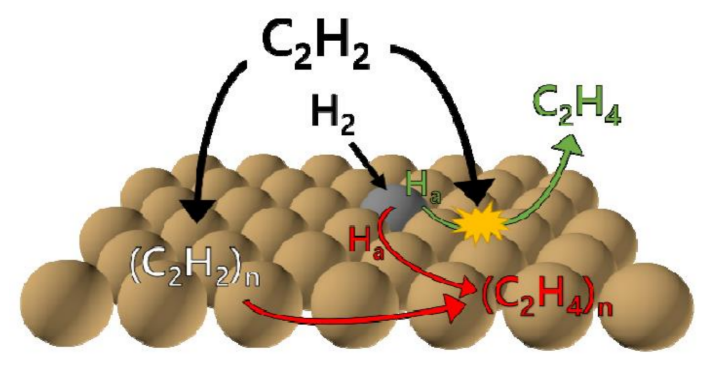

Figure 21. Proposed mechanism of acetylene hydrogenation over a $\mathrm{Pd} / \mathrm{Cu}$ catalyst with deposited carbonaceous layer (reproduced with permission from $\mathrm{r}$ [287]. Copyright 2017, American Chemical Society.).

A silica gel-supported alloyed $\mathrm{Pd} / \mathrm{Cu}$ single atom catalyst showed $85 \%$ ethylene selectivity at full acetylene conversion [288]. The mechanistic investigations confirmed the role electron transfer from $\mathrm{Cu}$ to $\mathrm{Pd}$ in promoting hydrogen (Figure 22). Pd-doped $\mathrm{Cu} / \mathrm{Al}_{2} \mathrm{O}_{3}$ catalysts with $50: 1 \mathrm{Cu} / \mathrm{Pd}$ ratio, prepared by co-impregnation, sequential impregnation, or colloidal approach, show $80 \% / 98 \%$ selectivity/conversion at only $353 \mathrm{~K}$ [289]. It is important to note that $\mathrm{Cu} / \mathrm{Pd}$ bimetallic catalysts with fixed $\mathrm{Pd}$ content and varied $\mathrm{Cu}$ loadings are not as sensitive to the reductive pretreatment as the $\mathrm{Pd} / \mathrm{Ag}$ catalysts [290]. However, being reduced at $400{ }^{\circ} \mathrm{C}$ and $250{ }^{\circ} \mathrm{C}$, these catalysts show similar behaviors.

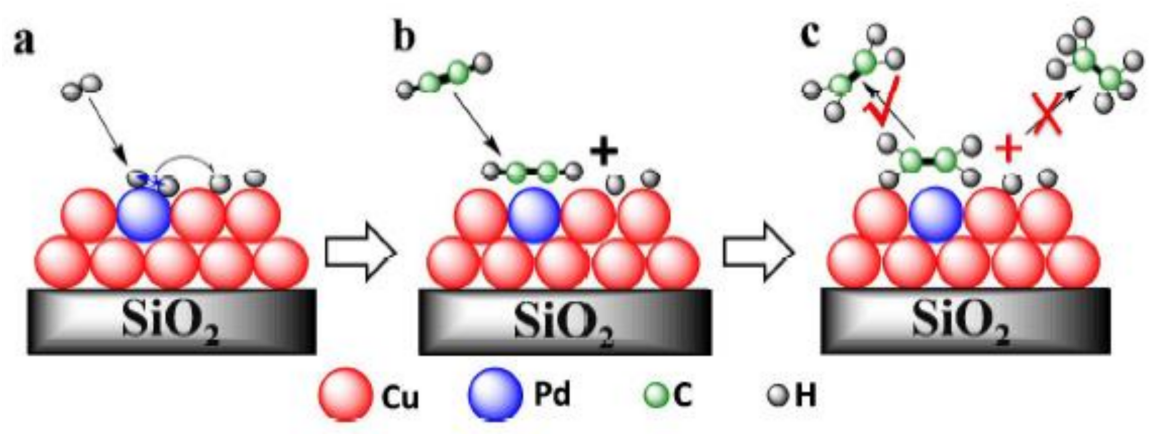

Figure 22. Proposed mechanism of acetylene hydrogenation over a silica-supported $\mathrm{Pd} / \mathrm{Cu}$ single atom catalyst: $\mathbf{a}$-dissociation of $\mathrm{H}_{2}$ and spillover of $\mathrm{H}$ atoms, $\mathbf{b}$-adsorption and hydrogenation of acetylene, c-desorption of ethylene (reproduced with permission from [288]. Copyright 2017 American Chemical Society.).

\subsubsection{Pd-Free Monometallic Catalysts: Mo}

A rare reported example of a non-precious metal catalyst for acetylene hydrogenation is based on tri-, tetra-, and hexanuclear mixed-valence molybdenum clusters [291]. The liquid phase reaction was carried out in the presence of $\mathrm{Na}$ or Eu amalgams, the $\left[\mathrm{Mo}_{4} \mathrm{Cl}_{4} \mathrm{O}_{2}\left(\mathrm{OCH}_{3}\right)_{6}\left(\mathrm{CH}_{3} \mathrm{OH}\right)_{4}\right]$ complex, and methanol as a medium. After the catalyst reduction, ethylene and ethane were detected in the parallel reactions simultaneously. After addition of tributylphosphine to Mo-complex, both ethylene and ethane yields increased more than $50 \%$ (Figure 23). 

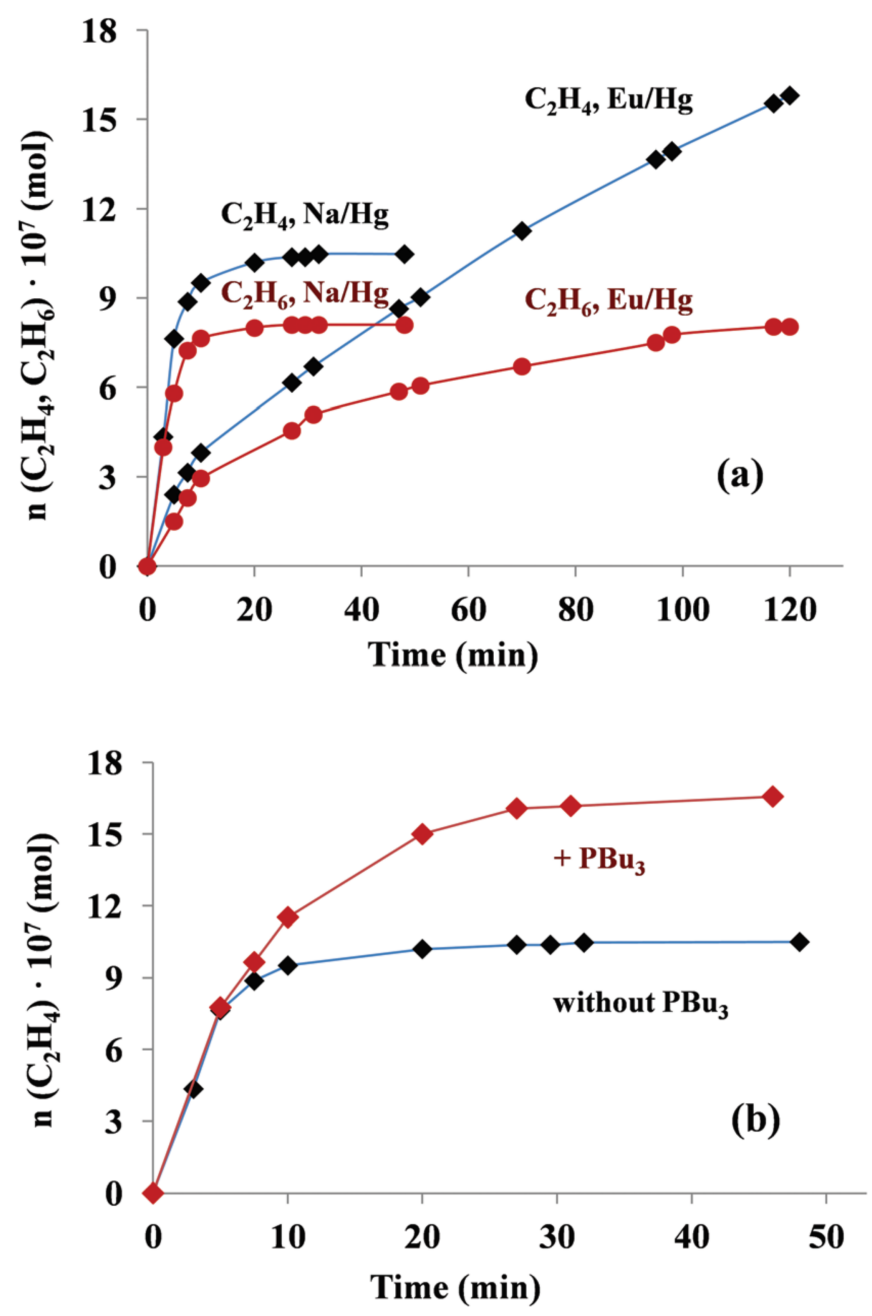

Figure 23. (a) Experimental kinetic curves of $\mathrm{C}_{2} \mathrm{H}_{4}$ and $\mathrm{C}_{2} \mathrm{H}_{6}$ accumulation in the reaction of $\mathrm{C}_{2} \mathrm{H}_{2}$ reduction by $\mathrm{Na}$ or $\mathrm{Eu}$ amalgam in the presence of Mo-complex. (b) The effect of $\mathrm{PBu}_{3}$ addition $\left(\mathrm{C}\left(\mathrm{PBu}_{3}\right)=5 \times 10^{-3} \mathrm{M}\right)$ on the $\mathrm{C}_{2} \mathrm{H}_{4}$ accumulation rate in $\mathrm{C}_{2} \mathrm{H}_{2}$ reduction by $\mathrm{Na}$ amalgam in the presence of Mo-complex. (Conditions: $\mathrm{C}(\mathrm{Mo})=2 \times 10^{-5} \mathrm{M} ; 0.5 \mathrm{~mL} \mathrm{Eu} / \mathrm{Hg}(0.9 \mathrm{M})$ or $0.5 \mathrm{~mL} \mathrm{Na} / \mathrm{Hg}$ $(3.5 \mathrm{M}) ; 8 \mathrm{ml} \mathrm{CH} 3 \mathrm{OH} ; \mathrm{P}\left(\mathrm{C}_{2} \mathrm{H}_{2}\right)=0.13 \mathrm{~atm}, \mathrm{C}\left(\mathrm{NaOCH}_{3}\right)=0.09 \mathrm{M}, \mathrm{C}\left(\mathrm{H}_{2} \mathrm{O}\right)=0.02 \mathrm{M}, \mathrm{C}(\mathrm{PC})=3 \times 10^{-4} \mathrm{M}$,

$21^{\circ} \mathrm{C}$ ) (reproduced with permission from [291]. Copyright 2016 the Royal Society of Chemistry.).

\subsubsection{Pd-Free Monometallic Catalysts: $\mathrm{Au}$}

Gold catalysts, obtained by photo-dependent synthesis, showed $80 \%$ ethylene selectivity at full acetylene conversion after $12 \mathrm{~h}$ at $225{ }^{\circ} \mathrm{C}$ [292]. The best of them, $1 \% \mathrm{Au} / \mathrm{C}-\mathrm{TiO}_{2}$ and $5 \%$ $\mathrm{Au} / \mathrm{C}-\mathrm{TiO}_{2}$, were tested for different $\mathrm{H}_{2} / \mathrm{C}_{2} \mathrm{H}_{2}$ ratios. At low $\mathrm{H}_{2} / \mathrm{C}_{2} \mathrm{H}_{2}$, both catalysts showed higher ethylene selectivities at limited acetylene conversion. Reciprocally, the excess of $\mathrm{C}_{2} \mathrm{H}_{2}$ favored its high conversion with low ethylene selectivity. After reduction at $250{ }^{\circ} \mathrm{C}$, the $1 \% \mathrm{Au} / \mathrm{C}-\mathrm{TiO}_{2}$ stably supported full acetylene conversion with $80 \%$ ethylene selectivity.

\subsubsection{Pd-Free Monometallic Catalysts: In}

Indium oxide catalysts showed extraordinary good results at $550 \mathrm{~K}$, with $85 \%$ ethylene selectivity at full conversion even for the ethylene excess conditions [293]. The most stable surface configuration, $\mathrm{In}_{2} \mathrm{O}_{3-y}(111)$, was chosen to investigate the mechanisms of the main reaction and side reactions. Formation of a unique $\mathrm{In}_{3} \mathrm{O}_{5}$ site with $\mathrm{O}$ vacancy was predicted by theoretical calculations. Acetylene and $\mathrm{H}_{2}$ molecules co-adsorb to the catalytic site composed of In trimer and adjacent $\mathrm{O}$ atoms. This is 
an example of single-ensemble heterogeneous catalysis, which requires several particular atoms surrounding the empty site for the reaction to occur.

\subsubsection{Pd-Free Bimetallic Catalysts: $\mathrm{Ni} / \mathrm{Zn}$}

Nickel-zinc catalysts specifically suppress the oligomeric species formation by decreasing acetylene adsorption energy. This effect contributes to the higher ethylene selectivity [294]. Isotope labeling studies in a batch reactor confirmed that ethane was produced from both acetylene and ethylene, while oligomeric species were produced from acetylene only. Partial hydrogenation of acetylene led to adsorbed vinyl, which immediately reacted with adsorbed acetylene yielding $\mathrm{C}_{4} \mathrm{H}_{5}$, whose reaction with adsorbed hydrogen yielded butadiene as a final product (1-butene, cis-2-butene, and trans-2-butene can also be formed depending on the hydrogen availability). The carbohydrates can desorb from the catalyst surface and further react with acetylene molecules to form higher molecular weight oligomers. Transition states for vinyl hydrogenation and C-C bond formation on Ni and NiZn are shown in Figure 24.
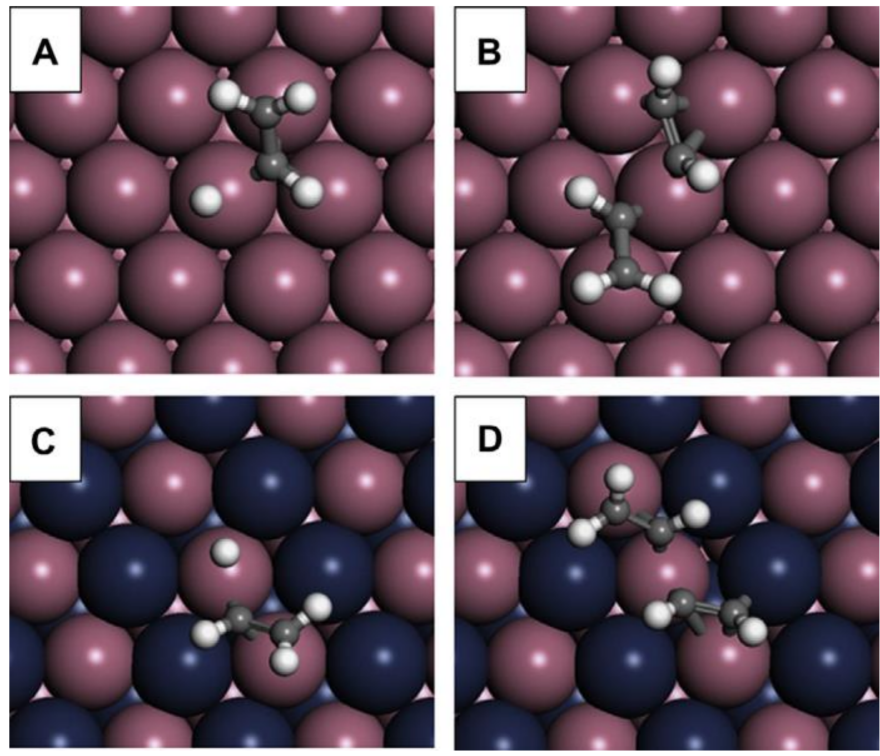

Figure 24. Transition states for vinyl hydrogenation and C-C bond formation on $\mathrm{Ni}(111)(\mathbf{A}$ and $\mathbf{B})$ and $\mathrm{NiZn}(101)$ (C and D), respectively. Ni atoms are light pink and Zn atoms are dark blue (reproduced with permission from [294]. Copyright 2014 Elsevier Inc.).

\subsubsection{Pd-Free Bimetallic Catalysts: Fe/Mo}

Nitrogenases (Nases) are able to reduce nitrogen to ammonia and acetylene to ethylene [295-301]. Inorganic $\mathrm{Fe} / \mathrm{Mo}$ clusters with a $\left[\mathrm{Fe}_{2} \mathrm{MoOS}_{3}\right]$ core resemble a part of FeMo-cofactor, the active center of nitrogenases [302]. The dihydride complex reduced acetylene to ethylene via the vinyl monohydride complex; the detailed mechanism, verified by using various combinations of reductants, substrates, and heavy water, is shown in Figure 25. Even very small $(2.0 \pm 0.5 \mathrm{~nm})$ and probably planar Fe $\mathrm{Fe}^{2,3+}$ oxide NPs on slightly acidic inorganic oxide supports $\left(\mathrm{TiO}_{2}, \mathrm{ZrO}_{2}\right.$, or $\left.\mathrm{ZnO}\right)$ are capable of mimicking the natural enzyme activities [303]. Surprisingly, these catalysts selectively and almost totally reduce acetylene and other alkynes not only in batch reactors, but also in flowing streams. Mixed Fe-oxides dissociate and transfer hydrogen onto alkynes in a chemo- and stereoselective manner. Cheap, nontoxic, ligand-free, and ambient condition-resistant, the solid iron catalysts ensure cis-selective semi-hydrogenation of different alkynes, including acetylene, in high yields and with good selectivities. 

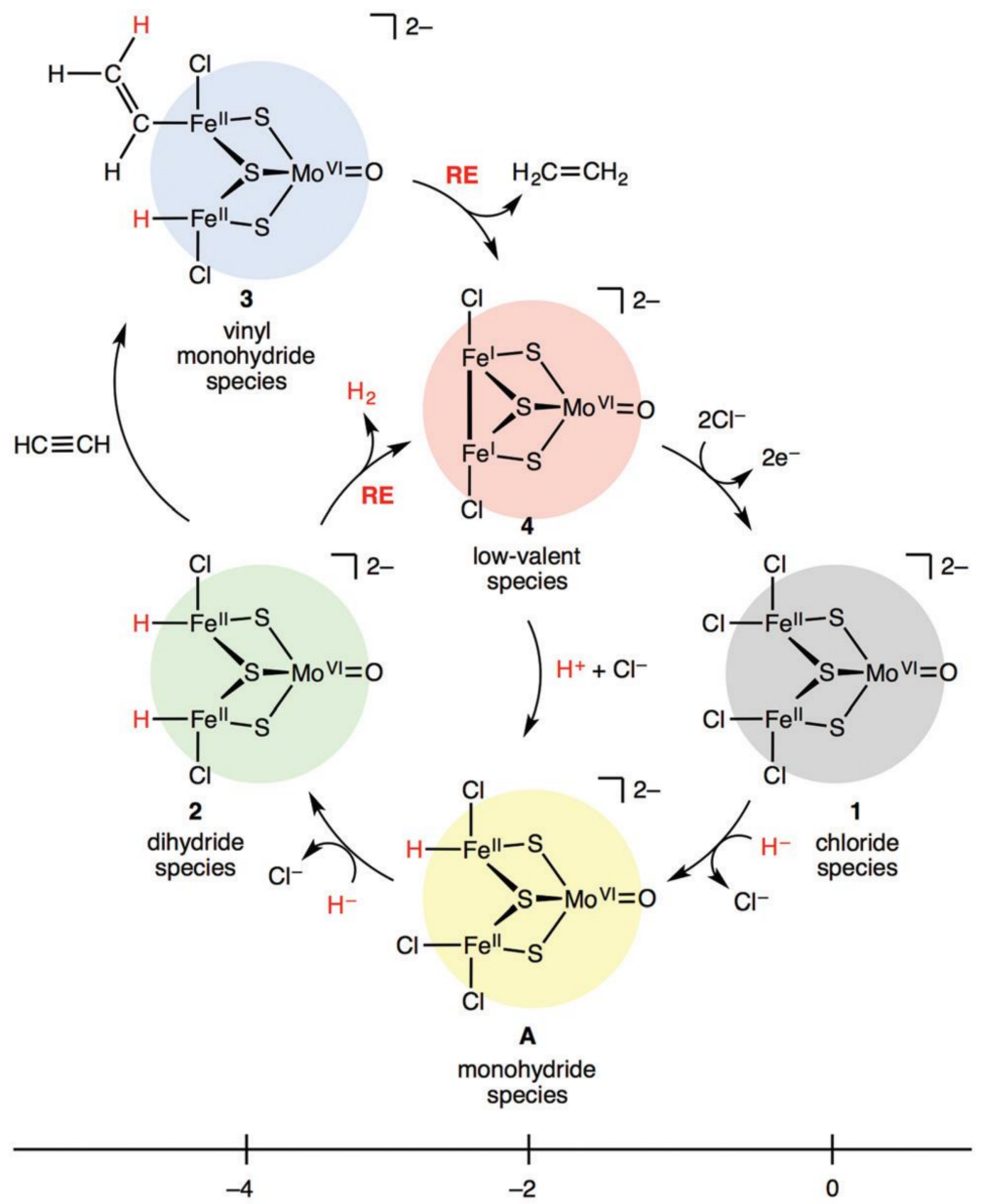

Figure 25. Proposed mechanism of reductive elimination (RE) of $\mathrm{H}_{2}$ from the dihydride Fe/Mo species 2 and $\mathrm{C}_{2} \mathrm{H}_{4}$ from the vinyl monohydride $\mathrm{Fe} / \mathrm{Mo}$ species 3 . The scale of horizontal axis represents oxidation states 0 to -4 , with the initial oxidation state of $\mathbf{1}$ corresponding to 0 . Accordingly, the two and four electron-deprived species correspond to -2 and -4 oxidation states, respectively (reproduced with permission from [302]. Copyright 2016 the Royal Society of Chemistry.).

\subsubsection{Pd-Free Bimetallic Catalysts: $\mathrm{Pt} / \mathrm{Sn}$}

Colloidally prepared platinum and platinum-tin nanocrystals with controllable structural properties were tested in the acetylene semi-hydrogenation [304]. The ligand-free and ligand-capped bimetallic catalysts were separately compared with Pt NPs to sort out possible specific effects of Sn and organic ligands (Figure 26). Using dodecylamine (DDA) promoted a decrease in the unwanted ethylene hydrogenation. Organic ligands are thought to act by diluting or blocking the large Pt ensembles (E sites), while diminishing the surface enrichment of $S n$, and thereby suppress ethylene hydrogenation. The bimetallic dodecylamine-capped $\mathrm{Pt} / \mathrm{Sn}$ catalyst showed the best selectivity in this series, especially relative to the ligand-free and pure Pt catalysts. 

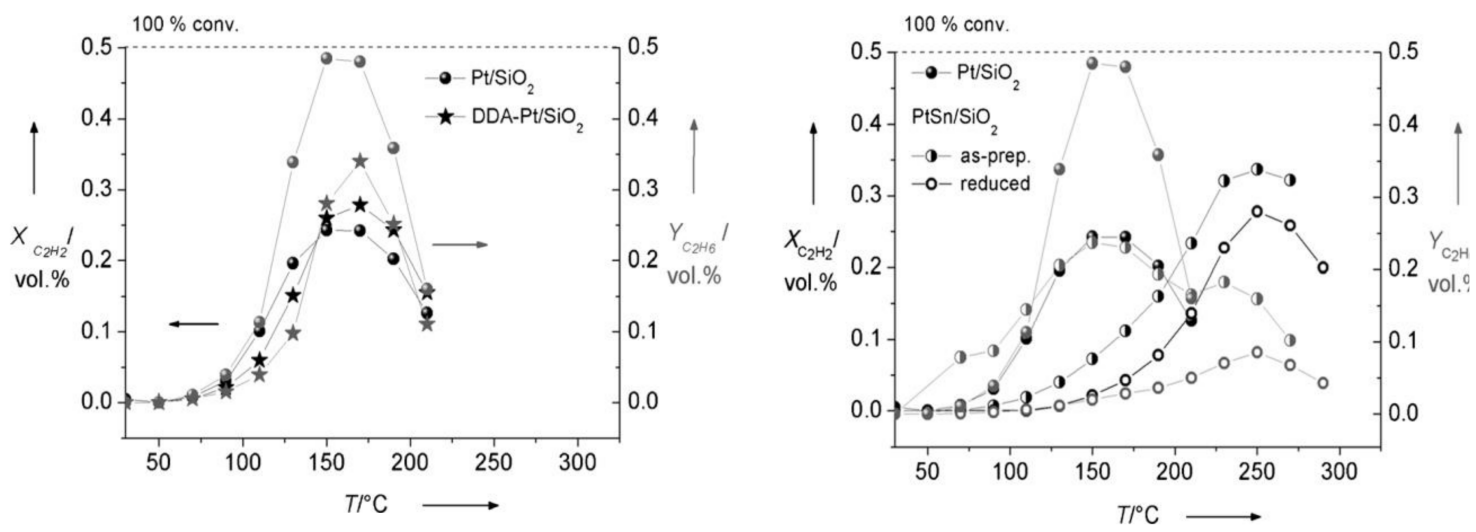

Figure 26. Acetylene conversion $X$ (black symbols, left axis) and ethane time yield $\mathrm{Y}$ (gray symbols, right axis) as functions of temperature for: Left monometallic $\mathrm{Pt} / \mathrm{SiO}_{2}$ (circles) and $\mathrm{DDA}-\mathrm{Pt} / \mathrm{SiO}_{2}$ (stars) catalysts. Right $\mathrm{Pt} / \mathrm{SiO}_{2}$ (filled symbols), $\mathrm{Pt} / \mathrm{Sn}(1: 1) / \mathrm{SiO}_{2}$ as prepared (half-filled symbols), and $\mathrm{PtSn}(1: 1) / \mathrm{SiO}_{2}$ prereduced (empty symbols) catalysts. Acetylene conversion is given by the difference in the reactor inlet and outlet concentrations in vol \%. Ethane yield is given by vol \% of ethane in the reactor off-gas. Reaction conditions: $0.5 \mathrm{vol} \% \mathrm{C}_{2} \mathrm{H}_{2} ; 1 \mathrm{vol} \% \mathrm{H}_{2} ; 70 \mathrm{vol} \% \mathrm{C}_{2} \mathrm{H}_{4}$; rest $\mathrm{N}_{2}$; flow velocity $50 \mathrm{mLmin}^{-1}$ (reproduced with permission from [304]. Copyright 2013 WILEY-VCH Verlag GmbH \& Co. KGaA).

\subsubsection{Pd-Free Bimetallic Catalysts: $\mathrm{Cu} / \mathrm{Au}$}

The synergistic effect of bimetallic $\mathrm{Cu} / \mathrm{Au}$ catalyst is provided by a combo of the electronic effect and the sintering resistance [305]. As it is, the bimetallic 1:3 Cu/Au catalyst shows an upgraded performance (Figure 27). Probably, the gold renders the copper more electron-deficient. The added amounts of $\mathrm{Au}$ reduce the size of $\mathrm{Cu}$ ensembles, which suppresses the $\mathrm{C}-\mathrm{C}$ coupling reactions and results in better ethylene desorption. When $\mathrm{Cu}$ dominates in the alloy, the selectivity is very low; the addition of Au leads to an increase in selectivity.

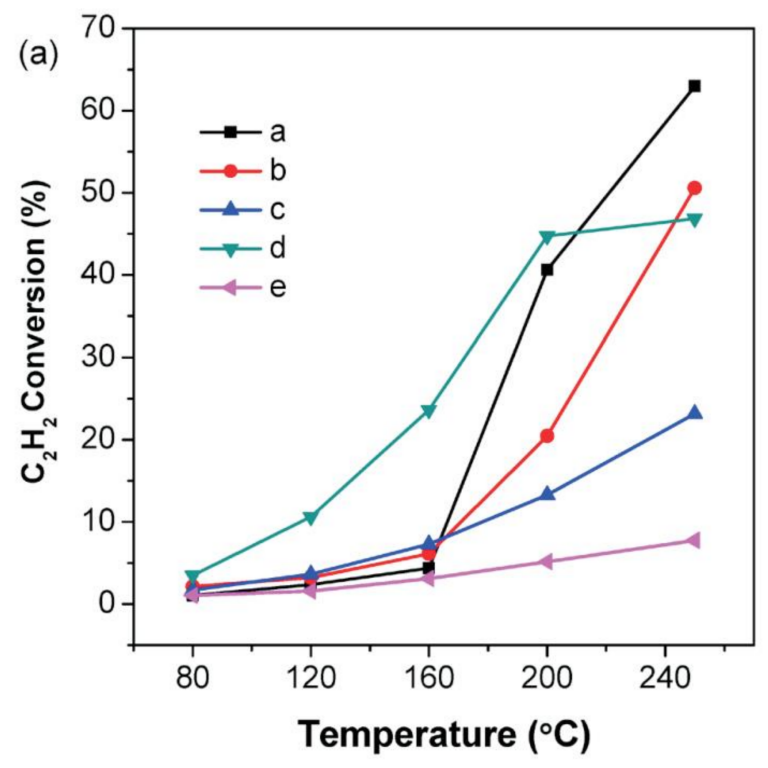

Figure 27. Cont. 


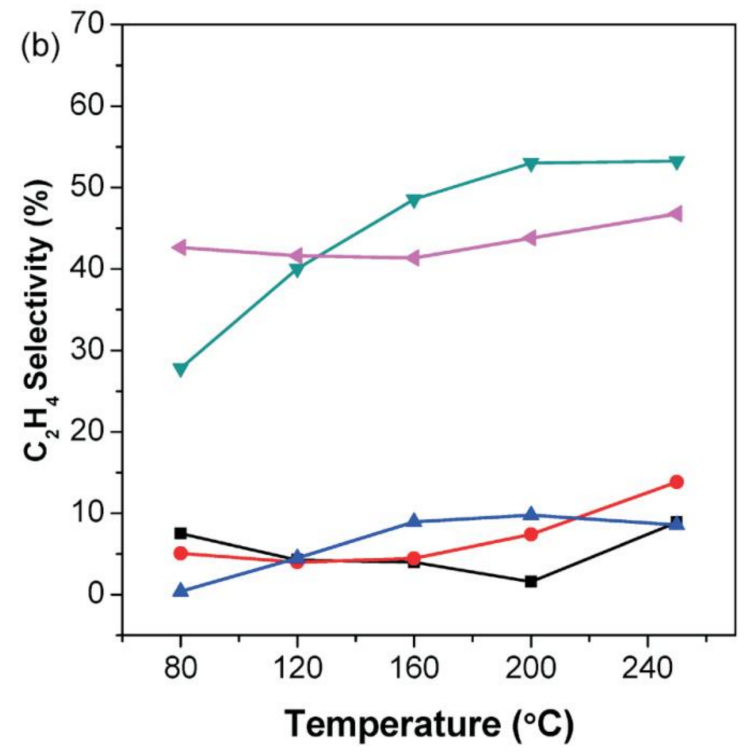

Figure 27. Reaction rate and ethylene selectivity over the SBA-15 supported $\mathrm{Cu}(\mathbf{a}), \mathrm{Cu}_{10} \mathrm{Au}_{1}(\mathbf{b}), \mathrm{Cu}_{3} \mathrm{Au}_{1}$ (c), $\mathrm{Cu}_{1} \mathrm{Au}_{3}(\mathrm{~d})$, and $\mathrm{Au}(\mathrm{e})$ catalysts. $\mathrm{C}_{2} \mathrm{H}_{2} / \mathrm{H}_{2} / \mathrm{He}=1.5 / 15 / 83.5$, GHSV $=40,000 \mathrm{~mL} \mathrm{~g}^{-1}$ cat $\mathrm{h}^{-1}$ (reproduced with permission from [305]. Copyright 2013 WILEY-VCH Verlag GmbH \& Co. KGaA).

\subsubsection{Non-Metallic Catalysts}

A one-atom-thick layer of carbon atoms effectively catalyzed the selective acetylene semi-hydrogenation in the absence of a metal [306]. This graphene-based material was catalytically active at room temperature, but achieved its utmost performance at $110-120^{\circ} \mathrm{C}$, with $99 \%$ acetylene conversion and $21 \%$ ethylene conversion. GO was able to convert $50.6 \%$ of acetylene with no measurable ethylene hydrogenation at $150{ }^{\circ} \mathrm{C}$, while rGO converted all acetylene with only $5 \%$ ethylene hydrogenation. These results indicate a very high potential of graphene-based catalysts (Table 3). Given that the graphene oxides were contaminated with ppm traces of metals (Fe and Mn) due to the presence of these metals in the parent graphite, the results were validated in additional experiments. Selected GO samples were purposefully contaminated with two known amounts of $\mathrm{MnCl}_{2}$ and $\mathrm{PdCl}_{2}$ before testing. The results confirmed the intrinsic catalytic potential of graphene materials.

Table 3. Catalytic performances of graphene-based catalysts.

\begin{tabular}{llllllll}
\hline Catalyst & \multicolumn{3}{c}{ Conversion (\%) } & \multicolumn{5}{c}{ Product Distribution (\%) } \\
\hline & $\mathrm{C}_{2} \mathrm{H}_{2}$ & $\mathrm{C}_{2} \mathrm{H}_{4}$ & $\mathrm{C}_{2} \mathrm{H}_{4}$ & $\mathrm{C}_{2} \mathrm{H}_{2}$ & $\mathrm{C}_{2} \mathrm{H}_{6}$ & $\mathrm{C}_{4}$ & $\mathrm{C}_{4}+$ \\
$\mathrm{Gr}$ & 81.0 & 14.0 & 92.2 & 3.2 & 1.1 & 3.5 & - \\
$\mathrm{Gr}{ }^{*}$ & 99.0 & 21.0 & 91.6 & 0.9 & 1.2 & 6.3 & - \\
$\mathrm{GO}$ & 22.5 & 0 & 48.1 & 5.0 & 0.3 & 46.6 & - \\
$\mathrm{rGO}$ & 87.5 & 4.7 & 55.1 & 1.2 & 1.3 & 42.4 & - \\
$(\mathrm{N}) \mathrm{Gr}$ & 26.7 & 6.7 & 62.5 & 7.2 & 0.7 & 11.5 & 25.2 \\
$(\mathrm{P}) \mathrm{Gr}$ & 14.6 & 2.7 & 72.7 & 8.8 & 0.7 & 17.7 & 0.1 \\
$(\mathrm{~S}) \mathrm{Gr}$ & 24.7 & 6.4 & 54.1 & 6.3 & 0.4 & 0.0 & 39.1 \\
\hline
\end{tabular}

GO, graphene oxide; Gr, graphene; rGO, reduced GO. Results of selective catalytic acetylene hydrogenation in the presence of ninefold excess of ethylene. Reaction conditions: $10 \% \mathrm{C}_{2} \mathrm{H}_{2}$ in $90 \% \mathrm{C}_{2} \mathrm{H}_{4} ;\left(\mathrm{C}_{2} \mathrm{H}_{2}+\mathrm{C}_{2} \mathrm{H}_{4}\right): \mathrm{H}_{2}=1: 3$, $110{ }^{\circ} \mathrm{C}, 7 \mathrm{mg}$ of catalyst, gas hourly space velocity (GHSV) of $14.600 \mathrm{mLh}^{-1} \mathrm{~g}^{-1}$. ${ }^{*} 10 \% \mathrm{C}_{2} \mathrm{H}_{2}$ in $90 \% \mathrm{C}_{2} \mathrm{H}_{4} ;\left(\mathrm{C}_{2} \mathrm{H}_{2}+\right.$ $\left.\mathrm{C}_{2} \mathrm{H}_{4}\right): \mathrm{H}_{2}=1: 3,120^{\circ} \mathrm{C}, 7 \mathrm{mg}$ of catalyst, GHSV of $7.800 \mathrm{mLh}^{-1} \mathrm{~g}^{-1}$.

Multiwalled carbon nanotubes (MWCNTs) showed $90 \%$ acetylene conversion at $350{ }^{\circ} \mathrm{C}$ [307]. The ethylene selectivity constituted $\sim 90 \%$ and loosely depended on the acetylene concentration. The higher temperatures led to acetylene decomposition and oligomerization, while the lower temperatures provided no support to acetylene conversion $\left(3 \%\right.$ at $\left.80^{\circ} \mathrm{C}\right)$. The nanotubes had cylindrical 
shape of 10 to $60 \mathrm{~nm}$ in diameter (Figure 28). The thicker tubes had thick walls and no sharp bends; the thinner tubes comprised thin walls and a large number of bends. Metal NPs contaminated the inner space of the tubes, and it was impossible to remove them even by heating at reflux in nitric acid. The high number of defects, the low oxygen content, and basicity of the surface compromised the MWCNT performance in selective acetylene hydrogenation.

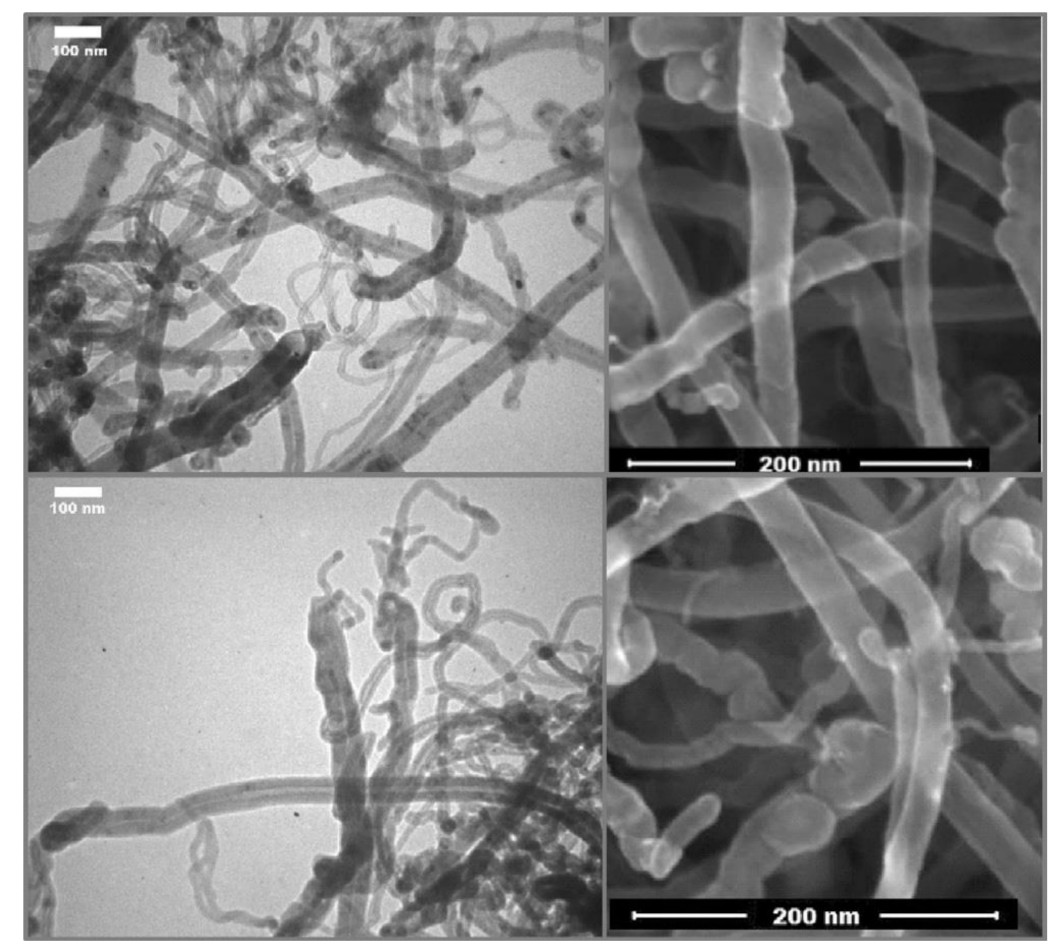

Figure 28. TEM and SEM images (on left and right, respectively) of the MWCNT and MWCNT-400 samples (top and bottom panels, respectively) (reproduced with permission from [307]. Copyright 2017 WILEY-VCH Verlag GmbH \& Co. KGaA).

In summary, the unique properties of Pd-based complexes and nanostructures make them the catalysts of choice for the ethylene-selective acetylene hydrogenation. Huge variety of the available Pd-based materials allows fine tuning of the catalytic process to optimize relative values of selectivity, conversion, and other parameters. Nevertheless, the Pd-based catalysts have certain drawbacks, hence the prospective relevance of their non-Pd and metal-free counterparts.

\subsection{Synthesis of Vinyl Chloride}

Polyvinyl chloride is a commodity chemical, which is employed in manufacturing of electric wires, water pipes and fittings, plastic membranes, and many other items. The monomer, vinyl chloride (VCM), is produced by two alternative routes. The first is based on chlorination and oxychlorination of ethylene, the second is the direct catalytic hydrochlorination of acetylene (Scheme 94).

$$
\mathrm{HC} \equiv \mathrm{CH}+\mathrm{HCl} \rightarrow \widehat{C l}, \Delta H=-124.8 \mathrm{~kJ} \mathrm{~mol}-1
$$

Scheme 94. Acetylene hydrochlorination.

In industry, the hydrochlorination proceeds at temperatures $130-180{ }^{\circ} \mathrm{C}$ with a catalyst, mercuric chloride $\mathrm{HgCl}_{2}$, supported on activated carbon (AC). However, $\mathrm{HgCl}_{2}$ is highly toxic and causes environmental pollution. An active search for environment-friendly alternative catalytic systems is currently under way. 
Noble $(\mathrm{Au}, \mathrm{Pt}, \mathrm{Pd})$ and some non-noble metal catalysts have been intensively studied as an alternative to catalize the hydrochlorination reaction. Hutchings and co-workers [308] was the first who demonstrated the high activity of $\mathrm{AuCl}_{3}$ and dynamic nature of catalyst caused $\mathrm{Au}^{3+}$ to $\mathrm{Au}^{0}$ reduction during the reaction. Treatment of the catalyst with aqua regia was proposed as an effective regeneration method for this system [309]. Specific effects of the aqua regia constituents, $\mathrm{HCl} / \mathrm{HNO}_{3}$, as well as the metal/support modifications in the course of deactivation/regeneration of Au catalysts, were also demonstrated [310-312]. Despite $\mathrm{HCl}$ and $\mathrm{HNO}_{3}$ being able to affect the carbon support prior to deposition, the enhancement effect of aqua regia was observed only in the presence of Au during the impregnation step of the catalyst preparation. This was considered to be due to the oxidizing effect of $\mathrm{HNO}_{3}$ on both the carbon support and gold, in combination with the nucleation effect of $\mathrm{HCl}$ on gold particles over the carbon surface. The activity depends on the presence of $\mathrm{Au}^{3+}$ species in the catalyst, and their spatial distribution in particular (not only the concentration matters).

Despite the glorious history of the catalysis by gold, its mechanistic understanding is still incomplete. A series of gold catalysts was prepared by using the aqueous $\mathrm{HCl} / \mathrm{HF}$ pretreated activated carbon at $300{ }^{\circ} \mathrm{C}\left(\mathrm{Cat}_{300}\right), 600{ }^{\circ} \mathrm{C}\left(\mathrm{Cat}_{600}\right)$, and $900{ }^{\circ} \mathrm{C}$ (Cat900, Figure 29) [313]. The $\mathrm{C}_{2} \mathrm{H}_{2}$ temperature-programmed desorption of the catalysts was also measured. Compared with $\mathrm{Cat}_{\text {original }}$ and $\mathrm{Cat}_{\mathrm{HF}}$, the Cat $\mathrm{HCl}_{\mathrm{H}}$ catalyst showed an increased initial activity with the same decrement over time.
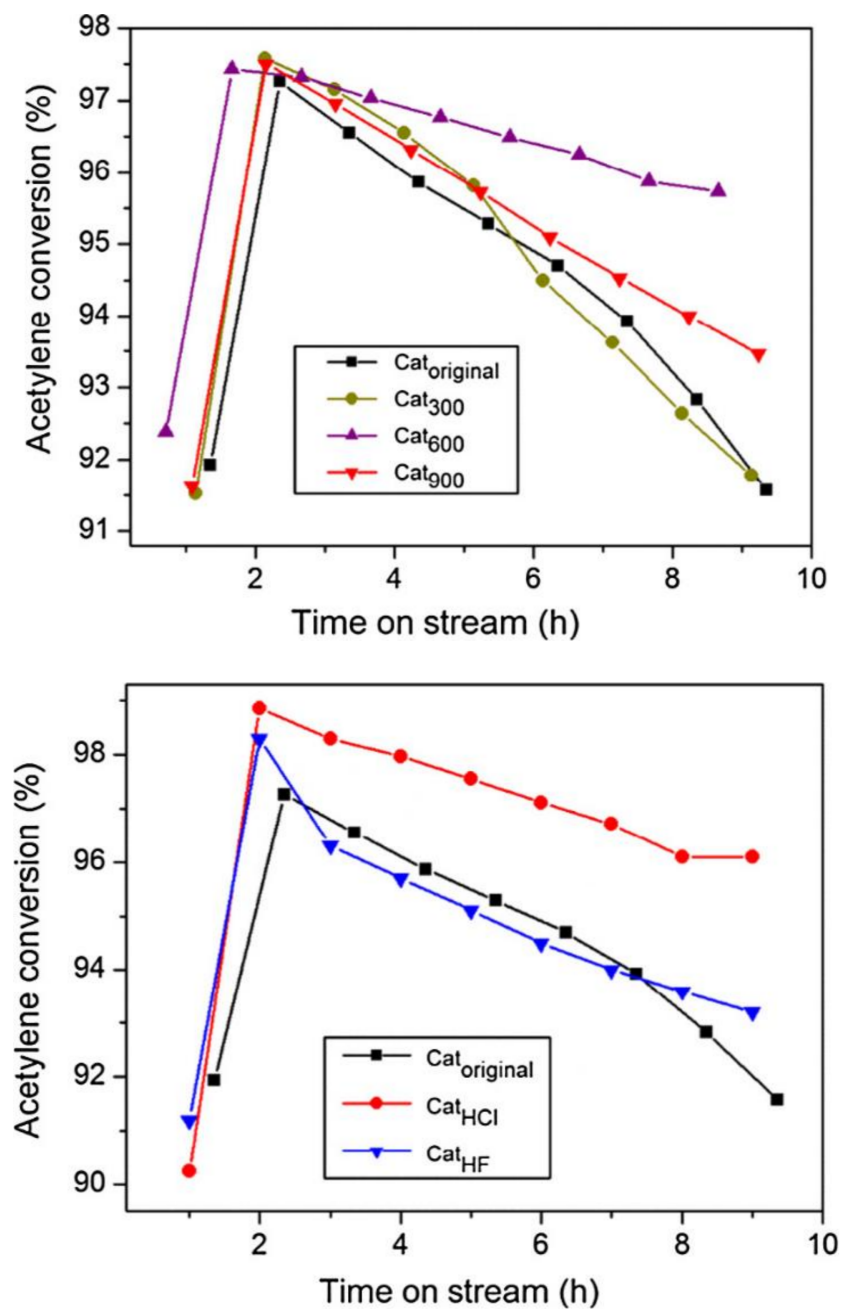

Figure 29. Acetylene conversion by $\mathrm{AuCl}_{3} / \mathrm{C}$ catalysts: temperature activation (up) and acid treatment (down). Reaction conditions: temperature $=180^{\circ} \mathrm{C}, \mathrm{C}_{2} \mathrm{H}_{2} \mathrm{GHSV}=360 \mathrm{~h}^{-1}$, feed volume ratio between $\mathrm{HCl}$ and $\mathrm{C}_{2} \mathrm{H}_{2}=1.1$ (reproduced with permission from [313]. Copyright 2015 Elsevier Inc.). 
The results indicate that dispersibility of gold positively correlates with the stability of the catalyst. Accordingly, the $\mathrm{C}_{2} \mathrm{H}_{2}$ adsorption/activation capacity negatively correlates with both the catalyst stability and gold dispersibility. Which means, that the active site is not composed entirely of gold dispersed on the carbon surface, and that the carbon itself works as a constituent part of the site responsible for the acetylene activation.

Stability of Au-catalysts can be enhanced by inhibiting $\mathrm{Au}^{3+}$ reduction [314], which can be achieved by strengthening the adsorption of hydrogen chloride to the catalyst. The enhanced catalytic activity and stability of $\mathrm{AuCl}_{3} / \mathrm{PPy}-\mathrm{MWCNTs}$ in acetylene hydrochlorination, as compared with $\mathrm{AuCl}_{3} / \mathrm{MWCNT}$, is explained as follows. During the reaction, a lone pair on the nitrogen atom of pyrrole is transferred to the $\mathrm{Au}^{3+}$ center via the metal-support interaction. This event increases the electron density of the $\mathrm{Au}^{3+}$ center to strengthen the bond between $\mathrm{HCl}$ and $\mathrm{AuCl}_{3}$. Other $\mathrm{N}$-doped material-based catalysts, such as carbon [315], carbon nanotubes [316], SiC [317], graphene [318] were studied with some interesting results; however, the low conversion efficiencies and high energy demands do not contribute to their commercial applicability. The nitrogen-containing ligands are able to inhibit the reduction of $\mathrm{Au}^{3+}$ to $\mathrm{Au}^{0}$ [319], although the synthesis of $\mathrm{AuCl}_{3}$ complex with 1,10-phenanthroline $\left[\mathrm{AuCl}_{2}\right.$ (phen) $] \mathrm{Cl}$ and its successful application in acetylene hydrochlorination have been reported [320].

Catalytic stability of Au catalysts can be improved by addition of a second metal component, for example, $\mathrm{CoCl}_{3}[321]$ or $\mathrm{CsCl}[322,323]$. Currently available Au catalysts for hydrochlorination contain more than $1 \mathrm{wt} \%$ of $\mathrm{Au}$. Addition of $\mathrm{Cu}$ as a third metallic component to an AC-supported AuCs catalyst allowed obtaining of a trimetallic catalyst with enhanced activity and stability at $\sim 0.25 \mathrm{wt} \%$ $\mathrm{Au}$ loading [324]. Particularly remarkable activity enhancement in this series was shown by a catalyst with 1:1:4 Au:Cu:Cs weight ratio, at turnover frequency of $73.8 \mathrm{~min}^{-1}$ based on Au. The synergy between $\mathrm{Au}, \mathrm{Cu}$, and $\mathrm{Cs}$ is associated with enhancements in dispersion of $\mathrm{Au}$ particles, stabilization of $\mathrm{Au}$ in the state of $\mathrm{Au}^{3+}$, and adsorption kinetics of the $\mathrm{C}_{2} \mathrm{H}_{2}$ substrate molecules.

Trimetallic $\mathrm{Au}-\mathrm{Co}(\mathrm{III})-\mathrm{Cu}(\mathrm{II})$ catalysts were prepared by using spherical AC (SAC) as a support [325]. The best performance in this series was achieved with Au1Co(III)3-Cu(II)1/SAC, showing $99.9 \%$ VCM selectivity at $99.7 \%$ acetylene conversion.

ACs have micropores and no interconnected porous network. Mesoporous carbons with regularly interconnected 2-50 $\mathrm{nm}$ mesopores could provide an excellent alternative support for the acetylene hydrochlorination catalysts. Mesoporous carbon materials with controllable pore sizes within the range of 5.6-40.2 nm were synthesized using colloidal silica as hard templates and boric acid as a pore expanding agent. The Au catalysts on mesoporous carbon showed excellent performances with increased acetylene conversion. Another material, $\gamma-\mathrm{Al}_{2} \mathrm{O}_{3}$, was used as support for an $\mathrm{AuCl}_{3}-\mathrm{CuCl}_{2}$ bimetallic catalyst. The $\mathrm{AuCl}_{3}-\mathrm{CuCl}_{2} / \gamma-\mathrm{Al}_{2} \mathrm{O}_{3}$ catalyst promoted $97 \%$ acetylene conversion, which is close to $\mathrm{AuCl}_{3}-\mathrm{CuCl}_{2} / \mathrm{AC}$. The advantages of using $\gamma-\mathrm{Al}_{2} \mathrm{O}_{3}$ as a support are provided by its mechanical strength and mesoporous structure. Some zeolite-supported Pd catalysts [326-328] are also good for acetylene hydrochlorination.

Another important trend in the acetylene hydrochlorination catalysis involves ruthenium. The calculated activation barriers for acetylene hydrochlorination over $\mathrm{HgCl}_{2}, \mathrm{AuCl}_{3}$ and $\mathrm{RuCl}_{3}$ constitute $16.3,11.9$, and $9.1 \mathrm{kcal} \mathrm{mol}^{-1}$, respectively [329]. Certain advantages of Ru catalysts make them a proper alternative to other metal catalysts.

Catalytic performance of Ru-catalysts including monometallic $\mathrm{Ru}$, bimetallic $\mathrm{Ru}-\mathrm{Cu}$ and $\mathrm{Ru}-\mathrm{Co}$ with spheric active carbon (SAC) as the support was studied [330]. $\mathrm{C}_{2} \mathrm{H}_{2}$ conversion and the selectivity to vinyl chloride (VCM) over monometallic and bimetallic Ru-catalysts are depicted at Figures 30 and 31 (reaction conditions: $\mathrm{T}=170{ }^{\circ} \mathrm{C}, \mathrm{C}_{2} \mathrm{H}_{2} \mathrm{GHSV}=180 \mathrm{~h}^{-1}, \mathrm{~V}(\mathrm{HCl}) / \mathrm{V}\left(\mathrm{C}_{2} \mathrm{H}_{2}\right)=1.1$ ). 

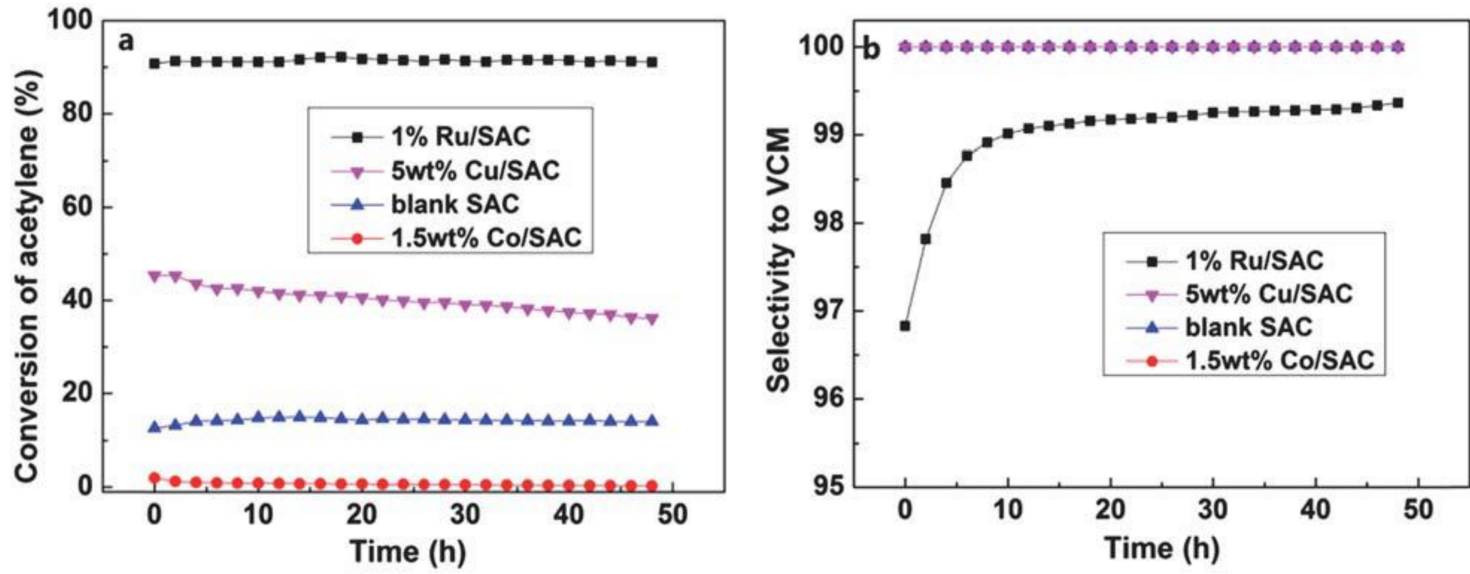

Figure 30. Acetylene conversion (a) and VCM selectivity (b) over monometallic $\mathrm{Ru}, \mathrm{Cu}$, and Co catalysts (reproduced with permission from [330]. Copyright 2013 the Royal Society of Chemistry.).
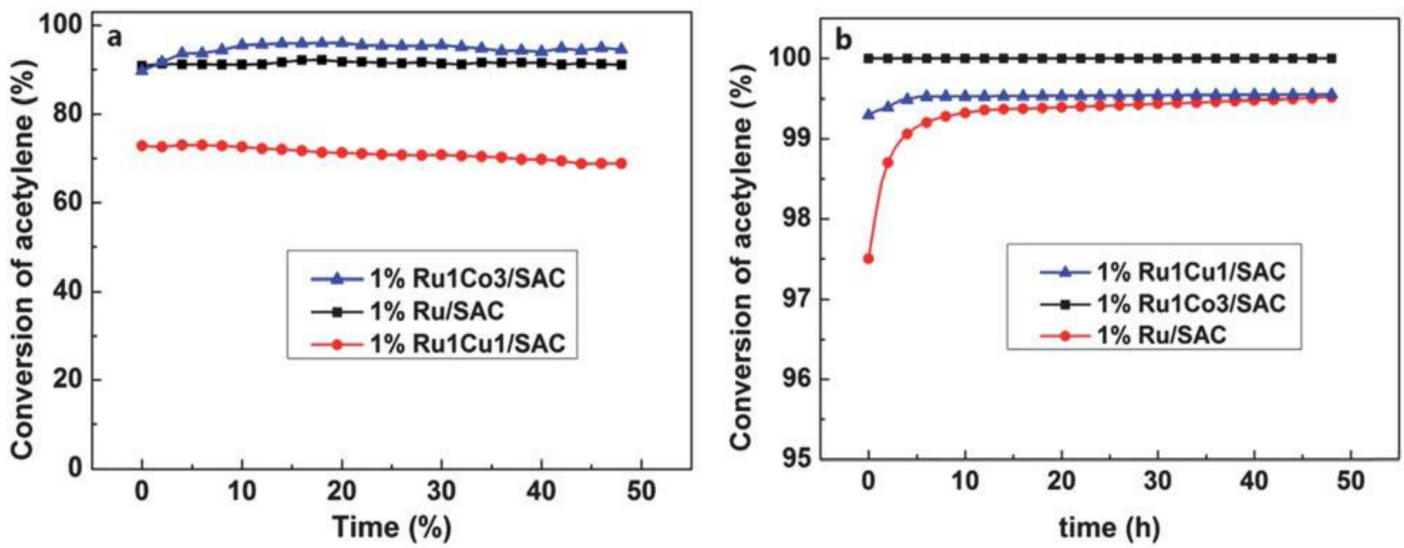

Figure 31. Acetylene conversion (a) and VCM selectivity (b) over 1\%Ru, 1\%Ru1Cu1, and 1\%Ru1Co3 catalysts (reproduced with permission from [330]. Copyright 2013 the Royal Society of Chemistry.).

The $1 \% \mathrm{Ru} / \mathrm{SAC}$ catalyst is capable of $91 \%$ acetylene conversion at $48 \mathrm{~h}$ on stream. Addition of cobalt significantly enhances its catalytic activity leading to $95 \%$ acetylene conversion at $48 \mathrm{~h}$ on stream, whereas addition of copper results in lower acetylene conversion. A remarkable $99.9 \%$ VCM selectivity at $95.0 \%$ acetylene conversion has been shown by $\mathrm{RuCl}_{3} / \mathrm{MWCNT}$ catalyst under $170{ }^{\circ} \mathrm{C}$, $\mathrm{C}_{2} \mathrm{H}_{2} \mathrm{GHSV}=90 \mathrm{~h}^{-1}$, and $\mathrm{V}(\mathrm{HCl}) / \mathrm{V}\left(\mathrm{C}_{2} \mathrm{H}_{2}\right)=1.1$ for $10 \mathrm{~h}$ [331].

Potassium represents a promising promoter for $\mathrm{Ru}$ catalysis [332]. $\mathrm{RuCl}_{3}-\mathrm{KCl} / \mathrm{SAC}$ catalysts perform better than $\mathrm{Ru} / \mathrm{SAC}$ catalysts, with the optimal conversion of acetylene over Ru1K1/SAC reaching $93.4 \%$ under $170{ }^{\circ} \mathrm{C}, \mathrm{C}_{2} \mathrm{H}_{2}$ hourly space velocity (GHSV) of $180 \mathrm{~h}^{-1}$, and $\mathrm{V}(\mathrm{HCl}) / \mathrm{V}\left(\mathrm{C}_{2} \mathrm{H}_{2}\right)=$ 1.1 feed volume ratio.

Among a variety of non-noble metals, $\mathrm{Cu}$ occupies a worthy position due to its low cost and good thermostability. A catalyst with $400 \mathrm{ppm} \mathrm{Ru}$ and $4.24 \mathrm{wt} \% \mathrm{Cu}$ on carbon nanotubes was highly active (TOF $=1.81 \mathrm{~min}^{-1}$ ) due the synergistic effect between $\mathrm{Cu}$ and $\mathrm{Ru}$ [333]. Despite the slower acetylene hydrogenation rates in comparison with $\mathrm{AuCl}_{3}$ catalysts, this catalyst is superior to other metal complexes known to catalyze this reaction (Figure 32). 


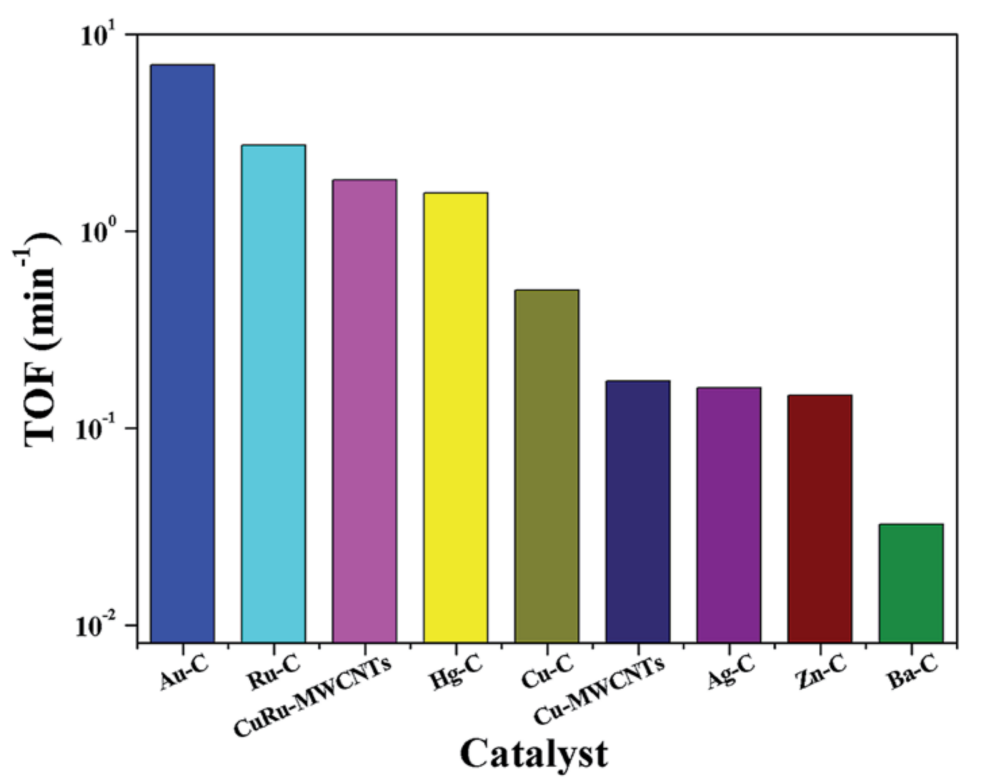

Figure 32. Calculated TOF values for $\mathrm{Cu} 400 \mathrm{Ru} / \mathrm{MWCNTs}$ in comparison with a variety of reported catalysts. The calculated TOF values for the different catalyst materials reported in literature and the Cu400Ru/MWCNTs catalyst material. (Reproduced with permission from ref. [333]. Copyright 2015 the Royal Society of Chemistry.).

Nitrogen-doping of AC [334] and its chemical modification by consecutive nitration, amination and reaction with pyridine [335] were also performed to improve the activity and stability of Ru-based catalysts.

Despite the obvious advantages of Ru catalysts, their usage is fraught with risks of coke deposition. The imidazolium-based ionic liquids 1-butyl-3-methylimidazolium tetrafluoroborate ([BMIM] $\left.\mathrm{BF}_{4}\right)$, 1-butyl-3-methylimidazoliumhexafluorophosphate ([BMIM] $\left.\mathrm{PF}_{6}\right)$, and 1-butyl-3-methylimidazolium chloride ([BMIM]Cl), were tested as possible inhibitors of the coke deposition [336]. An exemplary Ru10\%[BMIM] $\mathrm{BF}_{4} / \mathrm{AC}$ catalyst achieved $99.8 \% \mathrm{VCM}$ selectivity at $98.9 \%$ acetylene conversion under $170{ }^{\circ} \mathrm{C}$ and $\mathrm{C}_{2} \mathrm{H}_{2}$ (GHSV) of $180 \mathrm{~h}^{-1}$. The results indicate that the addition of imidazolium-based ionic liquids can significantly improve the dispersion of ruthenium species and prevent the coke deposition.

\subsection{Emerging Fundamental Concepts for Alkynes Transformations}

As has been shown in the previous sections (2.1-2.9), the chemistry of acetylene is diverse and occupies a unique position in organic synthesis. Undoubtedly, the synthetic utility of acetylene will be further expanded to a number of new opportunities. Effective translation of new concepts from the emerging areas of alkyne chemistry plays an important role and essentially increases synthetic potential of acetylene. Examples of useful concepts from the area of substituted alkyne chemistry will be briefly discussed in this section. It should be noted, that no detailed coverage of alkyne chemistry will be provided in this section. Instead, it provides a representative selection of recent examples as conceptual highlights. The key emphasis is made on efficient increase in molecular complexity, which is a priority goal in modern organic chemistry [337].

The orthogonality of the two $\pi$-orbitals in alkynes can be used for the metal-free cascade transformations [338]. The existing examples include ionic chemistry of neutral hydrocarbons, preparation of radicals without radical initiators, generation of excited states without light, "1,2-dicarbene reactivity" of alkynes in "boomerang" radical processes, selective conversion of alkynes into carbonyl compounds, and full disassembly of the alkyne moiety (Figure 33) [338]. This feature provides an access to a wide scope of organic molecules. 
Metal-Free:

four new bonds
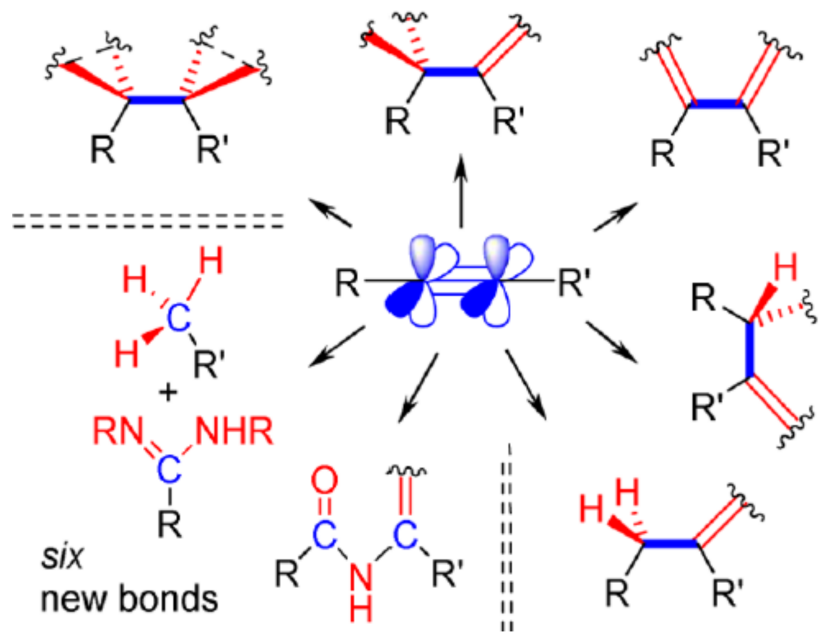

Figure 33. Using both alkyne $\pi$-bonds as "two functional groups in one package". (Reproduced with permission from ref. [338]. Copyright 2013 American Chemical Society.).

The unique property of triple bond is in a high exergonic effect in comparison with the analogous double bond. It explains one of the reasons of the richness of acetylene chemistry in comparison with the unsaturated compounds with double bond (Figure 34) [339]. The high exergonic effect provides a driving force for a number of fascinating transformations. On the other hand, the unique combination of electronic and structural properties balances the activation energy barriers and favors the formation of relatively stable intermediate species. Trapping of relatively stable intermediates provides the mechanistic means for a diversity of organic functionalizations.
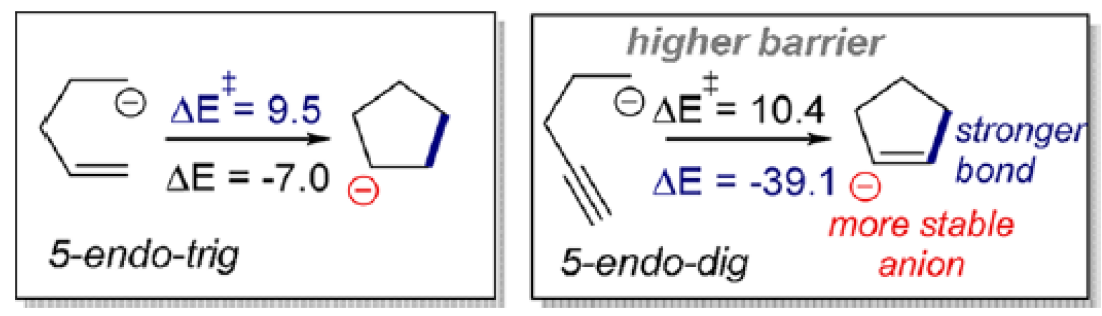

Figure 34. Comparison of alkene and alkyne reactivities in terms of kinetics and thermodynamics (reproduced with permission from [339]. Copyright 2018 American Chemical Society).

Cascade reactions with polyacetylenic derivatives have been recently described as an effective one-pot route to increased molecular complexity [338,339]. Interestingly, a minor activating influence on a triple bond of the polyacetylene molecule is sufficient to initiate the avalanche-like process with all the other reactive centers (Figure 35). The use of metal catalysis or a radical initiator triggers the cascade process and directs the pathway toward polyaromatics [340,341].

The methodology is advantageous since it requires the minimal quantities of a catalyst or other initiator. This advantage is explained by the specific properties of triple bond mentioned above (see Figure 34); the mechanism has been discussed in the literature [341]. Compatibility of the cascade reactions with Sonogashira cross-coupling and other transformations [342,343] makes them relevant for fine organic synthesis. Although this concept of increasing molecular complexity was not yet applied to the unsubstituted acetylene, we believe that its potential should be thoroughly evaluated. 

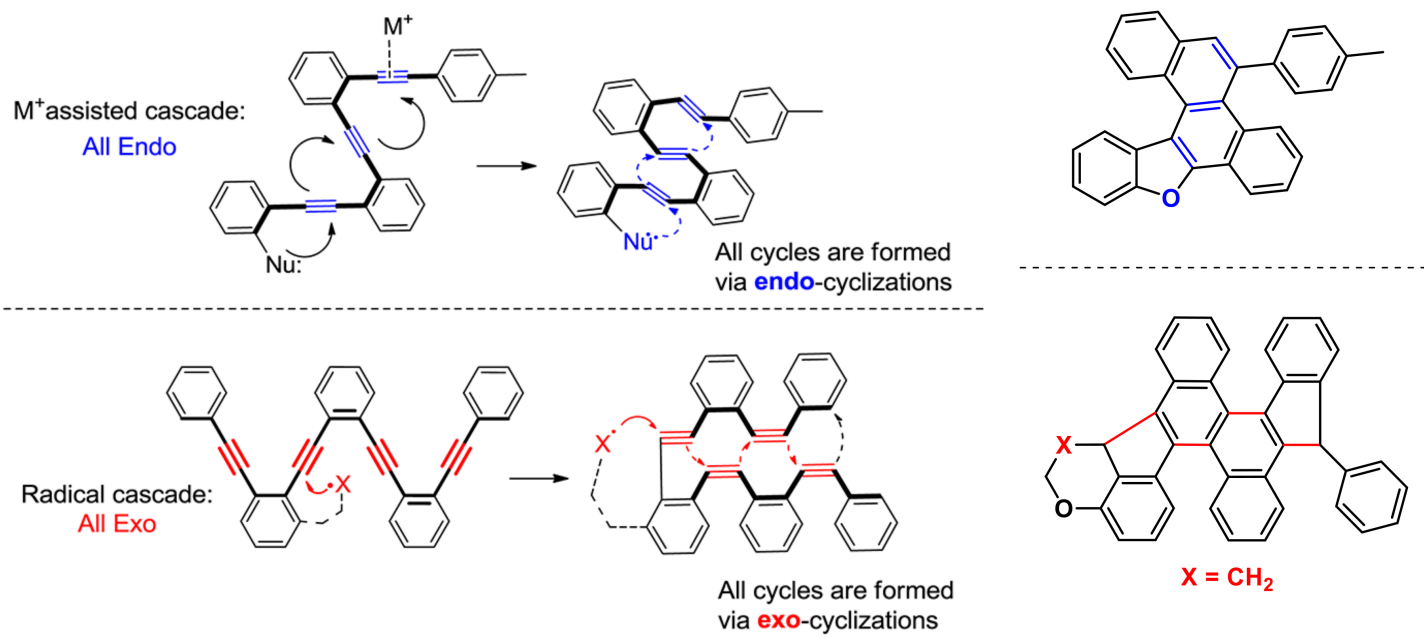

Figure 35. Examples of polyaromatic self-assembling based on the cascade oligocyclization of alkynes (reproduced with permission from [341]. Copyright 2012 American Chemical Society).

Synthesis of macrocyclic polyethynes is another way of rapid assembling of complex molecular structures, especially in combination with the involvement of energy-reach macrocycles in further transformations. In a recent article, an example of successive phenyl acetylene 168 polymerization was described [344]. By subsequent propagation-insertion on a catalyst 169, a cyclic polyethyne 170 of $\mathrm{M}_{n}=45,600 \mathrm{Da}$ was obtained in a high yield (Scheme 95). Since the cyclic polymers have no terminal groups, they show a number of unique physical properties [344]. For example, the density [345], refractive index [346,347], glass-transition temperature [348], viscoelasticity [349] and surface properties [350] of cyclic polymers differ from those of their linear analogues. Partial replacement of alkynes with acetylene allows obtaining a unique cyclic copolymer material, which is worth studying.
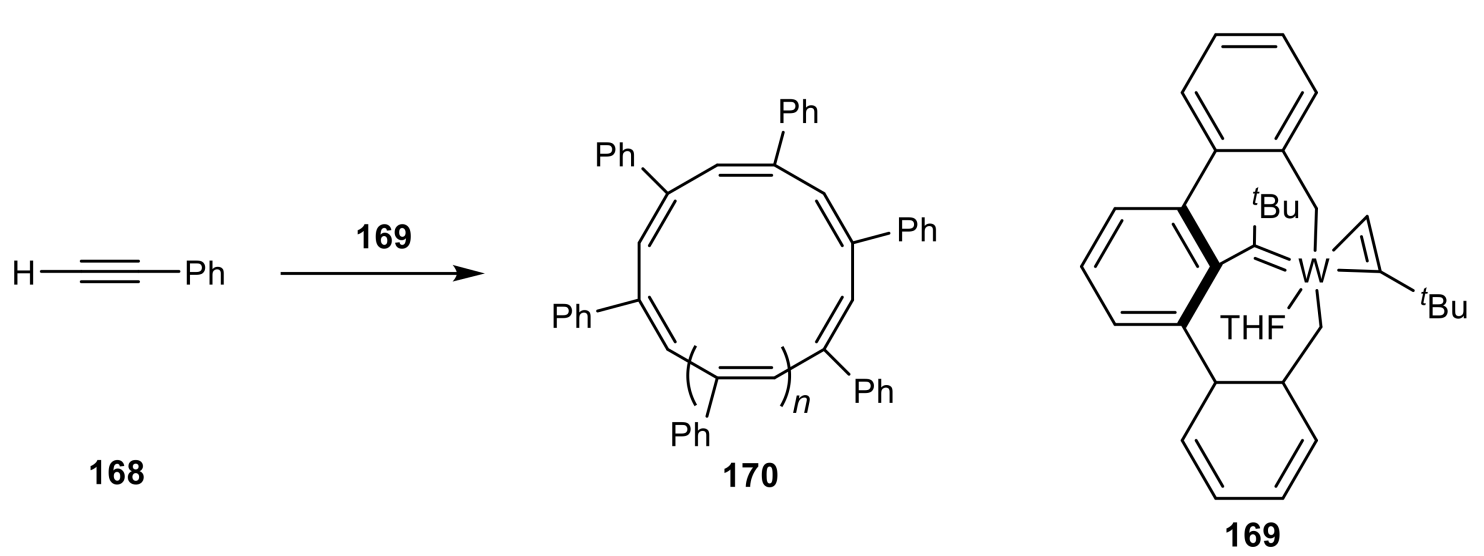

Scheme 95. Phenylacetylene polymerization.

Other potential applications of acetylene are related to additive manufacturing technologies. These technologies have been dramatically upgraded in recent years, due to the progress in research and industrial development. 3D printing provides a rapid link from computer-designed digital models to prototyping/production of materials and objects of desired shape and composition. 3D printing at the molecular level seems promising for direct construction of complex molecules; however the idea is highly challenging. To pump it up to the level of technology, it would be necessary to select a scope of simple molecules (versatile, accessible and modifiable) to be used as building blocks. The simplest low-molecular weight hydrocarbons-methane, ethylene and acetylene-can be certainly considered. The key restrictions for molecular 3D printing with hydrocarbons are related to the limited 
possibilities of the $\mathrm{C}$-H-activation and atom-economical modification. By contrast with more saturated candidates, acetylene is capable of being engaged in two atom-economical addition reactions; it has a relatively reactive hydrogen atom at each of the carbons and no unreactive C-H bonds (Table 4) [351]. Hence, it is highly probable that alkyne molecules will serve as a main building material for molecular 3D printing [351].

Table 4. Potential chemical building blocks for a molecular 3D printer [351].

\begin{tabular}{cccc}
\hline $\begin{array}{c}\text { Building Block } \\
\text { Molecule }\end{array}$ & $\begin{array}{c}\text { Number of Low-Reactive } \\
\text { Substituents at the } \mathrm{C} \\
\text { Atom }\end{array}$ & $\begin{array}{c}\text { Number of Activated } \\
\text { Substituents at the } \mathrm{C} \\
\text { Atom }\end{array}$ & $\begin{array}{c}\text { Number of } \\
\text { Atom-Economical Steps }\end{array}$ \\
\hline & 4 & 0 & 0 \\
& 2 & 0 & 1 \\
\hline
\end{tabular}

In this section, only few examples are shown to illustrate some important directions of acetylene chemistry. Given the rapidity of contemporary progress, many other possibilities of acetylene utilization may arise in the nearest future.

\section{Conclusions}

Chemistry of alkynes is a well-developed area, which represents a fundamental tool for organic synthesis. In contrast with other alkynes, the use of acetylene in research practice is rather limited, mostly due to the technical difficulties of handling gaseous acetylene and for the concomitant safety reasons. Circumvention of these obstacles would undoubtedly boost the use of acetylene in organic synthesis. A corresponding rapid trend observed in recent years favors a renaissance of acetylene chemistry, with full actualization of its rich potential.

Literature analysis carried out in the present review shows a wide scope of chemical transformations, which relate acetylene with such processes as vinylation, cross-coupling reactions, access to substituted alkynes and synthesis of heterocycles. These transformations provide an access to new drugs, pharmaceutical substances, biologically active molecules and valuable building blocks (synthones). Safe and reliable procedures for preparation of vinyl derivatives are in high demand, as they allow production of monomers for the synthesis of polymers and copolymers with unique properties. Particularly tempting are applications of acetylene-derived functionalized molecules in materials science.

Besides the noticeable progress in acetylene chemistry, several problems still remain a challenge. Of particular importance is the development of convenient practical procedures with high safety standards to utilize acetylene-based syntheses in everyday laboratory practice. Another challenging topic concerns the development of Green reactions involving acetylene, directed towards minimization of wastes and increased cost-efficiency.

Exceptional reaction capacities of acetylene are associated with several different reaction channels and complex mechanisms. Comprehensive understanding of the mechanisms of organic transformations of acetylene is one of the primary challenges. Even the well-known acetylene transformations (for example, selective hydrogenation or hydrochlorination) have rather complex mechanisms, which must be taken into account when developing chemical procedures and industrial technologies. 
Considered in the present review, the current research trends clearly show that the great potential of acetylene molecule is far from being completely utilized, and a number of fascinating studies can be anticipated in the nearest future. Translation of new basic findings from alkyne chemistry to applied fields is of special importance. Cutting-edge research projects reinforce a dedicated search for effective routes of transforming acetylene into the products of increasing molecular complexity. This direction will remain a top priority in the nearest future.

Author Contributions: The review was prepared by joint work of all the co-authors on all parts of the manuscript.

Funding: Activity on the topics of organic chemistry, synthesis and applications was supported by Russian Science Foundation (RSF grant 16-13-10301). Activity on the topics of catalysis and carbon materials was supported by Russian Science Foundation (RSF grant 14-13-01030).

Conflicts of Interest: The authors declare no conflict of interest.

\section{References}

1. Hay, A.S. Oxidative coupling of acetylenes. II. J. Org. Chem. 1962, 27, 3320-3321. [CrossRef]

2. Larock, R.C.; Yum, E.K. Synthesis of indoles via palladium-catalyzed heteroannulation of internal alkynes. J. Am. Chem. Soc. 1991, 113, 6689-6690. [CrossRef]

3. Lin, V.S.; DiMagno, S.G.; Therien, M.J. Highly conjugated, acetylenyl bridged porphyrins: New models for light-harvesting antenna systems. Science 1994, 264, 1105. [CrossRef] [PubMed]

4. Siemsen, P.; Livingston Robert, C.; Diederich, F. Acetylenic coupling: A powerful tool in molecular construction. Angew. Chem. Int. Ed. 2000, 39, 2632-2657. [CrossRef]

5. Sonogashira, K. Development of Pd-Cu catalyzed cross-coupling of terminal acetylenes with sp $^{2}$-carbon halides. J. Organomet. Chem. 2002, 653, 46-49. [CrossRef]

6. Winterfeldt, E. Additions to the activated CC triple bond. Angew. Chem. Int. Ed. 1967, 6, 423-434. [CrossRef]

7. Teles, J.H.; Brode, S.; Chabanas, M. Cationic gold(I) complexes: Highly efficient catalysts for the addition of alcohols to alkynes. Angew. Chem. Int. Ed. 1998, 37, 1415-1418. [CrossRef]

8. Studt, F.; Abild-Pedersen, F.; Bligaard, T.; Sørensen, R.Z.; Christensen, C.H.; Nørskov, J.K. Identification of non-precious metal alloy catalysts for selective hydrogenation of acetylene. Science 2008, 320, 1320. [CrossRef] [PubMed]

9. Matsuda, R.; Kitaura, R.; Kitagawa, S.; Kubota, Y.; Belosludov, R.V.; Kobayashi, T.C.; Sakamoto, H.; Chiba, T.; Takata, M.; Kawazoe, Y.; et al. Highly controlled acetylene accommodation in a metal-organic microporous material. Nature 2005, 436, 238. [CrossRef] [PubMed]

10. Chen, B.; Xiang, S.; Qian, G. Metal-organic frameworks with functional pores for recognition of small molecules. Acc. Chem. Res. 2010, 43, 1115-1124. [CrossRef] [PubMed]

11. Getman, R.B.; Bae, Y.-S.; Wilmer, C.E.; Snurr, R.Q. Review and analysis of molecular simulations of methane, hydrogen, and acetylene storage in metal-organic frameworks. Chem. Rev. 2012, 112, 703-723. [CrossRef] [PubMed]

12. Diederich, F.; Stang, P.J.; Tykwinski, R.R. Acetylene Chemistry: Chemistry, Biology, and Material Science; Wiley-VCH Verlag GmbH \& Co. KGaA: Weinheim, Germany, 2005; p. 508.

13. Trofimov, B.A.; Gusarova, N.K. Acetylene: New prospects of classical reactions. Russ. Chem. Rev. 2007, 76, 507. [CrossRef]

14. Trotuş, I.-T.; Zimmermann, T.; Schüth, F. Catalytic reactions of acetylene: A feedstock for the chemical industry revisited. Chem. Rev. 2014, 114, 1761-1782. [CrossRef] [PubMed]

15. Tedeschi, R.J. Acetylene-Based Chemical from Coal and Other Natural Resources; Dekker: New York, NY, USA, 1982; p. 232.

16. Pässler, P.; Hefner, W.; Buckl, K.; Meinass, H.; Meiswinkel, A.; Wernicke, H.J.; Ebersberg, G.; Müller, R.; Bässler, J.; Behringer, H.; et al. Acetylene; Wiley-VCH Verlag GmbH \& Co. KGaA: Weinheim, Germany, 2011; Volume 1.

17. Williams, A.; Smith, D.B. Combustion and oxidation of acetylene. Chem. Rev. 1970, 70, 267-293. [CrossRef]

18. Weman, K. Gas welding. Welding Processes Handbook, 2nd ed.; Woodhead Publishing: Cambridge, UK, 2012; pp. 13-18. 
19. Morehead, J.T.; de Chalmot, G. The manufacture of calcium carbide. J. Am. Chem. Soc. 1896, 18, 311-331. [CrossRef]

20. Ledovskaya, M.S.; Voronin, V.V.; Rodygin, K.S. Methods for the synthesis of O-, S- and N-Vinyl derivatives. Russ. Chem. Rev. 2018, 87, 167-191. [CrossRef]

21. Maki, Y.; Mori, H.; Endo, T. Xanthate-mediated controlled radical polymerization of N-Vinylindole derivatives. Macromolecules 2007, 40, 6119-6130. [CrossRef]

22. Bühler, V. Polyvinylpyrrolidone Excipients for Pharmaceuticals: Povidone, Crospovidone and Copovidone; Springer: Berlin, Germany, 2005.

23. Allsopp, M.W.; Vianello, G. Poly(vinyl chloride). In Ullmann's Encyclopedia of Industrial Chemistry; Wiley-VCH Verlag GmbH \& Co. KGaA: Weinheim, Germany, 2000; Volume 28, pp. 441-468.

24. Zhang, J.; Liu, N.; Li, W.; Dai, B. Progress on cleaner production of vinyl chloride monomers over non-mercury catalysts. Front. Chem. Sci. Eng. 2011, 5, 514-520. [CrossRef]

25. Ohara, T.; Sato, T.; Shimizu, N.; Prescher, G.; Schwind, H.; Weiberg, O.; Marten, K. Acrylic acid and derivatives. In Ullmann's Encyclopedia of Industrial Chemistry; Wiley-VCH Verlag GmbH \& Co. KGaA: Weinheim, Germany, 2003; Volume 1, pp. 347-364.

26. Cokoja, M.; Bruckmeier, C.; Rieger, B.; Herrmann Wolfgang, A.; Kühn Fritz, E. Transformation of carbon dioxide with homogeneous transition-metal catalysts: A molecular solution to a global challenge? Angew. Chem. Int. Ed. 2011, 50, 8510-8537. [CrossRef] [PubMed]

27. Herth, G.; Schornick, G.; Fredric, L.B. Polyacrylamides and Poly(acrylic acids); Wiley-VCH Verlag GmbH \& Co. KGaA: Weinheim, Germany, 2015; Volume 28.

28. Hou, J.; Xie, J.H.; Zhou, Q.L. Palladium-catalyzed hydrocarboxylation of alkynes with formic acid. Angew. Chem. Int. Ed. 2015, 54, 6302-6305. [CrossRef] [PubMed]

29. Osswald, J.; Kovnir, K.; Armbrüster, M.; Giedigkeit, R.; Jentoft, R.E.; Wild, U.; Grin, Y.; Schlögl, R. Palladium-gallium intermetallic compounds for the selective hydrogenation of acetylene: Part II: Surface characterization and catalytic performance. J. Catal. 2008, 258, 219-227. [CrossRef]

30. Osswald, J.; Giedigkeit, R.; Jentoft, R.E.; Armbrüster, M.; Girgsdies, F.; Kovnir, K.; Ressler, T.; Grin, Y.; Schlögl, R. Palladium-gallium intermetallic compounds for the selective hydrogenation of acetylene: Part I: Preparation and structural investigation under reaction conditions. J. Catal. 2008, 258, 210-218. [CrossRef]

31. Khan, N.A.; Shaikhutdinov, S.; Freund, H.J. Acetylene and ethylene hydrogenation on alumina supported Pd-Ag model catalysts. Catal. Lett. 2006, 108, 159-164. [CrossRef]

32. Borodziński, A.; Bond, G.C. Selective hydrogenation of ethyne in ethene-rich streams on palladium catalysts, part 2: Steady-state kinetics and effects of palladium particle size, carbon monoxide, and promoters. Catal. Rev. 2008, 50, 379-469. [CrossRef]

33. Han, Y.; Peng, D.; Xu, Z.; Wan, H.; Zheng, S.; Zhu, D. Tio 2 supported Pd@Ag as highly selective catalysts for hydrogenation of acetylene in excess ethylene. Chem. Commun. 2013, 49, 8350-8352. [CrossRef] [PubMed]

34. Sobenina, L.N.; Tomilin, D.N.; Petrova, O.V.; Mikhaleva, A.I.; Trofimov, B.A. Synthesis of secondary propargyl alcohols from aromatic and heteroaromatic aldehydes and acetylene in the system $\mathrm{KOH}-\mathrm{H}_{2} \mathrm{O}-\mathrm{DMSO}$. Russ. J. Org. Chem. 2013, 49, 356-359. [CrossRef]

35. Kutepow, N.; Viehe, H.G. Chemistry of Acetylenes; Marcel Dekker Inc.: New York, NY, USA, 1969.

36. Vasilevsky, S.F.; Klyatskaya, S.V.; Elguero, J. One-pot synthesis of monosubstituted aryl(hetaryl)acetylenes by direct introduction of the $\mathrm{C} \equiv \mathrm{CH}$ residue into arenes and hetarenes. Tetrahedron 2004, 60, 6685-6688. [CrossRef]

37. Fu, R.; Li, Z. Direct synthesis of symmetric diarylethynes from calcium carbide and arylboronic acids/esters. Eur. J. Org. Chem. 2017, 2017, 6648-6651. [CrossRef]

38. Turberg, M.; Ardila-Fierro, K.J.; Bolm, C.; Hernández, J.G. Altering copper-catalyzed A ${ }^{3}$ couplings by mechanochemistry: One-pot synthesis of 1,4-diamino-2-butynes from aldehydes, amines, and calcium carbide. Angew. Chem. Int. Ed. 2018, 57, 10718-10722. [CrossRef] [PubMed]

39. Trofimov, B.A. Acetylene and its derivatives in reactions with nucleophiles: Recent advances and current trends. Curr. Org. Chem. 2002, 6, 1121-1162. [CrossRef]

40. Kaewchangwat, N.; Sukato, R.; Vchirawongkwin, V.; Vilaivan, T.; Sukwattanasinitt, M.; Wacharasindhu, S. Direct synthesis of aryl substituted pyrroles from calcium carbide: An underestimated chemical feedstock. Green Chem. 2015, 17, 460-465. [CrossRef] 
41. Ledovskaya, M.S.; Rodygin, K.S.; Ananikov, V.P. Calcium-mediated one-pot preparation of isoxazoles with deuterium incorporation. Org. Chem. Front. 2018, 5, 226-231. [CrossRef]

42. Matake, R.; Niwa, Y.; Matsubara, H. Phase-vanishing method with acetylene evolution and its utilization in several organic syntheses. Org. Lett. 2015, 17, 2354-2357. [CrossRef] [PubMed]

43. Voronin, V.V.; Ledovskaya, M.S.; Gordeev, E.G.; Rodygin, K.S.; Ananikov, V.P. [3 + 2]-cycloaddition of in situ generated nitrile imines and acetylene for assembling of 1,3-disubstituted pyrazoles with quantitative deuterium labeling. J. Org. Chem. 2018, 83, 3819-3828. [CrossRef] [PubMed]

44. Wu, L.; Yan, B.; Yang, G.; Chen, Y. Green synthesis of 1-monosubstituted 1,2,3-triazoles via 'click chemistry' in water. Heterocycl. Commun. 2013, 19, 397. [CrossRef]

45. Schmidt, C.D.; Kaschel, J.; Schneider, T.F.; Kratzert, D.; Stalke, D.; Werz, D.B. Donor-substituted nitrocyclopropanes: Immediate ring-enlargement to cyclic nitronates. Org. Lett. 2013, 15, 6098-6101. [CrossRef] [PubMed]

46. Garve, L.K.B.; Barkawitz, P.; Jones, P.G.; Werz, D.B. Ring-opening 1,3-dichlorination of donor-acceptor cyclopropanes by iodobenzene dichloride. Org. Lett. 2014, 16, 5804-5807. [CrossRef] [PubMed]

47. Cavitt, M.A.; France, S. Aluminum(III)-catalyzed, formal homo-nazarov-type ring-opening cyclizations toward the synthesis of functionalized tetrahydroindolizines. Synthesis 2016, 48, 1910-1919. [CrossRef]

48. Jiménez-Moreno, E.; Guo, Z.; Oliveira Bruno, L.; Albuquerque Inês, S.; Kitowski, A.; Guerreiro, A.; Boutureira, O.; Rodrigues, T.; Jiménez-Osés, G.; Bernardes Gonçalo, J.L. Vinyl ether/tetrazine pair for the traceless release of alcohols in cells. Angew. Chem. 2016, 129, 249-253. [CrossRef]

49. Jia, Z.; Wang, K.; Tan, B.; Gu, Y. Ruthenium complexes immobilized on functionalized knitted hypercrosslinked polymers as efficient and recyclable catalysts for organic transformations. Adv. Synth. Catal. 2017, 359, 78-88. [CrossRef]

50. Wallbaum, J.; Garve, L.K.B.; Jones, P.G.; Werz, D.B. Ring-opening 1,3-halochalcogenation of cyclopropane dicarboxylates. Org. Lett. 2017, 19, 98-101. [CrossRef] [PubMed]

51. Leger, P.R.; Murphy, R.A.; Pushkarskaya, E.; Sarpong, R. Synthetic efforts toward the lycopodium alkaloids inspires a hydrogen iodide mediated method for the hydroamination and hydroetherification of olefins. Chem. Eur. J. 2015, 21, 4377-4383. [CrossRef] [PubMed]

52. Lu, H.-H.; Pronin, S.V.; Antonova-Koch, Y.; Meister, S.; Winzeler, E.A.; Shenvi, R.A. Synthesis of (+)-7,20-diisocyanoadociane and liver-stage antiplasmodial activity of the isocyanoterpene class. J. Am. Chem. Soc. 2016, 138, 7268-7271. [CrossRef] [PubMed]

53. Koh Ming, J.; Khan, R.K.M.; Torker, S.; Hoveyda Amir, H. Broadly applicable Z- and diastereoselective ring-opening/cross-metathesis catalyzed by a dithiolate ru complex. Angew. Chem. Int. Ed. 2014, 53, 1968-1972.

54. Torker, S.; Koh, M.J.; Khan, R.K.M.; Hoveyda, A.H. Regarding a persisting puzzle in olefin metathesis with ru complexes: Why are transformations of alkenes with a small substituent Z-selective? Organometallics 2016, 35, 543-562. [CrossRef]

55. Nishimoto, Y.; Kita, Y.; Ueda, H.; Imaoka, H.; Chiba, K.; Yasuda, M.; Baba, A. Coupling reaction of enol derivatives with silyl ketene acetals catalyzed by gallium trihalides. Chem. Eur. J. 2016, 22, 11837-11845. [CrossRef] [PubMed]

56. Iwasaki, T.; Miyata, Y.; Akimoto, R.; Fujii, Y.; Kuniyasu, H.; Kambe, N. Diarylrhodates as promising active catalysts for the arylation of vinyl ethers with grignard reagents. J. Am. Chem. Soc. 2014, 136, 9260-9263. [CrossRef] [PubMed]

57. Favorskii, A.E. Action of potassium hydroxide on mixtures of ketones and phenylacetylene. Zhurnal Russkago Fiziko-Khimicheskago Obshchestva 1905, 37, 643-645.

58. Favorskii, A.E. Action de la potasse caustique sur les mélanges des cétones avec le phénylacétylène. Bulletin de la Société Chimique de France 1907, 2, 1087-1088.

59. Rodygin, K.S.; Werner, G.; Kucherov, F.A.; Ananikov, V.P. Calcium carbide: A unique reagent for organic synthesis and nanotechnology. Chem. Asian J. 2016, 11, 965-976. [CrossRef] [PubMed]

60. Ban, M.; Yamamoto, T.; Otsuka, S. Vinylation of phenols in aqueous solution. (the researches of vinylation reaction. X.). Nippon kagaku Zassi 1956, 77, 176-182. [CrossRef]

61. Potapov, V.A.; Panov, V.A.; Musalov, M.V.; Zhivet'eva, S.A.; Musalova, M.V.; Khabibulina, A.G.; Amosova, S.V. Efficient synthetic methods for unsaturated 3,4,5-trimethoxybenzyl sulfides and ethers. Russ. J. Org. Chem. 2016, 52, 1571-1575. [CrossRef] 
62. Orlov, A.V.; Komissarova, N.G.; Shitikova, O.V.; Spirikhin, L.V.; Yunusov, M.S. Intramolecular cyclization involving O-vinyl or O-vinylketoxime function in a number of pentacyclic triterpenoids in superbasic medium. Russ. Chem. Bull. 2013, 62, 687-691. [CrossRef]

63. Trofimov, B.A.; Oparina, L.A.; Tarasova, O.A.; Artem'ev, A.V.; Kobychev, V.B.; Gatilov, Y.V.; Albanov, A.I.; Gusarova, N.K. Tuneable superbase-catalyzed vinylation of $\alpha$-hydroxyalkylferrocenes with alkynes. Tetrahedron 2014, 70, 5954-5960. [CrossRef]

64. Schobert, H. Production of acetylene and acetylene-based chemicals from coal. Chem. Rev. 2014, 114, 1743-1760. [CrossRef] [PubMed]

65. Miller, S.I.; Shkapenko, G. Vinylation: Kinetics and mechanism of the methoxide-catalyzed addition of methanol to phenylacetylene1. J. Am. Chem. Soc. 1955, 77, 5038-5041. [CrossRef]

66. Matake, R.; Adachi, Y.; Matsubara, H. Synthesis of vinyl ethers of alcohols using calcium carbide under superbasic catalytic conditions (KOH/DMSO). Green Chem. 2016, 18, 2614-2618. [CrossRef]

67. Teong, S.P.; Chua, A.Y.H.; Deng, S.; Li, X.; Zhang, Y. Direct vinylation of natural alcohols and derivatives with calcium carbide. Green Chem. 2017, 19, 1659-1662. [CrossRef]

68. Rattanangkool, E.; Vilaivan, T.; Sukwattanasinitt, M.; Wacharasindhu, S. An atom-economic approach for vinylation of indoles and phenols using calcium carbide as acetylene surrogate. Eur. J. Org. Chem. 2016, 2016, 4347-4353. [CrossRef]

69. Rodygin, K.S.; Werner, I.; Ananikov, V.P. A green and sustainable route to carbohydrate vinyl ethers for accessing bioinspired materials with a unique microspherical morphology. ChemSusChem 2017, 11, $292-298$. [CrossRef] [PubMed]

70. Werner, G.; Rodygin, K.S.; Kostin, A.A.; Gordeev, E.G.; Kashin, A.S.; Ananikov, V.P. A solid acetylene reagent with enhanced reactivity: Fluoride-mediated functionalization of alcohols and phenols. Green Chem. 2017, 19, 3032-3041. [CrossRef]

71. Beletskaya, I.P.; Ananikov, V.P. Transition-metal-catalyzed C-S, C-Se, and C-Te bond formation via cross-coupling and atom-economic addition reactions. Chem. Rev. 2011, 111, 1596-1636. [CrossRef] [PubMed]

72. Alonso, F.; Beletskaya, I.P.; Yus, M. Transition-metal-catalyzed addition of heteroatom-hydrogen bonds to alkynes. Chem. Rev. 2004, 104, 3079-3160. [CrossRef] [PubMed]

73. Paulmier, C. Selenium Reagents and Intermediates in Organic Synthesis; Pergamon Press: Oxford, UK, 1986.

74. Marcantoni, E.; Massaccesi, M.; Petrini, M.; Bartoli, G.; Bellucci, M.C.; Bosco, M.; Sambri, L. A novel route to the vinyl sulfide nine-membered macrocycle moiety of griseoviridin. J. Org. Chem. 2000, 65, 4553-4559. [CrossRef] [PubMed]

75. Perez-Pineiro, R.; Dai, S.; Alvarez-Puebla, R.; Wigginton, J.; Al-Hourani, B.J.; Fenniri, H. Synthesis of sulfur-containing aryl and heteroaryl vinyls via suzuki-miyaura cross-coupling for the preparation of sers-active polymers. Tetrahedron Lett. 2009, 50, 5467-5469. [CrossRef] [PubMed]

76. Nakabayashi, K.; Abiko, Y.; Mori, H. RAFT polymerization of $S$-vinyl sulfide derivatives and synthesis of block copolymers having two distinct optoelectronic functionalities. Macromolecules 2013, 46, 5998-6012. [CrossRef]

77. Silveira, C.C.; Martins, G.M.; Mendes, S.R. Regio- and stereoselective synthesis of (Z)-2-arylsulfanyl allylic alcohols using anhydrous $\mathrm{CeCl}_{3}$ as catalyst under solvent free conditions. Tetrahedron Lett. 2013, 54, 5492-5495. [CrossRef]

78. Liu, J.-G.; Ueda, M. High refractive index polymers: Fundamental research and practical applications. J. Mater. Chem. 2009, 19, 8907-8919. [CrossRef]

79. Huang, H.M.; Chang, C.Y.; Liu, I.C.; Tsai, H.C.; Lai, M.K.; Tsiang Raymond, C.C. Synthesis of gold nanocomposite via chemisorption of gold nanoparticles with poly(p-methylstyrene) containing multiple bonding groups on the chain side. J. Polym. Sci. A Polym. Chem. 2005, 43, 4710-4720. [CrossRef]

80. Gusarova, N.K.; Chernysheva, N.A.; Yas'ko, S.V.; Trofimov, B.A. Highly efficient atom economical "green chemistry" synthesis of vinyl sulfides from thiols and acetylene in water. Russ. Chem. Bull. 2013, 62, 438-440. [CrossRef]

81. Rodygin, K.S.; Ananikov, V.P. An efficient metal-free pathway to vinyl thioesters with calcium carbide as the acetylene source. Green Chem. 2016, 18, 482-486. [CrossRef]

82. Rodygin, K.S.; Kostin, A.A.; Ananikov, V.P. Calcium carbide as a convenient acetylene source in the synthesis of unsaturated sulfides, promising functionalized monomers. Mendeleev Commun. 2015, 25, 415-416. [CrossRef] 
83. Potapov, V.A.; Malinovich, D.A.; Amosova, S.V.; Bhasin, K.K. Synthesis of 2-(vinylselanyl)pyridine. Russ. J. Org. Chem. 2015, 51, 443-444. [CrossRef]

84. Potapov, V.A.; Musalova, M.V.; Ishigeev, R.S.; Musalov, M.V.; Panov, V.A.; Khabibulina, A.G.; Amosova, S.V.; Bhasin, K.K. Efficient and selective syntheses of novel unsaturated chalcogen-containing pyridine derivatives. Tetrahedron Lett. 2016, 57, 5341-5343. [CrossRef]

85. Rodygin, K.S.; Gyrdymova, Y.V.; Zarubaev, V.V. Synthesis of vinyl thioethers and bis-thioethenes from calcium carbide and disulfides. Mendeleev Commun. 2017, 27, 476-478. [CrossRef]

86. Zhang, Y.; Chen, X.; Lan, J.; You, J.; Chen, L. Synthesis and biological applications of imidazolium-based polymerized ionic liquid as a gene delivery vector. Chem. Biol. Drug. Des. 2009, 74, 282-288. [CrossRef] [PubMed]

87. Oshiro, Y.; Shirota, Y.; Mikawa, H. Synthesis of polymers with polar side groups. III. Tricyanovinylation of poly(N-Vinylindole) and N-Vinylindole-fumaronitrile copolymer, and dielectric properties of these polymers. Polym. J. 1974, 6, 364. [CrossRef]

88. Hoegl, H. On photoelectric effects in polymers and their sensitization by dopants1. J. Phys. Chem. 1965, 69, 755-766. [CrossRef]

89. Grazulevicius, J.V.; Strohriegl, P.; Pielichowski, J.; Pielichowski, K. Carbazole-containing polymers: Synthesis, properties and applications. Prog. Polym. Sci. 2003, 28, 1297-1353. [CrossRef]

90. Shmidt, E.Y.; Protsuk, N.I.; Vasil'tsov, A.M.; Ivanov, A.V.; Mikhaleva, A.I.; Trofimov, B.A. Improved method for the synthesis of 1-vinylindole. Chem. Heterocycl. Compd. 2013, 49, 404-407. [CrossRef]

91. Rodygin, K.S.; Bogachenkov, A.S.; Ananikov, V.P. Vinylation of a secondary amine core with calcium carbide for efficient post-modification and access to polymeric materials. Molecules 2018, 23, 648. [CrossRef] [PubMed]

92. Wünsch, J.R. Polystyrene: Synthesis, Production and Applications; Rapra Technology Limited: Croydon, UK, 2000; p. 171.

93. Xue, F.; Deng, H.; Xue, C.; Mohamed, D.K.B.; Tang, K.Y.; Wu, J. Reaction discovery using acetylene gas as the chemical feedstock accelerated by the "stop-flow" micro-tubing reactor system. Chem. Sci. 2017, 8, 3623-3627. [CrossRef] [PubMed]

94. Luong, T.; Chen, S.; Qu, K.; McInturff, E.L.; Krische, M.J. Ruthenium(0)-catalyzed C-C coupling of alkynes and 3-hydroxy-2-oxindoles: Direct C-H vinylation of alcohols. Org. Lett. 2017, 19, 966-968. [CrossRef] [PubMed]

95. Bertleff, W.; Roeper, M.; Sava, X. Carbonylation. In Ullmann's Encyclopedia of Industrial Chemistry; Wiley-VCH: Weinheim, Germany, 2000.

96. Reppe, W. Carbonylierung i. Über die umsetzung von acetylen mit kohlenoxyd und verbindungen mit reaktionsfähigen wasserstoffatomen synthesen $\alpha, \beta$-ungesättigter carbonsäuren und ihrer derivate. Liebigs Ann. 1953, 582, 1-37. [CrossRef]

97. Xie, H.; Lin, T.; Shi, L.; Meng, X. Acetylene carbonylation over Ni-containing catalysts: Role of surface structure and active site distribution. RSC Adv. 2016, 6, 97285-97292. [CrossRef]

98. Lin, T.J.; Meng, X.; Shi, L. Catalytic hydrocarboxylation of acetylene to acrylic acid using $\mathrm{Ni}_{2} \mathrm{O}_{3}$ and cupric bromide as combined catalysts. J. Mol. Catal. A Chem. 2015, 396, 77-83. [CrossRef]

99. Bond, J.Q.; Alonso, D.M.; Wang, D.; West, R.M.; Dumesic, J.A. Integrated catalytic conversion of $\gamma$-valerolactone to liquid alkenes for transportation fuels. Science 2010, 327, 1110. [CrossRef] [PubMed]

100. Lin, T.J.; Meng, X.; Shi, L. Ni-exchanged Y-zeolite: An efficient heterogeneous catalyst for acetylene hydrocarboxylation. Appl. Catal. A General 2014, 485, 163-171. [CrossRef]

101. Wu, L.; Liu, Q.; Jackstell, R.; Beller, M. Carbonylations of alkenes with co surrogates. Angew. Chem. Int. Ed. 2014, 53, 6310-6320. [CrossRef] [PubMed]

102. Chinchilla, R.; Nájera, C. Chemicals from alkynes with palladium catalysts. Chem. Rev. 2014, 114, $1783-1826$. [CrossRef] [PubMed]

103. Chen, X.; Zhu, H.; Wang, T.; Li, C.; Yan, L.; Jiang, M.; Liu, J.; Sun, X.; Jiang, Z.; Ding, Y. The 2V-P,N polymer supported palladium catalyst for methoxycarbonylation of acetylene. J. Mol. Catal. A Chem. 2016, 414, 37-46. [CrossRef]

104. Chen, X.; Zhu, H.; Wang, W.; Du, H.; Wang, T.; Yan, L.; Hu, X.; Ding, Y. Multifunctional single-site catalysts for alkoxycarbonylation of terminal alkynes. ChemSusChem 2016, 9, 2451-2459. [CrossRef] [PubMed] 
105. Sonogashira, K.; Tohda, Y.; Hagihara, N. A convenient synthesis of acetylenes: Catalytic substitutions of acetylenic hydrogen with bromoalkenes, iodoarenes and bromopyridines. Tetrahedron Lett. 1975, 16, 4467-4470. [CrossRef]

106. Hosseini, A.; Pilevar, A.; Hogan, E.; Mogwitz, B.; Schulze, A.S.; Schreiner, P.R. Calcium carbide catalytically activated with tetra-n-butyl ammonium fluoride for sonogashira cross coupling reactions. Org. Biomol. Chem. 2017, 15, 6800-6807. [CrossRef] [PubMed]

107. Iqbal, M.; Picken, S.J.; Dingemans, T.J. Synthesis and properties of aligned all-aromatic liquid crystal networks. High Perform. Polym. 2014, 26, 381-391. [CrossRef]

108. Kozhemyakin, Y.; Kretzschmar, A.; Krämer, M.; Rominger, F.; Dreuw, A.; Bunz Uwe, H.F. Synthesis and properties of functional twisted tolanes. Chem. Eur. J. 2017, 23, 9908-9918. [CrossRef] [PubMed]

109. Kitching Matthew, O.; Dixon Olivia, E.; Baumann, M.; Baxendale Ian, R. Flow-assisted synthesis: A key fragment of SR 142948A. Eur. J. Org. Chem. 2017, 2017, 6540-6553. [CrossRef]

110. Potapov, V.; Musalov, M.; Panov, V.A.; Musalova, M.; Amosova, S. Allylation of acetylene under atmospheric pressure. Russ. J. Org. Chem. 2013, 2013, 1834-1835. [CrossRef]

111. Boronat, M.; Laursen, S.; Leyva-Pérez, A.; Oliver-Meseguer, J.; Combita, D.; Corma, A. Partially oxidized gold nanoparticles: A catalytic base-free system for the aerobic homocoupling of alkynes. J. Catal. 2014, 315, 6-14. [CrossRef]

112. Favorskii, A.E.; Skosarevskii, M.P. O reaktsii poroshkovatogo edkogo kali na smes fenilatsetilena s atsetonom. Zh. Russ. Khim. Ob-va. 1900, 32, 652.

113. Tomilin, D.N.; Petrova, O.V.; Sobenina, L.N.; Mikhaleva, A.I.; Trofimov, B.A. A convenient synthesis of hetarylethynyl ketones from hetarylcarbaldehydes and acetylene. Chem. Heterocycl. Compd. 2013, 49, 341-344. [CrossRef]

114. Shmidt, E.Y.; Bidusenko, I.A.; Protsuk, N.I.; Mikhaleva, A.I.; Trofimov, B.A. Improved synthesis of tertiary propargyl alcohols by the favorskii reaction of alkyl aryl (hetaryl) ketones with acetylene. Russ. J. Org. Chem. 2013, 49, 8-11. [CrossRef]

115. Schmidt, E.Y.; Cherimichkina, N.A.; Bidusenko, I.A.; Protzuk, N.I.; Trofimov, B.A. Alkynylation of aldehydes and ketones using the $\mathrm{Bu}_{4} \mathrm{NOH} / \mathrm{H}_{2} \mathrm{O} / \mathrm{DMSO}$ catalytic composition: A wide-scope methodology. Eur. J. Org. Chem. 2014, 2014, 4663-4670. [CrossRef]

116. Valova, T.M.; Gorelik, A.M.; Barachevsky, V.A. Synthesis of photochromic optically transparent polycarbonate glasses and study of their properties. Russ. J. Appl. Chem. 2017, 90, 501-506. [CrossRef]

117. Deng, Q.; Shen, R.; Ding, R.; Zhang, L. Generation of ethynyl-grignard reagent in a falling film microreactor: An expeditious flow synthesis of propargylic alcohols and analogues. Adv. Synth. Catal. 2014, 356, 2931-2936. [CrossRef]

118. Hylse, O.; Maier, L.; Kučera, R.; Perečko, T.; Svobodová, A.; Kubala, L.; Paruch, K.; Švenda, J. A concise synthesis of forskolin. Angew. Chem. 2017, 129, 12760-12763. [CrossRef]

119. Hosseini, A.; Seidel, D.; Miska, A.; Schreiner, P.R. Fluoride-assisted activation of calcium carbide: A simple method for the ethynylation of aldehydes and ketones. Org. Lett. 2015, 17, 2808-2811. [CrossRef] [PubMed]

120. Sum, Y.N.; Yu, D.; Zhang, Y. Synthesis of acetylenic alcohols with calcium carbide as the acetylene source. Green Chem. 2013, 15, 2718-2721. [CrossRef]

121. Clarke, P.A.; Santos, S.; Martin, W.H.C. Combining pot, atom and step economy (pase) in organic synthesis. Synthesis of tetrahydropyran-4-ones. Green Chem. 2007, 9, 438-440. [CrossRef]

122. Diaz Velazquez, H.; Ruiz Garcia, Y.; Vandichel, M.; Madder, A.; Verpoort, F. Water-soluble NHC-cu catalysts: Applications in click chemistry, bioconjugation and mechanistic analysis. Org. Biomol. Chem. 2014, 12, 9350-9356. [CrossRef] [PubMed]

123. Brahma, K.; Achari, B.; Chowdhury, C. Facile synthesis of [1,2,3]-triazole-fused isoindolines, tetrahydroisoquinolines, benzoazepines and benzoazocines by palladium-copper catalysed heterocyclisation. Synthesis 2013, 45, 545-555.

124. Sharma, S.; Saquib, M.; Verma, S.; Mishra, N.N.; Shukla, P.K.; Srivastava, R.; Prabhakar, Y.S.; Shaw, A.K. Synthesis of 2,3,6-trideoxy sugar triazole hybrids as potential new broad spectrum antimicrobial agents. Eur. J. Med. Chem. 2014, 83, 474-489. [CrossRef] [PubMed] 
125. Avula Vijay Kumar, R.; Vallela, S.; Anireddy Jaya, S.; Chamarthi Naga, R. Copper-catalyzed synthesis of $N$-alkylated 2-(4-substituted-1H-1,2,3-triazol-1-yl)-1H-indole-3-carbaldehyde by step-wise and one-pot three-component huisgen's 1,3-dipolar cycloaddition reaction. J. Heterocycl. Chem. 2017, 54, 3071-3076. [CrossRef]

126. Yu, Y.; Huang, W.; Chen, Y.; Gao, B.; Wu, W.; Jiang, H. Calcium carbide as the acetylide source: Transition-metal-free synthesis of substituted pyrazoles via [1,5]-sigmatropic rearrangements. Green Chem. 2016, 18, 6445-6449. [CrossRef]

127. Albertin, G.; Antoniutti, S.; Bortoluzzi, M.; Botter, A.; Castro, J. Reactivity with alkene and alkyne of pentamethylcyclopentadienyl half-sandwich diazoalkane complexes of ruthenium. J. Organomet. Chem. 2016, 822, 259-268. [CrossRef]

128. Demina, O.V.; Khodonov, A.A.; Sinauridze, E.I.; Shvets, V.I.; Varfolomeev, S.D. 5-substituted pyridylisoxazoles as effective inhibitors of platelet aggregation. Russ. Chem. Bull. 2014, 63, 2092-2113. [CrossRef]

129. Canlas, G.M.R.; Gilbertson, S.R. [4 + 2+2] cycloaddition catalyzed by a new cationic rhodium-bisphosphine monooxide complex. Chem. Comm. 2014, 50, 5007-5010. [CrossRef] [PubMed]

130. More, A.A.; Ramana, C.V. Total synthesis of the putative structure of xylarinol B. Chem. Asian J. 2014, 9, 1557-1562. [CrossRef] [PubMed]

131. Arrowsmith, M.; Böhnke, J.; Braunschweig, H.; Celik Mehmet, A.; Claes, C.; Ewing William, C.; Krummenacher, I.; Lubitz, K.; Schneider, C. Neutral diboron analogues of archetypal aromatic species by spontaneous cycloaddition. Angew. Chem. Int. Ed. 2016, 55, 11271-11275. [CrossRef] [PubMed]

132. Schäfer, M.; Schäfer, J.; Dewhurst Rian, D.; Ewing William, C.; Krahfuß, M.; Kuntze-Fechner Maximilian, W.; Wehner, M.; Lambert, C.; Braunschweig, H. Regioselective catalytic and stepwise routes to bulky, functional-group-appended, and luminescent 1,2-azaborinines. Chem. Eur. J. 2016, 22, 8603-8609. [CrossRef] [PubMed]

133. Sugahara, T.; Guo, J.-D.; Sasamori, T.; Karatsu, Y.; Furukawa, Y.; Ferao, A.E.; Nagase, S.; Tokitoh, N. Reaction of a stable digermyne with acetylenes: Synthesis of a 1,2-digermabenzene and a 1,4-digermabarrelene. Bull. Chem. Soc. Jpn. 2016, 89, 1375-1384. [CrossRef]

134. Lee, V.Y.; Gapurenko, O.A.; Minkin, V.I.; Horiguchi, S.; Sekiguchi, A. [2 + 2] cycloaddition of the schrock titanium silylidene and acetylene. Russ. Chem. Bull. 2016, 65, 1139-1141. [CrossRef]

135. Trofimov, B.A. Preparation of pyrroles from ketoximes and acetylenes. In Advances in Heterocyclic Chemistry; Katritzky, A.R., Ed.; Academic Press: Cambridge, MA, USA, 1990; Volume 51, pp. 177-301.

136. Trofimov, B.A.; Korostova, S.E.; Balabanova, L.N.; Mikhaleva, A.l. Pyrroles from ketoximes and acetylene. 7. 3-alkyl(phenyl)-2-phenylpyrroles and their N-Vinyl derivatives. Zh. Org. Khim. 1978, 14, 2182-2184.

137. Petrova, O.V.; Sobenina, L.N.; Mikhaleva, A.I. 3-Alkyl-2-phenyl-1-vinylpyrroles from ketoximes and acetylene: An improved synthesis by the trofimov reaction. Chem. Heterocycl. Compd. 2013, 48, 1628-1633. [CrossRef]

138. Schmidt, E.Y.; Zorina, N.V.; Ivanova, E.V.; Tatarinova, I.V.; Ushakov, I.A.; Mikhaleva, A.I.; Trofimov, B.A. One-pot synthesis of 3-(E)-styrylpyrroles from (E)-styrylmethyl ketoximes and acetylene. Mendeleev Commun. 2013, 23, 340-341. [CrossRef]

139. Sobenina, L.N.; Stepanova, Z.V.; Petrova, O.V.; Ma, J.S.; Yang, G.; Tatarinova, A.A.; Mikhaleva, A.I.; Trofimov, B.A. Synthesis of 3-[5-(biphenyl-4-yl)pyrrol-2-yl]-1-phenylprop-2-yn-1-ones by palladium-free cross-coupling between pyrroles and haloalkynes on aluminum oxide. Russ. Chem. Bull. 2013, 62, 88-92. [CrossRef]

140. Petrova, O.V.; Sobenina, L.N.; Ushakov, I.A.; Budaev, A.B.; Ivanov, A.V.; Samsonov, V.A.; Tikhonov, A.Y.; Trofimov, B.A. Multi-channel annulation of acetylene with 3-methyl-7,8-dihydrocinnolin-5(6H)-one oxime in the $\mathrm{KOH} / \mathrm{DMSO}$ superbasic system. Mendeleev Commun. 2017, 27, 344-345. [CrossRef]

141. Shabalin, D.A.; Dvorko, M.Y.; Schmidt, E.Y.; Protsuk, N.I.; Trofimov, B.A. Synthesis of 5-hydroxy- $\delta 1$-pyrrolines from aryl isoalkyl ketoximes and acetylene in a tuned superbase medium. Tetrahedron Lett. 2016, 57, 3156-3159. [CrossRef]

142. Shabalin, D.A.; Dvorko, M.Y.; Schmidt, E.Y.; Ushakov, I.A.; Trofimov, B.A. Synthesis of 5-hydroxy- $\delta 1$-pyrrolines from sec-alkyl aryl ketoximes and acetylene. Tetrahedron 2016, 72, 6661-6667. [CrossRef] 
143. Shabalin, D.A.; Glotova, T.E.; Schmidt, E.Y.; Ushakov, I.A.; Mikhaleva, A.b.I.; Trofimov, B.A. Synthesis of 3,3-dimethyl-2-phenyl-3H-pyrrole from isopropyl phenyl ketoxime and acetylene: A side formation of 4,4-dimethyl-5-phenyl-1-vinyl-2-pyrrolidinone as clue to the reaction mechanism. Mendeleev Commun. 2014, 24, 100-101. [CrossRef]

144. Shabalin, D.A.; Glotova, T.E.; Ushakov, I.A.; Dvorko, M.Y.; Vashchenko, A.V.; Smirnov, V.I.; Schmidt, E.Y.; Mikhaleva, A.b.I.; Trofimov, B.A. 2-(2-Ethynyl-1-aziranyl)-3,4-dihydro-2H-pyrrole: A one-pot assembly from isopropyl phenyl ketoxime and acetylene during the synthesis of $3 H$-pyrrole. Mendeleev Commun. 2014, 24, 368-369. [CrossRef]

145. Schmidt, E.Y.; Bidusenko, I.A.; Cherimichkina, N.A.; Ushakov, I.A.; Trofimov, B.A. Polycyclic bridgehead acetals with enol functionality: One-pot assembly from aliphatic ketones and acetylene in $\mathrm{KOH} / \mathrm{DMSO}$ suspension. Tetrahedron 2016, 72, 4510-4517. [CrossRef]

146. Trofimov, B.A.; Schmidt, E.Y.; Ushakov, I.A.; Mikhaleva, A.I.; Zorina, N.V.; Protsuk, N.I.; Senotrusova, E.Y.; Skital'tseva, E.V.; Kazheva, O.N.; Alexandrov, G.G.; et al. One-pot assembly of 7-methylene-6,8-dioxabicyclo[3.2.1]octanes, congeners of frontalin, from ketones and acetylene. Eur. J. Org. Chem. 2009, 2009, 5142-5145. [CrossRef]

147. Schmidt, E.Y.; Bidusenko, I.A.; Ushakov, I.A.; Vashchenko, A.V.; Trofimov, B.A. Decorated cyclopentadienes from acetylene and ketones in just two steps. Org. Lett. 2017, 19, 3127-3130. [CrossRef] [PubMed]

148. Schmidt, E.Y.; Bidusenko, I.A.; Protsuk, N.I.; Ushakov, I.A.; Trofimov, B.A. Superbase-promoted selective cascade cyclization reaction of 1,5-diketones with acetylenes to methylene-6,8-dioxabicyclo[3.2.1]octanes. Eur. J. Org. Chem. 2013, 2013, 2453-2460. [CrossRef]

149. Trofimov, B.A.; Schmidt, E.Y.; Bidusenko, I.A.; Cherimichkina, N.A.; Ushakov, I.A. Assemblage of 1-hydroxy-2-cyclopentene and 7-methylene-6,8-dioxabicyclo[3.2.1]octane from acetylene and 4-acetylpyridine molecules in a suspension of KOH-DMSO. Russ. Chem. Bull. 2014, 63, 2402-2404. [CrossRef]

150. Trofimov, B.A.; Schmidt, E.Y.; Bidusenko, I.A.; Ushakov, I.A.; Cherimichkina, N.A.; Protsuk, N.I. Diastereoselective self-organization of acetylene and acetophenone molecules into 1-benzoyl-3-hydroxy-cyclopentene in the presence of potassium hydroxide. Russ. J. Org. Chem. 2014, 50, 1207-1209. [CrossRef]

151. Fu, R.; Li, Z. Direct synthesis of 2-methylbenzofurans from calcium carbide and salicylaldehyde p-tosylhydrazones. Org. Lett. 2018, 20, 2342-2345. [CrossRef] [PubMed]

152. Fakharian, M.; Keivanloo, A.; Nabid Mohammad, R. Using calcium carbide as an acetylene source for cascade synthesis of pyrrolo[2,3-b]quinoxalines via copper-free sonogashira coupling reaction. Helv. Chim. Acta 2018, 101, e1800004. [CrossRef]

153. Shukys, J.G.; Township, C.; County, M. Trifluoroethyl Vinyl Ether Compositions and Methods for Preparing and Using the Same. US Patent 2830007A, 4 August 1958.

154. Townsend, P.W.; Park, F. Method of Preparing 2,2,2-Trifluoroethyl Vinyl Ether. US Patent 2870218A, 20 January 1959.

155. Campbell, K.N.; Campbell, B.K.; Eby, L.T. The preparation of acetylenic carbinols. J. Am. Chem. Soc. 1938, 60, 2882-2884. [CrossRef]

156. Isler, O.; Wiss, O. Chemistry and biochemistry of the $\mathrm{K}$ vitamins. In Vitamins $\mathcal{E}$ Hormones; Harris, R.S., Marrian, G.F., Thimann, K.V., Eds.; Academic Press: Cambridge, MA, USA, 1959; Volume 17, pp. 53-90.

157. McLamore, W.M.; P'An, S.Y.; Bavley, A. Hypnotics and anticonvulsants. Ii. Halogenated tertiary acetylenic carbinols. J. Org. Chem. 1955, 20, 109-117. [CrossRef]

158. Grimme, W.; Emde, U.-M.; Emde, H. Allophanates of alpha-ethynylcarbinols. US Patent 2822379A, 4 February 1958.

159. Elks, J. The Dictionary of Drugs: Chemical Data: Chemical Data, Structures and Bibliographies; Springer: Berlin, Germany, 2014.

160. Morton, I.K.; Hall, J.M. Concise Dictionary of Pharmacological Agents: Properties and Synonyms; Springer: Berlin, Germany, 2012; p. 342.

161. Moutou, J.-L.; Mouton, F.; Pellegrino, G.; Dillenschneider, J.-M.; Lafay, J. A Process for Introducing a Double Bond into Position 15,16 of a Steroid. WO2011098439 (A2), 18 August 2011.

162. Inhoffen Hans, H.; Logemann, W.; Hohlweg, W.; Serini, A. Untersuchungen in der sexualhormon-reihe. Ber. Dtsch. Chem. Ges. A/B 1971, 71, 1024-1032. [CrossRef] 
163. Ercoli, A. 3-Cyclopentyl and Cyclopentenyl Ethers of Estrone and Derivatives there of. US Patent 3159543A, 1 December 1961.

164. Tietze, L.F.; Krimmelbein, I.K. Enantioselective total synthesis of the oral contraceptive desogestrel by a double heck reaction. Chem. Eur. J. 2008, 14, 1541-1551. [CrossRef] [PubMed]

165. Wuts, P.G.M.; Anderson, A.M.; Ashford, S.W.; Goble, M.P.; White, M.J.; Beck, D.; Gilbert, I.; Hrab, R.E. A chemobiological synthesis of eplerenone. Synlett 2008, 2008, 418-422. [CrossRef]

166. Kuhnz, W.; Fritzemeier, K.H.; Hegele-Hartung, C.; Krattenmacher, R. Comparative progestational activity of norgestimate, levonorgestrel-oxime and levonorgestrel in the rat and binding of these compounds to the progesterone receptor. Contraception 1995, 51, 131-139. [CrossRef]

167. Blickenstaff, R.T.; Ghosh, A.C.; Wolf, G.C. Total Synthesis of Steroids; Academic Press: New York, NY, USA; London, UK, 1974; p. 328.

168. Ren, T. Diruthenium $\sigma$-alkynyl compounds: A new class of conjugated organometallics. Organometallics 2005, 24, 4854-4870. [CrossRef]

169. Buschbeck, R.; Low, P.J.; Lang, H. Homoleptic transition metal acetylides. Coord. Chem. Rev. 2011, 255, 241-272. [CrossRef]

170. Long, N.J.; Williams, C.K. Metal alkynyl $\sigma$ complexes: Synthesis and materials. Angew. Chem. Int. Ed. 2003, 42, 2586-2617. [CrossRef] [PubMed]

171. Berenguer, J.R.; Lalinde, E.; Teresa Moreno, M. An overview of the chemistry of homo and heteropolynuclear platinum complexes containing bridging acetylide $(\mu-C \equiv C R)$ ligands. Coord. Chem. Rev. 2010, 254, 832-875. [CrossRef]

172. Green, K.A.; Cifuentes, M.P.; Samoc, M.; Humphrey, M.G. Metal alkynyl complexes as switchable nlo systems. Coord. Chem. Rev. 2011, 255, 2530-2541. [CrossRef]

173. Grelaud, G.; Cifuentes, M.P.; Paul, F.; Humphrey, M.G. Group 8 metal alkynyl complexes for nonlinear optics. J. Organomet. Chem. 2014, 751, 181-200. [CrossRef]

174. Mei, J.; Ogawa, K.; Kim, Y.-G.; Heston, N.C.; Arenas, D.J.; Nasrollahi, Z.; McCarley, T.D.; Tanner, D.B.; Reynolds, J.R.; Schanze, K.S. Low-band-gap platinum acetylide polymers as active materials for organic solar cells. ACS Appl. Mater. Interfaces 2009, 1, 150-161. [CrossRef] [PubMed]

175. Wong, W.-Y.; Ho, C.-L. Organometallic photovoltaics: A new and versatile approach for harvesting solar energy using conjugated polymetallaynes. Acc. Chem. Res. 2010, 43, 1246-1256. [CrossRef] [PubMed]

176. Lüning, A.; Schur, J.; Hamel, L.; Ott, I.; Klein, A. Strong cytotoxicity of organometallic platinum complexes with alkynyl ligands. Organometallics 2013, 32, 3662-3672. [CrossRef]

177. Meyer, A.; Bagowski, C.P.; Kokoschka, M.; Stefanopoulou, M.; Alborzinia, H.; Can, S.; Vlecken, D.H.; Sheldrick, W.S.; Wölfl, S.; Ott, I. On the biological properties of alkynyl phosphine gold(I) complexes. Angew. Chem. Int. Ed. 2012, 51, 8895-8899. [CrossRef] [PubMed]

178. Tong, G.S.M.; Law, Y.C.; Kui Steven, C.F.; Zhu, N.; Leung King, H.; Phillips David, L.; Che, C.M. Ligand-to-ligand charge-transfer transitions of platinum(II) complexes with arylacetylide ligands with different chain lengths: Spectroscopic characterization, effect of molecular conformations, and density functional theory calculations. Chem. Eur. J. 2010, 16, 6540-6554. [CrossRef] [PubMed]

179. Wong, K.M.-C.; Yam, V.W.-W. Self-assembly of luminescent alkynylplatinum(II) terpyridyl complexes: Modulation of photophysical properties through aggregation behavior. Acc. Chem. Res. 2011, 44, 424-434. [CrossRef] [PubMed]

180. Bonuccelli, V.; Funaioli, T.; Leoni, P.; Marchetti, F.; Marchetti, L.; Pasquali, M. Synthesis and characterization of non-bridging mono- and bis- $\sigma-\eta^{1}$-alkynyl derivatives of the phosphido-bridged hexaplatinum core $\left[\mathrm{Pt6}\left(\mu-\mathrm{PBut}_{2}\right)_{4}(\mathrm{CO})_{4}\right]^{2+}$. Dalton Trans. 2016, 45, 6878-6892. [CrossRef] [PubMed]

181. Benedetti, M.; Lamacchia, V.; Antonucci, D.; Papadia, P.; Pacifico, C.; Natile, G.; Fanizzi, F.P. Insertion of alkynes into Pt-X bonds of square planar $\left[\mathrm{PtX}_{2}\left(N^{\wedge} N\right)\right](\mathrm{X}=\mathrm{Cl}, \mathrm{Br}, \mathrm{I})$ complexes. Dalton Trans. 2014, 43, 8826-8834. [CrossRef] [PubMed]

182. Mitchenko, S.A.; Khazipov, O.V.; Krasnyakova, T.V. New stereoselective $\mathrm{C}_{\mathrm{sp} 2}-\mathrm{C}_{\mathrm{sp} 3}$ coupling: Catalytic iodomethylation of acetylene with methyl iodide into E-1-iodopropene. Kinet. Catal. 2014, 55, 304-310. [CrossRef]

183. Campos, J. Dihydrogen and acetylene activation by a gold(I)/platinum(0) transition metal only frustrated lewis pair. J. Am. Chem. Soc. 2017, 139, 2944-2947. [CrossRef] [PubMed] 
184. Hahn, C.; Miranda, M.; Chittineni, N.P.B.; Pinion, T.A.; Perez, R. Mechanistic studies on platinum(II) catalyzed hydroarylation of alkynes. Organometallics 2014, 33, 3040-3050. [CrossRef]

185. Ortega-Moreno, L.; Peloso, R.; López-Serrano, J.; Iglesias-Sigüenza, J.; Maya, C.; Carmona, E. A cationic unsaturated platinum(II) complex that promotes the tautomerization of acetylene to vinylidene. Angew. Chem. Int. Ed. 2017, 56, 2772-2775. [CrossRef] [PubMed]

186. Cristóbal, C.; Hernández Yohar, A.; López-Serrano, J.; Paneque, M.; Petronilho, A.; Poveda Manuel, L.; Salazar, V.; Vattier, F.; Álvarez, E.; Maya, C.; et al. Reactivity studies of iridium pyridylidenes $\left[\mathrm{Tp}^{\mathrm{me} 2} \mathrm{Ir}\left(\mathrm{C}_{6} \mathrm{H}_{5}\right)_{2}\left(\mathrm{C}(\mathrm{CH})_{3} \mathrm{C}(\mathrm{R}) \mathrm{NH}\right.\right.$ ] $(\mathrm{R}=\mathrm{H}, \mathrm{Me}, \mathrm{Ph})$. Chem. Eur. J. 2013, 19, 4003-4020. [CrossRef] [PubMed]

187. Esteruelas, M.A.; Oñate, E.; Palacios, A.U. Selective synthesis and photophysical properties of phosphorescent heteroleptic iridium(III) complexes with two different bidentate groups and two different monodentate ligands. Organometallics 2017, 36, 1743-1755. [CrossRef]

188. Espada, M.A.F.; Poveda, M.L.; Carmona, E. Reactivity of a cationic $\left(\mathrm{C}_{5} \mathrm{Me}_{5}\right) \mathrm{Ir}^{\mathrm{III}}$-cyclometalated phosphine complex with alkynes. Organometallics 2014, 33, 7164-7175. [CrossRef]

189. Komine, N.; Kuramoto, A.; Nakanishi, K.; Hirano, M.; Komiya, S. Alkene and alkyne insertion into hydrogen-transition metal bonds catalyzed by palladium(0) complex. Top. Catal. 2014, 57, 960-966. [CrossRef]

190. Helmdach, K.; Ludwig, S.; Villinger, A.; Hollmann, D.; Kosters, J.; Seidel, W.W. Synthesis and activation potential of an open shell diphosphine. Chem. Commun. 2017, 53, 5894-5897. [CrossRef] [PubMed]

191. Helmdach, K.; Dork, S.; Villinger, A.; Seidel, W.W. Sterically encumbered metalla-diphosphines: Unlocking alkyne rotation by ptii coordination. Dalton Trans. 2017, 46, 11140-11144. [CrossRef] [PubMed]

192. Ananikov, V.P.; Beletskaya, I.P. Alkyne and alkene insertion into metal-heteroatom and metal-hydrogen bonds: The key stages of hydrofunctionalization process. In Hydrofunctionalization; Ananikov, V.P., Tanaka, M., Eds.; Springer: Berlin, Heidelberg, 2013; pp. 1-19.

193. Musalova, M.V.; Potapov, V.A.; Musalov, M.V.; Amosova, S.V. Stereoselective synthesis of (e)-(2-bromovinyl)tellurium tribromide. Russ. J. Org. Chem. 2013, 49, 1397-1398. [CrossRef]

194. Zeni, G.; Lüdtke, D.S.; Panatieri, R.B.; Braga, A.L. Vinylic tellurides: From preparation to their applicability in organic synthesis. Chem. Rev. 2006, 106, 1032-1076. [CrossRef] [PubMed]

195. Mitchenko, S.A.; Khazipov, O.V.; Krasnyakova, T.V. Platinum-catalyzed addition of iodomethane to acetylene. Russ. Chem. Bull. 2013, 62, 984-988. [CrossRef]

196. Yoshimura, A.; Saga, Y.; Sato, Y.; Ogawa, A.; Chen, T.; Han, L.-B. An efficient base-catalyzed double addition of H-phosphine oxides to alkynes. Tetrahedron Lett. 2016, 57, 3382-3384. [CrossRef]

197. Huang, F.; Zhang, Y.; Yao, Y.; Yang, W.; Tao, Y. Synthesis of (4E,6Z,10Z)-hexadeca-4,6,10-trien-1-ol and (4E,6E,10Z)-hexadeca-4,6,10-trien-1-ol, the pheromone components of cocoa pod borer moth conopomorpha cramerella. RSC Adv. 2017, 7, 35575-35580. [CrossRef]

198. Beevor, P.S.; Cork, A.; Hall, D.R.; Nesbitt, B.F.; Day, R.K.; Mumford, J.D. Components of female sex pheromone of cocoa pod borer moth,conopomorpha cramerella. J. Chem. Ecol. 1986, 12, 1-23. [CrossRef] [PubMed]

199. Wang, X.; Lim Yu, N.; Lee, C.; Jang, H.Y.; Lee Bun, Y. 1,5,7-Triazabicyclo[4.4.0]dec-1-ene-mediated acetylene dicarboxylation and alkyne carboxylation using carbon dioxide. Eur. J. Org. Chem. 2013, 2013, 1867-1871. [CrossRef]

200. Yu, D.; Sum Yin, N.; Ean Amanda Chng, C.; Chin Mei, P.; Zhang, Y. Acetylide ion $\left(\mathrm{C}_{2}{ }^{2-}\right)$ as a synthon to link electrophiles and nucleophiles: A simple method for enaminone synthesis. Angew. Chem. Int. Ed. 2013, 52, 5125-5128. [CrossRef] [PubMed]

201. Inagaki, Y.; Nakamoto, M.; Sekiguchi, A. A diels-alder super diene breaking benzene into $\mathrm{C}_{2} \mathrm{H}_{2}$ and $\mathrm{C}_{4} \mathrm{H}_{4}$ units. Nat. Commun. 2014, 5, 3018. [CrossRef] [PubMed]

202. Khan, A.; Lough, A.J.; Gossage, R.A.; Foucher, D.A. Pd-catalysed reactions of alkynes with model distannanes and poly[di-(n-butyl)]stannane. Dalton Trans. 2013, 42, 2469-2476. [CrossRef] [PubMed]

203. Rossi, R.A.; Martín, S.E. Syntheses and applications of organostannanes bonded to elements of groups XIV, XV, and XVI. Coord. Chem. Rev. 2006, 250, 575-601. [CrossRef]

204. Sachtler, W.M.H. Handbook of Heterogeneous Catalysis; Wiley-VCH: Weinheim, Germany, 2008.

205. Leviness, S.; Nair, V.; Weiss, A.H.; Schay, Z.; Guczi, L. Acetylene hydrogenation selectivity control on $\mathrm{PdCu} / \mathrm{Al}_{2} \mathrm{O}_{3}$ catalysts. J. Mol. Catal. 1984, 25, 131-140. [CrossRef] 
206. Wehrli, J.T.; Thomas, D.J.; Wainwright, M.S.; Trimm, D.L.; Cant, N.W. Selective hydrogenation of propyne over an ion-exchanged copper on silica catalyst. Appl. Catal. 1990, 66, 199-208. [CrossRef]

207. Vilé, G.; Baudouin, D.; Remediakis Ioannis, N.; Copéret, C.; López, N.; Pérez-Ramírez, J. Silver nanoparticles for olefin production: New insights into the mechanistic description of propyne hydrogenation. ChemCatChem 2013, 5, 3750-3759. [CrossRef]

208. Gieshoff, T.N.; Villa, M.; Welther, A.; Plois, M.; Chakraborty, U.; Wolf, R.; Jacobi von Wangelin, A. Iron-catalyzed olefin hydrogenation at 1 bar $\mathrm{H}_{2}$ with a $\mathrm{FeCl}_{3}-\mathrm{LiAlH}_{4}$ catalyst. Green Chem. 2015, 17, 1408-1413. [CrossRef]

209. Trimm, D.L.; Cant, N.W.; Liu, I.O.Y. The selective hydrogenation of acetylene in the presence of carbon monoxide over $\mathrm{Ni}$ and $\mathrm{Ni}-\mathrm{Zn}$ supported on $\mathrm{MgAl}_{2} \mathrm{O}_{4}$. Catal. Today 2011, 178, 181-186. [CrossRef]

210. Trimm, D.L.; Liu, I.O.Y.; Cant, N.W. The selective hydrogenation of acetylene over a Ni/SiO 2 catalyst in the presence and absence of carbon monoxide. Appl. Catal. A General 2010, 374, 58-64. [CrossRef]

211. Segura, Y.; López, N.; Pérez-Ramírez, J. Origin of the superior hydrogenation selectivity of gold nanoparticles in alkyne + alkene mixtures: Triple-versus double-bond activation. J. Catal. 2007, 247, 383-386. [CrossRef]

212. Nikolaev, S.A.; Smirnov, V.V.; Vasil'kov, A.Y.; Podshibikhin, V.L. Synergism of the catalytic effect of nanosized gold-nickel catalysts in the reaction of selective acetylene hydrogenation to ethylene. Kinet. Catal. 2010, 51, 375-379. [CrossRef]

213. Nikolaev, S.A.; Smirnov, V.V. Synergistic and size effects in selective hydrogenation of alkynes on gold nanocomposites. Catal. Today 2009, 147, S336-S341. [CrossRef]

214. Liu, X.; Li, Y.; Lee, J.W.; Hong, C.-Y.; Mou, C.-Y.; Jang, B.W.L. Selective hydrogenation of acetylene in excess ethylene over $\mathrm{SiO}_{2}$ supported Au-Ag bimetallic catalyst. Appl. Catal. A General 2012, 439, 8-14. [CrossRef]

215. Bridier, B.; López, N.; Pérez-Ramírez, J. Partial hydrogenation of propyne over copper-based catalysts and comparison with nickel-based analogues. J. Catal. 2010, 269, 80-92. [CrossRef]

216. Bridier, B.; Pérez-Ramírez, J. Cooperative effects in ternary $\mathrm{Cu}-\mathrm{Ni}-\mathrm{Fe}$ catalysts lead to enhanced alkene selectivity in alkyne hydrogenation. J. Am. Chem. Soc. 2010, 132, 4321-4327. [CrossRef] [PubMed]

217. Vilé, G.; Bridier, B.; Wichert, J.; Pérez-Ramírez, J. Ceria in hydrogenation catalysis: High selectivity in the conversion of alkynes to olefins. Angew. Chem. Int. Ed. 2012, 51, 8620-8623. [CrossRef] [PubMed]

218. Carrasco, J.; Vilé, G.; Fernández-Torre, D.; Pérez, R.; Pérez-Ramírez, J.; Ganduglia-Pirovano, M.V. Molecular-level understanding of $\mathrm{CeO}_{2}$ as a catalyst for partial alkyne hydrogenation. J. Phys. Chem. C 2014, 118, 5352-5360. [CrossRef]

219. Johnson, M.M.; Walker, D.W.; Nowack, G.P. Selective Hydrogenation Catalyst. US Patent 4404124, 13 September 1983.

220. Than, C.N.; Didillion, B.; Sarrazin, P.; Cameron, C. Selective Hydrogenation Catalyst and A Process Using That Catalyst. US Patent 6054409 (A), 24 April 2000.

221. Gabasch, H.; Hayek, K.; Klötzer, B.; Knop-Gericke, A.; Schlögl, R. Carbon incorporation in pd(111) by adsorption and dehydrogenation of ethene. J. Phys. Chem. B 2006, 110, 4947-4952. [CrossRef] [PubMed]

222. García-Mota, M.; Bridier, B.; Pérez-Ramírez, J.; López, N. Interplay between carbon monoxide, hydrides, and carbides in selective alkyne hydrogenation on palladium. J. Catal. 2010, 273, 92-102. [CrossRef]

223. Teschner, D.; Borsodi, J.; Wootsch, A.; Révay, Z.; Hävecker, M.; Knop-Gericke, A.; Jackson, S.D.; Schlögl, R. The roles of subsurface carbon and hydrogen in palladium-catalyzed alkyne hydrogenation. Science 2008, 320, 86. [CrossRef] [PubMed]

224. Sá, J.; Arteaga, G.D.; Daley, R.A.; Bernardi, J.; Anderson, J.A. Factors influencing hydride formation in a $\mathrm{Pd} / \mathrm{TiO}_{2}$ catalyst. J. Phys. Chem. B 2006, 110, 17090-17095. [CrossRef] [PubMed]

225. Armbrüster, M.; Behrens, M.; Cinquini, F.; Föttinger, K.; Grin, Y.; Haghofer, A.; Klötzer, B.; Knop-Gericke, A.; Lorenz, H.; Ota, A.; et al. How to control the selectivity of palladium-based catalysts in hydrogenation reactions: The role of subsurface chemistry. Chem. Catal. Chem. 2012, 4, 1048-1063. [CrossRef]

226. Ludwig, W.; Savara, A.; Dostert, K.-H.; Schauermann, S. Olefin hydrogenation on pd model supported catalysts: New mechanistic insights. J. Catal. 2011, 284, 148-156. [CrossRef]

227. Nikolaev, S.A.; Zanaveskin, L.N.; Smirnov, V.V.; Averyanov, V.A.; Zanaveskin, K.L. Catalytic hydrogenation of alkyne and alkadiene impurities from alkenes. Practical and theoretical aspects. Russ. Chem. Rev. 2009, 78, 231. [CrossRef] 
228. Kovnir, K.; Armbrüster, M.; Teschner, D.; Venkov, T.V.; Jentoft, F.C.; Knop-Gericke, A.; Grin, Y.; Schlögl, R. A new approach to well-defined, stable and site-isolated catalysts. Sci. Technol. Adv. Mater. 2007, 8, 420-427. [CrossRef]

229. Vilé, G.; Almora-Barrios, N.; Mitchell, S.; López, N.; Pérez-Ramírez, J. From the lindlar catalyst to supported ligand-modified palladium nanoparticles: Selectivity patterns and accessibility constraints in the continuous-flow three-phase hydrogenation of acetylenic compounds. Chem. Eur. J. 2014, 20, 5926-5937. [CrossRef] [PubMed]

230. Witte, P.T.; Berben, P.H.; Boland, S.; Boymans, E.H.; Vogt, D.; Geus, J.W.; Donkervoort, J.G. Basf nanoselect ${ }^{\mathrm{TM}}$ technology: Innovative supported Pd- and Pt-based catalysts for selective hydrogenation reactions. Top. Catal. 2012, 55, 505-511. [CrossRef]

231. Mori, A.; Mizusaki, T.; Miyakawa, Y.; Ohashi, E.; Haga, T.; Maegawa, T.; Monguchi, Y.; Sajiki, H. Chemoselective hydrogenation method catalyzed by $\mathrm{Pd} / \mathrm{C}$ using diphenylsulfide as a reasonable catalyst poison. Tetrahedron 2006, 62, 11925-11932. [CrossRef]

232. Mori, A.; Mizusaki, T.; Kawase, M.; Maegawa, T.; Monguchi, Y.; Takao, S.; Takagi, Y.; Sajiki, H. Novel palladium-on-carbon/diphenyl sulfide complex for chemoselective hydrogenation: Preparation, characterization, and application. Adv. Synth. Catal. 2008, 350, 406-410. [CrossRef]

233. McKenna, F.M.; Mantarosie, L.; Wells, R.P.K.; Hardacre, C.; Anderson, J.A. Selective hydrogenation of acetylene in ethylene rich feed streams at high pressure over ligand modified $\mathrm{Pd} / \mathrm{TiO}_{2}$. Catal. Sci. Technol. 2012, 2, 632-638. [CrossRef]

234. McKenna, F.-M.; Wells, R.P.K.; Anderson, J.A. Enhanced selectivity in acetylene hydrogenation by ligand modified $\mathrm{Pd} / \mathrm{TiO}_{2}$ catalysts. Chem. Commun. 2011, 47, 2351-2353. [CrossRef] [PubMed]

235. Kim, W.-J.; Moon, S.H. Modified Pd catalysts for the selective hydrogenation of acetylene. Catal. Today 2012, 185, 2-16. [CrossRef]

236. Tauster, S.J.; Fung, S.C. Strong metal-support interactions: Occurrence among the binary oxides of groups IIA-VB. J. Catal. 1978, 55, 29-35. [CrossRef]

237. Fleisch, T.H.; Hicks, R.F.; Bell, A.T. An xps study of metal-support interactions on $\mathrm{PdSiO}_{2}$ and $\mathrm{PdLa}_{2} \mathrm{O}_{3}$. J. Catal. 1984, 87, 398-413. [CrossRef]

238. Sun, S.; Zhang, G.; Gauquelin, N.; Chen, N.; Zhou, J.; Yang, S.; Chen, W.; Meng, X.; Geng, D.; Banis, M.N.; et al. Single-atom catalysis using Pt/graphene achieved through atomic layer deposition. Sci. Rep. 2013, 3, 1775. [CrossRef]

239. Yang, M.; Li, S.; Wang, Y.; Herron, J.A.; Xu, Y.; Allard, L.F.; Lee, S.; Huang, J.; Mavrikakis, M.; Flytzani-Stephanopoulos, M. Catalytically active $\mathrm{Au}-\mathrm{O}(\mathrm{OH})_{\mathrm{x}}$-species stabilized by alkali ions on zeolites and mesoporous oxides. Science 2014, 346, 1498. [CrossRef] [PubMed]

240. Xie, S.; Lu, N.; Xie, Z.; Wang, J.; Kim Moon, J.; Xia, Y. Synthesis of Pd-Rh core-frame concave nanocubes and their conversion to rh cubic nanoframes by selective etching of the pd cores. Angew. Chem. 2012, 124, 10412-10416. [CrossRef]

241. Shao, M.; He, G.; Peles, A.; Odell, J.H.; Zeng, J.; Su, D.; Tao, J.; Yu, T.; Zhu, Y.; Xia, Y. Manipulating the oxygen reduction activity of platinum shells with shape-controlled palladium nanocrystal cores. Chem. Comm. 2013, 49, 9030-9032. [CrossRef] [PubMed]

242. Xia, X.; Xie, S.; Liu, M.; Peng, H.-C.; Lu, N.; Wang, J.; Kim, M.J.; Xia, Y. On the role of surface diffusion in determining the shape or morphology of noble-metal nanocrystals. Proc. Natl. Acad. Sci. USA 2013, 110, 6669. [CrossRef] [PubMed]

243. Xie, S.; Choi, S.-I.; Lu, N.; Roling, L.T.; Herron, J.A.; Zhang, L.; Park, J.; Wang, J.; Kim, M.J.; Xie, Z.; et al. Atomic layer-by-layer deposition of $\mathrm{Pt}$ on $\mathrm{Pd}$ nanocubes for catalysts with enhanced activity and durability toward oxygen reduction. Nano Lett. 2014, 14, 3570-3576. [CrossRef] [PubMed]

244. Zhang, L.; Roling, L.T.; Wang, X.; Vara, M.; Chi, M.; Liu, J.; Choi, S.-I.; Park, J.; Herron, J.A.; Xie, Z.; et al. Platinum-based nanocages with subnanometer-thick walls and well-defined, controllable facets. Science 2015, 349, 412. [CrossRef] [PubMed]

245. Baldi, A.; Narayan, T.C.; Koh, A.L.; Dionne, J.A. In situ detection of hydrogen-induced phase transitions in individual palladium nanocrystals. Nat. Mater. 2014, 13, 1143. [CrossRef] [PubMed]

246. Collins, G.; Schmidt, M.; McGlacken, G.P.; O’Dwyer, C.; Holmes, J.D. Stability, oxidation, and shape evolution of PVP-capped Pd nanocrystals. J. Phys. Chem. C 2014, 118, 6522-6530. [CrossRef] 
247. Wu, J.; Helveg, S.; Ullmann, S.; Peng, Z.; Bell, A.T. Growth of encapsulating carbon on supported Pt nanoparticles studied by in situ tem. J. Catal. 2016, 338, 295-304. [CrossRef]

248. Niu, Y.; Zhang, B.; Luo, J.; Zhang, L.; Chen, C.M.; Su Dang, S. Correlation between microstructure evolution of a well-defined cubic palladium catalyst and selectivity during acetylene hydrogenation. ChemCatChem 2017, 9, 3435-3439. [CrossRef]

249. Kim, S.K.; Kim, C.; Lee, J.H.; Kim, J.; Lee, H.; Moon, S.H. Performance of shape-controlled pd nanoparticles in the selective hydrogenation of acetylene. J. Catal. 2013, 306, 146-154. [CrossRef]

250. He, Y.; Fan, J.; Feng, J.; Luo, C.; Yang, P.; Li, D. Pd nanoparticles on hydrotalcite as an efficient catalyst for partial hydrogenation of acetylene: Effect of support acidic and basic properties. J. Catal. 2015, 331, 118-127. [CrossRef]

251. Chesnokov, V.V.; Podyacheva, O.Y.; Richards, R.M. Influence of carbon nanomaterials on the properties of $\mathrm{Pd} / \mathrm{C}$ catalysts in selective hydrogenation of acetylene. Mater. Res. Bull. 2017, 88, 78-84. [CrossRef]

252. Zhang, H.; Cao, J.; Wu, B.; Dai, W.; Chen, Z.; Ma, M. An alumina-coated, egg-shell Pd/ $\alpha-\mathrm{Al}_{2} \mathrm{O}_{3} @ S i C$ catalyst with enhanced ethylene selectivity in the selective hydrogenation of acetylene. RSC Adv. 2016, 6, 57174-57182. [CrossRef]

253. Liu, Z.; Zhu, Q.; Hou, N.; Fu, Y.; Wen, L.; Chen, J. Development of novel monolithic catalyst with porous hollow silica nanoparticles for selective hydrogenation reactions. Catal. Today 2013, 216, 205-210. [CrossRef]

254. Song, H.; Yan, N.; Fei, Z.; Kilpin, K.J.; Scopelliti, R.; Li, X.; Dyson, P.J. Evaluation of ionic liquid soluble imidazolium tetrachloropalladate pre-catalysts in suzuki coupling reactions. Catal. Today 2012, 183, 172-177. [CrossRef]

255. Yuan, X.; Sun, G.; Asakura, H.; Tanaka, T.; Chen, X.; Yuan, Y.; Laurenczy, G.; Kou, Y.; Dyson Paul, J.; Yan, N. Development of palladium surface-enriched heteronuclear Au-Pd nanoparticle dehalogenation catalysts in an ionic liquid. Chem. Eur. J. 2013, 19, 1227-1234. [CrossRef] [PubMed]

256. Dupont, J.; Fonseca, G.S.; Umpierre, A.P.; Fichtner, P.F.P.; Teixeira, S.R. Transition-metal nanoparticles in imidazolium ionic liquids: Recycable catalysts for biphasic hydrogenation reactions. J. Am. Chem. Soc. 2002, 124, 4228-4229. [CrossRef] [PubMed]

257. Huang, J.; Jiang, T.; Han, B.; Gao, H.; Chang, Y.; Zhao, G.; Wu, W. Hydrogenation of olefins using ligand-stabilized palladium nanoparticles in an ionic liquid. Chem. Commun. 2003, 1654-1655. [CrossRef]

258. Ruta, M.; Laurenczy, G.; Dyson, P.J.; Kiwi-Minsker, L. Pd nanoparticles in a supported ionic liquid phase: Highly stable catalysts for selective acetylene hydrogenation under continuous-flow conditions. J. Phys. Chem. C 2008, 112, 17814-17819. [CrossRef]

259. Zhou, T.; Jang, K.; Jang, B.W.L. Ionic liquid and plasma effects on sio2 supported pd for selective hydrogenation of acetylene. Catal. Today 2013, 211, 147-155. [CrossRef]

260. Xie, Y.B.; Liu, C.J. Stability of ionic liquids under the influence of glow discharge plasmas. Plasma Processes Polym. 2008, 5, 239-245. [CrossRef]

261. Riyapan, S.; Boonyongmaneerat, Y.; Mekasuwandumrong, O.; Praserthdam, P.; Panpranot, J. Effect of surface $\mathrm{Ti}^{3+}$ on the sol-gel derived $\mathrm{TiO}_{2}$ in the selective acetylene hydrogenation on $\mathrm{Pd} / \mathrm{TiO}_{2}$ catalysts. Catal. Today 2015, 245, 134-138. [CrossRef]

262. Riyapan, S.; Boonyongmaneerat, Y.; Mekasuwandumrong, O.; Yoshida, H.; Fujita, S.-I.; Arai, M.; Panpranot, J. Improved catalytic performance of $\mathrm{Pd} / \mathrm{TiO}_{2}$ in the selective hydrogenation of acetylene by using h2-treated sol-gel tio2. J. Mol. Catal. A Chem. 2014, 383-384, 182-187. [CrossRef]

263. McCue, A.J.; McKenna, F.-M.; Anderson, J.A. Triphenylphosphine: A ligand for heterogeneous catalysis too? Selectivity enhancement in acetylene hydrogenation over modified $\mathrm{Pd} / \mathrm{TiO}_{2}$ catalyst. Catal. Sci. Technol. 2015, 5, 2449-2459. [CrossRef]

264. Kim, E.; Shin, E.W.; Bark, C.W.; Chang, I.; Yoon, W.J.; Kim, W.-J. Pd catalyst promoted by two metal oxides with different reducibilities: Properties and performance in the selective hydrogenation of acetylene. Appl. Catal. A General 2014, 471, 80-83. [CrossRef]

265. Hou, R.; Wang, T.; Lan, X. Enhanced selectivity in the hydrogenation of acetylene due to the addition of a liquid phase as a selective solvent. Ind. Eng. Chem. Res. 2013, 52, 13305-13312. [CrossRef]

266. Smirnova, N.S.; Mironenko, O.O.; Shlyapin, D.A.; Kochubey, D.I.; Tsyrulnikov, P.G. Exafs study of model $\mathrm{Pd} / \mathrm{Ga}_{2} \mathrm{O}_{3}$ catalysts for the liquid-phase hydrogenation of acetylene before and after the reaction. Bull. Russ. Acad. Sci. Phys. 2013, 77, 1151-1153. [CrossRef] 
267. Smirnova, N.S.; Shlyapin, D.A.; Shitova, N.B.; Kochubey, D.I.; Tsyrul'nikov, P.G. Exafs study of Pd/Sibunit and Pd-Ga/Sibunit catalysts for liquid-phase hydrogenation of acetylene to ethylene. J. Mol. Catal. A Chem. 2015, 403, 10-14. [CrossRef]

268. Afonasenko, T.N.; Smirnova, N.S.; Temerev, V.L.; Leont'eva, N.N.; Gulyaeva, T.I.; Tsyrul'nikov, P.G. $\mathrm{Pd} / \mathrm{Ga}_{2} \mathrm{O}_{3}-\mathrm{AL}_{2} \mathrm{O}_{3}$ catalysts for the selective liquid-phase hydrogenation of acetylene to ethylene. Kinet. Catal. 2016, 57, 490-496. [CrossRef]

269. He, Y.; Liang, L.; Liu, Y.; Feng, J.; Ma, C.; Li, D. Partial hydrogenation of acetylene using highly stable dispersed bimetallic Pd-Ga/MgO- $\mathrm{AL}_{2} \mathrm{O}_{3}$ catalyst. J. Catal. 2014, 309, 166-173. [CrossRef]

270. Zimmermann René, R.; Hahn, T.; Reschetilowski, W.; Armbrüster, M. Kinetic parameters for the selective hydrogenation of acetylene on $\mathrm{GaPd}_{2}$ and GaPd. Chem. Phys. Chem. 2017, 18, 2517-2525. [CrossRef] [PubMed]

271. Siebert, M.; Zimmermann René, R.; Armbrüster, M.; Dittmeyer, R. Inkjet printing of $\mathrm{GaPd}_{2}$ into micro-channels for the selective hydrogenation of acetylene. Chem. Catal. Chem. 2017, 9, 3733-3742. [CrossRef]

272. Jin, Q.; He, Y.; Miao, M.; Guan, C.; Du, Y.; Feng, J.; Li, D. Highly selective and stable pdni catalyst derived from layered double hydroxides for partial hydrogenation of acetylene. Appl. Catal. A General 2015, 500, 3-11. [CrossRef]

273. Ding, L.; Yi, H.; Zhang, W.; You, R.; Cao, T.; Yang, J.; Lu, J.; Huang, W. Activating edge sites on pd catalysts for selective hydrogenation of acetylene via selective $\mathrm{Ga}_{2} \mathrm{O}_{3}$ decoration. ACS Catal. 2016, 6, 3700-3707. [CrossRef]

274. Zhou, H.; Yang, X.; Wang, A.; Miao, S.; Liu, X.; Pan, X.; Su, Y.; Li, L.; Tan, Y.; Zhang, T. Pd/ZnO catalysts with different origins for high chemoselectivity in acetylene semi-hydrogenation. Chin. J. Catal. 2016, 37, 692-699. [CrossRef]

275. Zhou, H.; Yang, X.; Li, L.; Liu, X.; Huang, Y.; Pan, X.; Wang, A.; Li, J.; Zhang, T. PdZn intermetallic nanostructure with $\mathrm{Pd}-\mathrm{Zn}-\mathrm{Pd}$ ensembles for highly active and chemoselective semi-hydrogenation of acetylene. ACS Catal. 2016, 6, 1054-1061. [CrossRef]

276. Yang, J.; Zhang, F.; Lu, H.; Hong, X.; Jiang, H.; Wu, Y.; Li, Y. Hollow Zn/Co ZIF particles derived from core-shell ZIF-67@ZIF-8 as selective catalyst for the semi-hydrogenation of acetylene. Angew. Chem. Int. Ed. 2015, 54, 10889-10893. [CrossRef] [PubMed]

277. Menezes, W.G.; Altmann, L.; Zielasek, V.; Thiel, K.; Bäumer, M. Bimetallic Co-Pd catalysts: Study of preparation methods and their influence on the selective hydrogenation of acetylene. J. Catal. 2013, 300, 125-135. [CrossRef]

278. Pei, G.X.; Liu, X.Y.; Wang, A.; Li, L.; Huang, Y.; Zhang, T.; Lee, J.W.; Jang, B.W.L.; Mou, C.-Y. Promotional effect of Pd single atoms on Au nanoparticles supported on silica for the selective hydrogenation of acetylene in excess ethylene. New J. Chem. 2014, 38, 2043-2051. [CrossRef]

279. Pongthawornsakun, B.; Mekasuwandumrong, O.; Santos Aires, F.J.C.; Büchel, R.; Baiker, A.; Pratsinis, S.E.; Panpranot, J. Variability of particle configurations achievable by 2-nozzle flame syntheses of the Au-Pd-TiO system and their catalytic behaviors in the selective hydrogenation of acetylene. Appl. Catal. A General 2018, 549, 1-7. [CrossRef]

280. Zhang, Y.; Diao, W.; Williams, C.T.; Monnier, J.R. Selective hydrogenation of acetylene in excess ethylene using $\mathrm{Ag}$ - and $\mathrm{Au}-\mathrm{Pd} / \mathrm{SiO}_{2}$ bimetallic catalysts prepared by electroless deposition. Appl. Catal. A General 2014, 469, 419-426. [CrossRef]

281. Komeili, S.; Ravanchi, M.T.; Taeb, A. The influence of alumina phases on the performance of the $\mathrm{Pd}-\mathrm{Ag} / \mathrm{Al}_{2} \mathrm{O}_{3}$ catalyst in tail-end selective hydrogenation of acetylene. Appl. Catal. A General 2015, 502, 287-296. [CrossRef]

282. Liu, Y.N.; Feng, J.T.; He, Y.F.; Sun, J.H.; Li, D.Q. Partial hydrogenation of acetylene over a niti-layered double hydroxide supported pdag catalyst. Catal. Sci. Technol. 2015, 5, 1231-1240. [CrossRef]

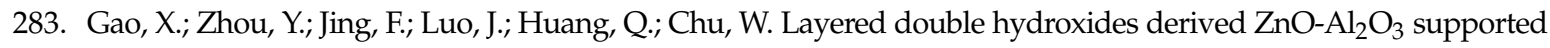
Pd-Ag catalysts for selective hydrogenation of acetylene. Chin. J. Chem. 2017, 35, 1009-1015. [CrossRef]

284. Liu, Y.; Zhao, J.; He, Y.; Feng, J.; Wu, T.; Li, D. Highly efficient PdAg catalyst using a reducible Mg-Ti mixed oxide for selective hydrogenation of acetylene: Role of acidic and basic sites. J. Catal. 2017, 348, 135-145. [CrossRef]

285. Pei, G.X.; Liu, X.Y.; Wang, A.; Lee, A.F.; Isaacs, M.A.; Li, L.; Pan, X.; Yang, X.; Wang, X.; Tai, Z.; et al. Ag alloyed Pd single-atom catalysts for efficient selective hydrogenation of acetylene to ethylene in excess ethylene. ACS Catal. 2015, 5, 3717-3725. [CrossRef] 
286. McCue, A.J.; McRitchie, C.J.; Shepherd, A.M.; Anderson, J.A. Cu/ $\mathrm{Al}_{2} \mathrm{O}_{3}$ catalysts modified with $\mathrm{Pd}$ for selective acetylene hydrogenation. J. Catal. 2014, 319, 127-135. [CrossRef]

287. Kruppe, C.M.; Krooswyk, J.D.; Trenary, M. Selective hydrogenation of acetylene to ethylene in the presence of a carbonaceous surface layer on a Pd/Cu(111) single-atom alloy. ACS Catal. 2017, 7, 8042-8049. [CrossRef]

288. Pei, G.X.; Liu, X.Y.; Yang, X.; Zhang, L.; Wang, A.; Li, L.; Wang, H.; Wang, X.; Zhang, T. Performance of $\mathrm{Cu}$-alloyed Pd single-atom catalyst for semihydrogenation of acetylene under simulated front-end conditions. ACS Catal. 2017, 7, 1491-1500. [CrossRef]

289. McCue, A.J.; Shepherd, A.M.; Anderson, J.A. Optimisation of preparation method for Pd doped $\mathrm{Cu} / \mathrm{Al}_{2} \mathrm{O}_{3}$ catalysts for selective acetylene hydrogenation. Catal. Sci. Technol. 2015, 5, 2880-2890. [CrossRef]

290. Pei, G.; Liu, X.; Chai, M.; Wang, A.; Zhang, T. Isolation of Pd atoms by Cu for semi-hydrogenation of acetylene: Effects of cu loading. Chin. J. Catal. 2017, 38, 1540-1548. [CrossRef]

291. Kuznetsov, D.A.; Bazhenova, T.A.; Fedyanin, I.V.; Martynenko, V.M.; Shestakov, A.F.; Petrova, G.N.; Komarova, N.Y.S. Tri-, tetra-, and hexanuclear mixed-valence molybdenum clusters: Structural diversity and catalysis of acetylene hydrogenation. Dalton Trans. 2016, 45, 16309-16316. [CrossRef] [PubMed]

292. Yan, X.; Wheeler, J.; Jang, B.; Lin, W.-Y.; Zhao, B. Stable Au catalysts for selective hydrogenation of acetylene in ethylene. Appl. Catal. A General 2014, 487, 36-44. [CrossRef]

293. Albani, D.; Capdevila-Cortada, M.; Vilé, G.; Mitchell, S.; Martin, O.; López, N.; Pérez-Ramírez, J. Semihydrogenation of acetylene on indium oxide: Proposed single-ensemble catalysis. Angew. Chem. 2017, 129, 10895-10900. [CrossRef]

294. Spanjers, C.S.; Held, J.T.; Jones, M.J.; Stanley, D.D.; Sim, R.S.; Janik, M.J.; Rioux, R.M. Zinc inclusion to heterogeneous nickel catalysts reduces oligomerization during the semi-hydrogenation of acetylene. J. Catal. 2014, 316, 164-173. [CrossRef]

295. Pickett, C.J. The chatt cycle and the mechanism of enzymic reduction of molecular nitrogen. J. Biol. Inorg. Chem. 1996, 1, 601-606. [CrossRef]

296. Lee, S.C.; Holm, R.H. The clusters of nitrogenase: Synthetic methodology in the construction of weak-field clusters. Chem. Rev. 2004, 104, 1135-1158. [CrossRef] [PubMed]

297. Dos Santos, P.C.; Dean, D.R.; Hu, Y.; Ribbe, M.W. Formation and insertion of the nitrogenase iron-molybdenum cofactor. Chem. Rev. 2004, 104, 1159-1174. [CrossRef] [PubMed]

298. Crossland, J.L.; Tyler, D.R. Iron-dinitrogen coordination chemistry: Dinitrogen activation and reactivity. Coord. Chem. Rev. 2010, 254, 1883-1894. [CrossRef]

299. Burgess, B.K.; Lowe, D.J. Mechanism of molybdenum nitrogenase. Chem. Rev. 1996, 96, 2983-3012. [CrossRef] [PubMed]

300. Jia, H.-P.; Quadrelli, E.A. Mechanistic aspects of dinitrogen cleavage and hydrogenation to produce ammonia in catalysis and organometallic chemistry: Relevance of metal hydride bonds and dihydrogen. Chem. Soc. Rev. 2014, 43, 547-564. [CrossRef] [PubMed]

301. Barrière, F. Modeling of the molybdenum center in the nitrogenase femo-cofactor. Coord. Chem. Rev. 2003, 236, 71-89. [CrossRef]

302. Yoshimoto, K.; Yatabe, T.; Matsumoto, T.; Tran, V.-H.; Robertson, A.; Nakai, H.; Asazawa, K.; Tanaka, H.; Ogo, S. Inorganic clusters with a $\left[\mathrm{Fe}_{2} \mathrm{MoOS}_{3}\right]$ core - a functional model for acetylene reduction by nitrogenases. Dalton Trans. 2016, 45, 14620-14627. [CrossRef] [PubMed]

303. Tejeda-Serrano, M.; Cabrero-Antonino, J.R.; Mainar-Ruiz, V.; López-Haro, M.; Hernández-Garrido, J.C.; Calvino, J.J.; Leyva-Pérez, A.; Corma, A. Synthesis of supported planar iron oxide nanoparticles and their chemo- and stereoselectivity for hydrogenation of alkynes. ACS Catal. 2017, 7, 3721-3729. [CrossRef]

304. Altmann, L.; Wang, X.; Stöver, J.; Klink, M.; Zielasek, V.; Thiel, K.; Kolny-Olesiak, J.; Al-Shamery, K.; Borchert, H.; Parisi, J.; et al. Impact of organic ligands on the structure and hydrogenation performance of colloidally prepared bimetallic ptsn nanoparticles. ChemCatChem 2013, 5, 1803-1810. [CrossRef]

305. Lee Jonathan, W.; Liu, X.; Mou, C.Y. Selective hydrogenation of acetylene over SBA-15 supported Au-Cu bimetallic catalysts. J. Chin. Chem. Soc. 2013, 60, 907-914.

306. Primo, A.; Neatu, F.; Florea, M.; Parvulescu, V.; Garcia, H. Graphenes in the absence of metals as carbocatalysts for selective acetylene hydrogenation and alkene hydrogenation. Nat. Commun. 2014, 5, 5291. [CrossRef] [PubMed]

307. Bychko, I.B.; Abakumov, A.A.; Lemesh, N.V.; Strizhak, P.E. Catalytic activity of multiwalled carbon nanotubes in acetylene hydrogenation. Chem. Catal. Chem. 2017, 9, 4470-4474. [CrossRef] 
308. Hutchings, G.J. Vapor phase hydrochlorination of acetylene: Correlation of catalytic activity of supported metal chloride catalysts. J. Catal. 1985, 96, 292-295. [CrossRef]

309. Conte, M.; Carley, A.F.; Hutchings, G.J. Reactivation of a carbon-supported gold catalyst for the hydrochlorination of acetylene. Catal. Lett. 2008, 124, 165-167. [CrossRef]

310. Conte, M.; Davies, C.J.; Morgan, D.J.; Davies, T.E.; Elias, D.J.; Carley, A.F.; Johnston, P.; Hutchings, G.J. Aqua regia activated $\mathrm{Au} / \mathrm{C}$ catalysts for the hydrochlorination of acetylene. J. Catal. 2013, 297, 128-136. [CrossRef]

311. Conte, M.; Davies, C.J.; Morgan, D.J.; Davies, T.E.; Carley, A.F.; Johnston, P.; Hutchings, G.J. Modifications of the metal and support during the deactivation and regeneration of au/c catalysts for the hydrochlorination of acetylene. Catal. Sci. Technol. 2013, 3, 128-134. [CrossRef]

312. Conte, M.; Davies, C.J.; Morgan, D.J.; Carley, A.F.; Johnston, P.; Hutchings, G.J. Characterization of $\mathrm{Au}^{3+}$ species in $\mathrm{Au} / \mathrm{C}$ catalysts for the hydrochlorination reaction of acetylene. Catal. Lett. 2014, 144, 1-8. [CrossRef]

313. Chao, S.; Guan, Q.; Li, W. Study of the active site for acetylene hydrochlorination in $\mathrm{AuCl}_{3} / \mathrm{C}_{\text {catalysts. }}$ J. Catal. 2015, 330, 273-279. [CrossRef]

314. Li, X.; Zhu, M.; Dai, B. $\mathrm{AuCl}_{3}$ on polypyrrole-modified carbon nanotubes as acetylene hydrochlorination catalysts. Appl. Catal. B: Environmental 2013, 142-143, 234-240. [CrossRef]

315. li, X.; Pan, X.; Bao, X. Nitrogen Doped Carbon Catalyzing Acetylene Conversion to Vinyl Chloride. J. Energy Chem. 2014, 23, 131-135.

316. Zhou, K.; Si, J.; Jia, J.; Huang, J.; Zhou, J.; Luo, G.; Wei, F. Reactivity enhancement of N-CNTs in green catalysis of $\mathrm{C}_{2} \mathrm{H}_{2}$ hydrochlorination by a cu catalyst. RSC Adv. 2014, 4, 7766-7769. [CrossRef]

317. Li, X.; Pan, X.; Yu, L.; Ren, P.; Wu, X.; Sun, L.; Jiao, F.; Bao, X. Silicon carbide-derived carbon nanocomposite as a substitute for mercury in the catalytic hydrochlorination of acetylene. Nat. Commun. 2014, 5, 3688. [CrossRef] [PubMed]

318. Dai, B.; Chen, K.; Wang, Y.; Kang, L.; Zhu, M. Boron and nitrogen doping in graphene for the catalysis of acetylene hydrochlorination. ACS Catal. 2015, 5, 2541-2547. [CrossRef]

319. Li, J.; Hu, J.; Li, G. Au(III)/N-containing ligand complex: A novel and efficient catalyst in carbonylation of alkyl nitrite. Catal. Comm. 2011, 12, 1401-1404. [CrossRef]

320. Huang, C.; Zhu, M.; Kang, L.; Dai, B. A novel high-stability Au(III)/schiff-based catalyst for acetylene hydrochlorination reaction. Catal. Commun. 2014, 54, 61-65. [CrossRef]

321. Zhang, H.; Dai, B.; Wang, X.; Li, W.; Han, Y.; Gu, J.; Zhang, J. Non-mercury catalytic acetylene hydrochlorination over bimetallic Au-Co(III)/SAC catalysts for vinyl chloride monomer production. Green Chem. 2013, 15, 829-836. [CrossRef]

322. Zhao, J.; Xu, J.; Xu, J.; Ni, J.; Zhang, T.; Xu, X.; Li, X. Activated-carbon-supported gold-cesium(I) as highly effective catalysts for hydrochlorination of acetylene to vinyl chloride. Chem. Plus. Chem. 2014, 80, 196-201. [CrossRef]

323. Zhao, J.; Zhang, T.; Di, X.; Xu, J.; Xu, J.; Feng, F.; Ni, J.; Li, X. Nitrogen-modified activated carbon supported bimetallic gold-cesium(I) as highly active and stable catalyst for the hydrochlorination of acetylene. RSC Adv. 2015, 5, 6925-6931. [CrossRef]

324. Zhao, J.; Gu, S.; Xu, X.; Zhang, T.; Di, X.; Pan, Z.; Li, X. Promotional effect of copper(II) on an activated carbon supported low content bimetallic gold-cesium(I) catalyst in acetylene hydrochlorination. RSC Adv. 2015, 5, 101427-101436. [CrossRef]

325. Zhang, H.; Dai, B.; Li, W.; Wang, X.; Zhang, J.; Zhu, M.; Gu, J. Non-mercury catalytic acetylene hydrochlorination over spherical activated-carbon-supported Au-Co(III)-Cu(II) catalysts. J. Catal. 2014, 316, 141-148. [CrossRef]

326. Wang, L.; Wang, F.; Wang, J.; Tang, X.; Zhao, Y.; Yang, D.; Jia, F.; Hao, T. Hydrochlorination of acetylene to vinyl chloride over Pd supported on zeolite y. React. Kinet. Mech. Catal. 2013, 110, 187-194. [CrossRef]

327. Wang, L.; Wang, F.; Wang, J. Catalytic properties of Pd/HY catalysts modified with $\mathrm{NH}_{4} \mathrm{~F}$ for acetylene hydrochlorination. Catal. Comm. 2015, 65, 41-45. [CrossRef]

328. Wang, L.; Wang, F.; Wang, J. Non-mercury catalytic acetylene hydrochlorination over a $\mathrm{NH}_{4} \mathrm{~F}$-urea-modified $\mathrm{Pd} / \mathrm{HY}$ catalyst for vinyl chloride monomer production. New J. Chem. 2016, 40, 3019-3023. [CrossRef]

329. Zhu, M.; Kang, L.; Su, Y.; Zhang, S.; Dai, B. $\mathrm{MCl}_{\mathrm{x}}(\mathrm{M}=\mathrm{Hg}$, $\mathrm{Au}, \mathrm{Ru} ; \mathrm{x}=2$, 3) catalyzed hydrochlorination of acetylene-A density functional theory study. Can. J. Chem. 2013, 91, 120-125. [CrossRef]

330. Zhang, J.; Sheng, W.; Guo, C.; Li, W. Acetylene hydrochlorination over bimetallic Ru-based catalysts. RSC Adv. 2013, 3, 21062-21068. [CrossRef] 
331. Li, G.; Li, W.; Zhang, H.; Pu, Y.; Sun, M.; Zhang, J. Non-mercury catalytic acetylene hydrochlorination over ru catalysts enhanced by carbon nanotubes. RSC Adv. 2015, 5, 9002-9008. [CrossRef]

332. Jin, Y.; Li, G.; Zhang, J.; Pu, Y.; Li, W. Effects of potassium additive on the activity of Ru catalyst for acetylene hydrochlorination. RSC Adv. 2015, 5, 37774-37779. [CrossRef]

333. Xu, J.; Zhao, J.; Zhang, T.; Di, X.; Gu, S.; Ni, J.; Li, X. Ultra-low Ru-promoted $\mathrm{CuCl}_{2}$ as highly active catalyst for the hydrochlorination of acetylene. RSC Adv. 2015, 5, 38159-38163. [CrossRef]

334. Hou, L.; Zhang, J.; Pu, Y.; Li, W. Effects of nitrogen-dopants on Ru-supported catalysts for acetylene hydrochlorination. RSC Adv. 2016, 6, 18026-18032. [CrossRef]

335. Xu, N.; Zhu, M.; Zhang, J.; Zhang, H.; Dai, B. Nitrogen functional groups on an activated carbon surface to effect the ruthenium catalysts in acetylene hydrochlorination. RSC Adv. 2015, 5, 86172-86178. [CrossRef]

336. Li, Y.; Dong, Y.; Li, W.; Han, Y.; Zhang, J. Improvement of imidazolium-based ionic liquids on the activity of ruthenium catalyst for acetylene hydrochlorination. Mo. Catal. 2017, 443, 220-227. [CrossRef]

337. Ananikov, V.P.; Khemchyan, L.L.; Yu, V.I.; Bukhtiyarov, V.I.; Sorokin, A.M.; Prosvirin, I.P.; Vatsadze, S.Z.; Medved'ko, A.V.; Nuriev, V.N.; Dilman, A.D.; et al. Development of new methods in modern selective organic synthesis: Preparation of functionalized molecules with atomic precision. Russ. Chem. Rev. 2014, 83, 885. [CrossRef]

338. Alabugin, I.V.; Gold, B. "Two functional groups in one package": Using both alkyne $\pi$-bonds in cascade transformations. J. Org. Chem. 2013, 78, 7777-7784. [CrossRef] [PubMed]

339. Alabugin, I.V.; Gonzalez-Rodriguez, E. Alkyne origami: Folding oligoalkynes into polyaromatics. Acc. Chem. Res. 2018, 51, 1206-1219. [CrossRef] [PubMed]

340. Byers, P.M.; Alabugin, I.V. Polyaromatic ribbons from oligo-alkynes via selective radical cascade: Stitching aromatic rings with polyacetylene bridges. J. Am. Chem. Soc. 2012, 134, 9609-9614. [CrossRef] [PubMed]

341. Byers, P.M.; Rashid, J.I.; Mohamed, R.K.; Alabugin, I.V. Polyaromatic ribbon/benzofuran fusion via consecutive endo cyclizations of enediynes. Org. Lett. 2012, 14, 6032-6035. [CrossRef] [PubMed]

342. Ravelli, D.; Protti, S.; Fagnoni, M. Carbon-carbon bond forming reactions via photogenerated intermediates. Chem. Rev. 2016, 116, 9850-9913. [CrossRef] [PubMed]

343. Wang, T.; Naredla, R.R.; Thompson, S.K.; Hoye, T.R. The pentadehydro-diels-alder reaction. Nature 2016, 532, 484. [CrossRef] [PubMed]

344. Roland, C.D.; Li, H.; Abboud, K.A.; Wagener, K.B.; Veige, A.S. Cyclic polymers from alkynes. Nat. Chem. 2016, 8, 791. [CrossRef] [PubMed]

345. Garcia Bernal, J.M.; Tirado, M.M.; Freire, J.J.; Garcia de la Torre, J. Monte carlo calculation of hydrodynamic properties of linear and cyclic polymers in good solvents. Macromolecules 1991, 24, 593-598. [CrossRef]

346. Bannister, D.J.; Semlyen, J.A. Studies of cyclic and linear poly(dimethyl siloxanes): 6. Effect of heat. Polymer 1981, 22, 377-381. [CrossRef]

347. Orrah, D.J.; Semlyen, J.A.; Ross-Murphy, S.B. Studies of cyclic and linear poly(dimethylsiloxanes): 28. Viscosities and densities of ring and chain poly(dimethylsiloxane) blends. Polymer 1988, 29, 1455-1458. [CrossRef]

348. Clarson, S.J.; Dodgson, K.; Semlyen, J.A. Studies of cyclic and linear poly(dimethylsiloxanes): 19. Glass transition temperatures and crystallization behaviour. Polymer 1985, 26, 930-934. [CrossRef]

349. Griffiths, P.C.; Stilbs, P.; Yu, G.E.; Booth, C. Role of molecular architecture in polymer diffusion: A PGSE-NMR study of linear and cyclic poly(ethylene oxide). J. Phys. Chem. 1995, 99, 16752-16756. [CrossRef]

350. Patel, A.; Cosgrove, T.; Semlyen, J.A. Studies of cyclic and linear poly(dimethylsiloxanes): 30. Adsorption studies on silica in solution. Polymer 1991, 32, 1313-1317. [CrossRef]

351. Galkin, K.I.; Ananikov, V.P. Alkynes as a versatile platform for construction of chemical molecular complexity and realization of molecular 3D printing. Russ. Chem. Rev. 2016, 85, 226. [CrossRef]

Sample Availability: Samples of the compounds are not available from the authors. 